\title{
ESPECTROSCOPIA A NÍVEL ATÔMICO USANDO UM MICROSCÓPIO DE TUNELAMENTO (STM)
}

\section{TOMÁS ERIKSON LAMAS}

ORIENTADOR: ALAIN ANDRÉ QUIVY

Comissão Examinadora:

Profa. Dra. Marina Amélia P. V. da Silveira Santos

Profa. Dra. Mônica Alonso Cotta

Prof. Dr. Alain André Quivy 
Dedico este trabalho aos meus pais,

Tomaz e Isilda. 


\section{Agradecimentos}

Ao Prof. Dr. Alain André Quivy pela orientação e pela dedicação dispensada a este trabalho.

Ao Mestre André S. Ferlauto, por me ensinar pacientemente cada detalhe de nosso STM.

A todos aqueles que já se dedicaram ao STM: Evandro, Jair, Jamil, Edmilson, César et. al.

Ao Prof. Dr. José Roberto Leite, pela oportunidade de desenvolver este trabalho no LNMS.

À Enza, Geraldo e Paulinho, pela permanente prontidão em atender as demandas deste projeto.

Ao Prof. Dr. Pedro Kiyohara, pelo trabalho na deposição dos filmes finos de ouro.

Ao Dr. Américo Tabata, Sandro Martini e Ademir Cavalheiro, pelas medidas de fotoluminescência.

Ao Prof. Dr. Paulo Sérgio Santos, pelo auxílio com os produtos químicos usados na preparação das amostras.

À Profa. Dra. Maria Cecília Salvadori, por permitir o acesso ao AFM de seu laboratório.

A todo o pessoal do laboratório: Ricardo, Marcelo, Alexander, Marcos, Cássio, Maurício, Pimenta et. al., por fazer deste lugar um ambiente descontraído e produtivo.

Aos incontáveis colegas da graduação e pós-graduação do IFUSP, bem como a todos os amigos e amigas de Jundiaí (não excluindo Elmo e Quinda), pelo alegre convívio de longos anos.

Aos meus pais e toda minha família, pelo incentivo constante.

À agência financiadora FAPESP, sem a qual este trabalho não poderia ter sido realizado.

...e, finalmente, a todos aqueles que foram involuntariamente esquecidos neste agradecimento, meu muito obrigado! 


\section{Resumo:}

O objetivo principal deste trabalho foi adicionar novos módulos (tanto eletrônicos quanto computacionais) necessários para efetuar medidas espectroscópicas com o microscópio de tunelamento construído há alguns anos no Laboratório de Novos Materiais Semicondutores do Instituto de Física da USP. Para checar a performance do novo sistema implementado, foram realizadas medidas sobre materiais condutores (grafite e ouro). Visando a análise topográfica e espectroscópica de amostras semicondutoras dos grupos III-V, estudamos alguns métodos para a preparação destas superfícies. Dentre eles, a passivação foi capaz de fornecer os resultados mais significativos. Finalmente, curvas da corrente de tunelamento em função da tensão aplicada à junção foram adquiridas sobre amostras de GaAs e pontos quânticos de InAs crescidos pela técnica de epitaxia por feixe molecular (MBE). 


\section{Abstract:}

The goal of the present work was to upgrade the home-made Scanning Tunneling Microscope present in our group, adding a new hardware necessary to carry out spectroscopic measurements. A new software was also developed to control the new functions of the microscope. In order to check the performance of the whole system, several types of experiments where carried out on graphite and gold. A special care was taken to adequately prepare the samples of III-V semiconductors. The passivation of the sample yielded the best results both for topographic and spectroscopic measurements. Finally, I-V curves were taken on GaAs layers and InAs quantum dots grown by molecular beam epitaxy (MBE). 


\section{Conteúdo:}

$\begin{array}{ll}\text { Introdução: } & 01\end{array}$

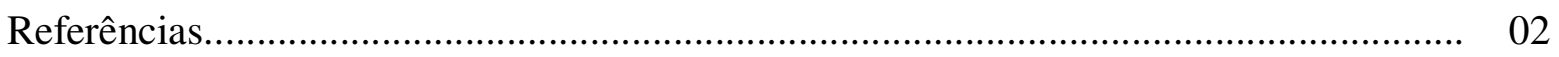

Capítulo 1 - A FÍSICA DO TUNELAMENTO: $\quad 03$

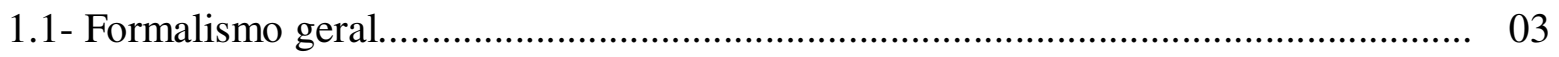

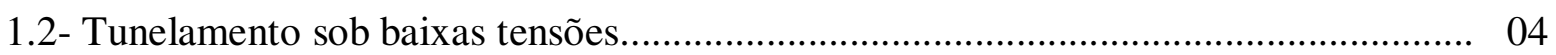

1.3- Tunelamento sob tensões intermediárias.............................................................. 06

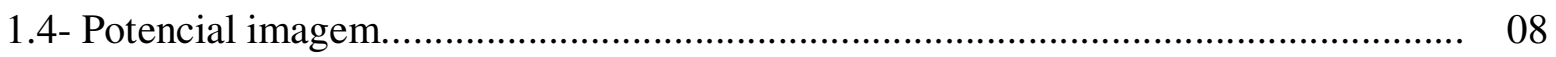

1.5- Altura da barreira e a Função trabalho................................................................ 09

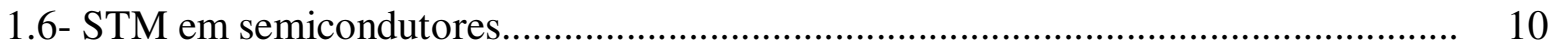

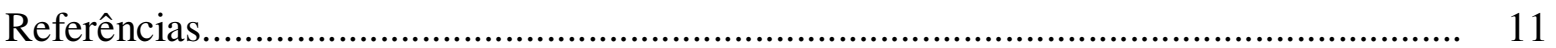

Capítulo 2 - MODOS DE OPERAÇÃO DE UM STM: 12

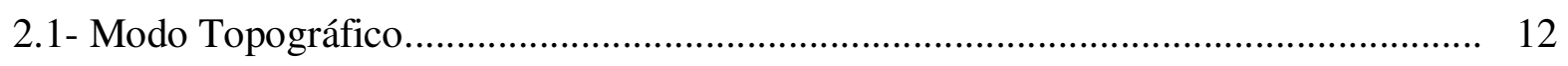

2.1.1- Método de Corrente Constante.......................................................................... 12

2.1.2- Método de Altura Constante.............................................................................. 13

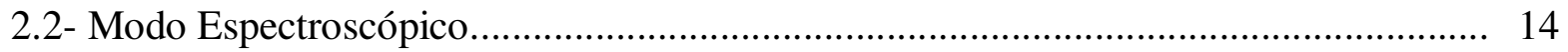

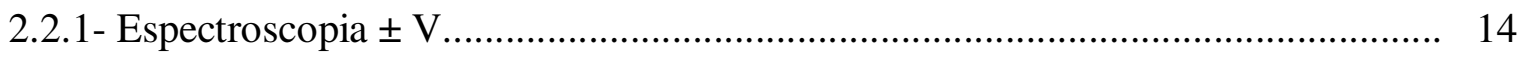

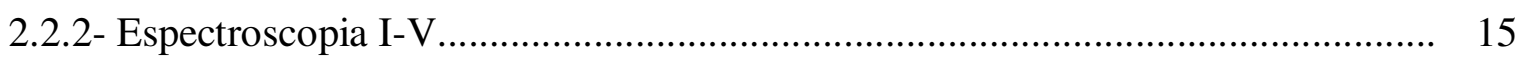

2.2.3 - Determinação da altura da barreira de tunelamento......................................... 17

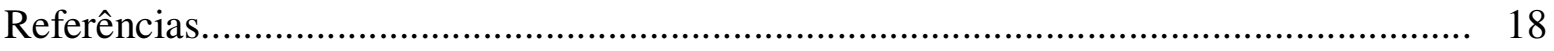

Capítulo 3 - CONSTRUÇÃO DE UM STM:

3.1- Sistema Mecânico......................................................................................... 20

3.1.1- Isolamento de Vibrações............................................................................. 20

3.1.2- Sistema de movimentação da ponta............................................................... 22

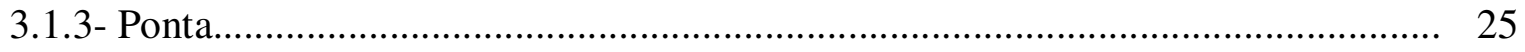

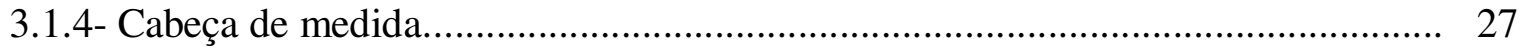


3.2- Sistema Eletrônico

3.2.1- Detecção da corrente.................................................................................... 30

3.2.2- Retroação e Controle da corrente....................................................................... 32

3.2.3- Módulo de seleção de sinais, ganho variável e filtros......................................... 33

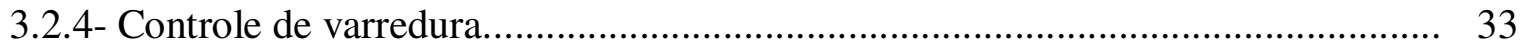

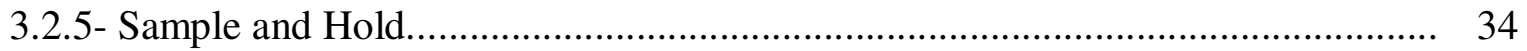

3.2.6- Módulo de alta tensão z.................................................................................. 35

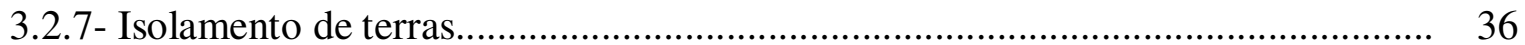

3.3- Microcomputador e Rotinas computacionais...................................................... 37

3.3.1- Sistema de aquisição da Topografia............................................................. 37

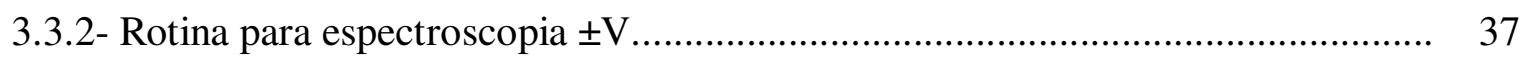

3.3.3- Rotinas para espectroscopia I-V ............................................................... 39

3.3.4- Rotina para medida da altura aparente da barreira............................................ 40

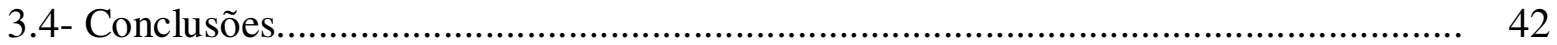

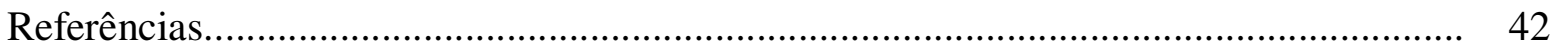

Capítulo 4 - ESPECTROSCOPIA SOBRE HOPG: $\quad 44$

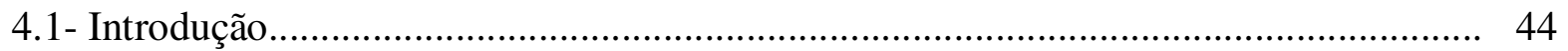

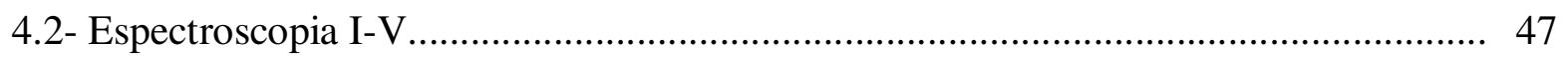

4.3- Espectroscopia de Altura da Barreira................................................................... 51

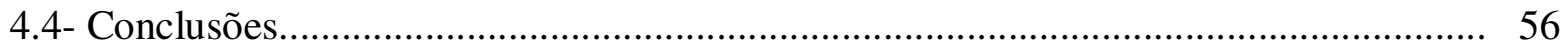

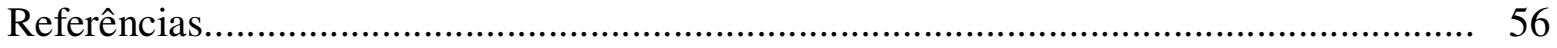

Capítulo 5 - ESPECTROSCOPIA SOBRE OURO: 58

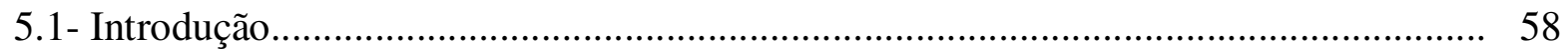

5.2- Otimização dos parâmetros de deposição por sputtering........................................... 59

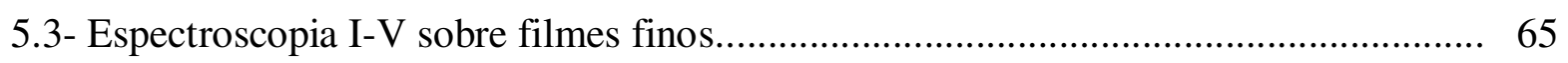

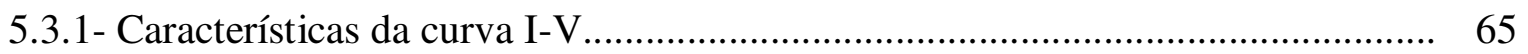

5.3.2- Caracterização da descontinuidade de um filme fino.......................................... 66

5.4- Espectroscopia de Altura da Barreira sobre Cristais de Ouro..................................... 68

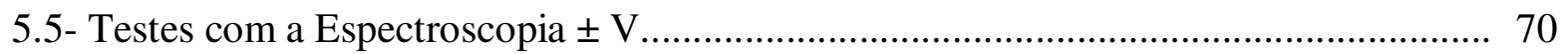

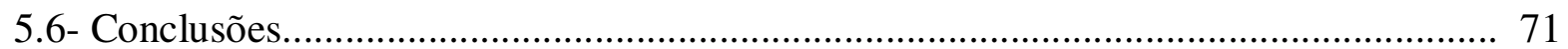

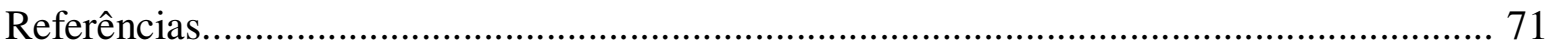




\section{Capítulo 6 - ESPECTROSCOPIA SOBRE SEMICONDUTORES}

DOS GRUPOS III-V:

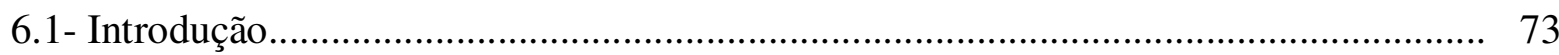

6.2- Métodos para a preparação de amostras semicondutoras......................................... 74

6.2.1- Cobertura da amostra com um líquido inerte...................................................... 74

6.2.2- Metalização da amostra com um filme fino de ouro............................................ 77

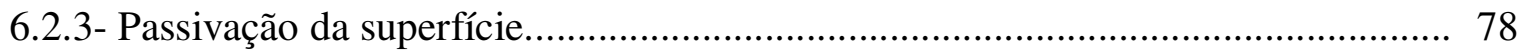

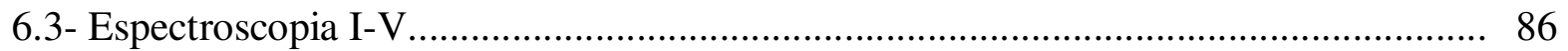

6.3.1- GaAs (100) dopado tipo n.............................................................................. 86

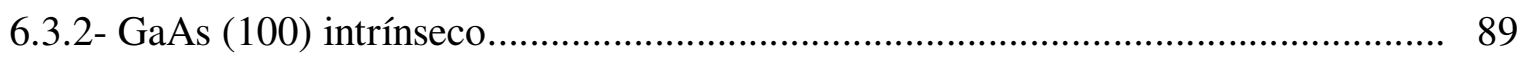

6.3.3- Pontos quânticos de InAs.............................................................................. 91

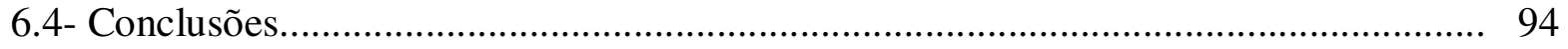

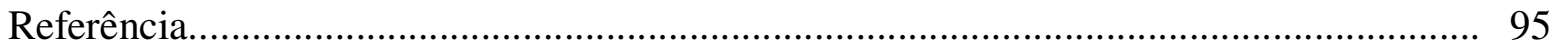

$\begin{array}{ll}\text { Conclusões } & 97\end{array}$ 


\section{Introdução:}

O uso das propriedades da corrente de tunelamento na investigação de amostras remonta a várias décadas. ${ }^{1}$ Estes estudos foram feitos utilizando junções compostas por camadas fixas de metal e óxido cobrindo completamente a amostra a ser analisada. Neste caso, a amostra e a camada metálica superior formavam os eletrodos através dos quais fluía a corrente de tunelamento. As medidas eram feitas variando-se a tensão aplicada entre os eletrodos e medindo a corrente de tunelamento correspondente. A camada de óxido constituía a barreira de potencial que precisava ser atravessada para obter-se o sinal elétrico. Desta forma, estudou-se, por exemplo, o estado supercondutor através da determinação de seu gap ${ }^{2}$ e de seu espectro de fônons. ${ }^{3}$ Também determinou-se o espectro vibracional de moléculas orgânicas ${ }^{4}$ e inorgânicas ${ }^{5}$ intercaladas em alta concentração durante a formação da barreira de óxido. Todavia, estes experimentos não possuíam resolução espacial, já que os eletrodos eram fixos e do tamanho da amostra, conduzindo a dados globais sobre a mesma. Neste contexto, tornou-se desejável uma ferramenta com a qual fosse possível obter informações equivalentes, porém sobre regiões bem definidas.

Um dos primeiros artigos apresentados pelos pioneiros da microscopia de tunelamento, G. Binnig e H. Rohrer, reportava a implementação de um sistema no qual era possível monitorar e controlar a corrente que fluía entre uma ponta de tungstênio (W) e uma amostra de platina (Pt) distantes de alguns angströns. ${ }^{6}$ Neste trabalho, foi observada a dependência exponencial, já prevista teoricamente, da corrente medida em função da distância ponta-amostra, confirmando o regime de tunelamento. Um enorme cuidado foi tomado para assegurar a estabilidade mecânica do sistema, sem a qual todas as tentativas anteriores haviam sido frustradas. ${ }^{7}$ Até o momento, a ponta ainda se mantinha em uma posição fixa em relação à amostra. $\mathrm{O}$ próximo passo dado em direção ao microscópio de tunelamento foi a implementação da varredura da ponta sobre a amostra, cujos primeiros resultados são reportados por G. Binnig, H. Rohrer e colaboradores na referência 8, de 1982. Degraus monoatômicos de $\mathrm{CaIrSn}_{4}(110)$ e $\mathrm{Au}(110)$ foram satisfatoriamente observados, mostrando a viabilidade desta nova técnica. Em 1986, G. Binnig e H. Rohrer foram agraciados com o Prêmio Nobel pela sua invenção.

Com seu desenvolvimento e conseqüente consolidação, o microscópio de tunelamento (STM, scanning tunneling microscope) assumiu um papel vital no estudo de superfícies. Ele conjuga diversas características desejadas na microscopia: possui altíssima resolução espacial, sendo comum a visualização da estrutura cristalina das amostras; pode ser operado em diversos

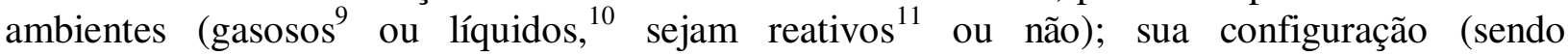
convenientemente otimizada) é pouco influenciada pela temperatura, permitindo estudos desde alguns Kelvin até a temperatura ambiente, ${ }^{12}$ com pressões partindo do ultra-alto vácuo ${ }^{13}$ até a pressão atmosférica. A gama de amostras passíveis de análise é ampla, incluindo majoritariamente os materiais condutores (metais e semimetais), além dos semicondutores e algumas classes de espécimes biológicos. ${ }^{14}$ A configuração de um STM permite também a obtenção de outras informações locais além da topografia da superfície. Esta modalidade, assunto deste trabalho, é chamada espectroscopia de tunelamento (STS, scanning tunneling spectroscopy) e alia a capacidade topográfica do STM à possibilidade de extrair informações intrínsecas da amostra analisada (como o gap, no caso de materiais semicondutores e 
supercondutores, função trabalho e comportamento de curvas I-V) a partir das características da corrente de tunelamento.

No desenvolvimento desta dissertação, são detalhados os conceitos teóricos básicos que tangem à microscopia e à espectroscopia de tunelamento, no Capítulo 1. Uma descrição detalhada dos métodos de aquisição dos dados, tanto em modo topográfico quanto espectroscópico, é dada no Capítulo 2. O Capítulo 3 discorre sobre os novos módulos eletrônicos implementados, bem como sua relação e compatibilidade com o circuito já existente. Resultados comprobatórios da acuidade do sistema recém-implementado são descritos nos Capítulos 4 e 5, onde foram adquiridas informações espectroscópicas sobre superfícies metálicas (grafite (HOPG, highly oriented pyrolitic graphite) e filmes de ouro, respectivamente), materiais consagrados para execução de testes em microscopia de tunelamento. O Capítulo 6, finalmente, traz as aplicações da espectroscopia de tunelamento sobre amostras semicondutoras de compostos dos grupos III-V, GaAs e pontos quânticos de InAs, crescidos por epitaxia por feixe molecular (MBE, molecular beam epitaxy).

\section{Referências:}

1 D. G. Walmsley, Surf. Sci. 181, 1 (1987) e as referências neste artigo.

2 I. Giaever, Phys. Rev. Lett. 5, 147 (1960).

3 W. L. McMillan e J. W. Rowell em Superconductivity vol. 1, Ed. R. D. Parks (Dekker, New York) 1969.

4 R. C. Jaklevic e J. Lambe, Phys. Rev. Lett. 17, 1139 (1966).

5 M. G. Simonsen, R. V. Coleman e P. K. Hansma, J. Chem. Phys. 61, 3789 (1974).

6 G. Binnig, H. Rohrer, Ch. Gerber e E. Weibel, Appl. Phys. Lett. 40, 178 (1982).

7 R. D. Young, J. Ward e F. Scire, Rev. Sci. Instrum. 43, 999 (1972).

8 G. Binning, H. Rohrer, Ch. Gerber e E. Weibel, Phys. Rev. Lett. 49, 57 (1982).

9 M. Schmidt, M. Nohlen, G. Bermes, M. Bohmer e K. Wandelt, Rev. Sci. Instrum. 68, 3866 (1997).

10 P. K. Hansma, R. Sonnenfeld, J. Schneir, O. Marti, S. A. C. Gould, C. B. Prater, A. L. Weisenhorn, B. Drake, H. Hansma, G. Slough, W. W. McNairy e R. V. Coleman em Scanning Tunneling Microscopy and Related Methods, cap. 15, NATO ASI series, editado por R. J. Behm, N. Garcia e H. Rohrer, Kluwer Academic Publishers, (1990).

11 P. B. Rasmussen, B. L. M. Hendriksen, H. Zeijlemaker, e H. G. Ficke, Rev. Sci. Instrum. 69, 3879 (1998).

12 S. Horch, P. Zeppenfeld, R. David e G. Comsa, Rev. Sci. Instrum. 65, 3204 (1994).

13 O. Zuger, H. P. Ott e U. Durig, Rev. Sci. Intrum. 63, 5634 (1992).

14 N. Nakagiri, H. Fujisaki e S. Aizawa, J. Vac. Sci. Tech. B 9, 1202 (1991). 


\section{Capítulo 1}

\section{A FÍSICA DO TUNELAMENTO:}

\section{1- Formalismo geral:}

Quando dois eletrodos metálicos são dispostos frente a frente no vácuo, o potencial na região intermediária entre ambos se apresenta como uma barreira, classicamente intransponível, aos elétrons de condução situados na superfície. Todavia, no âmbito da Mecânica Quântica, elétrons são representados por funções de onda que podem estender-se por essa barreira, decaindo exponencialmente em amplitude. Se tais eletrodos se encontram muito próximos, de forma que haja uma sobreposição das respectivas funções de onda, elétrons têm a probabilidade de passar de uma superfície à outra, constituindo então a corrente de tunelamento. A Figura 1 mostra um diagrama da variação do potencial ao longo de dois eletrodos.

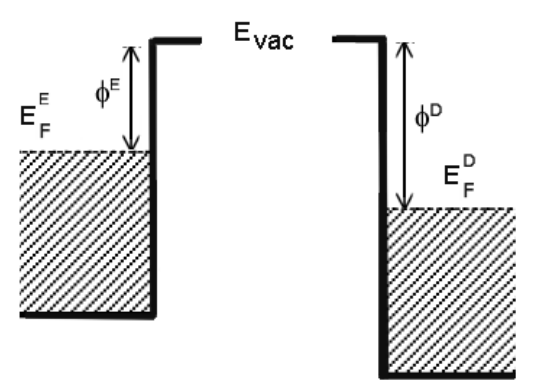

a

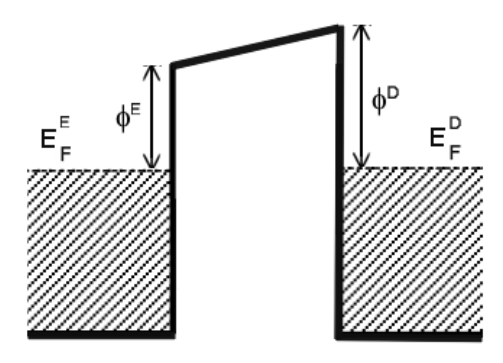

b

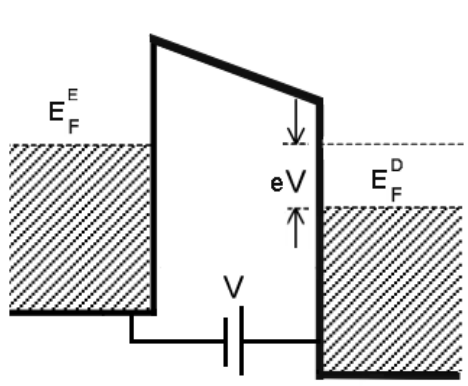

C

Figura 1: esquema da barreira de potencial entre eletrodos para tunelamento no vácuo. (a) Dois eletrodos metálicos sem interação entre si. Os níveis de Fermi $E_{F}$ dos dois materiais diferem por uma quantia igual à diferença da função trabalho $\phi_{E}$ e $\phi_{D}\left(E_{F}{ }^{E}\right.$ e $E_{F}{ }^{D}$ denotam os níveis de Fermi dos eletrodos da esquerda e da direita, respectivamente). (b) Os dois eletrodos atingem o equilíbrio elétrico, fazendo com que o nível de Fermi seja igual em ambos. A diferença na função trabalho agora é manifestada por um campo elétrico na junção. (c) Uma diferença de potencial arbitrária $\boldsymbol{V}$ é aplicada através da junção, criando uma desigualdade entre os níveis de Fermi dada por eV. $\boldsymbol{O}$ campo na barreira inclui agora as contribuições tanto do potencial aplicado quanto da diferença entre as funções trabalho dos dois eletrodos. As setas verticais nesta última figura indicam os limites de energia (eV) dentre os quais o tunelamento poderá ocorrer. Para tensões acima deste limite, não há elétrons no eletrodo da esquerda para sofrerem tunelamento. No caso de tensões inferiores, não existem estados vazios no eletrodo à direita passíveis de serem ocupados pelos elétrons, impedindo o tunelamento da mesma forma.

Considerando o problema em uma dimensão, a solução da equação de Schrödinger dentro de uma barreira retangular de altura $\mathrm{V}_{\mathrm{B}}$, mostrada na Figura 2, é dada por ${ }^{1}$ 


$$
\psi=e^{ \pm \kappa \cdot z}, \text { sendo } \kappa^{2}=\frac{2 m}{\hbar^{2}} \cdot\left(V_{B}-E\right)
$$

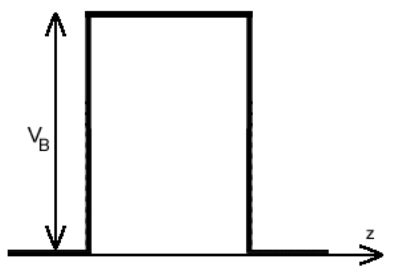

Figura 2: representação da barreira de potencial em uma dimensão.

onde $\mathrm{E}$ é a energia e $\mathrm{m}$ a massa da partícula, $\mathrm{V}_{\mathrm{B}} \mathrm{o}$ potencial ao longo da barreira (coordenada $\mathrm{z}$ ) e $\hbar$ a constante de Planck. Associando este resultado a uma experiência real, na qual a junção de tunelamento é composta por dois eletrodos idênticos, $V_{B}-E$ será a função trabalho $\phi$ para os estados localizados no nível de Fermi.

Em um tratamento mais apurado, fazendo a suposição de que a interação entre a ponta e a amostra (no caso de um STM) seja fraca, a probabilidade de tunelamento pode ser quantificada através da matriz de tunelamento $\mathrm{M}_{\mu \nu}$, que acopla as funções de onda de ambos os eletrodos $\left(\psi_{\mu}\right.$ e $\left.\psi_{v}\right)$. A corrente total é dada pela soma sobre todos os estados:

$$
\mathrm{I}=\frac{2 \pi \mathrm{e}}{\hbar} \sum_{\mu v}\left|\mathrm{M}_{\mu v}\right|^{2} \delta\left(\mathrm{E}_{\mu}-\mathrm{E}_{v}\right)\left[\mathrm{f}\left(\mathrm{E}_{\mu}\right)-\mathrm{f}\left(\mathrm{E}_{v}+\mathrm{eV}\right)\right]
$$

onde a função $\delta$ indica que não pode haver perda de energia do elétron durante o percurso pela barreira. Este regime é chamado de tunelamento elástico, em oposição ao tunelamento inelástico, no qual ocorre a perda de energia, devido à presença de moléculas por exemplo, no interior da barreira. As funções de Fermi-Dirac $f(E)$ levam em conta o fato dos elétrons poderem passar apenas de um estado ocupado para um estado vazio do outro eletrodo. A matriz de tunelamento é dada, segundo o formalismo de Bardeen, ${ }^{2}$ por:

$$
M_{\mu \nu}=\frac{\hbar^{2}}{2 m} \int d \mathbf{S} \cdot\left(\psi_{\mu}^{*} \nabla \psi_{v}-\psi_{v} \nabla \psi_{\mu}^{*}\right)
$$

onde $\psi_{\mu}$ e $\psi_{v}$ correspondem às funções de onda de ambos os eletrodos. A integral deve ser calculada sobre qualquer superfície confinada inteiramente dentro da região da barreira que separa os dois eletrodos.

Grande parte do esforço teórico demandado na compreensão do fenômeno de tunelamento e na interpretação das imagens de STM se encontra no cálculo da matriz de tunelamento. Diversos modelos, simplificações e suposições tornam possível a obtenção de uma expressão analítica e aplicável ao contexto experimental para a corrente de tunelamento. As próximas seções discorrem sobre alguns resultados (relevantes para este trabalho) presentes na literatura.

\section{2- Tunelamento sob baixas tensões:}

A amplitude da tensão aplicada à junção é de fundamental importância na interpretação do fenômeno do tunelamento. Se a tensão for muito menor que a função trabalho da superfície, 
constitui-se o chamado limite de baixas tensões. No contexto teórico, este limite permite simplificações quanto ao formato da barreira de potencial, conduzindo a resultados significativos no estudo de superfícies metálicas e semimetálicas.

Simmons $^{3}$ encontrou a expressão para a densidade de corrente no caso de uma junção planar, com eletrodos de mesma função trabalho, e submetida a uma baixa tensão:

$\mathrm{I}=\frac{\mathrm{C}_{1} \mathrm{~V}}{\mathrm{~s}} \sqrt{\phi} \exp \left(-\mathrm{C}_{2} \mathrm{~s} \sqrt{\phi}\right)$

onde $\mathrm{V}$ é a tensão aplicada, s a largura da barreira e $\phi$ a função trabalho da superfície. As constantes $\mathrm{C}_{1}$ e $\mathrm{C}_{2}$ valem $4,74 \times 10^{-6} \mathrm{~A} \AA\left[\mathrm{V}(\mathrm{eV})^{1 / 2}\right]^{-1}$ e $1,025 \AA^{-1} \mathrm{eV}^{-1 / 2}$, respectivamente. A expressão para barreiras dissimilares (com diferentes valores de função trabalho para cada eletrodo) ${ }^{4}$ é muito semelhante a esta, bastando mudar o valor de $\phi$ pela média das funções trabalho. Este resultado mostra o acentuado comportamento exponencial da corrente de tunelamento em função da distância entre eletrodos. Tomando um valor típico da função trabalho (por exemplo, $5 \mathrm{eV}$ em superfícies metálicas), a corrente diminuirá em uma ordem de grandeza para um aumento de $1 \AA$ na distância s. Esta expressão também descreve o comportamento da corrente de tunelamento em função da tensão aplicada à junção (curva I-V) para eletrodos metálicos, que deve ser linear a baixas tensões. Um comportamento diferente ocorre no caso de tensões mais altas, como será mostrado na próxima seção.

Vários estudos teóricos voltados para a interpretação das imagens de STM foram feitos por Tersoff e Hamann. ${ }^{5}$ Assumindo o limite no qual a ponta do STM seja reduzida a um único ponto, a corrente de tunelamento para baixas tensões será dada por

$\mathrm{I} \propto \sum_{v}\left|\psi_{v}\left(\mathbf{r}_{\mathrm{t}}\right)\right|^{2} \delta\left(\mathrm{E}_{v}-\mathrm{E}_{\mathrm{F}}\right) \equiv \rho\left(\mathbf{r}_{\mathrm{t}}, \mathrm{E}_{\mathrm{F}}\right)$

Esta expressão sintetiza a grandeza que um STM ideal deveria medir: a densidade local de estados da amostra no nível de Fermi $\rho\left(\mathbf{r}_{\mathrm{t}}, \mathrm{E}_{\mathrm{F}}\right)$ (LDOS, Local Density Of States) na posição $\mathbf{r}_{\mathrm{t}}$ ocupada pela ponta (ver Figura 3). Uma vez que a imagem por STM seja adquirida sob corrente constante, ela poderá ser interpretada como um contorno de regiões com mesma LDOS, ou seja, mesma densidade de cargas. Nos elementos metálicos e semimetálicos, a distribuição de cargas segue a posição dos átomos da rede cristalina e, portanto, uma imagem com STM a nível atômico destes materiais, adquirida sob baixas tensões, representará a verdadeira distribuição dos átomos da superfície no espaço real.

A referência 5 ainda prevê que a expressão acima continue válida, mesmo para perfis esféricos da ponta (ou seja, a ponta não é mais representada por um ponto matemático de dimensão nula). Neste caso, $\psi_{v}\left(\mathbf{r}_{t}\right)$ será função também do raio de curvatura $\mathrm{R}$ da ponta, surgindo nesta dependência a limitação na resolução lateral do instrumento, dada por $[2 \AA(R+s)]^{1 / 2}$. Tomando valores típicos para $\mathrm{R}$ e $\mathrm{s}$, os autores comprovam teoricamente a capacidade do STM em resolver a estrutura atômica da superfície das amostras analisadas. 


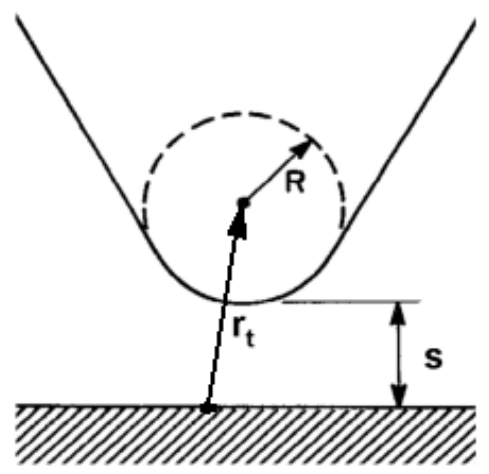

Figura 3: representação de uma ponta do STM segundo o modelo assumido por Tersoff. Seu centro se localiza na posição $\mathbf{r}_{\mathbf{t}}$. Em um caso mais realista, também considerado por Tersoff, a ponta possui um raio de curvatura $\mathrm{R}$.

\section{3- Tunelamento sob tensões intermediárias:}

Nos resultados apresentados até agora, os autores assumiram que a tensão de tunelamento era muito menor que a função trabalho dos eletrodos. Isto permite uma série de simplificações cujo teor não prejudica a compreensão dos mecanismos de aquisição das imagens topográficas. Todavia, na aquisição de dados espectroscópicos, a magnitude da tensão aplicada à junção pode assumir frações significativas da função trabalho, demandando um estudo teórico específico. Em casos extremos, a tensão de tunelamento pode mesmo superar a função trabalho de um dos eletrodos. Nesta condição, a altura da barreira não será mais a mesma para todos os elétrons; aqueles que possuírem energia próxima ao nível de Fermi terão maior probabilidade de tunelamento. No item corrente, vamos relatar, devido ao escopo deste trabalho, apenas os casos nos quais a tensão está no limite $0<\mathrm{V}<\phi / \mathrm{e}$.

Um primeiro resultado foi apresentado por Simmons, ${ }^{6}$ mostrando a não-linearidade da corrente em função da tensão em uma junção metal-isolante-metal com eletrodos de função trabalho idênticas. Usando tratamento semelhante ao do caso de baixas tensões, ele obteve a expressão:

$I=I_{L}\left(V+\beta V^{3}\right)$

onde $I_{L}$ e $\beta$ são constantes dependentes do material que compõe os eletrodos. Este comportamento já havia sido observado experimentalmente por Knauss e Breslow. ${ }^{7}$ Aproximadamente sete anos depois, Brinkman, Dynes e Rowell ${ }^{8}$ desenvolveram um estudo mais elaborado sobre o mesmo experimento, considerando diferentes funções trabalho para cada eletrodo. Dispondo de processos computacionais, os autores calcularam a corrente de tunelamento numericamente, ponto a ponto, para uma barreira trapezoidal. Este é um processo diferente do adotado por Simmons, que substituiu a barreira de potencial $\varphi(x, V)$ pelo seu valor médio $\bar{\varphi}(\mathrm{V})$. Derivando a corrente assim obtida em função da tensão (o que fornece a condutância da junção), foi encontrada a expressão: 


$$
\frac{\mathrm{G}(\mathrm{V})}{\mathrm{G}(0)}=1-\left(\frac{\mathrm{A}_{0}}{16} \frac{\Delta \phi}{(\bar{\phi})^{3 / 2}}\right) \mathrm{V}+\left(\frac{9}{128} \frac{\mathrm{A}_{0}}{(\bar{\phi})}\right)(\mathrm{eV})^{2}
$$

onde $\mathrm{G}(0)=3,16 \cdot 10^{10} \frac{(\bar{\phi})^{1 / 2}}{\mathrm{~s}} \exp \left(-1,025(\bar{\phi})^{1 / 2} \mathrm{~s}\right)$, semelhante ao resultado de Simmons para baixas tensões, $\Delta \phi=\phi_{2}-\phi_{1}$ é a diferença e $\bar{\phi}$ o valor médio da função trabalho de ambos os eletrodos e $\mathrm{A}_{0}=4(2 \mathrm{~m})^{1 / 2} \mathrm{~s} / 3 \hbar$. Se integrarmos esta expressão (obtendo a fórmula da corrente de tunelamento) e compararmos o resultado com a equação 6, será possível notar um termo adicional proporcional a $\mathrm{V}^{2}$. Este termo tem origem na diferença de função trabalho dos dois eletrodos ( $\Delta \phi$ na expressão 7$)$, desconsiderada por Simmons. Ambos os resultados conduzem ao comportamento linear da corrente em relação à tensão no limite $\mathrm{V} \approx 0$.

É importante lembrar, mais uma vez, que os resultados apresentados se aplicam satisfatoriamente às junções metal-isolante-metal. Em um STM, tem-se uma ponta extremamente afilada defronte a amostra, gerando efeitos não levados em conta por estes trabalhos, além da característica tridimensional do problema. Claramente, qualquer tentativa de ajuste aos dados tomados com um STM será passível de um erro superior ao estimado pelos autores (tipicamente 10\%). Não obstante, tais estudos fornecem o comportamento esperado para os dados, ou seja, não linearidade, simetria das curvas I-V, etc.

Curvas I-V adquiridas com um STM trazem resultados diretamente relacionados com a densidade de estados próximos ao nível de Fermi. Selloni e colaboradores ${ }^{9}$ realizaram um estudo detalhado sobre o assunto. Eles partiram do resultado de Tersoff e Hamann, aplicando-o na condição de tensões intermediárias:

$$
\mathrm{I}(\mathrm{V}) \propto \int_{\mathrm{E}_{\mathrm{F}}}^{\mathrm{E}_{\mathrm{F}}+\mathrm{V}} \mathrm{D}_{\mathrm{t}}(\mathrm{E}) \tilde{\rho}_{\mathrm{s}}\left(\mathbf{r}_{\mathrm{t}}, \mathrm{E}-\mathrm{E}_{\mathrm{F}}\right) \mathrm{dE}
$$

onde $D_{t}(E)$ e $\tilde{\rho}_{s}$ representam a densidade de estados da ponta e a densidade local de estados (LDOS) da amostra na posição $r_{t}$, respectivamente. Aproximando $\tilde{\rho}_{\mathrm{s}}\left(\mathbf{r}_{\mathrm{t}}, \mathrm{E}-\mathrm{E}_{\mathrm{F}}\right)$ por $\rho_{\mathrm{s}}\left(\mathbf{r}_{\mathrm{t}}, \mathrm{E}-\mathrm{E}_{\mathrm{F}}\right) \cdot \mathrm{T}(\mathrm{V})(\mathrm{T}(\mathrm{V})$ é o coeficiente de transmissão dos elétrons através da barreira, que traz toda a informação da mudança na tensão) e assumindo uma ponta com densidade de estados constante $\left(\mathrm{D}_{\mathrm{t}}=\right.$ constante $)$, a equação 8 pode ser diferenciada em relação à V:

$$
\frac{\mathrm{dI}}{\mathrm{dV}} \propto \rho_{\mathrm{s}}\left(\mathbf{r}_{\mathrm{t}}, \mathrm{V}\right) \mathrm{T}(\mathrm{V})
$$

Este é o resultado importante para a espectroscopia de tunelamento com um STM: a condutância diferencial $\mathrm{dI} / \mathrm{dV}$, determinada sob a tensão $\mathrm{V}$, é diretamente relacionada à LDOS da amostra na energia $\mathrm{E}_{\mathrm{F}}+\mathrm{eV}$. Chen ${ }^{10}$ encontrou uma relação similar, não envolvendo diretamente o coeficiente de transmissão no resultado:

$$
\frac{\mathrm{d} \ln |\mathrm{I}|}{\mathrm{dV}}=-\frac{\mathrm{e} \kappa \mathrm{s}}{2 \phi_{\mathrm{s}}}+\frac{|\mathrm{M}(\mathrm{eV})|^{2} \rho_{\mathrm{s}}(\mathrm{eV})}{\left.\left|\int_{0}^{\mathrm{eV}}\right| \mathrm{M}(\mathrm{E})\right|^{2} \rho_{\mathrm{s}}(\mathrm{E}) \mathrm{dE} \mid}
$$


Stroscio e colaboradores ${ }^{11}$ descobriram que a expressão (dI/dV)/(I/V), ou de modo equivalente $d \operatorname{lnI} / \mathrm{d} \ln V$, dá a melhor caracterização da LDOS. Uma prova desta correspondência foi conduzida por N. D. Lang. ${ }^{12}$ Em seu trabalho, foi calculada a densidade de estados de um átomo de sódio $(\mathrm{Na})$ adsorvido em um eletrodo plano constituído de elétrons livres (jellium model). Repetindo o procedimento para um átomo de $\mathrm{Ca}$ e combinando ambos os eletrodos em uma junção de tunelamento, a corrente foi calculada para diferentes tensões, mantendo a largura da barreira constante. O gráfico resultante $\mathrm{d}(\operatorname{lnI}) / \mathrm{d}(\ln \mathrm{V})$ versus $\mathrm{V}$ mostrou-se semelhante ao gráfico da LDOS (obtido também teoricamente) para o mesmo sistema.

\section{4- Potencial imagem:}

Um efeito ainda não discutido que pode influenciar os resultados descritos acima é o potencial imagem. Considerando a amostra como um plano, sua interface com o ambiente pode ser representada por uma superfície equipotencial. Neste contexto, cargas elétricas dispostas defronte a amostra devem induzir o surgimento de cargas de sinal oposto sobre a superfície, de forma a manter a condição de contorno do potencial ( $\varphi=$ constante sobre a superfície). Esta nova configuração de cargas gera o potencial imagem, estimado por Simmons ${ }^{3}$ como sendo:

$\varphi_{\mathrm{i}}(\mathrm{x})=-1,15 \lambda\left(\frac{\mathrm{s}^{2}}{\mathrm{x}(\mathrm{s}-\mathrm{x})}\right)$,

onde $\lambda=\left(\mathrm{e}^{2} \ln 2\right) / 8 \pi \mathrm{K} \varepsilon_{0} \mathrm{~s}$, K é a constante dielétrica do meio entre os eletrodos e $\varepsilon_{0}$ é a permissividade do vácuo. Esta correção deve ser somada ao potencial ideal, conduzindo ao potencial real que é medido: $\varphi_{\text {medido }}=\varphi_{\text {ideal }}+\varphi_{\mathrm{i}}$. Quanto maior a constante $\mathrm{K}$ menor será a correção imposta pelo potencial imagem, cujo efeito global é tornar a barreira mais fina e atenuada, como mostra a Figura 4. O cálculo da corrente de tunelamento desprezando a atuação deste potencial conduz a resultados superiores aos reais.

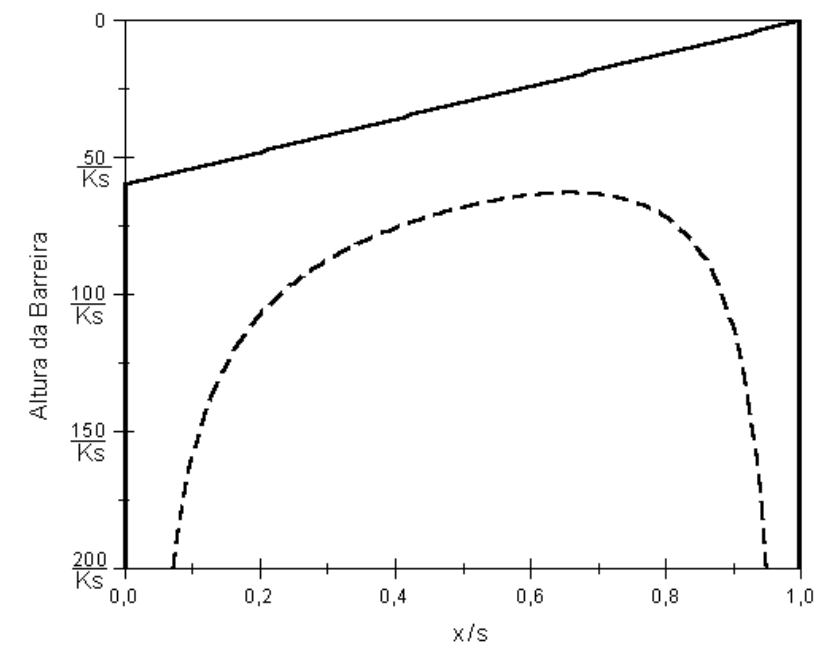

Figura 4: esquema da barreira trapezoidal ideal (linha contínua) em comparação com o resultado calculado (através da expressão de Simmons), levando-se em conta a atuação do potencial imagem (linha tracejada). As magnitudes são relativas. $\boldsymbol{K}$ é a constante dielétrica do material que constitui a barreira e s é a sua largura. 


\section{5- Altura da barreira e a Função trabalho:}

Historicamente, o termo "função trabalho" foi dado à classe de parâmetros que quantificava o trabalho necessário para remover um elétron da superfície de um sólido, sem a presença de campos elétricos. ${ }^{13}$ Devido à atuação do potencial imagem e de inúmeras influências experimentais na configuração de um STM, a corrente medida não fornece informações diretas da função trabalho da superfície, como é esperado pela teoria. A grandeza sondada na verdade é a altura da barreira de tunelamento acima do nível de Fermi. Não obstante, vários trabalhos teóricos e experimentais relacionaram estas duas grandezas, permitindo a medida da função trabalho e ampliando ainda mais a gama de aplicações deste tipo de instrumento.

Assumindo o caso simples de uma barreira unidimensional, de formato retangular e com altura $\varphi$ acima do nível de Fermi, a corrente de tunelamento I que flui sob uma pequena diferença de potencial $\mathrm{V}$ é proporcional a $\mathrm{V} \exp (-2 \mathrm{~s} \sqrt{2 \mathrm{~m} \varphi} / \hbar)$, onde s é a largura da barreira. $\mathrm{Na}$ condição $\mathrm{V}=$ constante, é possível isolar $\varphi$ nesta expressão, conduzindo à definição da altura aparente da barreira (também conhecida como função trabalho efetiva):

$$
\varphi_{\mathrm{A}} \equiv \frac{\hbar^{2}}{8 \mathrm{~m}}\left(\frac{\mathrm{d}(\ln \mathrm{I})}{\mathrm{ds}}\right)_{\mathrm{V}=\mathrm{cte} .}^{2}
$$

Expressando s em angströns, o fator multiplicativo $\left(\hbar^{2} / 8 \mathrm{~m}\right)$ assume o valor 0,952 . De forma análoga, a mesma expressão pode ser deduzida na condição de corrente constante: ${ }^{14}$

$\varphi_{\mathrm{A}} \equiv \frac{\hbar^{2}}{8 \mathrm{~m}}\left(\frac{\mathrm{d}(\ln \mathrm{V})}{\mathrm{ds}}\right)_{\mathrm{I}=\mathrm{cte} .}^{2}$

Binnig e colaboradores ${ }^{15}$ estimaram teoricamente uma expressão para os valores da altura da barreira $\left(\phi_{\mathrm{T}}\right)$ como função da distância ponta-amostra:

$\phi_{\mathrm{T}}=\phi_{\infty}-\frac{\alpha}{\mathrm{s}}$

onde $\phi_{\infty}$ é a função trabalho média da superfície e $\alpha \approx 9,97 \mathrm{eV} \AA$. Desde então, ficou claro que conforme a distância ponta-amostra aumenta, a altura aparente da barreira se aproxima da função trabalho do material. Segundo estes autores, a taxa desta variação tende a diminuir com o aumento da distância.

No contexto experimental, é desejável conhecer (mesmo que aproximadamente) a distância a partir da qual pode-se assimilar a altura aparente da barreira à função trabalho da amostra. Este limite não era bem claro no trabalho supracitado de Binnig. O artigo de N. D. Lang (referência 16) traz um estudo teórico elucidativo sobre este limite. Foi usado um modelo de duas placas paralelas, uma delas contendo um átomo de $\mathrm{Na}$ adsorvido (representando a ponta do STM), com uma pequena diferença de potencial entre ambas. Como mostra a Figura 5, no caso específico abordado pelo autor, a partir de 13 bohrs $(\cong 7 \AA)$ obtém-se a igualdade entre a altura aparente da barreira e a função trabalho. Para distâncias maiores, a altura aparente chega mesmo a superar este limite. Em outro trabalho, Pitarke e seus colaboradores ${ }^{14}$ concluíram que este 
efeito vinha do potencial imagem, não considerado por Lang. Este resultado prova definitivamente a possibilidade do STM em obter a função trabalho da superfície analisada.

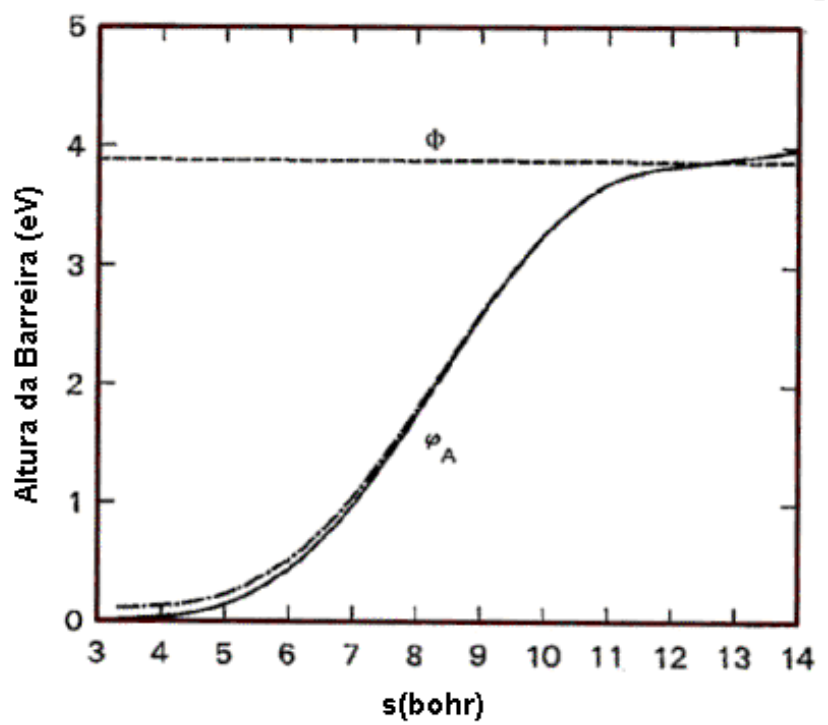

Figura 5: altura aparente da barreira $\varphi_{A}$ calculada por Lang no caso de uma ponta composta por um átomo de Na. No cálculo da curva contínua, foi desprezada a área da junção, enquanto que na curva tracejada foi considerada uma área correspondente à três átomos do substrato. A função trabalho $\Phi$ para a amostra é também apresentada para comparação. A distância entre eletrodos é representada por $s$ (1 bohr=0,529̊̊).[figura extraída da referência 16].

\section{6- STM em semicondutores:}

Diferentemente dos metais, os semicondutores apresentam uma variação acentuada da densidade de estados com a energia que muda descontinuamente nas bordas das bandas. Na superfície de amostras não dopadas (ou levemente dopadas), o nível de Fermi se localiza entre o topo da banda de valência e o fundo da banda de condução. ${ }^{17}$ Desta forma, apenas os estados de mais alta energia da banda de valência (ocupados) ou os estados de mais baixa energia na banda de condução (vazios) contribuirão para a corrente de tunelamento. Na condição de polaridade negativa (ou seja, a amostra submetida a um potencial elétrico inferior ao da ponta), os elétrons sofrem tunelamento no sentido da amostra para a ponta, sendo observados então os estados ocupados da superfície da amostra. Por outro lado, com polaridade positiva são observados os estados não ocupados (vazios). Com efeito, as imagens correspondentes em cada caso podem ser qualitativamente diferentes. Um exemplo ilustrativo é a estrutura do GaAs (110). Em um estudo teórico, Tersoff e seus colaboradores ${ }^{18}$ demonstraram que a imagem seria dependente da polaridade da tensão de tunelamento. A origem deste efeito se deve ao fato dos estados ocupados serem concentrados preferencialmente nos átomos de As da superfície enquanto os átomos de Ga abrigam os estados não ocupados, devido a uma diferença de carga (eletronegatividade) entre os dois tipos de átomos. ${ }^{19}$ Tersoff, na referência 18 , duvidava da possibilidade experimental da resolução atômica desta estrutura, cujo parâmetro de rede é menor que $6 \AA$. Surpreendentemente, Feenstra e colaboradores ${ }^{20}$ (dentre eles Tersoff) publicaram, dois anos mais tarde, as primeiras imagens desta estrutura com resolução atômica. Imagens adquiridas com tensão de $1,9 \mathrm{~V}$ mostravam os átomos de $\mathrm{Ga}$, enquanto que, invertendo a polaridade, observou-se os átomos de As. Combinando as duas imagens, a cadeia atômica da superfície (110) pôde ser claramente resolvida. A Figura 6 traz uma reprodução da imagem obtida. 

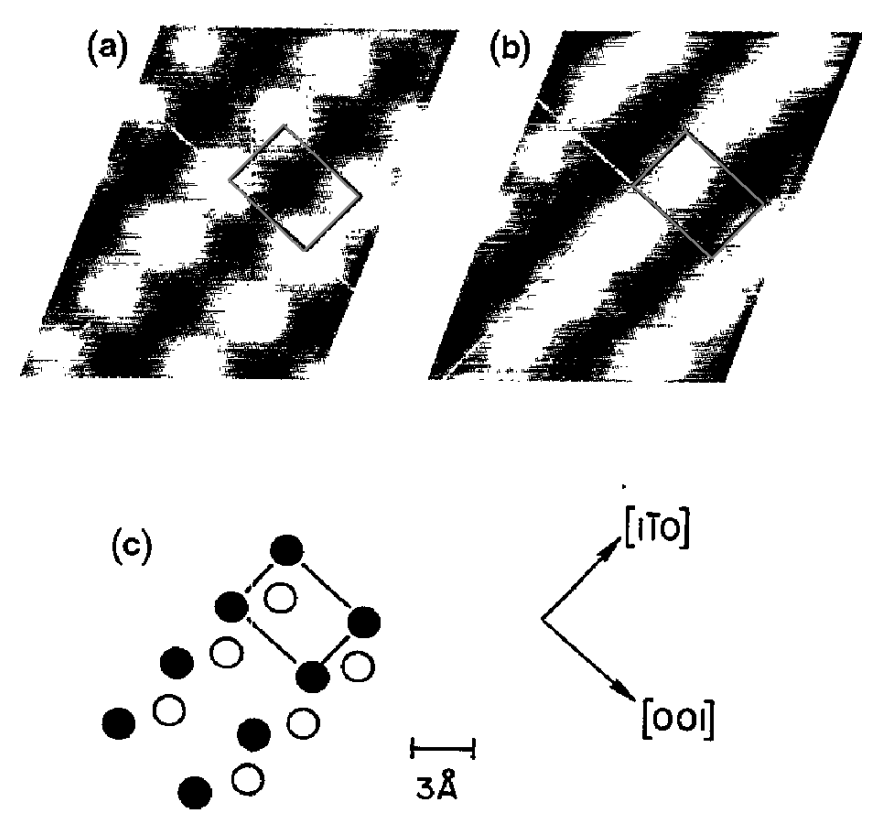

Figura 6: imagens topográficas da superfície de GaAs (110) adquiridas simultaneamente com (a) +1,9 e (b) -1,9V. (c) Vista de topo dos átomos da superfície. Os círculos abertos representam os átomos de As e os fechados, átomos de Ga. O retângulo indica a célula unitária, cuja posição é a mesma em todas as três figuras. [Imagem extraída da referência 20]

\section{Referências:}

${ }^{1}$ J. Tersoff e N. D. Lang em Scanning Tunneling Microscopy, cap.1, Methods of Experimental Physics 27, editado por J. A. Stroscio e W. J. Kaiser, Academic Press, Inc., San Diego, 1993.

2 J. Bardeen, Phys. Rev. Lett. 6, 57 (1961).

3 J. G. Simmons, J. Appl. Phys. 34, 1793 (1963).

${ }^{4}$ J. G. Simmons, J. Appl. Phys. 34, 2581 (1963).

${ }^{5}$ J. Tersoff e D. R. Hamann, Phys. Rev. Lett. 50, 1998 (1983).

${ }^{6}$ J. G. Simmons, J. Appl. Phys. 34, 238 (1963).

${ }^{7}$ P. Knauss e R. A. Breslow, Proc. IRE 50, 1834 (1962).

${ }^{8}$ W. F. Brinkman, R. C. Dynes e J. M. Rowell, J. Appl. Phys. 41, 1915 (1970).

${ }^{9}$ A. Selloni, P. Carnevali, E. Tosatti e C. D. Chen, Phys. Rev. B 31, 2602 (1985).

${ }^{10}$ C. Julian Chen, J. Vac. Sci. Technol. A 6, 319 (1988).

${ }^{11}$ J. A. Stroscio, R. M. Feenstra e A. P. Fein, Phys. Rev. Lett. 57, 2579 (1986).

${ }^{12}$ N. D. Lang, Phys. Rev. B 34, 5947 (1986).

${ }^{13}$ R. G. Forbes em Scanning Tunneling Microscopy and Related Methods, cap. 9, NATO ASI series, editado por R. J. Behm, N. Garcia e H. Rohrer, Kluwer Academic Publishers, (1990).

${ }^{14}$ J. M. Pitarke, P. M. Echenique, Surf. Sci. 217, 267 (1989).

${ }^{15}$ G. Binnig, N. Garcia, H. Rohrer, J. M. Soler e F. Flores, Phys. Rev. B 30, 4816 (1984).

${ }^{16}$ N. D. Lang, Phys. Rev. B 37, 10395 (1988).

${ }^{17}$ H. Neddermeyer, Rep. Prog. Phys. 59, 701 (1996)

${ }^{18}$ J. Tersoff e D. R. Hamann, Phys. Rev. B 31, 805 (1985).

${ }^{19}$ A. R. Lubisnk, C. B. Duke, B. W. Lee e P. Mark, Phys. Rev. Lett. 36, 1058 (1976).

${ }^{20}$ R. M. Feenstra, J. A. Stroscio, J. Tersoff e A. P. Fein, Phys. Rev. Lett. 58, 1192 (1987). 


\section{Capítulo 2}

\section{MODOS DE OPERAÇÃO DE UM STM:}

\section{1- Modo Topográfico:}

A junção de tunelamento em um STM é composta pela amostra (que deve ser condutora) e por uma ponta afilada vinculada ${ }^{*}$ a um sistema de movimentação eletro-mecânico, constituído por uma cerâmica piezelétrica. Aplicando neste sistema tensões elétricas de forma conveniente, é possível efetuar o movimento preciso e controlado da ponta nas direções paralela (x e y) e perpendicular (z) em relação à superfície da amostra. A corrente de tunelamento é estabelecida aplicando-se uma diferença de potencial à junção e aproximando a ponta da amostra até o limite de alguns angströns. Devido à própria natureza do fenômeno, a magnitude desta corrente pode assumir valores desde a faixa de pA até alguns nA, dependendo da distância ponta-amostra. A dependência exponencial da corrente com a distância entre os eletrodos é o elemento chave da microscopia de tunelamento. Em modo topográfico, destacam-se dois métodos de aquisição de dados, descritos à seguir.

\subsection{1- Método de Corrente Constante:}

Este é o método mais utilizado na aquisição de topografias. Consiste em manter a corrente de tunelamento constante (em um valor estipulado previamente pelo operador) através de um circuito de controle (retroação) que atua sobre a distância ponta-amostra (eixo z). ${ }^{1}$ Este circuito faz com que a ponta contorne o relevo da superfície da amostra durante a varredura. A topografia desta superfície é construída gravando-se o sinal elétrico aplicado por este circuito no elemento piezelétrico $\mathrm{z}$ em cada posição $(\mathrm{x}, \mathrm{y})$ da área analisada. A Figura 1 traz um diagrama de blocos ilustrando o funcionamento deste método. A velocidade de aquisição das imagens é limitada pelo tempo necessário para o movimento e a estabilização da ponta sobre cada ponto de amostragem. Este tempo depende da resposta do circuito de retroação e da inércia do movimento do sistema piezelétrico nas três direções espaciais. Valores típicos da frequiência de varredura variam entre décimos até dezenas de Hz. No início da técnica, grande parte dos sistemas de aquisição eram baseados em geradores de ondas (para efetuar a varredura) e osciloscópios com memória (para a visualização da topografia). Com o passar do tempo, sistemas mais flexíveis e eficientes foram construídos, baseados em microcomputadores que substituíram com vantagens os outros equipamentos.

\footnotetext{
* Dependendo da configuração experimental, a amostra é vinculada ao sistema de movimentação enquanto a ponta é fixa, fato que não influi no entendimento da operação do instrumento.
} 


\subsection{2- Método de Altura Constante:}

Neste método, a varredura $\mathrm{x}-\mathrm{y}$ é efetuada a uma freqüência acima da resposta do circuito de retroação. Desta forma, o circuito não é capaz de acompanhar as mudanças repentinas do relevo analisado, fazendo com que a ponta se desloque em um plano acima da amostra. A imagem é então construída monitorando-se as variações da corrente de tunelamento. Este método só pode ser empregado em amostras suficientemente lisas. ${ }^{2}$ Caso contrário, a ponta pode se chocar contra as irregularidades da superfície, o que geralmente gera uma perda de resolução. A freqüência de varredura neste método é vinculada às respostas em freqüência do circuito de retroação e do pré-amplificador de corrente, sendo comum atingir $1 \mathrm{kHz}$. A Figura 2 traz um diagrama deste modo de operação.

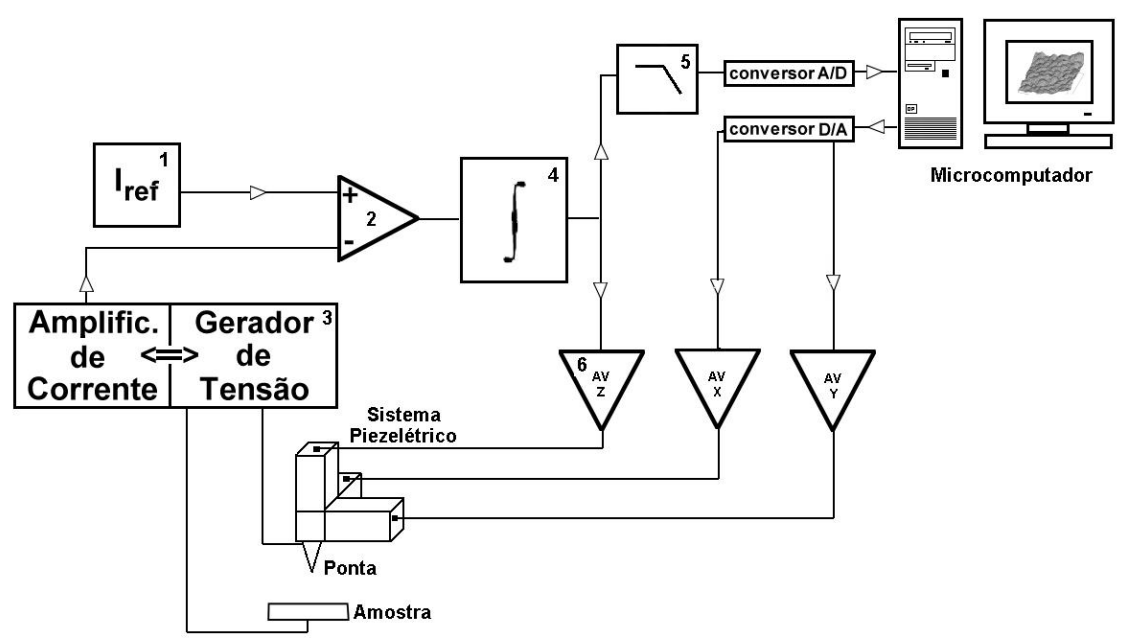

Figura 1: diagrama esquemático do funcionamento de um STM no modo de corrente constante. O microcomputador gera a varredura $x$-y através de um conversor digital/analógico (D/A), coleta os dados e constrói a imagem. A corrente de tunelamento de referência é escolhida pelo operador (1); a diferença (2) entre a corrente de tunelamento (3) e esta referência é integrada pelo circuito de retroação (4) $e$ aplicada ao elemento piezelétrico z através de um amplificador de alta tensão (6). Este mesmo sinal é conduzido através de um filtro passa-baixas (5) ao conversor analógico-digital $(A / D)$ e registrado pelo microcomputador.

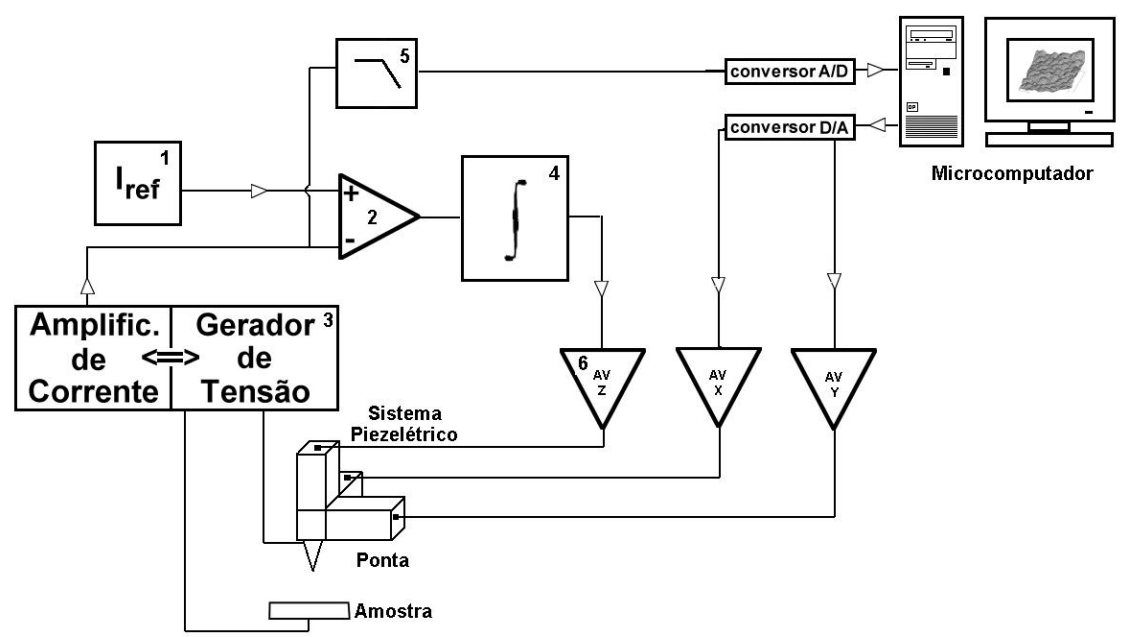

Figura 2: diagrama esquemático do funcionamento de um STM em modo de altura constante. Os componentes presentes são os mesmos que no modo de corrente constante. Todavia, neste modo a freqüência de varredura $x$-y é muito superior. Note que o circuito de retroação continua no sistema, porém sua função agora é manter a corrente média constante, e não mais fazer com que a ponta siga o perfil da superfície. O microcomputador constrói a imagem monitorando as variações da corrente de tunelamento. 
$\mathrm{Na}$ descrição dos dois métodos de aquisição, foi feita tacitamente a suposição de que a superfície analisada era homogênea. Relembrando a expressão de Simmons para a corrente de tunelamento, observa-se a dependência desta grandeza com a função trabalho da amostra. Neste contexto, qualquer diferença no valor da função trabalho entre dois pontos da mesma superfície será revelada como um desnível topográfico pelo STM. Um efeito semelhante ocorre em amostras semicondutoras expostas ao ar, nas quais a oxidação causa diversos efeitos sobre as características eletrônicas da superfície. ${ }^{3,4}$ Portanto, no caso de superfícies inomogêneas, uma imagem de STM possui uma mistura de dados topográficos e espectroscópicos. A solução desta questão será abordada no item seguinte.

\section{2- Modo Espectroscópico:}

Dos processos de aquisição das imagens citados acima, destacam-se cinco variáveis que caracterizam as medidas: três correspondentes à posição da ponta (x, y e z), além da tensão (V) e corrente de tunelamento (I). Na aquisição topográfica sob corrente constante, as duas últimas grandezas são mantidas invariáveis (ou, alternativamente, no modo de altura constante z e V são invariáveis). De modo geral, as medidas espectroscópicas são realizadas mudando-se a tensão aplicada através da junção (ou a posição z da ponta) e verificando as variações correspondentes na corrente de tunelamento. As diversas formas de medida neste modo, que conduzem a diferentes informações sobre a amostra, são descritas à seguir.

\subsection{1- Espectroscopia $\pm V$ :}

Este modo de aquisição é operacionalmente simples, embora possa conduzir a resultados muito interessantes. ${ }^{5}$ Para implementá-lo, basta efetuar duas imagens distintas de uma mesma área da amostra, com polaridades opostas da tensão na junção. Na condição de polaridade negativa (ou seja, quando a amostra se encontra em um potencial elétrico negativo em relação à ponta), os elétrons sofrem tunelamento no sentido da amostra para a ponta, sendo observados então os estados ocupados da superfície da amostra. Por outro lado, com polaridade positiva são observados os estados não ocupados (vazios).

Tecnicamente, esta modalidade de medida é limitada pelo tempo necessário a cada aquisição. Seria muito fácil efetuar uma imagem completa com a polaridade positiva e, em seguida, outra imagem com a polaridade inversa. Todavia, entre o início da primeira e o final da segunda varredura, podem ocorrer efeitos indesejáveis como deslocamentos térmicos e histerese no elemento piezelétrico que controla a varredura. Isto levaria a uma segunda imagem representando uma área diferente da primeira. Para contornar tais problemas, a solução ideal é adquirir as duas imagens simultaneamente, tomando no mesmo ponto da amostra dados com polaridade positiva e negativa consecutivamente. ${ }^{6}$ Não obstante, diversos autores mostram a possibilidade de efetuar a varredura da linha com polaridade positiva e, no final dela, inverter a polaridade e varrer a mesma linha novamente. ${ }^{7}$ Outro método relatado na literatura é a inversão da polaridade da tensão em linhas alternadas da varredura. ${ }^{8} \mathrm{O}$ tempo de transição da polaridade deve ser o mais rápido possível para minimizar o tempo da medida, mas antes que a aquisição seja feita é preciso esperar que o circuito de retroação estabilize a ponta no novo valor da corrente. ${ }^{7}$ Se estas condições não puderem ser implementadas de maneira satisfatória, pode-se usar o elemento Sample and Hold que paralisa o circuito de retroação durante esta transição, impedindo qualquer resposta inconveniente do sistema. 


\subsection{2- Espectroscopia I-V:}

Uma vez que a corrente de tunelamento depende da densidade local de estados próximos à energia de Fermi, é possível mapear a estrutura eletrônica da amostra em questão alterando o modo de operação do STM. Efetuando a varredura contínua dos valores da tensão V na junção, por exemplo de $-3 \mathrm{~V}$ a $+3 \mathrm{~V}$, ocorre uma variação da janela de energias $\Delta \mathrm{E}=\mathrm{e} . \mathrm{V}$ (ver Figura 3) dos estados eletrônicos que contribuem para a corrente de tunelamento. Características locais da estrutura eletrônica do material, como gap de energia e comportamento da corrente relacionado com os estados ocupados e vazios, podem ser reveladas monitorando-se o sinal da corrente de tunelamento em função da tensão aplicada. Resumidamente, é possível dizer que as informações contidas numa curva I-V caracterizam a LDOS da região analisada.

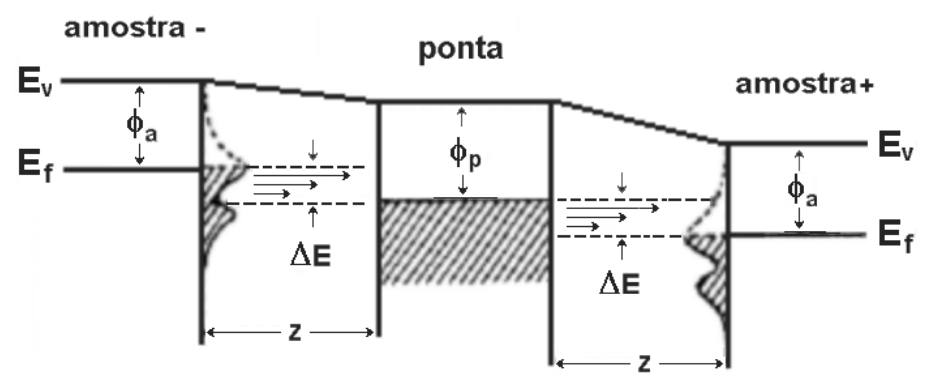

Figura 3: representação de uma junção de tunelamento constituída por uma ponta e uma superfície metálica. O esquema da esquerda (direita) corresponde a uma situação em que uma tensão negativa (positiva) é aplicada à amostra, permitindo ocorrer tunelamento dos estados ocupados da amostra (ponta) para os estados vazios da ponta (amostra). Note-se que apenas os estados com energia no intervalo $\Delta E$ podem contribuir. A densidade de estados da amostra é esboçada: a região achurada em linhas cheias corresponde aos estados ocupados e a parte tracejada corresponde aos estados vazios. As setas indicam a probabilidade de tunelamento, enquanto $\phi_{\mathrm{a}} e \phi_{\mathrm{p}}$ indicam a função trabalho da amostra e da ponta, respectivamente (figura extraída da referência 14).

$\mathrm{Na}$ maioria dos aparatos experimentais descritos na literatura, o microcomputador aplica a rampa de tensão à junção de tunelamento e lê os respectivos valores da corrente. Durante este processo, o sinal da retroação é paralisado através do módulo Sample and Hold. Deste modo, é possível variar a tensão de tunelamento mantendo a distância ponta-amostra constante. Além da implicação teórica envolvida neste aspecto, experimentalmente este procedimento impede que a ponta colida contra a amostra quando a tensão passa pelo valor nulo. A Figura 4 traz um esquema deste modo de medida. Uma forma alternativa é gerar a rampa a uma freqüência acima da resposta do circuito de retroação. A distância ponta-amostra é então mantida constante sem a necessidade do módulo Sample and Hold. Todavia, a aquisição é limitada pela resposta em freqüência do circuito pré-amplificador de corrente que deve ter um valor de corte superior àquela com a qual a rampa é gerada. 


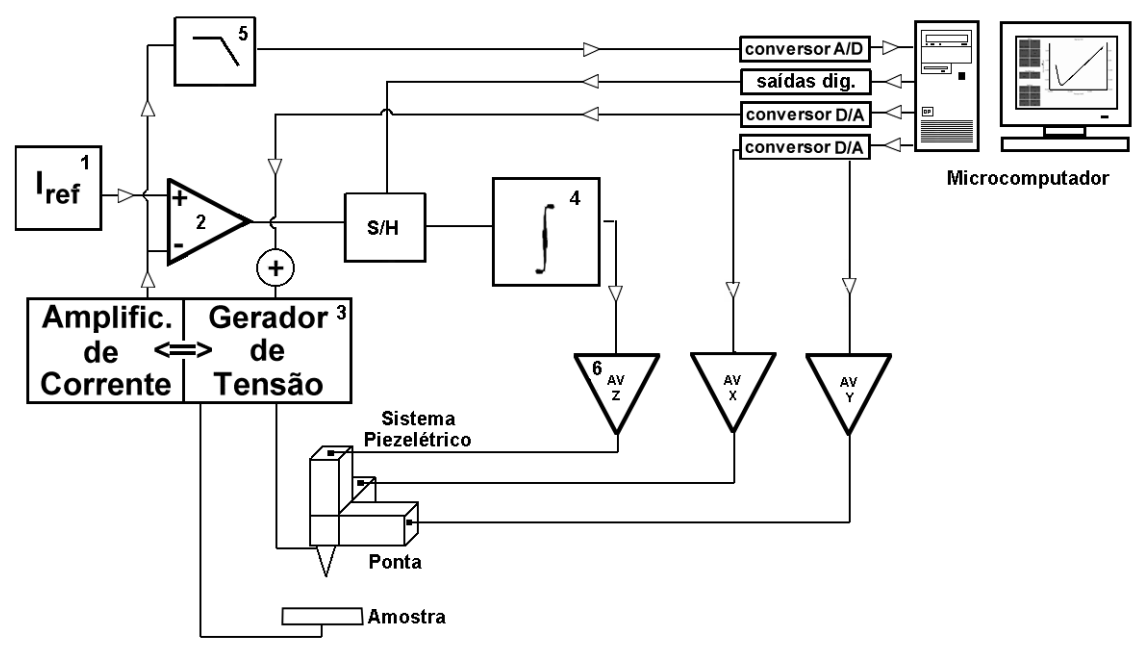

Figura 4: esquema da configuração experimental para a aquisição de uma curva I-V. Os módulos envolvidos são basicamente os mesmos usados no modo topográfico. Em adição, existe agora o componente Sample and Hold (S/H na figura) posicionado no ramo da retroação. Seu acionamento é controlado pelo microcomputador, via um bit de controle. Um canal do conversor D/A gera uma rampa de tensão que é somada à tensão DC da junção. Os respectivos valores da corrente são lidos pelo microcomputador através da placa conversora $A / D$.

As vantagens da espectroscopia de tunelamento através do vácuo em relação às junções metal-isolante-metal sólidas são claras:

- Com um STM, é possível variar facilmente a distância entre eletrodos (no caso, ponta e amostra) bem como a posição lateral relativa entre ambos. Em uma junção sólida, este procedimento demanda o preparo de uma amostra diferente para cada configuração a ser analisada;

- Não há o inconveniente da quebra de isolação da junção. Isto permite uma variação maior na janela de tensões, possibilitando o acesso a uma gama maior de informações das amostras;

- Possibilidade da aquisição de informações espectroscópicas locais, cuja resolução é limitada fundamentalmente pela dimensão lateral da ponta.

Estudos espectroscópicos muito interessantes relatados na literatura (ver por exemplo as referências 9, 10 e 11) foram realizados sem a necessidade da obtenção de informações topográficas concomitantemente, graças ao caráter homogêneo da amostra. No entanto, para extrair o máximo da capacidade da espectroscopia de tunelamento com um STM, é muitas vezes necessário obter uma curva I-V para cada ponto da imagem. Esta técnica é conhecida por CITS (current imaging tunneling spectroscopy), ${ }^{6,12}$ e possui algumas características restritivas. Supondo que, juntamente com uma imagem topográfica de 100x100 pontos, deseja-se efetuar uma curva I-V de 100 valores em cada uma dessas locações. Se cada dado espectroscópico corresponder a dois bytes, tem-se um montante de 100x100x100x2 bytes, que corresponde à 1,9Mbytes de informação. Outro fator marcante é o tempo necessário para a aquisição de todos estes dados. Um valor típico para a geração da rampa é de alguns milisegundos, fazendo que um tempo da ordem de dezenas de segundos seja adicionado ao montante normal de aquisição da topografia. Todavia, a capacidade de sondar, a nível atômico, propriedades eletrônicas locais compensa toda onerosidade da técnica. 
Diversos autores ${ }^{13,14}$ chamam a atenção para a dificuldade da reprodução e interpretação dos dados espectroscópicos obtidos por esta técnica. O primeiro fator é a estrutura eletrônica da ponta. Experimentalmente, verificou-se que a presença de impurezas na ponta pode afetar de modo indesejável os resultados. ${ }^{15}$ Não obstante, foi provado que, tomando os devidos cuidados na preparação, sua influência sobre os dados torna-se desprezível. ${ }^{16}$ Outro fator argüido é a geometria da ponta. Considerando uma configuração ideal, com um único átomo no ápice, haveria um limite na resolução do momento devido ao princípio de incerteza $\Delta \mathrm{k} \cdot \Delta \mathrm{x} \geq \mathrm{h} / 4 \pi$. Por outro lado, se a dimensão da ponta for aumentada, haverá perda na resolução espacial. ${ }^{14} \mathrm{Na}$ prática porém, a despeito desses problemas teóricos, vários autores relatam resultados espectroscópicos a nível atômico, comprovando a viabilidade da técnica. Hamers e colaboradores, na referência 6 , relatam estudos sobre $\operatorname{Si}(111) 7 \times 7$. Outro exemplo é o trabalho de Bando e colaboradores,${ }^{17}$ com estudos similares sobre grafite. A continuidade de filmes finos de ouro depositados sobre GaAs(001) foi estudado por Chorniy e Adkins ${ }^{18}$ adquirindo simultaneamente topografia e distribuição da condutividade (relacionada diretamente à curva IV) sobre a superfície.

\subsection{3- Determinação da altura da barreira de tunelamento:}

No capítulo anterior, foi revisada a teoria da altura da barreira de tunelamento bem como sua relação com a função trabalho. No âmbito teórico, a altura da barreira é relacionada com a derivada do logaritmo da corrente de tunelamento em relação à distância ponta-amostra, mantendo constante a diferença de potencial através da junção (ver expressão 12 do capítulo anterior). Vários autores ${ }^{19,20}$ apresentam a superfície da amostra usando os valores da altura aparente da barreira a cada ponto em complemento à topografia. Experimentalmente, este modo de medida pode ser implementado de diversas formas. A mais intuitiva delas é aplicar uma rampa de tensão ao elemento piezelétrico $\mathrm{z}$, mantendo a retroação desativada através do elemento Sample and Hold. Isto muda a posição vertical s da ponta em relação à amostra. Adquirindo os valores correspondentes da corrente de tunelamento, obtém-se uma curva I-s a partir da qual é possível calcular a altura da barreira. Uma variação de alguns angströns deve ser estabelecida, de modo a obter-se um limite dinâmico adequado para a análise. A desvantagem deste método, em contrapartida à simplicidade experimental, é a necessidade de uma análise posterior dos dados, o que impede a coleta de dados com resolução lateral em tempo real. Uma forma alternativa é o uso do módulo lock-in na aquisição. Adicionando uma pequena modulação (correspondente a uma fração de angströns na distância ponta-amostra) na tensão do elemento piezelétrico z, é possível obter a derivada da corrente em relação à distância, em tempo real, através do lock-in. Inserindo ainda um amplificador logarítmico (que gera em sua saída o logaritmo do sinal de entrada) entre o pré-amplificador de corrente e este módulo, obtém-se uma grandeza proporcional à raiz quadrada da altura da barreira. $\mathrm{O}$ valor da frequiência de modulação deve ser superior à resposta do circuito de retroação, permitindo que a distância entre a ponta e a amostra possa variar, e inferior ao valor de corte do circuito pré-amplificador de corrente. Neste modo de aquisição, o circuito Sample and Hold é desnecessário. A Figura 5 mostra um esquema do aparato experimental. 


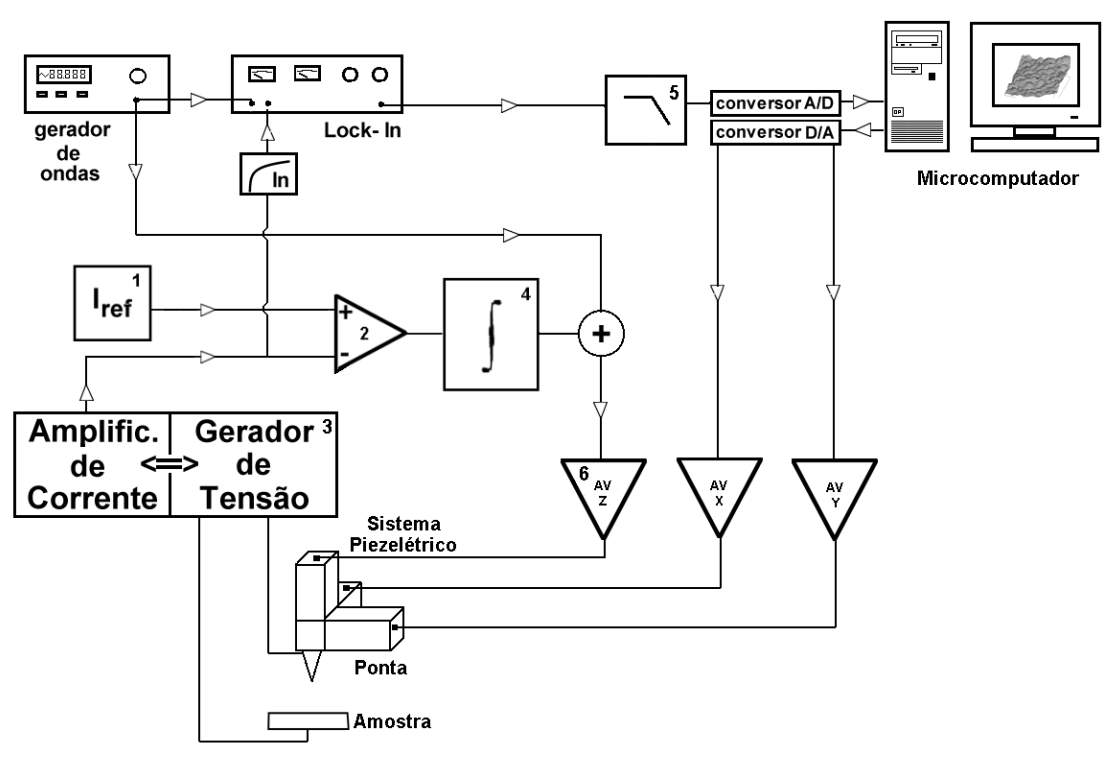

Figura 5: esquema do aparato experimental comumente usado na medida da altura aparente da barreira de tunelamento. O gerador de ondas cria uma modulação que é somada ao sinal aplicado no elemento piezelétrico z. Se a freqüência desta modulação for superior à resposta do circuito integrador (4), a distância ponta-amostra s será alterada, conduzindo a uma variação correspondente na corrente de tunelamento I. Um amplificador logarítmico gera em sua saída o $\ln (\mathrm{I})$. O módulo lock-in recebe este sinal e fornece a derivada dlnI/ds, proporcional à altura da barreira. O microcomputador lê este sinal em cada ponto da superfície e constrói a imagem correspondente.

Com o uso de um multiplexador, uma chave analógica que permite a seleção de um entre vários sinais, é possível obter seqüencialmente a topografia e a variação da função trabalho na amostra. Esta técnica foi usada na referência 21, onde os autores estudaram a variação desta grandeza nas bordas de terraços em uma amostra de $\mathrm{Au} / \mathrm{Cu}(111)$. Ainda nos primórdios da técnica, Binnig e Rohrer ${ }^{19}$ realizaram estudos desta ordem sobre uma amostra de Si com uma fina cobertura de ouro formando algumas ilhas. Os autores verificaram que os perfis obtidos monitorando-se a altura da barreira apresentavam relevos mais acentuados que os correspondentes perfis topográficos. Paralelamente, o grande potencial deste modo de medida é a possibilidade de associar um relevo da imagem à própria variação de topografia da amostra, ou à uma eventual diferença de funções trabalho ou mesmo à ambas as causas. Se, por exemplo, na imagem topográfica observar-se uma saliência, enquanto na imagem correspondente à função trabalho não forem observadas variações, pode-se associar univocamente este relevo à topografia real da amostra. No caso do trabalho supra citado de Binnig e Rohrer, o relevo topográfico proveio tanto do formato das ilhas de ouro sobre o substrato de Si como da diferença acentuada de função trabalho destes dois materiais.

\section{Referências:}

1 G. Binnig e H. Rohrer, Helv. Phys. Acta 55, 726 (1982).

2 D. Sarid, T. D. Henson, N. R. Armstrong e L. S. Bell, Appl. Phys. Lett. 52, 2252 (1988).

3 G. M. Guryanov, G. E. Cirlin, V. N. Petrov, N. K. Polyakov, A. O. Golubok, S. Ya. Tipissev, V. B. Gubanov, Yu. B. Samsonenko, N. N. Ledentsov, V. A. Shchukin, M. Grundmann, D. Bimberg, Zh. I. Alferov, Surf. Sci. 352-354, 651 (1996). 
4 A. S. Ferlauto e A. A. Quivy, Modern Physics Letters B 10(24), 189 (1996).

5 R. M. Feenstra e J. A. Stroscio, Phys. Scr. T19, 55 (1987).

6 R. J. Hamers, R M. Tromp e J. E. Demuth, Phys. Rev. Lett. 56, 1972 (1986).

7 L. E. C. Leemput em Tunneling Microscopy and Spectroscopy of High Tc Superconductor and Mesoscopic Systems, tese de Doutorado pela Katholieke Universiteit te Nijmegen, 1991.

8 J. A. Stroscio, R. M. Feenstra e A. P. Fein, Phys. Rev. Lett. 57, 2579 (1986).

9 R. J. Colton, S. M. Baker, R. J. Driscoll, M. G. Youngquist e J. D. Baldeschwieler, J. Vac. Sci. Technol. A 6, 349 (1988).

10 R. M. Feenstra e J. A. Stroscio, J. Vac. Sci. Technol. B 5, 923 (1987).

11 S. N. Patitsas, T. Tiedje e S. Eisebitt, Precedings of 23 Int. Conf. on The Phys. of Semiconductor, Vol. 2, 827 (1996).

12 P. H. Schroer e J. Becker, IBM J. Res. Dev. 30, 543 (1986).

13 R. M. Tromp, J. Phys.: Condens. Matter 1, 10211 (1989).

14 F. Besenbacher, Rep. Prog. Phys. 59, 1737 (1996).

15 R. M. Tromp, E. J. van Loenen, J. E. Demuth e N. D. Lang, Phys. Rev. B 37, 9042 (1988).

16 R. M. Feenstra, Surf. Sci. 299, 965 (1994).

17 H. Bando, N. Morita, H. Tokumoto, W. Mizutani, K. Watanabe, A. Homa, S. Wakiyama, M. Shigeno, K. Endo e K. Kajimura, J. Vac. Sci. Techonol. A 6, 344 (1988).

18 V.Z. Chorniy e C. J. Adkin, Phys. Rev. B 53, 9606 (1996).

19 G. Binnig e H. Rohrer, Surf. Sci. 126, 236 (1983).

${ }^{20}$ B. Marchon, P. Bernhardt, M. E. Bussel, G. A. Somorjai, M. Salmeron e W. Siekhaus, Phys. Rev. Lett. 60, 1166 (1988).

21 J. F. Jia, K. Inoue, Y. Hasegawa, W. S. Yang, T. Sakurai, Phys. Rev. B 58, 1193 (1998). 


\section{Capítulo 3}

\section{CONSTRUÇÃO DE UM STM:}

Neste capítulo se encontra a descrição do STM desenvolvido no Laboratório de Novos Materiais Semicondutores do IFUSP. Sua construção foi iniciada no ano de 1995, e no começo de 1996 o equipamento já era capaz de investigar a topografia da estrutura cristalina de amostras ao nível atômico. Como parte do objetivo desta dissertação, discorro também sobre as rotinas e circuitos de aquisição adicionados para coleta de dados em modo espectroscópico, bem como sua relação com os módulos já existentes. Sempre quando pertinente, uma breve revisão das características dos equipamentos presentes na literatura também é apresentada.

De modo geral, um STM pode ser dividido em três partes bem distintas: a parte mecânica, na qual o fenômeno de tunelamento ocorre; o sistema eletrônico, cuja função é detectar a corrente de tunelamento e aplicar os sinais convenientes ao elemento piezelétrico e, finalmente, um microcomputador que comanda a varredura e constrói a imagem da superfície estudada.

\section{1- Sistema Mecânico:}

\subsection{1- Isolamento de Vibrações:}

As vibrações mecânicas presentes no ambiente têm uma influência acentuada sobre um instrumento como o STM. A maior contribuição vem das vibrações presentes no prédio do laboratório, que abrangem um espectro de freqüências entre 1 e $100 \mathrm{~Hz}$, com amplitudes desde 0,5 a 150nm. ${ }^{1}$ Comparando estas amplitudes com a resolução necessária para obter-se uma imagem à nível atômico, $0,01 \mathrm{~nm}$ na direção vertical e $0,1 \mathrm{~nm}$ na direção paralela à amostra, fica clara a necessidade de um sistema eficiente no isolamento de vibrações.

Sob um ponto de vista cronológico, os sistemas de isolamento mecânico aplicados em microscópios de tunelamento sofreram uma grande simplificação. No primeiro protótipo de Binnig e Rohrer, ${ }^{2}$ foi utilizado um aparato de levitação magnética baseado em um imã permanente e um recipiente supercondutor resfriado com He líquido. Desde então, este sistema foi abandonado. Um grande passo em direção à simplicidade foi o uso de molas que suspendem o corpo do STM. Tais sistemas atuam como filtros que deixam passar as baixas frequiências (passa-baixas). Assumindo um modelo simplificado de massa-mola, a freqüência de corte $\mathrm{f}_{0}$ é dada por $2 \pi \mathrm{f}_{0}=\sqrt{ }(\mathrm{g} / \Delta \mathrm{l})$, onde $\Delta \mathrm{l}$ é o alongamento da mola e $\mathrm{g}$ a aceleração da gravidade. Por exemplo, com uma distensão de $25 \mathrm{~cm}$ da mola de suporte (em seu regime elástico) obtém-se uma frequiência de corte de $1 \mathrm{~Hz}$.

Um outro método de isolação foi sugerido por Gerber $^{3}$ e é constituído por várias placas metálicas intercaladas com pedaços de viton, que assumem ao mesmo tempo a função de molas e 
dissipadores de energia mecânica (amortecedores ou dampers). O amortecimento é essencial em um sistema antivibratório devido a um pico de ressonância geralmente presente no valor da frequiência de corte. Esta ressonância pode aumentar consideravelmente a amplitude da vibração (ao invés de atenuá-la) na ausência de uma dissipação eficiente. No entanto, a frequiência de corte deste tipo de montagem é superior àquela do sistema descrito anteriormente. Por exemplo, supondo uma compressão típica de $1 \mathrm{~mm}$ dos pedaços de viton entre as placas, a frequiência de corte assume um valor de $16 \mathrm{~Hz}$. Esta restrição pode ser contornada aumentando o número de estágios do sistema, assegurando assim uma maior atenuação.

No sistema implementado em nosso equipamento, utilizou-se uma mistura dos dois últimos esquemas descritos. Uma placa metálica foi suspensa por quatro tensores de borracha fixos no forro do laboratório. O ponto de fixação escolhido situa-se próximo à interseção de duas vigas de sustentação da laje, fato que diminui a propagação de vibrações através da própria construção. $\mathrm{O}$ uso dos tensores fornece ao mesmo tempo atenuação e amortecimento das vibrações, graças à fricção visco-elástica das tiras de borracha que os constituem. Para assegurar um maior amortecimento, sobre a placa foi montado um sistema com três discos de metal intercalados por pedaços de viton. Em cima deste conjunto, é colocado um dos módulos eletrônicos que detecta e amplifica a corrente de tunelamento, acondicionado em um pequeno cilindro oco de latão ao qual são fixados diversos conectores. Acima deste cilindro, são colocadas mais duas camadas de placas metálicas e viton para atenuar vibrações residuais propagadas através dos cabos a ele conectados. Finalmente, a cabeça de medida é disposta sobre este conjunto, como mostra a Figura 1. Com esta montagem, é possível adquirir imagens com um mínimo de interferência do ambiente.

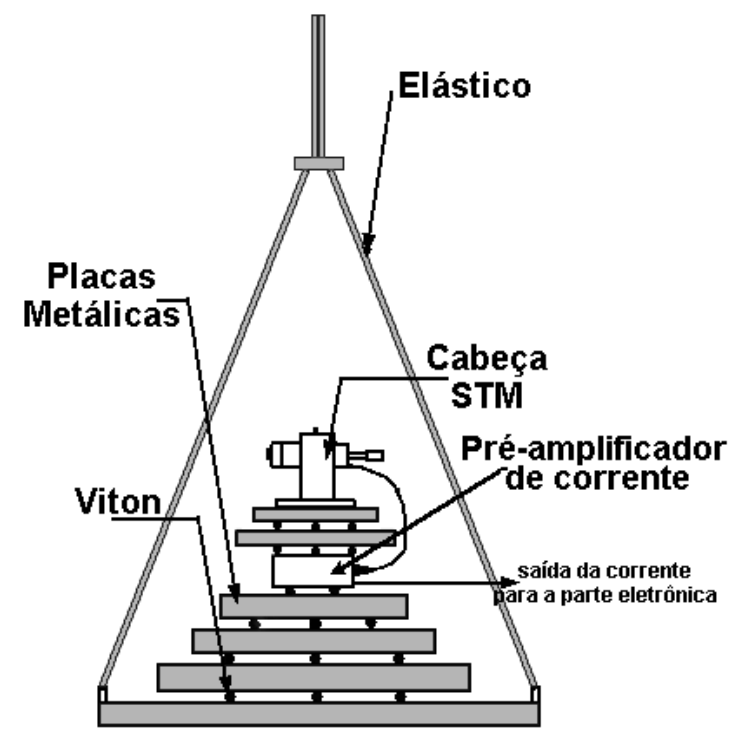

Figura 1: sistema de isolamento de vibrações existente no STM construído no LNMS. As partes em cinza constituem os elementos ativos neste aparato, enquanto os desenhos em branco representam a cabeça de medida e, logo abaixo, o pré-amplificador da corrente de tunelamento conectado externamente ao restante dos módulos eletrônicos.

Em conjunto com este sistema externo de isolação, a própria cabeça de medida deve operar como um elemento supressor de vibrações. ${ }^{4,5}$ A escolha adequada das dimensões e da rigidez do conjunto constituído pelo elemento piezelétrico, ponta e porta-amostras pode ser o fator determinante no desempenho do equipamento. A cabeça em si constitui um filtro passaaltas, devido à sua rigidez intrínseca. Desta forma, baixas freqüências movem ponta e amostra 
em conjunto (não interferindo na junção), enquanto que vibrações de valor superior à da menor freqüência interna de ressonância da cabeça podem variar tanto a distância vertical quanto a posição lateral da ponta em relação à amostra. A resposta do conjunto como um todo é o produto da ação do filtro passa-baixas (formado pelo sistema anti-vibratório) e do filtro passa-altas constituído pelo próprio STM. Assumindo para este conjunto o modelo de osciladores acoplados, ${ }^{5}$ a curva de transferência do sistema resulta em um platô de atenuação constante, limitado pelas frequiências de corte de cada filtro. A Figura 2 traz um exemplo deste tipo de função.

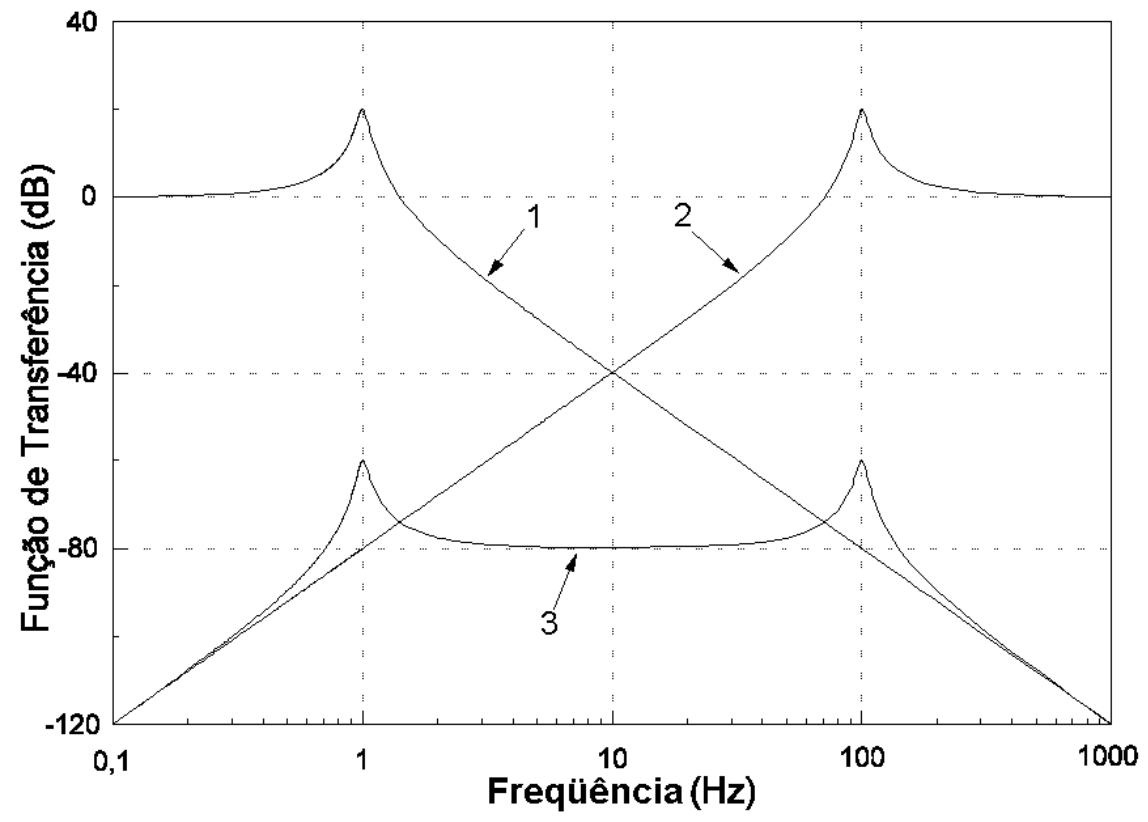

Figura 2: exemplo da função de transferência de um sistema de isolamento de vibrações (curva 1) (com freqüência de corte $1 \mathrm{~Hz}$ ), do STM (valor de corte $100 \mathrm{~Hz}$ )( curva 2) e da combinação dos dois (curva 3) assumindo o modelo de osciladores acoplados (ver referência 5).

\subsection{2- Sistema de movimentação da ponta:}

Este sistema é responsável por efetuar a varredura da ponta acima da amostra (direções x e y) bem como controlar a distância ponta-amostra (z). É importante que sua configuração conduza a altas freqüências internas de ressonância, já que elas permitem uma grande rejeição das vibrações do ambiente e são um fator limitante da velocidade máxima de varredura. A sensibilidade também é fundamental, tanto para a obtenção de uma faixa extensa de áreas possíveis para varredura quanto para sondar relevos com diferenças acentuadas na altura. A ortogonalidade é desejada, de modo a prover independência entre o movimento em cada uma das três direções. A linearidade também é indispensável, ou seja, os deslocamentos devem variar linearmente com as tensões aplicadas.

Desde o primeiro protótipo desenvolvido por Binnig e Rohrer, o efeito piezelétrico inverso obtido em cerâmicas PZT foi usado para criar mecanismos que satisfaçam estes requisitos. De fato, este tipo de material já era largamente utilizado em dispositivos de microposicionamento. As cerâmicas PZT são ligas de óxidos de chumbo, zircônio e titânio ( $\mathrm{PbO}$, $\mathrm{ZrO}_{2}$ e $\left.\mathrm{TiO}_{2}\right)$. Em sua composição, deve existir um número igual de cátions bivalentes $\left(\mathrm{Pb}^{2+}\right)$ e tetravalentes $\left(\mathrm{Zr}^{4+}, \mathrm{Ti}^{4+}\right)$, que conduzem à fórmula geral $\mathrm{Pb}\left(\mathrm{Zr}_{\mathrm{x}} \mathrm{Ti}_{1-\mathrm{x}}\right) \mathrm{O}_{3}$, onde $\mathrm{x}$ pode variar de 0 
a $1 .^{6}$ Este material pode ser moldado em qualquer formato e tamanho, gerando peças mecanicamente resistentes e quimicamente inertes. A propriedade piezelétrica é estabelecida durante a manufatura, através da polarização dos momentos elétricos dipolares dos microcristais que constituem o material. Isto cria um momento elétrico dipolar macroscópico na direção desejada para o uso em questão. A superfície da peça acabada é recoberta por uma camada fina de metal que constituirá seus eletrodos. A manifestação do efeito piezelétrico pode ocorrer através de dois mecanismos intimamente relacionados. $\mathrm{O}$ efeito gerador ocorre quando $\mathrm{o}$ material muda seu estado de polarização (gerando uma diferença de potencial) devido a uma tensão mecânica nele exercida. Já o efeito motor (ou efeito inverso) é a mudança na geometria do material causada pela aplicação de campos elétricos.

No início da técnica, os sistemas de movimentação da ponta eram baseados em um conjunto de barras de cerâmica PZT. Três dessas barras (uma para cada direção) eram fixadas em direções ortogonais, encontrando-se em um vértice comum no qual localizava-se a ponta (configuração tripod). Seu funcionamento é direto: uma diferença de potencial aplicada nos eletrodos de uma das barras efetua o movimento na direção correspondente, devido ao efeito motor. Este tipo de montagem apresenta baixa sensibilidade $\left(15 \AA / \mathrm{V}\right.$, no caso citado por Binnig $\left.{ }^{7}\right)$ e baixas frequiências de ressonância mecânica (entre 1 e $8 \mathrm{kHz},{ }^{8}$ dependendo do comprimento das barras). Binnig e $\mathrm{Smith}^{7}$ foram os primeiros a proporem o sistema de movimentação baseado em um tubo oco de cerâmica piezelétrica. Para obter o deslocamento nas três direções espaciais, os autores dividiram o eletrodo externo de um cilindro em quatro partes iguais ao longo de seu comprimento. Aplicando uma voltagem (cuja polaridade dependerá da polarização da cerâmica) a um desses eletrodos, o segmento correspondente do tubo se expandirá na direção perpendicular ao campo elétrico (efeito motor). ${ }^{*}$ Isto causa uma flexão do tubo na direção perpendicular ao seu eixo. O movimento de varredura é obtido controlando-se as voltagens aplicadas em dois eletrodos adjacentes, enquanto os outros dois eletrodos são aterrados. O movimento na direção z é obtido aplicando-se uma tensão elétrica no eletrodo interno ao cilindro, causando um alongamento uniforme. Esta montagem é muito mais rígida e compacta que aquela descrita anteriormente, possuindo freqüências de ressonância mecânica superiores $(8 \mathrm{kHz}$ na direção perpendicular ao eixo do tubo e $40 \mathrm{kHz}$ na direção paralela, na construção relatada por Binnig e Smith) e maior sensibilidade (da ordem de centenas de $\AA / V$ ). Quando a ponta é fixada no centro do tubo, seu movimento x-y não é totalmente ortogonal à z. Este empecilho pode ser minimizado fixando-a sobre um dos eletrodos externos, através de um isolamento elétrico conveniente.

C. J. Chen ${ }^{9}$ analisou as deflexões deste tipo de montagem. Usando cálculos envolvendo diretamente a teoria da elasticidade, o autor obteve a expressão para a deflexão do tubo na direção perpendicular ao seu eixo: $x(V)=\sqrt{ } 2 d_{31} V_{L}^{2} / \pi D h$, onde $d_{31}$ é a constante piezelétrica da cerâmica, L o comprimento, $\mathrm{D}$ seu diâmetro e $\mathrm{h}$ a espessura da parede. A expressão para y é similar, devido à simetria do tubo.

A configuração implementada para nosso equipamento é uma modificação da montagem descrita acima. Foram usados tubos de cerâmica piezelétrica PZT-5H, ${ }^{10}$ com dimensões $12,7 \mathrm{~mm}$ de comprimento, $6,35 \mathrm{~mm}$ de diâmetro externo e paredes de $0,51 \mathrm{~mm}$ de espessura. Sua superfície é originalmente coberta por uma fina camada metálica contínua. A separação dos eletrodos é feita através de corrosão química usando uma solução alcalina de hidróxido de amônia $\left(\mathrm{NH}_{4} \mathrm{OH}\right)$ e peróxido de hidrogênio $\left(\mathrm{H}_{2} \mathrm{O}_{2}\right)$ na proporção 1:1. Para defini-los, é feita uma máscara de

\footnotetext{
* Este é um efeito secundário: o campo elétrico faz com que as paredes do cilindro se retraiam em sua direção; para manter constante a quantidade de material nesta região, o cilindro deve aumentar sua altura, conduzindo ao resultado desejado.
} 
esmalte ou verniz sobre as áreas que não se deseja corroer antes de mergulhar o cilindro na solução. Nesta construção, apenas quatro eletrodos são definidos, sendo um deles o interno (z), outros dois responsáveis pelo movimento x e y e o último reservado para aterrar os sinais x e y, como mostra a Figura 3. Uma fina tira do eletrodo também é retirada das partes superior e inferior do cilindro, de modo a assegurar o isolamento elétrico do resto do microscópio. A calibração final foi feita por interferometria óptica e pela observação direta da estrutura atômica de uma amostra de grafita. ${ }^{11}$ Os valores obtidos foram $100 \AA / \mathrm{V}$ para as direções x e y e $77 \AA / \mathrm{V}$ na direção z. Estes números afirmam a necessidade de um sistema de alta tensão na aplicação dos sinais, com a finalidade de obter áreas de varredura da ordem de micrometros.

Uma configuração alternativa foi também implementada em nosso microscópio. Nela, são usados dois tubos unidos de forma concêntrica. O tubo interno é responsável somente pelo movimento da ponta na direção $\mathrm{z}$, enquanto o externo é divido verticalmente em quatro quadrantes (tanto no eletrodo externo quanto no eletrodo interno ao tubo) e efetua o movimento $\mathrm{x}-\mathrm{y}$. Aplicando tensões de polaridades opostas em quadrantes opostos, uma das paredes se eleva enquanto a outra é retraída, permitindo uma deflexão duas vezes maior na direção paralela à amostra. Em adição, o movimento $\mathrm{x}-\mathrm{y}$ não causa nenhuma influência na posição $\mathrm{z}$ da ponta. Apesar das vantagens claras desta configuração, sua montagem é mais onerosa pois necessita um número maior de contatos elétricos e a colagem entre os dois tubos. Isto aumenta sua sensibilidade às vibrações externas.

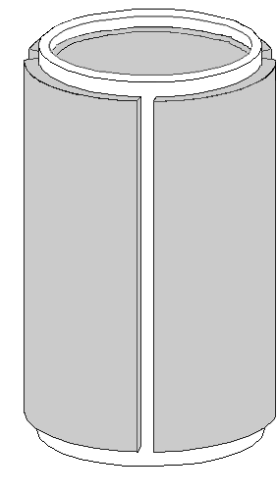

a

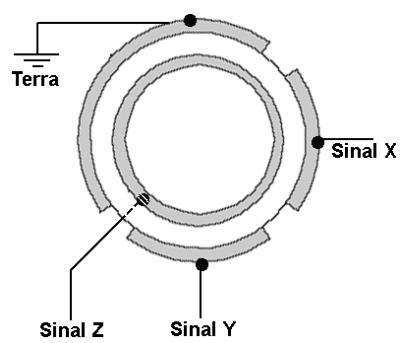

b
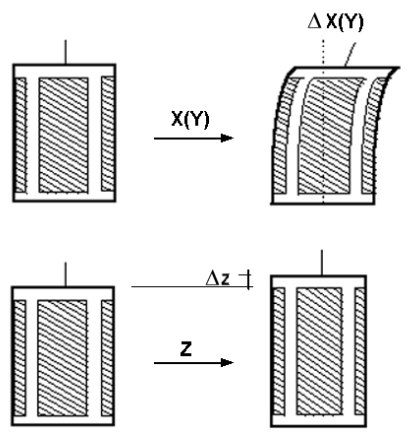

$\mathrm{c}$

Figura 3: (a) aspecto externo do elemento piezelétrico utilizado no movimento da ponta de nosso STM. (b) vista de topo do elemento, mostrando os contatos elétricos estabelecidos e os respectivos sinais aplicados. (c) diagrama de seu funcionamento. A parte de cima mostra o movimento $x-y$, enquanto a inferior ilustra o alongamento na direção $z$.

Alguns efeitos indesejáveis podem ocorrer no uso das cerâmicas PZT. O creep consiste num atraso na resposta da deflexão do elemento piezelétrico em relação à tensão aplicada. A histerese por sua vez faz com que a ponta não retorne à mesma posição após um ciclo completo na tensão. Estes dois efeitos são relevantes apenas durante a aplicação de campos elétricos elevados em cerâmicas de alta sensibilidade (correspondente a grandes deslocamentos da ponta). Muitas das propriedades das cerâmicas piezelétricas tendem a mudar logaritmicamente com o tempo após sua manufatura (polarização). Quanto maior este tempo, mais estáveis elas se tornam. Alguns fatores podem acelerar sua degradação, como a atuação de esforços mecânicos intensos, altos campos elétricos ou temperaturas elevadas (próximas ao ponto de Curie do material). 


\subsection{3- Ponta:}

Um fator importante para a acuidade da imagem é o formato da ponta utilizada. Segundo o modelo de Tersoff, uma ponta ideal deveria ter um raio de curvatura $\mathrm{R}$, de tamanho reduzido o suficiente para satisfazer a condição da resolução $[2 \AA(R+s)]^{1 / 2}$, onde s é a distância pontaamostra. Freqüentemente, o processo de manufatura não logra êxito, podendo gerar uma ponta cujo formato não é conveniente. Dentre os casos bem conhecidos na literatura, ${ }^{12}$ destacam-se pontas arredondadas, planas, e até mesmo duas ou mais pontas num mesmo ápice.

Se a ponta for constituída por diversas minipontas, cada uma delas próxima à superfície, ao longo da varredura a corrente de tunelamento poderá fluir por várias delas, simultaneamente ou alternadamente. Esta situação conduz a imagens confusas, com repetição periódica de estruturas (ver esquema na Figura 4).

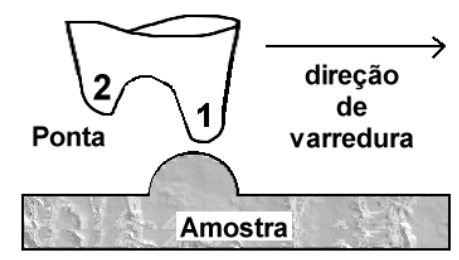

a
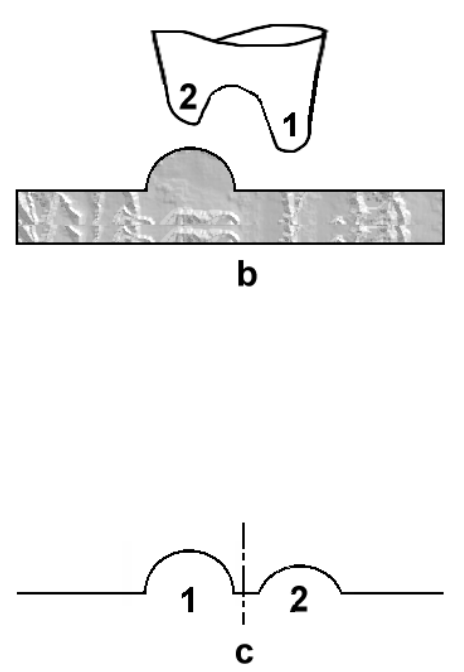
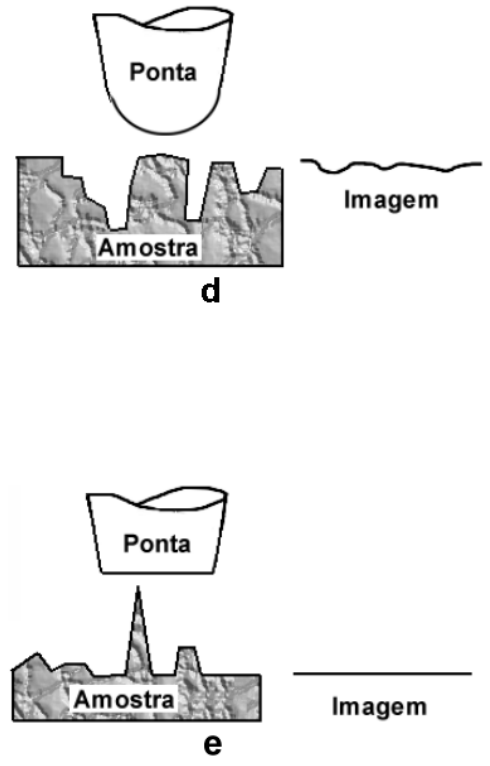

Figura 4: (a) esquema mostrando uma configuração (não desejada) de ponta dupla sondando uma protuberância na amostra. (b) a outra ponta passa sobre o mesmo relevo, o que é interpretado pelo STM como sendo uma segunda protuberância. O perfil medido será similar ao exibido em (c). (d) diagrama mostrando efeito do arredondamento da ponta sobre a rugosidade medida da superfície. (e) caso extremo de uma ponta achatada, onde ocorre a troca de funções entre a ponta e a amostra.

No caso de pontas arredondadas, ou seja, cujo raio de curvatura não é pequeno o bastante, observa-se redução na resolução do instrumento, podendo também conduzir à atenuação do valor da rugosidade da imagem em relação a seu valor real. ${ }^{13}$ Neste caso, pode ocorrer uma mistura 
entre as informações topográficas da amostra e da própria ponta. ${ }^{14}$ Em uma situação limite, quando há alguma protuberância aguda na amostra, a imagem revela apenas a topografia da ponta, ou seja, ponta e amostra trocam suas funções. A Figura 4 traz um exemplo destes casos.

Além do fator geométrico original da ponta, é comum a mudança de sua geometria, durante a varredura, devido à adsorção de impurezas ou mesmo pedaços da amostra. Este efeito é muitas vezes usado para melhorar a resolução das imagens. Ao efetuarem-se variações bruscas na tensão de tunelamento, ou mesmo fazendo uma varredura rápida a uma distância pequena da superfície, a ponta pode colidir levemente com a amostra. Dependendo de sua constituição, a amostra pode ceder parte de seu material para a ponta, formando então um novo ápice capaz de sondar propriamente sua superfície. ${ }^{15}$ A Figura 5 ilustra um exemplo deste fenômeno obtido com nosso microscópio.

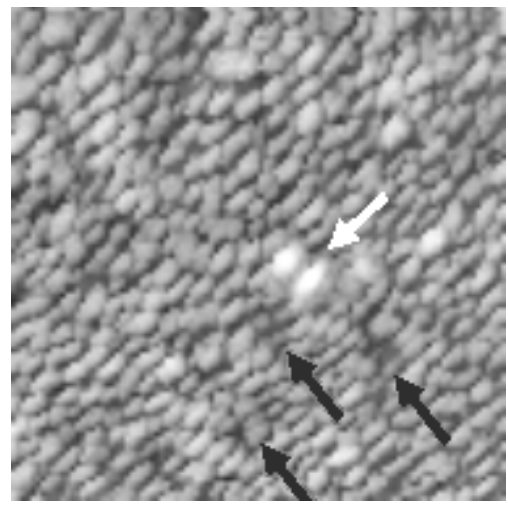

a

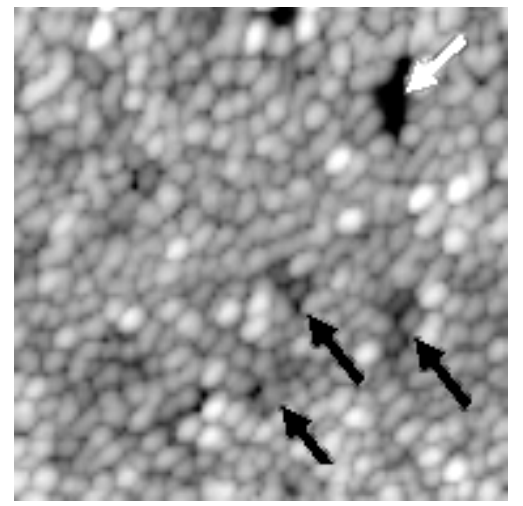

b

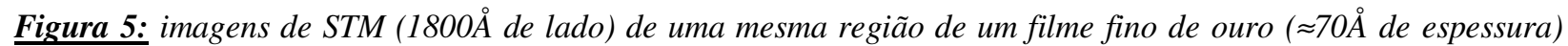
depositado sobre um substrato de grafite. A imagem (a) apresenta uma resolução baixa, impedindo a visualização conveniente das bordas dos clusters de ouro. Após a obtenção desta imagem, uma segunda varredura (não apresentada) foi realizada com alta freqüencia e uma corrente de tunelamento elevada (baixa distância ponta-amostra). Tais parâmetros tornaram possíveis colisões suaves entre a ponta e a amostra, permitindo a migração de alguns clusters do filme para a ponta, o que poderia melhorar a sua geometria. Isto é confirmado pela obtenção de uma imagem (b) com resolução satisfatória, obtida logo em seguida usando parâmetros de varredura idênticos aos da imagem (a). Algumas estruturas em comum são notadas em ambas imagens, indicadas pelas setas em preto. Também é possível observar diferenças, indicadas pelas setas brancas, confirmando a extração de algum material do filme fino.

O material que constitui a ponta contribui fundamentalmente em sua performance. Para operação no ar, deve-se escolher metais inertes, pois camadas de óxido sobre a ponta podem prejudicar tanto sua geometria quanto suas propriedades eletrônicas. Neste contexto, são muito utilizados os metais nobres (ouro e platina). Alguns tipos exóticos de ponta são obtidos com minas de grafite usadas em lapiseiras comuns, mostrando bom desempenho no ar. ${ }^{16}$ Para operação em ultra-alto vácuo, o tungstênio é usado sem problemas, com o adendo de apresentar certas vantagens na preparação. Todos estes materiais são disponíveis em fios de $0,1 \mathrm{a} 1 \mathrm{~mm}$ de diâmetro. Esta dimensão é importante, pois a freqüência mecânica de ressonância aumenta quanto mais finas e curtas forem as pontas.

Existem numerosos métodos descritos na literatura para tornar as pontas agudas. Na maioria dos processos, a ponta é afilada macroscopicamente usando corrosão eletroquímica, ${ }^{17,18}$ desgaste mecânico ou mesmo através do corte com uma tesoura. Estes métodos produzem pontas de qualidade suficiente para a obtenção de imagens com resolução atômica sobre superfícies lisas. Isto é devido à própria dependência exponencial da corrente de tunelamento com a 
distância ponta-amostra. Mesmo que uma ponta não possua um único átomo em seu ápice, aquele que estiver mais próximo da amostra contribuirá com quase a totalidade da corrente de tunelamento. Uma segunda classe de preparação pode ser aplicada sobre as pontas afiladas macroscopicamente para conseguirem-se melhores resultados. Estes métodos incluem o bombardeamento da ponta com íons e a aplicação de altas voltagens (de modo a constituir o regime de emissão de campo), dentre muitos outros. Um fator que estimula a preparação de pontas através do bombardeamento de íons é a reprodutibilidade deste processo. ${ }^{19}$

Em nosso microscópio, o material escolhido para as pontas é uma liga de platina e irídio (Pt90/Ir10). O Ir é adicionado para prover rigidez ao material. O fio tem um diâmetro de 0,5mm, e é cortado com uma tesoura comum de modo a formar uma pequena protuberância no final da ponta (cujo comprimento total é de $\approx 1 \mathrm{~cm}$ ). Após o corte, a ponta é limpa com um banho de metanol em um aparelho de ultra-som para remover quaisquer impurezas orgânicas.

\subsection{4- Cabeça de medida:}

Este módulo é responsável por integrar a ponta, o elemento piezelétrico vinculado a ela e o porta-amostras em um mesmo conjunto compacto e manipulável. Uma descrição completa das etapas de seu desenvolvimento é encontrada na referência 11. Este item apenas discorre sobre as partes que a compõem.

Um esquema da cabeça de medida usada encontra-se na Figura 6. Um tubo de aço inoxidável abriga internamente um pistão oco que pode deslizar ao longo de seu eixo. O elemento piezelétrico é vinculado a este pistão através de um disco de macor (uma cerâmica isolante e com baixo coeficiente de dilatação térmica) que impede qualquer contato entre os sinais elétricos do elemento piezelétrico e o resto do aparato. Um pequeno cilindro de latão perfurado serve como porta-pontas, e é colado no mesmo eixo do elemento piezelétrico, isolado por outra placa de macor. Um parafuso lateral permite a fixação rígida da ponta e facilidade na sua troca. O porta-amostras é fixado através de um parafuso central em uma tampa também de aço inoxidável. Esta tampa é unida ao cilindro principal por mais quatro parafusos. Uma mola pressiona o pistão interno contra um micrômetro diferencial usado na aproximação grosseira da ponta em direção à amostra. Esta aproximação é monitorada por um microscópio óptico através de duas fendas localizadas no cilindro principal. Uma vez fechado, este corpo metálico fornece blindagem eletromagnética à junção de tunelamento. Todo este conjunto é mantido na posição horizontal por um suporte de latão.

Do lado externo da cabeça, dois conectores efetuam as ligações elétricas aos módulos eletrônicos. Um conector com quatro pinos conduz os sinais de alta tensão (terra, z, x e y) ao elemento piezelétrico. Os fios de cobre utilizados são extremamente finos (100 $\mu \mathrm{m}$ de diâmetro), de modo a minimizar a propagação de vibrações mecânicas. O outro conector se acopla a um cabo coaxial que conduz a corrente de tunelamento da junção ao pré-amplificador. A parte externa do cabo (malha) é colocada no mesmo potencial que o fio interno, minimizando efeitos capacitivos no transporte deste sinal. Esta mesma malha entra em contato também com a cabeça do STM, fazendo com que todo o conjunto compartilhe do mesmo potencial, o que é importante para a blindagem eletromagnética. 


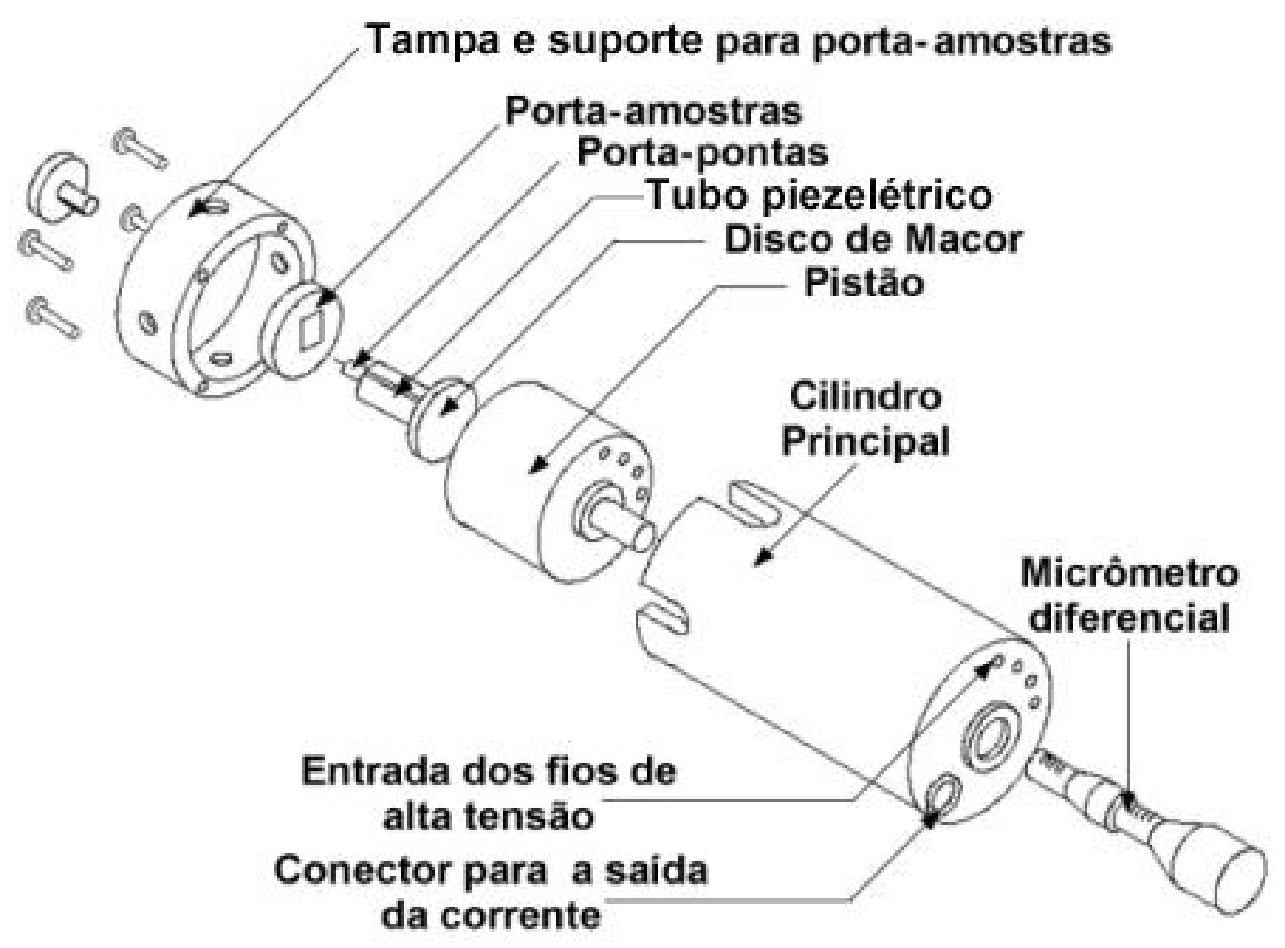

a

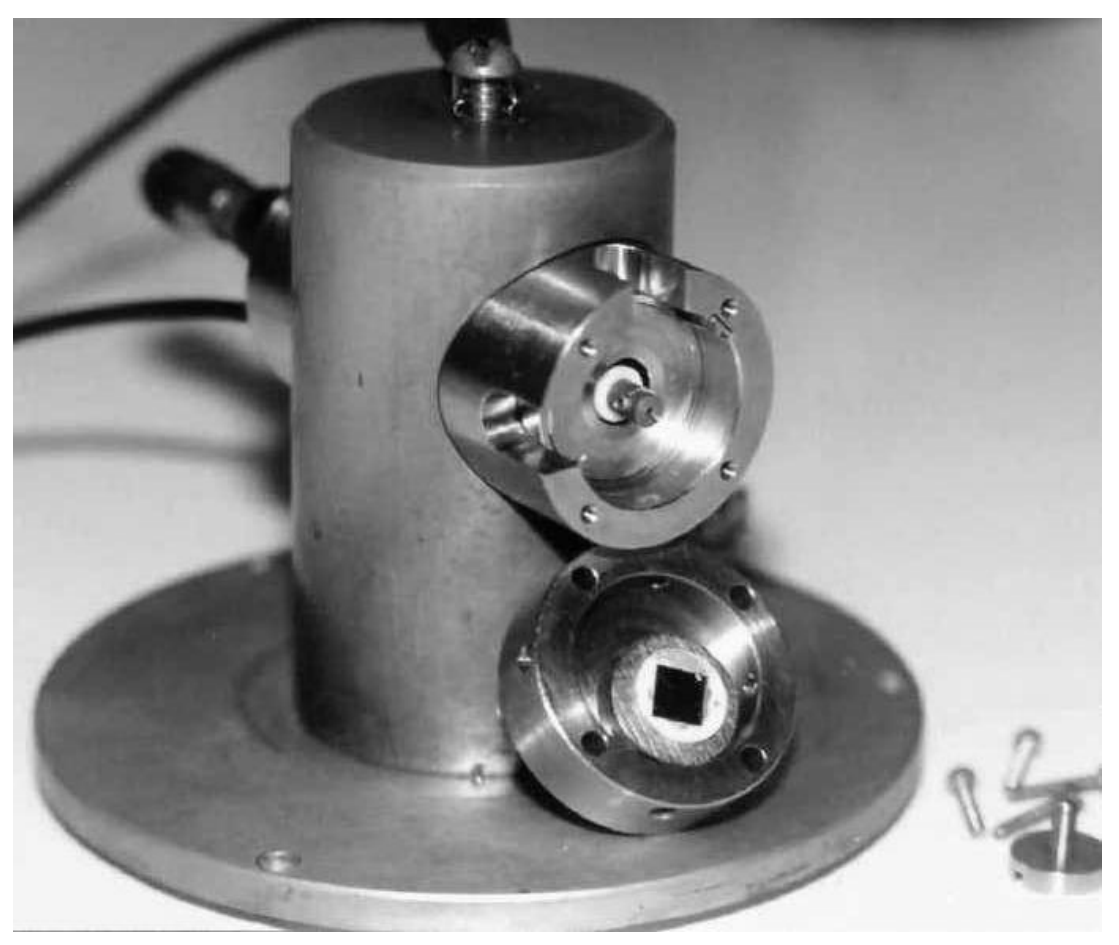

b

Figura 6: (a) vista explodida da cabeça do STM, mostrando os componentes de seu corpo principal. Por clareza, a mola situada entre o pistão e o suporte para o porta-amostras não é mostrada. (b) fotografia do conjunto completo, mostrando a cabeça inserida em seu suporte de latão. 


\section{2- Sistema Eletrônico:}

Em geral, a parte eletrônica de um STM é relativamente simples, consistindo de poucos módulos a serem implementados de forma básica. O circuito eletrônico desenvolvido para nosso microscópio se baseou em um protótipo utilizado pelo Prof. Dr. Alain André Quivy em seu trabalho de doutorado. ${ }^{20}$ Diversas melhorias foram desenvolvidas de forma a tornar seu funcionamento o mais automático possível. A construção foi executada de maneira modular, ou seja, cada circuito com sua função específica foi acondicionado em uma caixa metálica individual e interligado aos demais por cabos blindados. Isto torna simples a mudança das partes existentes ou a adição de novas funções ao microscópio. Uma grande caixa metálica abriga todos os módulos, a fim de melhorar a blindagem eletromagnética. Esta caixa possui ainda um painel frontal com diversos controles e conexões tanto para a cabeça do microscópio quanto para o microcomputador. A Figura 7 traz uma foto de todo o conjunto.

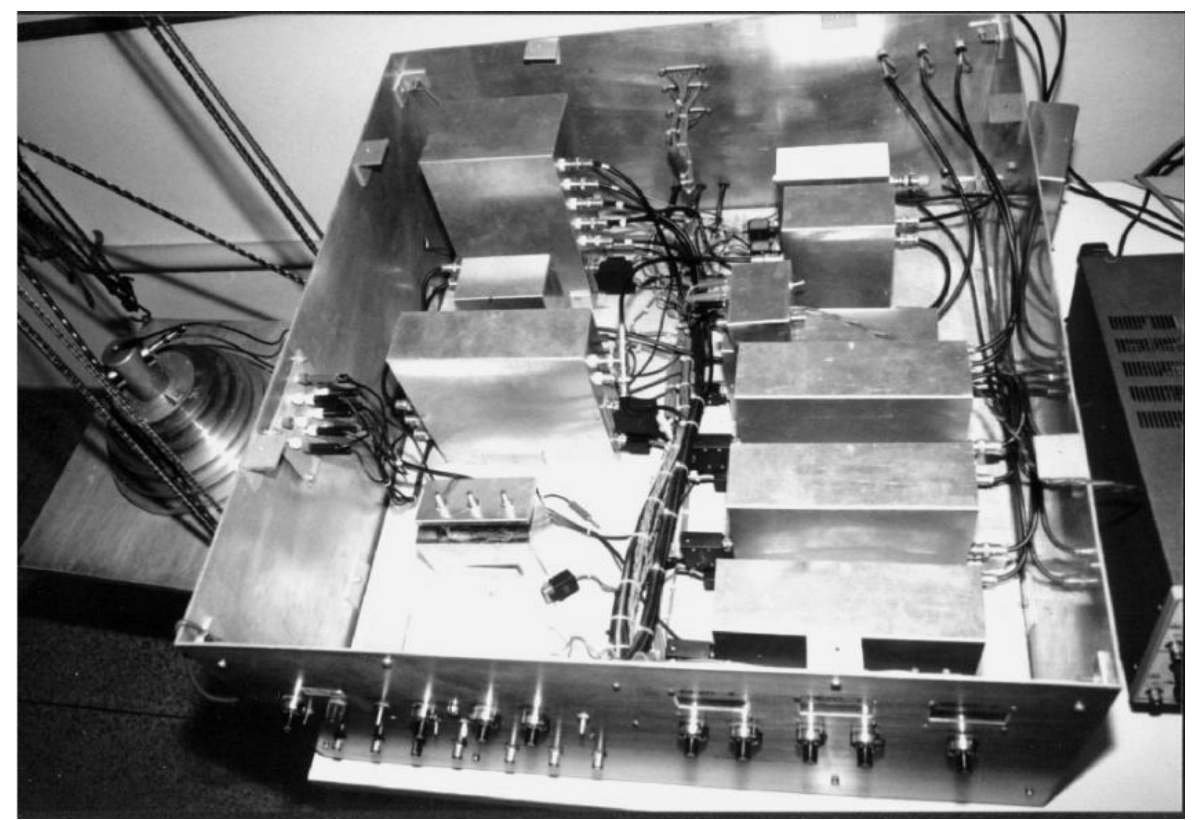

Figura 7: foto do sistema eletrônico de nosso STM. No painel do módulo principal (parte inferior da imagem) é possível observar os controles externos e conectores existentes para monitorar diversos sinais (corrente, tensão de tunelamento e retroação). À esquerda, se encontra a cabeça de medida disposta sobre o sistema de isolamento de vibrações.

Nos próximos itens, são descritos os diversos módulos eletrônicos já existentes para estudos topográficos e, como um dos objetivos desta dissertação, os novos módulos para coleta de dados em modo espectroscópico. 


\subsection{1- Detecção da corrente:}

A corrente que flui pela junção de tunelamento pode variar de dezenas de nA até alguns pA, uma magnitude muito baixa em se tratando de circuitos eletrônicos comuns. Portanto, o STM exige um sistema sensível na detecção da corrente. Esta função é implementada através de um conversor corrente-tensão $(\mathrm{I}-\mathrm{V}){ }^{21} \mathrm{Um}$ circuito integrado de alto desempenho (amplificador operacional OPA128 da companhia Burr-Brown) é o principal componente deste circuito. Sua corrente de polarização é de $75 f$ A, muito baixa se comparada à de componentes comuns (por volta de dezenas de $\mathrm{nA}$ ). Um resistor de alta precisão de $10 \mathrm{M} \Omega$ faz a realimentação negativa deste componente, conferindo um ganho de $10^{7} \mathrm{~V} / \mathrm{A}$ à corrente proveniente da junção de tunelamento. Um capacitor de $1 \mathrm{pF}$ é associado em paralelo com este resistor a fim de prover estabilidade ao circuito. A tensão de tunelamento é aplicada indiretamente à ponta utilizando o mesmo módulo. Um circuito específico gera esta tensão (o operador escolhe seu valor usando um potenciômetro no painel frontal do STM), que é aplicada à entrada não-inversora do amplificador operacional. Devido à uma de suas propriedades, a tensão é transferida para a entrada inversora à qual a ponta é diretamente ligada. Quando a amostra é conectada ao terra do microscópio, surge uma queda de tensão através da junção, responsável pelo tunelamento. A conexão deste circuito com a junção de tunelamento e os demais módulos eletrônicos se encontra na Figura 8. Após ser convertida, a corrente é enviada ao módulo de seleção da polaridade. Um circuito faz com que a corrente medida tenha sempre sinal positivo, independentemente da polaridade escolhida para a tensão aplicada à junção. Depois disto, a corrente pode ser recebida pelos demais módulos.

Particularmente em aplicações espectroscópicas, a capacitância da junção de tunelamento, juntamente com o cabo que conduz a corrente, restringe a velocidade máxima possível nas medidas. Qualquer mudança $\Delta \mathrm{V}$ na tensão de tunelamento causa uma transferência de carga $\Delta \mathrm{Q}=\mathrm{C} \Delta \mathrm{V}$ neste "capacitor". Isto gera uma corrente que não está relacionada com propriedades espectroscópicas da amostra. Na medida de uma curva I-V, o atraso entre a aplicação da tensão e a medida da corrente correspondente deve ser cautelosamente escolhido de forma a satisfazer o tempo desta carga. Outra solução é reduzir ao máximo a capacitância, posicionando o circuito pré-amplificador o mais próximo possível da junção de tunelamento. Assim, o comprimento do cabo necessário para condução do sinal é reduzido, diminuindo tanto a capacitância quanto a captação de ruído eletromagnético. Em nosso microscópio, o préamplificador é acondicionado em um cilindro de latão e disposto logo abaixo da cabeça de medidas. A carcaça do cilindro é colocada sob o mesmo potencial imposto à ponta e à cabeça. Devido às altas impedâncias envolvidas no pré amplificador, um sistema especial de blindagem (guard $)^{22}$ é utilizado para evitar correntes de fuga capazes de sobrepujar a corrente de tunelamento. Todo o cuidado deve ser tomado também para que não existam impurezas condutoras sobre a placa na qual o circuito é implementado (como umidade, fluxo de solda elétrica, etc.)

\footnotetext{
* Este termo designa a mínima corrente requerida pelo componente em cada uma de suas entradas.
} 


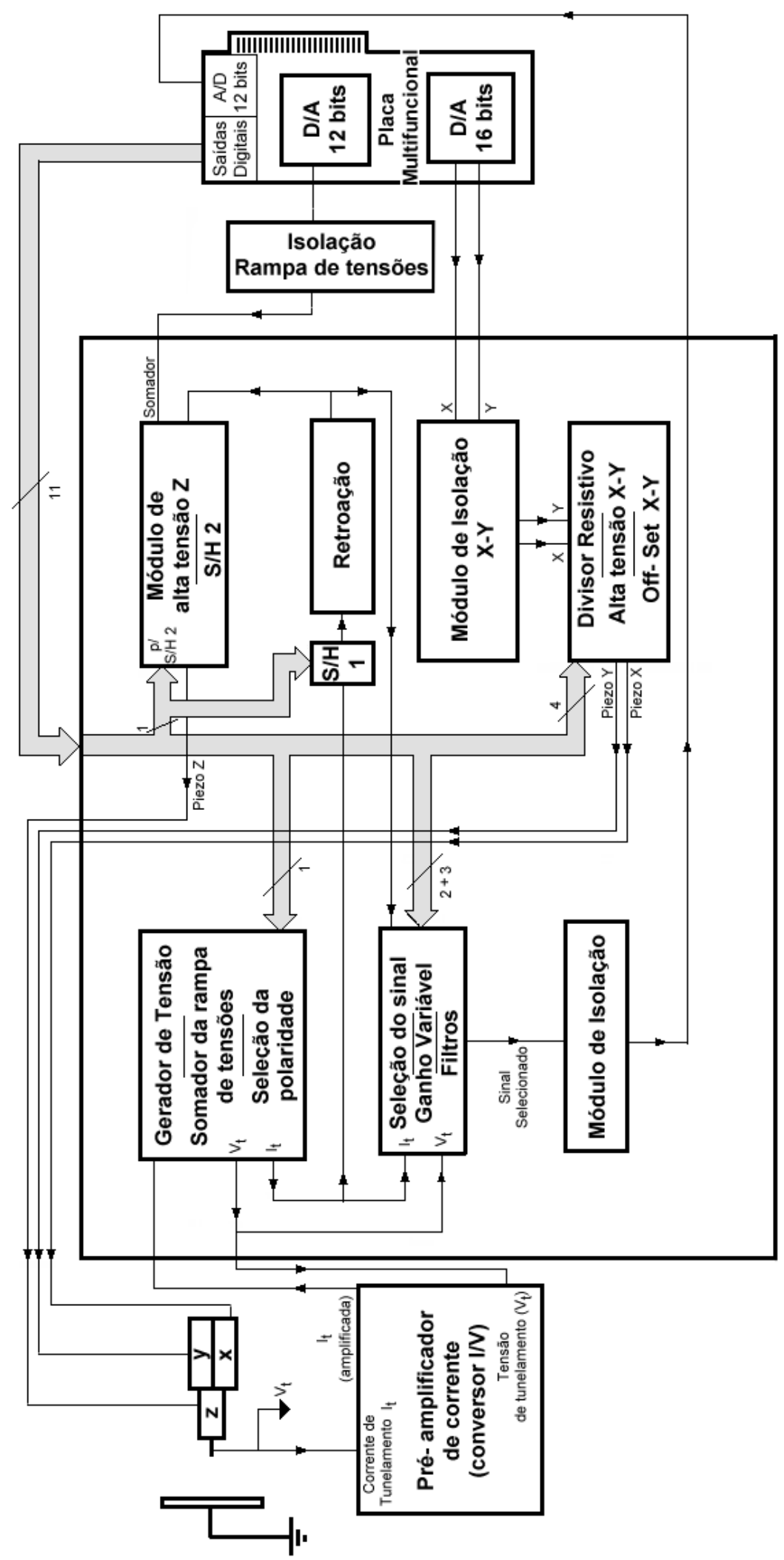

Figura 8: diagrama esquemático dos diversos módulos eletrônicos que constituem o STM. As vias preenchidas em cinza no diagrama correspondem a sinais digitais. $O$ número de bits transportados no trecho é indicado junto à barra inclinada. Linhas finas com setas indicam sinais analógicos. O sinal injetado pelo conversor D/A no Módulo de alta tensão z pode ser aplicado ao Somador da rampa de tensões, mudando a conexão do cabo correspondente, quando se deseja operar em outro modo espectroscópico. Conexões adicionais externas para monitoramento ou ajuste de sinais não são mostradas. 


\subsection{2- Retroação e Controle da corrente:}

Uma vez detectada, a corrente é conduzida ao circuito de controle (retroação, ou também chamado circuito integrador). $\mathrm{O}$ operador escolhe o valor de referência da corrente de tunelamento através de um potenciômetro no painel frontal do microscópio. O módulo de retroação compara este valor com a corrente medida, atuando de forma a minimizar a diferença entre ambos (que é relacionada a flutuações na distância ponta-amostra) e manter assim o valor da corrente de tunelamento sempre constante. Este módulo se baseia em um controle do tipo proporcional-integrativo (PI). A diferença entre o sinal da corrente e o sinal de referência é integrada no tempo e, paralelamente, multiplicada por uma constante. O sinal de saída, correspondente à soma destas duas componentes, é amplificado por um módulo de alta tensão (cuja amplitude pode variar de $-150 \mathrm{a}+150 \mathrm{~V}$ ) e aplicado ao eletrodo que controla o movimento na direção $\mathrm{z}$ do elemento piezelétrico. É importante salientar que este processo ocorre em um ramo fechado: a corrente é detectada, sua diferença em relação ao valor de referência é processada pelo integrador e a correção pertinente é aplicada ao elemento piezelétrico, fazendo variar a distância ponta-amostra e, juntamente, a corrente de tunelamento, que passa novamente pelo mesmo processo. Por isso este módulo é chamado de retroação, ou seja, sua ação tem influência direta sobre o sinal aplicado à sua entrada.

Na concepção deste módulo, deve sempre haver um compromisso entre velocidade e estabilidade, fato caracterizado pela frequiência de corte. Este valor será mais alto quanto maior a velocidade do circuito, implicando na possibilidade de executar varreduras em altas frequiências sem perder qualidade na imagem. Os ganhos proporcional e integral (ajustados em nossa montagem através do valor de capacitores e resistores) definem a nuança da curva de resposta em freqüência. Estes ganhos foram empiricamente otimizados ao longo do tempo de uso, de modo que hoje nosso microscópio é provido de um sistema de retroação muito eficiente para as aplicações desenvolvidas. A curva da resposta em freqüência deste módulo é apresentada na Figura 9.
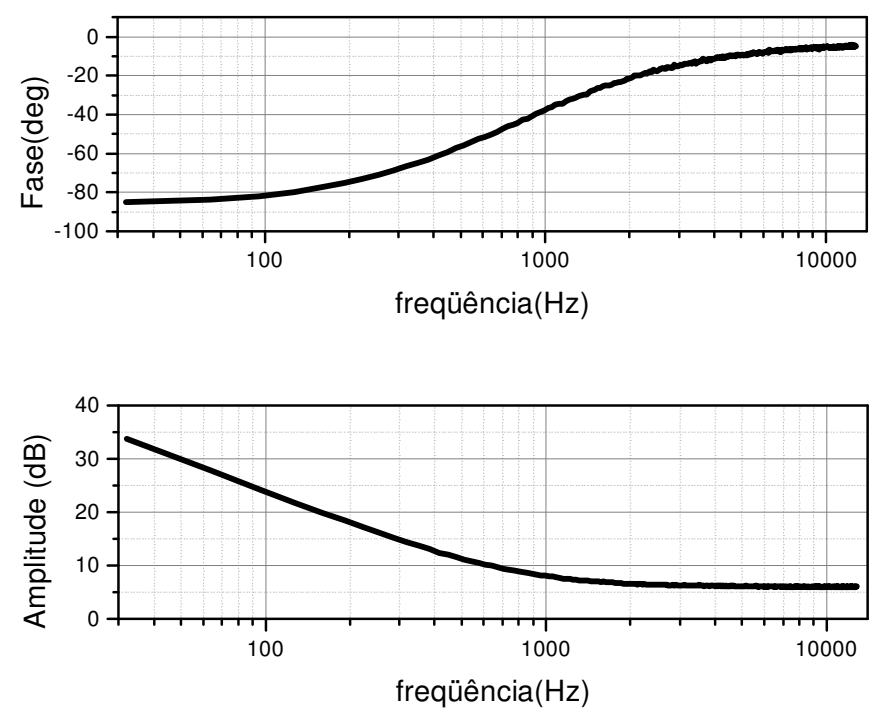

Figura 9: resposta em freqüência do módulo de retroação do STM. Na parte superior, encontra-se o gráfico da defasagem do sinal e, em baixo, da amplitude. 


\subsection{3- Módulo de seleção de sinais, ganho variável e filtros:}

Neste módulo se concentra todo o potencial de mudança dos métodos de aquisição de dados com nosso STM. Ele é provido de entradas individuais para quatro sinais: corrente de tunelamento, tensão na junção, saída do circuito de retroação e lock-in. Um multiplexador permite a seleção, por dois bits enviados pela placa multifuncional (PCI-20098C da marca Intelligent Instrumentation, Inc. instalada no microcomputador), de um desses sinais para ser remetido à saída do módulo. Em adição, há um circuito que permite subtrair um nível DC no ramo em que é ligado o sinal da retroação, de forma a permitir o aumento do alcance dinâmico de sua medida. Após a seleção, há um circuito amplificador cujo ganho é escolhido, usando outro multiplexador, através de três bits adicionais. Este passo é fundamental, pois o sinal de interesse geralmente é da ordem de alguns milivolts, representando apenas 2 ou 3 bits de nosso conversor A/D de 12 bits, limitando a precisão da medida. Os oito ganhos disponíveis cobrem uma faixa desde 0 até $60 \mathrm{~dB}$. O terceiro componente deste módulo é um filtro ativo (tipo Butterworth) passa-baixas. Uma chave múltipla no painel frontal permite a seleção de seis valores de corte diferentes (cobrindo desde $100 \mathrm{~Hz}$ até $40 \mathrm{KHz}$ ), suprimindo ruídos de alta frequiência que possam causar picos tanto em imagens quanto em curvas espectroscópicas. A saída deste módulo é dirigida para um circuito de isolamento de terras e enviado à placa de aquisição multifuncional, através da qual o microcomputador efetua a leitura. Esta placa possui um canal de conversão A/D de 12 bits que cobre uma faixa de -10 a $+10 \mathrm{~V}$.

\subsection{4- Controle de varredura:}

A varredura da ponta é controlada pelo microcomputador que a sincroniza com a aquisição dos dados. No sistema de nosso microscópio, existem dois canais de conversão de sinais digitais para analógicos (D/A) de 16 bits (na placa PCI-20006M marca Intelligent Instrumentation, Inc.) dedicados a gerar os sinais $\mathrm{x}$ e y da varredura. $\mathrm{O}$ sinal de saída é uma onda triangular que varia de -10 à $+10 \mathrm{~V}$. O número de passos usado para o incremento dos valores da tensão é escolhido pelo usuário no programa de aquisição. Esta escolha determina a velocidade de varredura, uma vez que o tempo entre cada passo é uma constante. O sinal gerado pelo conversor D/A é enviado para um circuito isolador de terras. Esta isolação é necessária tanto para impedir que ruídos existentes no terra do microcomputador (provenientes de sua fonte interna chaveada) sejam passados para a eletrônica do STM quanto para evitar loops de terra. O circuito principal que implementa a varredura é provido de um divisor resistivo de tensões que permite atenuar o sinal vindo do microcomputador em uma gama de 16 amplitudes diferentes (correspondendo a 16 possibilidades de áreas de varredura). A seleção é controlada através de um componente multiplexador comandado por quatro bits vindos da placa multifuncional. Estes bits são definidos a partir da escolha da área de varredura feita pelo usuário no programa de aquisição. Depois de atenuado até o valor conveniente, este sinal passa por um amplificador de alta tensão e é dirigido ao respectivo eletrodo (x ou y) do elemento piezelétrico. Existe ainda a possibilidade de deslocar o ponto central da área de varredura sobre a amostra. Isto é feito manualmente através de um potenciômetro presente no painel frontal do STM. O ajuste deste componente permite escolher uma tensão (nível DC) que será somada ao sinal atenuado, fazendo com que o elemento piezelétrico efetue uma varredura do tamanho definido pelo programa sobre um ponto diferente da amostra. Cada sinal (x e y) é tratado por um circuito individual. Com este sistema, é possível obter uma área máxima de varredura de $9 \mu \mathrm{m}^{2}$ com um único tubo piezelétrico e $36 \mu \mathrm{m}^{2}$ para o esquema de dois tubos concêntricos. 


\subsection{5- Sample and Hold:}

O componente Sample and Hold $(\mathrm{S} / \mathrm{H})$ é de importância fundamental para aquisição de dados em modo espectroscópico. Uma de suas portas é uma entrada que recebe o sinal que se deseja amostrar ou segurar. O comando de segurar (Hold) ou amostrar (Sample) a saída é feito por dois bits de controle (no caso do componente SHC 298 marca Burr Brown ${ }^{23}$ utilizado), de modo que, quando os pinos recebem o mesmo nível lógico, a tensão é mantida constante na saída no último valor amostrado. Em nossa montagem, um dos pinos é aterrado, de forma que a determinação do estado é feita com apenas um bit da placa multifuncional. Um parâmetro importante do S/H é a queda da tensão de saída com o tempo (drop rate) em modo Hold. $\mathrm{O}$ drop rate é determinado pelo tempo de descarga de um capacitor externo acoplado ao componente. É preciso escolher um capacitor de valor adequado para que esta mudança na tensão da saída, que será amplificada e aplicada ao elemento piezelétrico z, não perturbe significativamente a junção durante o tempo necessário à aquisição dos dados. Este tempo foi estimado em $2 \mathrm{~ms}$ para que sejam adquiridos 100 valores de corrente para a construção de uma curva I-V. Neste intervalo, uma variação de $0,25 \mathrm{mV}$ da voltagem de retroação corresponde a um deslocamento vertical de $0,1 \AA$ da ponta, que constitui um valor aceitável. Isto fixa um drop rate de $125 \mathrm{mV} / \mathrm{s}$. Com um capacitor de $10 \mathrm{nF}$, obtivemos $12 \mathrm{mV} / \mathrm{s}$, satisfatório para nossa aplicação. $\mathrm{O}$ valor do capacitor não pode ser alto demais (associado a um menor valor do drop rate), pois provocaria um pico de tensão quando o componente passa novamente ao modo Sample, deformando consideravelmente o sinal de saída. Uma outra característica deste elemento é a adição de um nível DC sobre o sinal de saída em modo Hold, ao qual os manuais se referem pelo nome charge offset. Apesar de aparentemente pequena (tipicamente $10 \mathrm{mV}$ ), depois de amplificada esta tensão pode corresponder a $4 \AA$ de variação na distância ponta-amostra entre os modos Sample e Hold, o que é indesejável por diversos motivos. ${ }^{24} \mathrm{Na}$ construção de nosso circuito, conseguimos obter um charge offset de aproximadamente $3 \mathrm{mV}$, implicando num aumento de pouco mais de $1 \AA$ na largura da junção.

Inicialmente, um único módulo $\mathrm{S} / \mathrm{H}$ foi implementado após o circuito de retroação. Nos primeiros dados adquiridos, não obtinha-se uma reprodução aceitável entre aquisições consecutivas. Uma análise expedita nos mostrou que o problema principal era uma instabilidade no circuito de retroação no instante em que o programa autorizava novamente a amostragem do sinal. Quando o circuito $\mathrm{S} / \mathrm{H}$ existente era comandado para segurar o sinal, a saída do amplificador de alta tensão mantinha-se constante, independentemente do sinal aplicado pela saída do módulo de retroação. Todavia, durante a variação das tensões na junção de tunelamento, a entrada deste módulo era susceptível aos impulsos provenientes do circuito de conversão I-V, fazendo-o responder naturalmente. Isto causava uma incoerência entre a posição $\mathrm{z}$ do elemento piezelétrico e o sinal de retroação no momento em que o programa terminava a aquisição e configurava o $\mathrm{S} / \mathrm{H}$ para amostrar novamente. Com isto, era necessário um tempo longo de espera, determinado pelas constantes de tempo do amplificador de alta tensão e do integrador, para que todos os sinais fossem estabilizados antes de uma nova aquisição. A solução encontrada foi a adição de um segundo componente $\mathrm{S} / \mathrm{H}$, posicionado antes do integrador e acionado ao mesmo tempo que o original, como mostra a Figura 10. Desta forma, temos certeza que em modo Hold nenhum componente do ramo da retroação estará atuando, conferindo estabilidade ao sistema logo após sua mudança de estado. Uma solução semelhante a esta foi relatada na literatura. ${ }^{25}$ Exaustivas medidas topográficas de diversos tipos de amostras foram efetuadas a fim de certificar que a inserção deste novo componente não prejudicaria o desempenho do microscópio. Também foi feita a comparação do espectro de frequiências de vários sinais antes e 
depois da implementação do circuito. Os resultados foram satisfatórios, uma vez que não houve diferenças entre os dados obtidos.

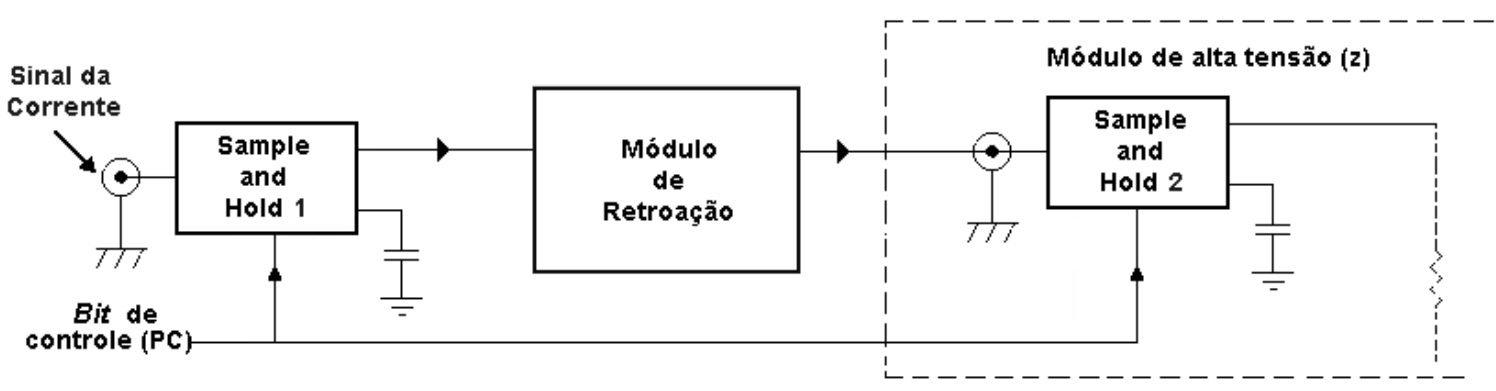

Figura 10: diagrama mostrando o posicionamento dos componentes Sample and Hold em relação ao módulo de retroação.

\subsection{6- Módulo de alta tensão Z:}

Este módulo tem a finalidade de amplificar o sinal que será aplicado ao eletrodo z do elemento piezelétrico. Uma vez que a sensibilidade deste é da ordem de dezenas de angströns por volt, é necessária uma faixa de centenas de volts para obter-se uma gama adequada de deslocamentos (até o limite de alguns micrometros). Sua implementação é feita com um componente específico de alta tensão (3584 da Burr Brown), cujo limite de saída é bipolar de magnitude $150 \mathrm{~V}$, na configuração de amplificador inversor. Esta montagem fornece um ganho 15 sobre o sinal de entrada, suficiente para proporcionar um alcance superior a $2 \mu \mathrm{m}$ no movimento na direção perpendicular à amostra.

Este mesmo módulo (ver Figura 11) abriga mais três elementos. Entre eles está um dos circuitos $\mathrm{S} / \mathrm{H}$, cuja descrição foi feita no item anterior, tendo em sua entrada o sinal de retroação. O outro circuito é um gerador de tensão DC que permite aumentar ou diminuir a tensão aplicada ao elemento piezelétrico através do ajuste de um potenciômetro no painel frontal do STM. Esta é uma forma indireta de suprimir o nível DC do sinal da retroação e assim aumentar o alcance dinâmico da medida. O último componente é um seguidor de sinais $\left(\right.$ buffer $\left.^{26}\right)$ utilizado para aplicação da rampa de tensões em medidas espectroscópicas de altura da barreira de tunelamento. Ele é precedido por um divisor resistivo que atenua a amplitude da rampa proveniente do conversor D/A de 12 bits, uma vez que os deslocamentos da ponta necessários para este tipo de medida são diminutos. A atenuação aplicada à rampa é de -60dB. Estes sinais (S/H, nível DC e rampa de tensões) são somados por um circuito específico e o resultado é aplicado ao amplificador de alta tensão, que dirige o sinal ao eletrodo $\mathrm{z}$ do elemento piezelétrico. 


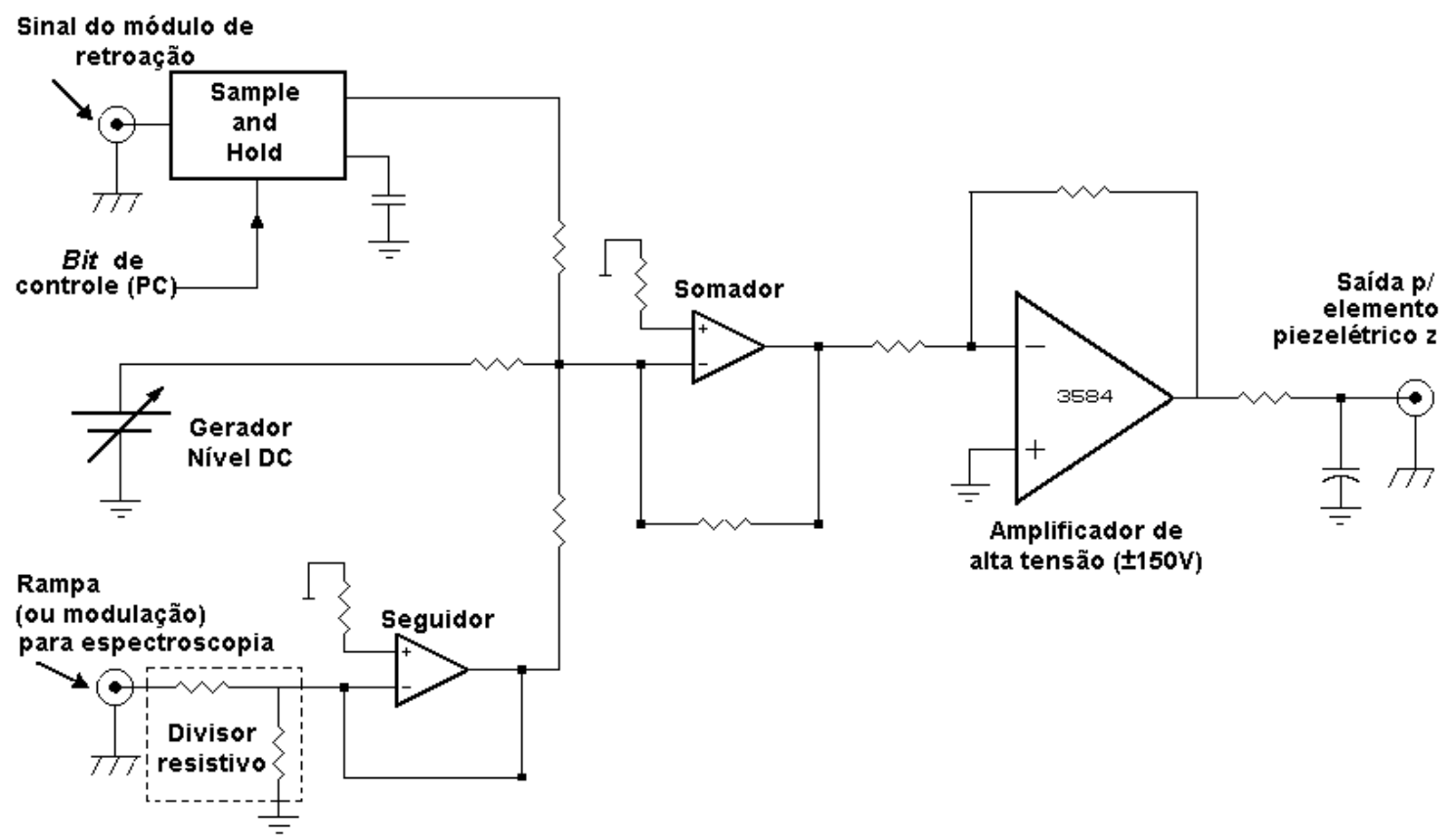

Figura 11: esquema do módulo de alta tensão z. Pode-se observar (à esquerda, de cima para baixo) a entrada do sinal vindo do integrador (seguida pelo componente Sample and Hold), o gerador de nível DC e a entrada para rampa (ou para modulação) usada nas medidas de altura da barreira. Logo após há um divisor resistivo e um buffer (seguidor) de sinais. Estas três componentes do sinal elétrico são então compostas pelo somador e o montante é amplificado pelo componente de alta tensão (3584).

\subsection{7- Isolamento de terras:}

Um dos problemas mais freqüentes da eletrônica de um STM é o loop de terra. Isto ocorre quando dois circuitos interligados são aterrados sob potenciais diferentes. Em nosso circuito, este efeito pode ocorrer em qualquer transferência de dados entre as placas conversoras e os módulos eletrônicos do STM, já que as placas compartilham o terra do microcomputador e a eletrônica é vinculada à fonte de alimentação. Uma influência ainda mais restritiva é o ruído proveniente da fonte chaveada presente no microcomputador. Para contornar estes problemas, dois métodos de isolamento de terras são utilizados em nosso microscópio. Os sinais digitais (níveis DC que assumem os valores 0 ou 3,8V) são isolados através de um opto-acoplador. Este circuito integrado consiste de um led (light emitting diode) e um foto-transistor montados juntos um ao outro. A luz emitida pelo diodo (ligado ao sinal vindo do PC) incide na base do transistor, cujo coletor é acoplado ao elemento que se deseja controlar, produzindo um sinal eletronicamente desacoplado do circuito original. Esta técnica é muito eficiente para sinais DC que não exigem precisão nem linearidade. Para os sinais mais importantes dependentes do tempo, utiliza-se um componente comercial da Burr-Brown (ISO 103) que possui uma banda larga de frequiências de operação $(20 \mathrm{kHz})$. Nosso sistema dispõe de quatro desses módulos, tanto para isolamento dos sinais provenientes do PC (varredura $\mathrm{x}, \mathrm{y}$, e rampas de tensão) quanto para aqueles remetidos à placa de aquisição (vindos do módulo de seleção de sinais, ver item 3.2.3). Os três primeiros são alimentados por uma fonte individual de tensões (+/-15V) para impedir o cruzamento de terra nos dois tipos de circuito. 


\section{3- Microcomputador e Rotinas computacionais:}

Todo controle necessário para a eletrônica do STM reside nas rotinas computacionais do microcomputador (em nosso caso, um Pentium II de 200MHz). A interface com o sistema exterior é implementada através de uma placa de aquisição acoplada à seu barramento interno. A placa é multifuncional (PCI 20098C), possuindo conversores A/D (um deles usado para leitura dos sinais), duas saídas digitais de 8 bits cada e dois slots para o acoplamento de placas conversoras D/A. Nesses slots, nosso sistema tem uma placa com dois conversores D/A de 16 bits (PCI 20006 para gerar a varredura $\mathrm{x}-\mathrm{y}$ ) e uma placa com dois conversores D/A de 12 bits (PCI 20003, que geram as rampas para a espectroscopia). Através de programação, é possível acessar todas as funções das placas e enviar ou ler os sinais pertinentes para a obtenção dos dados.

Nos itens seguintes, são descritos o programa inicialmente implementado para a aquisição topográfica bem como as novas rotinas implementadas para a espectroscopia.

\subsection{1- Sistema de aquisição da Topografia:}

Este programa foi implementado durante a construção do STM e é capaz de realizar a aquisição de curvas topográficas além de tratar as imagens obtidas. Ele foi desenvolvido com o compilador $\mathrm{C}++$ para Windows da empresa Borland, com programação orientada ao objeto. As facilidades gráficas do ambiente Windows conduziram a um programa de uso muito simples. Uma janela permite a escolha dos parâmetros de varredura: tamanho da área (em $\AA$ ), ganho a ser aplicado ao sinal (que influencia no contraste da imagem), velocidade e direção de varredura (XY ou Y-X). Também é possível efetuar várias imagens seqüencialmente e utilizar um recurso de animação do próprio programa para estudo de processos dinâmicos. A aquisição das imagens é feita com 100 pontos nas direções horizontal e vertical. Uma vez adquirida, é possível visualizar a imagem tanto em duas dimensões, com 256 níveis de cinza, como em três dimensões, com a facilidade de rotação nos três eixos espaciais. $O$ tratamento pode ser feito através da subtração de plano (pelo método de três pontos) e do filtro espacial, que toma o valor médio dos níveis de cinza dos pontos vizinhos. Um recurso existente de visualização de seções transversais se presta à análise de perfis e comparações entre alturas de relevos nas imagens. O programa também permite salvar ou carregar imagens através de um formato próprio de arquivo. Uma descrição minuciosa deste programa pode ser encontrada na referência 11.

\subsection{2- Rotina para espectroscopia $\pm V$ :}

Esta rotina, bem como todas as demais para aquisição em modo espectroscópico, foi implementada em linguagem C no sistema operacional DOS. Abrindo mão de uma interface gráfica sofisticada, foi possível simplificar a programação e concentrar todo o esforço na otimização dos algoritmos de aquisição. Futuramente, os métodos descritos neste e nos próximos itens serão conjugados em um único programa em ambiente Windows, dispondo então de todos seus recursos. $\mathrm{O}$ método de aquisição escolhido para implementar o modo $\pm \mathrm{V}$, após algumas tentativas frustadas, foi alterar a polaridade da tensão a cada linha de varredura. Partindo da polaridade negativa, o algoritmo principal deste programa executa os seguintes passos: 
- Varre a linha, adquirindo os dados da topografia (sinal da retroação) com esta polaridade;

- Inverte a polaridade, através da mudança de estado de seu bit de controle;

- Retorna ao início da linha;

- Varre novamente a mesma linha, adquirindo os dados topográficos agora com a polaridade positiva;

- Muda a polaridade de volta para seu valor negativo;

- Move a ponta para o início da próxima linha e repete todo o processo novamente, até a conclusão das duas imagens.

A Figura 12 traz uma carta de tempos dos principais sinais envolvidos neste processo. No programa, o usuário pode selecionar o ganho do sinal, a velocidade e o tamanho da varredura. As duas imagens (com polaridade positiva e negativa) são mostradas simultaneamente na tela durante a aquisição. É possível salvar os dados no mesmo formato utilizado no programa de aquisição da topografia, para posterior tratamento e análise. Dependendo da taxa de variação da tensão durante a troca de polaridade, pode haver colisão entre ponta e a amostra, o que é danoso na maioria dos casos. Na literatura, ${ }^{24}$ alguns autores fazem uso do elemento Sample \&Hold para paralisar a retroação durante a transição. A princípio, não vimos necessidade do uso deste artifício em nosso procedimento. De fato, o circuito já existente fazia essa transição ser bem rápida, da ordem de $200 \mu$ s para as magnitudes de tensões utilizadas, impossibilitando qualquer resposta brusca do circuito de controle. Por outro lado, a aquisição deve esperar um certo tempo até que este sinal se estabilize na nova condição de tensão. Testes exaustivos foram conduzidos com este programa em amostras de filmes finos de ouro que possuem relevos bem definidos, levando a resultados satisfatórios que serão descritos em um capítulo mais adiante.

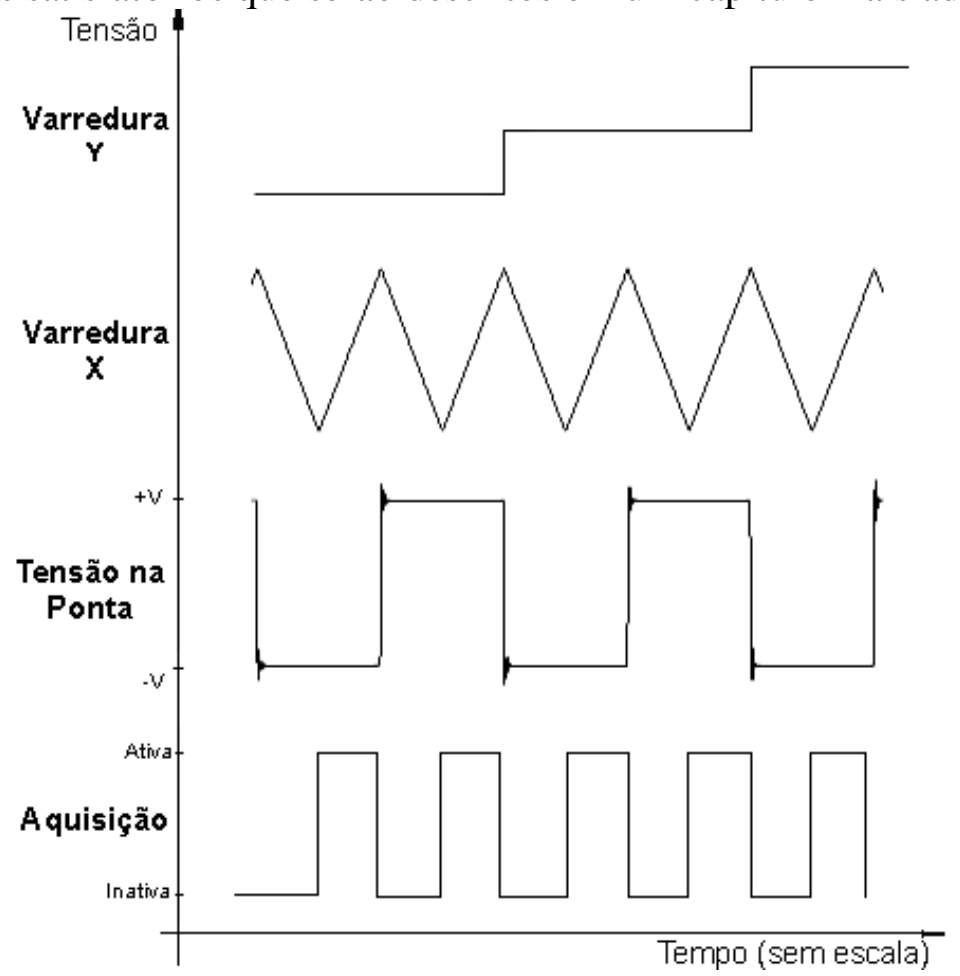

Figura 12: carta de tempos dos sinais envolvidos na aquisição da espectroscopia + /-V. (os sinais Varredura X $e$ Tensão na Ponta desta figura foram gravados diretamente do circuito eletrônico utilizando o analisador digital HP 35670A). A amplitude do sinal de varredura Y foi ampliada para melhor visualização da transição. 


\subsection{3- Rotinas para espectroscopia I-V:}

O primeiro passo desta etapa foi a elaboração de uma rotina de aquisição para uma única curva I-V sobre um ponto fixo da amostra. O programa deve executar as seguintes funções:

- ativar o componente Sample \& Hold de modo a paralisar o sinal da retroação, com o objetivo de manter fixa a distância ponta-amostra durante a variação da tensão na junção de tunelamento;

- adquirir o valor atual da tensão da ponta, de forma que o programa tenha a informação necessária para gerar uma rampa simétrica em relação ao valor zero da tensão;"

- iniciar a aquisição dos dados, aplicando a tensão na junção de tunelamento e lendo o respectivo valor da corrente, repetindo este procedimento para valores crescentes de tensão até serem tomados cem pontos na curva;

- retornar a tensão incremental ao valor nulo, para que a tensão total na junção de tunelamento volte a ser aquela do início do processo;

- permitir novamente a atuação do sinal de retroação através da ativação do componente Sample \& Hold.

A carta de tempo dos principais sinais envolvidos neste processo se encontra na Figura 13. O programa permite a escolha da faixa de tensões que será aplicada à junção (meio, um ou três volts em modo bipolar) além do ganho imposto ao sinal da corrente. $O$ gráfico correspondente a cada aquisição é mostrado diretamente na tela. O salvamento dos dados é feito através de um arquivo ASCII, contendo os cem pontos de corrente e tensão, que pode ser importado posteriormente por qualquer planilha eletrônica para análise. Este programa é capaz de gerar e ler 100 valores de tensão e corrente em um tempo de 2,2ms. Os valores citados em diversos artigos para realizar-se a mesma função são $0,5 \mathrm{~ms},{ }^{27} 3 \mathrm{~ms},{ }^{28} 10 \mathrm{~ms}^{29}$ e $50 \mathrm{~ms} .{ }^{30}$ Portanto, nosso tempo total de aquisição de uma curva I-V de 100 pontos representa um bom desempenho que foi possível graças ao acesso direto dos registros da placa de conversão a partir do código C ao invés da utilização da rotina fornecida pelo fabricante, que era muito mais lenta. A realização de uma curva I-V em todos os pontos de uma imagem topográfica de 10.000 pontos deveria assim acrescentar apenas $22 \mathrm{~s}$ ao tempo total de aquisição (que pode ser de vários minutos no caso de uma imagem de grande tamanho). Uma vez que a aquisição de uma única curva é otimizada, o próximo passo consiste na implementação da rotina que adquire seqüencialmente topografia e curva I-V de cada ponto da amostra. Com o uso do Módulo de Seleção de Sinais presente em nosso microscópio, esta é uma tarefa simples. Em cada ponto da imagem, basta adquirir o dados da topografia e, em seguida, gerar a rampa de tensões na junção enquanto o programa lê os valores da corrente. No entanto, muito cuidado deve ser tomado na otimização dos tempos de atraso entre a leitura desses dois sinais. Quando este atraso é muito pequeno, a imagem obtida é de qualidade satisfatória, enquanto as curvas I-V adquiridas apresentam uma deformação devido à defasagem do sinal ao longo dos diversos módulos eletrônicos. Por outro lado, se o atraso for muito grande, a topografia ficará eventualmente comprometida devido à variações e instabilidades acumuladas no tempo sobre o sinal de retroação. Dados de boa qualidade foram obtidos sobre amostras de ouro com um atraso de $1 \mathrm{~ms}$ (adicional aos 2,2ms necessários à geração da rampa). Experimentalmente, observamos que este tempo deve ser

\footnotetext{
* A rampa gerada é aplicada a um circuito que a soma com a tensão DC de tunelamento. O programa gera a rampa descontando este valor $\mathrm{DC}$, de modo que a junção recebe uma rampa simétrica de $-\mathrm{V}$ até $+\mathrm{V}$.
} 
otimizado de amostra para amostra, dependendo basicamente dos limites de tensão usados na rampa e da resposta correspondente da corrente.

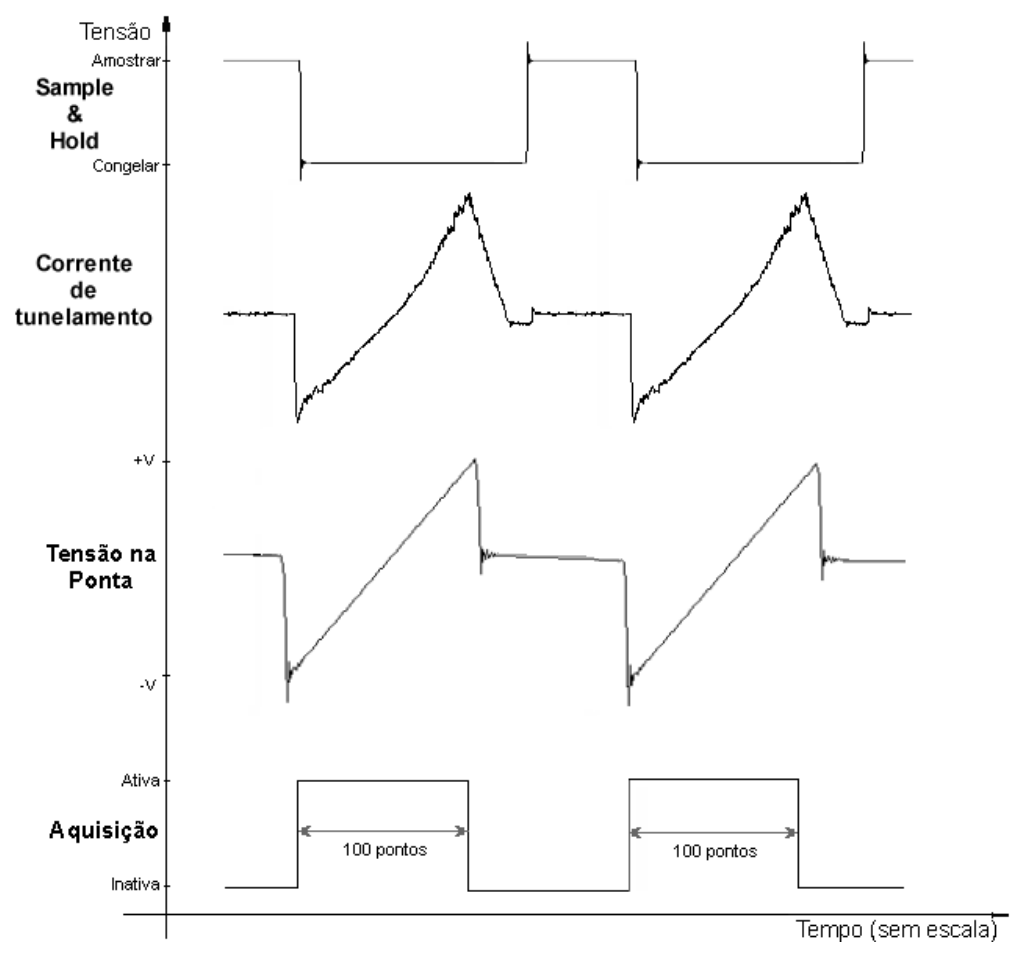

Figura 13: carta de tempos dos sinais envolvidos no processo de aquisição de curvas I-V. Todos os sinais (exceto a representação da aquisição) foram medidos diretamente do circuito com um analisador digital (HP35670A).

\subsection{4- Rotina para medida da altura aparente da barreira:}

Do ponto de vista computacional, este algoritmo é semelhante ao descrito anteriormente. Enquanto o componente $\mathrm{S} / \mathrm{H}$ paralisa o sinal de retroação, uma rampa deve ser aplicada ao somador presente no módulo de alta tensão z. Isto causará uma variação na distância pontaamostra, cuja mudança correspondente da corrente de tunelamento será lida pelo microcomputador. O programa implementado permite a escolha de três faixas de deslocamentos (entre $1,2 \AA, 2,4 \AA$ e $4,0 \AA$ ) e o ganho a ser aplicado sobre a corrente. A ponta é então aproximada em relação à amostra desta distância, enquanto cem valores de corrente são adquiridos. $O$ salvamento de dados é feito em formato ASCII para análise posterior em uma planilha eletrônica (obtenção do logaritmo da corrente e derivada da curva). A Figura 14 mostra uma reprodução da tela deste programa, que é muito semelhante à do programa descrito no item anterior.

A Figura 15 mostra uma fotografia com a vista de todo o sistema (parte mecânica, eletrônica e microcomputador) que constitui nosso STM. 

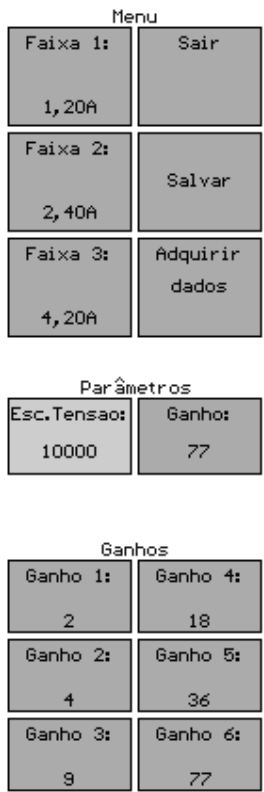

Curva I-s

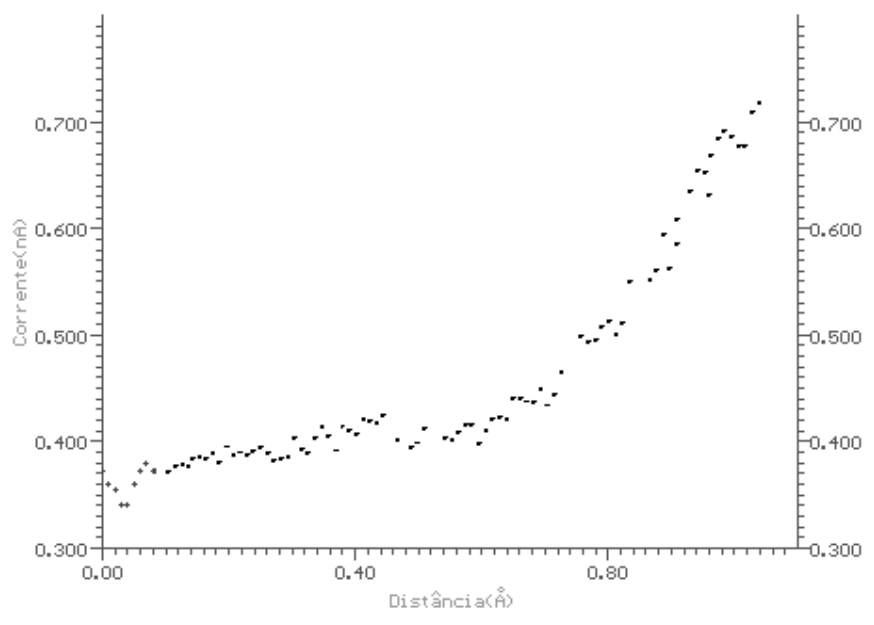

Figura 14: reprodução da tela do programa de aquisição da altura da barreira de tunelamento (curva I-s).

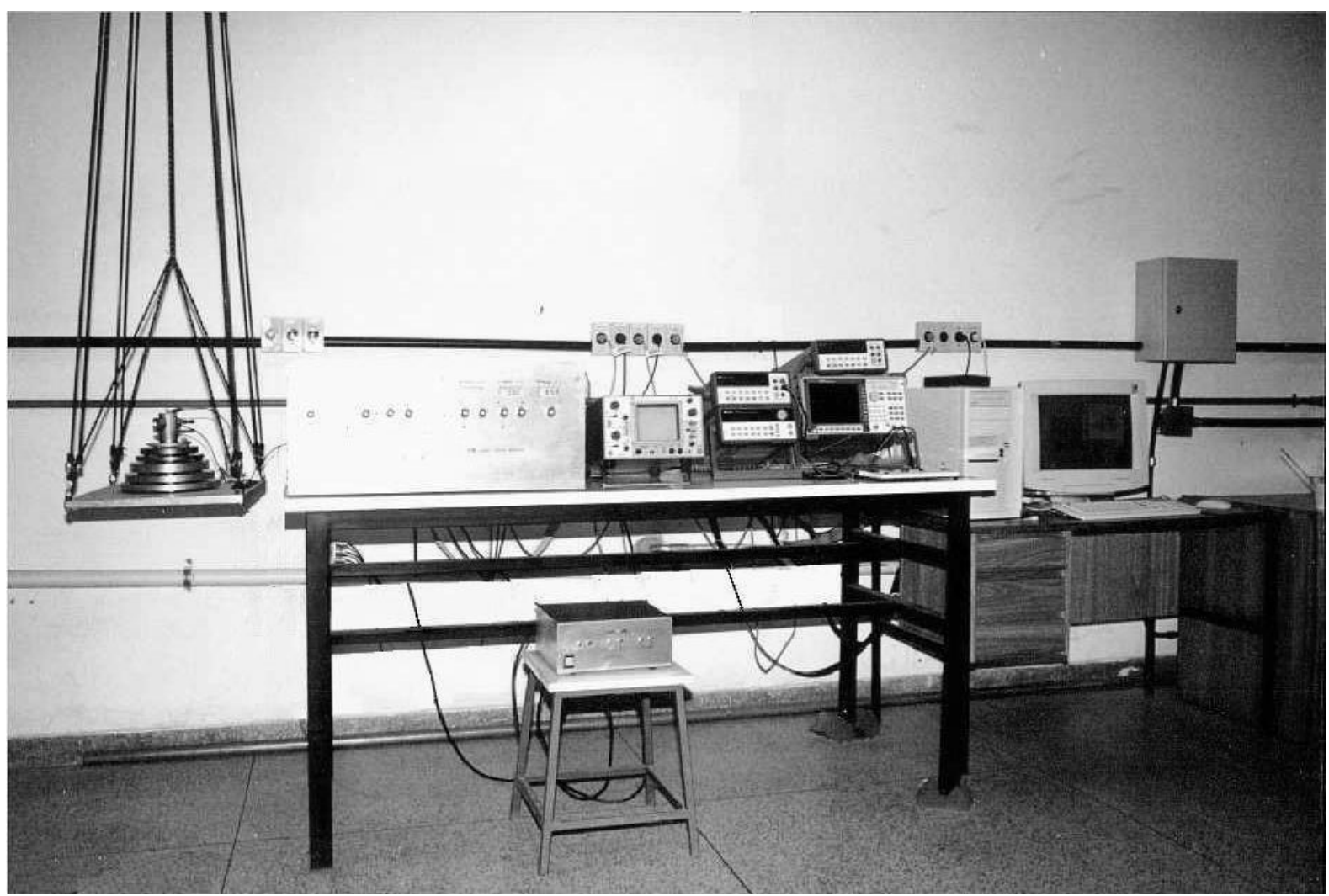

Figura 15: fotografia mostrando o sistema completo que constitui o STM do LNMS. 


\section{4- Conclusões:}

Neste capítulo foi dada uma descrição da versão atual do microscópio construído no LNMS assim como dos módulos eletrônicos e dos programas de controle necessários para seu funcionamento. A cabeça de medida, assim como os circuitos e o programa destinado à operação em modo topográfico já tinham sido desenvolvidos por um outro aluno de mestrado de nosso grupo. Minha contribuição foi a implementação, nos circuitos existentes, das novas funções de espectroscopia I-V, I-s e $\pm \mathrm{V}$ (pelo uso de um Sample and Hold, seguidor de sinais para o elemento piezelétrico e um isolador de sinais), assim como o desenvolvimento das rotinas computacionais específicas para a coleta de dados em modo espectroscópico. Um cuidado especial foi tomado para que as novas funções não degradassem as funções topográficas implementadas anteriormente.

\section{Referências:}

1 L. E. C. Leemput em Tunneling Microscopy and Spectroscopy of High Tc Superconductor and Mesoscopic Systems, tese de Doutorado pela Katholieke Universiteit te Nijmegen, 1991.

2 G. Binnig, H. Rohrer, Ch. Gerber e E. Weibel, Appl. Phys. Lett. 40, 178 (1982).

3 Ch. Gerber, G. Binnig, H. Fuchs, O. Marti e H. Rohrer, Rev. Sci. Instrum. 57, 221 (1986).

4 D. W. Pohl, IBM J. Res. Dev. 30, 355 (1986).

5 M. Okano, K. Kajimura, S. Wakiyama, F. Sakai, W. Mizutani e M. Ono, J. Vac. Sci. Technol. A 5, 3313 (1987).

6 Electronic Materials, editado por Nicholas Braithwaite e Graham Weaver, editora Butterworth, Boston (1990).

7 G. Binnig e D. P. E. Smith, Rev. Sci. Instrum. 57, 1688 (1986).

8 D. A. Bonnell, em Scanning Tunneling Microscopy and Spectroscopy, cap. 2, editado por D.

A. Bonnell, VCH Publishers, (1993).

9 C. Julian Chen, Appl. Phys Lett. 60, 132 (1992).

${ }_{10}$ Morgan Matroc, Inc. Electro Ceramics Division.

11 A. S. Ferlauto em Construção e Aplicações de um Microscópio de Tunelamento, dissertação de mestrado pelo Instituto de Física da USP, 1996.

12 G. Rohrer em Scanning Tunneling Microscopy and Spectroscopy, cap. 6, editado por D. A. Bonnel, VCH Publishers, (1993).

${ }^{13}$ Y. Kuk e P. J. Silverman, Appl. Phys. Lett. 48, 1597 (1986).

14 J. Abellan, R. Chicon e M. Ortuno, Phys. Status Solidi A 101, 463 (1987).

15 J. Wintterlin, J. Wiechers, H. Brune, T. Gritsch, H. Hofer e R. J. Behm, Phys. Rev. Lett. 62, 59 (1989).

16 R. J. Colton, S. M. Baker, J. D. Baldeschwieler e W. J. Kaiser, Appl. Phys. Lett. 51, 305 (1987).

17 M. Fotino, Rev. Sci. Instrum. 64, 159 (1993).

18 J. O. Fiering e F. M. Ellis, Rev. Sci. Instrum. 61, 3911 (1990).

19 M. J. Vasile, D. A. Grigg, J. E. Griffith, E. A. Fitzgerald e P. E. Russel, Rev. Sci. Instrum. 62, 2167 (1991).

20 A. A. Quivy em Techniques and Applications of a room-temperature Scanning Tunneling Microscope, tese de doutoramento pela Universidade Livre de Bruxelas (1991). 
21 C. L. Phillips e R. D. Harbor em Feedback Control Systems, pág. 19, Segunda edição, Prentice Hall, Inc. (1991).

${ }^{22}$ Low Level Measurement-For effective Low Current Voltage and High Impedance Measurements, Keithley Instruments, Inc.

${ }^{23}$ Manual de Componentes Burr Brown, 1994.

24 J. A. Stroscio e R. M. Feesntra em Scanning Tunneling Microscopy, cap.4, Methods of Experimental Physics 27, editado por J. A. Strocio e W. J. Kaiser, Academic Press, Inc., San Diego, 1993.

25 T. Kato e I. Tanaka, Rev. Sci. Instrum. 61, 1664 (1990).

${ }^{26}$ S.D. Senturia e B. D. Wedlock, Electronic Circuits and Applications, cap. 5, (Jonh Willey and Sons, 1974).

27 R. J. Hamers, R. M. Tromp e J. E. Demuth, Phys. Rev. Lett. 56, 1972 (1986).

${ }^{28}$ M. Tanaka, W. Mizutani, T. Nakashizu, N. Morita, S. Yamazaki, H. Bando, M. Ono, K. Kajimura, J. Microsc. 152, 183 (1988).

${ }^{29}$ J. A. Stroscio, R. M. Feenstra, D. M. Newns e A. P. J. Fein, J. Vac. Sci. Technol A6, 494 (1988).

30 R. M. Feenstra, J. A. Stroscio e A. P. J. Fein, Surf. Sci. 181, 295 (1987). 


\section{Capítulo 4}

\section{ESPECTROSCOPIA SOBRE HOPG:}

\section{1- Introdução:}

Com a finalidade de testar o aparato recém-implementado para aquisição de dados em modo espectroscópico, executamos diversas medidas em amostras de grafite. Este material tornou-se padrão para testes com um STM por várias razões. É possível obter uma superfície limpa e lisa ao nível atômico simplesmente clivando-a com uma fita adesiva. Quimicamente, o grafite não reage com os elementos atmosféricos, permitindo imagens com resolução atômica mesmo no ar. A estrutura do grafite apresenta camadas empilhadas, cada uma delas com arranjo hexagonal de átomos de carbono (ver Figura 1). O empilhamento ocorre de forma que metade dos átomos de uma mesma camada sejam localizados sobre outros átomos da camada inferior (sítios A), e os demais situem-se sobre os buracos centrais dos hexágonos do plano inferior (sítios B). A distância entre primeiros vizinhos em um mesmo plano é de $1,42 \AA$, conduzindo a um parâmetro de rede $a=2,46 \AA$. Os planos são unidos entre si por forças de van der Waals e separados por uma distância de $3,35 \AA$. Eletronicamente, o grafite apresenta um caráter semimetálico, possuindo uma resistividade baixa o bastante para permitir a análise com um STM.

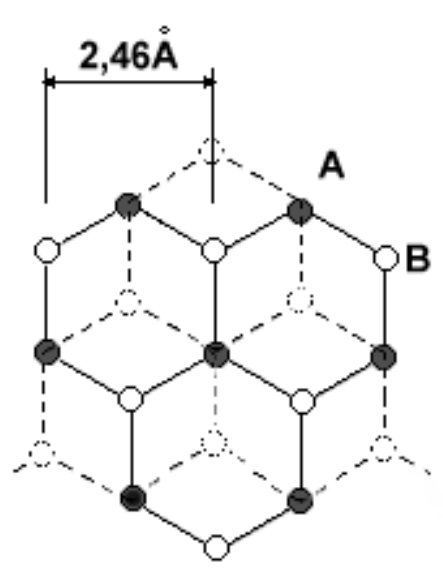

a

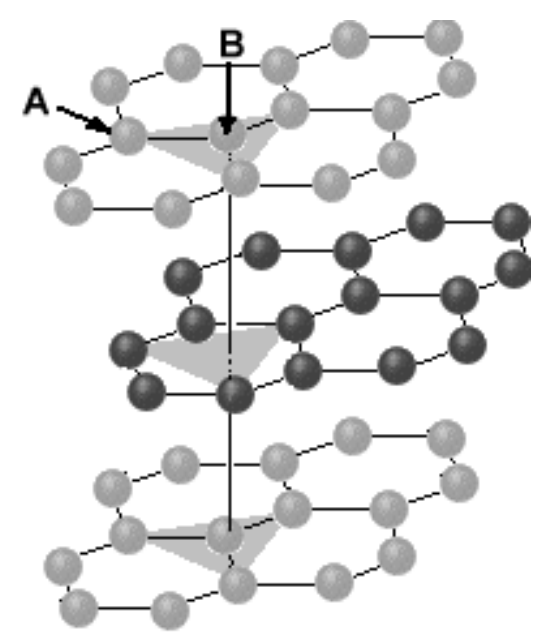

b

Figura 1: (a) representação (vista de topo) da estrutura do grafite (HOPG). Os sítios A (mais escuros) e B são indicados. A camada atômica inferior é representada por linhas pontilhadas. (b) representação lateral em perspectiva da mesma estrutura. A linha vertical indica os sítios $B$.

Imagens de grafite com resolução atômica podem ser facilmente obtidas no ar, ${ }^{1}$ em ultraalto vácuo (ultra-high vaccum, $\mathrm{UHV})^{2}$ ou sob diversos tipos de líquidos. ${ }^{3}$ No entanto, existem algumas particularidades envolvendo estes resultados: 
- as imagens apresentam geralmente uma rede com simetria triangular, na qual apenas metade dos átomos da estrutura é observada;

- a altura aparente dos átomos de carbono chega a ser da ordem de $20 \AA$ em alguns casos, muito maior que o espaçamento entre planos atômicos $(3,35 \AA)$ e que o relevo real da LDOS;

- é possível visualizar também padrões com simetria diferente da triangular.

Algumas imagens obtidas sobre HOPG com nosso microscópio mostram exemplos dessas anomalias (ver Figura 2).

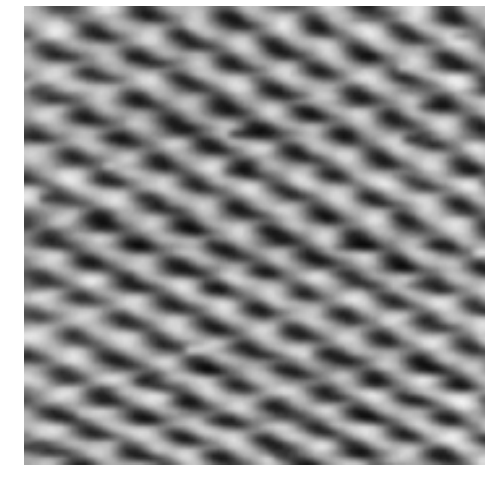

a

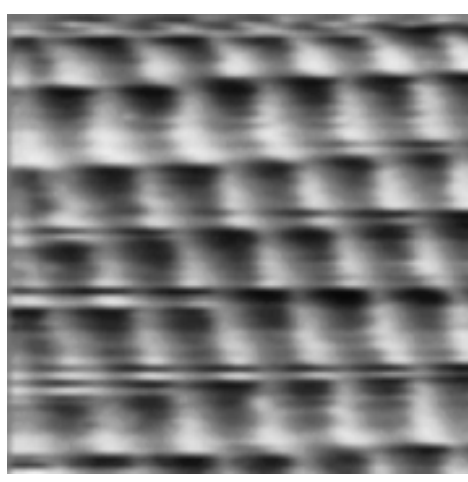

c

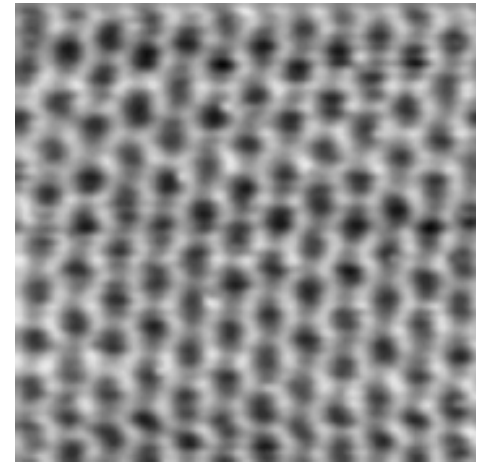

b

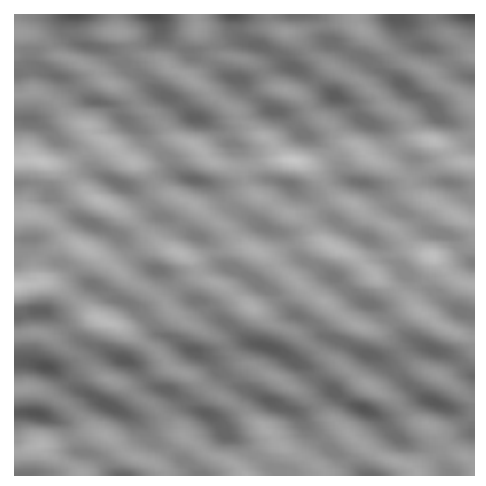

d

Figura 2: alguns exemplos de imagens de grafite obtidas por STM: (a) arranjo com simetria triangular esperado segundo o modelo de Batra (tamanho $22 \AA x 22 \AA$, escala de cinza na faixa de $8 \AA$ ); (b) arranjo hexagonal

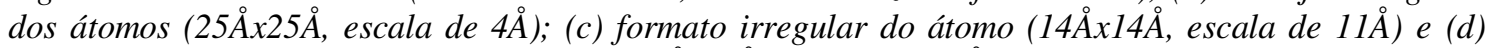
configuração atômica em linhas (tamanho $22 \AA x 22 \AA$, escala de $11 \AA$ ). As varreduras foram executadas com freqüência em $x$ de aproximadamente $10 \mathrm{~Hz}$.

A literatura traz uma série de estudos que procuraram entender estas discrepâncias. Inicialmente, Binnig e colaboradores ${ }^{2}$ associaram as protusões presentes nas imagens com simetria triangular como sendo os sítios A da estrutura do grafite. Posteriormente, Batra e colaboradores $^{4}$ concluíram teoricamente que os átomos apresentados correspondiam aos sítios B. 
A explicação reside na assimetria entre a posição dos dois sítios. Os sítios A localizam-se sobre um outro átomo da camada inferior, enquanto que nos sítios $B$ isto não ocorre. Conseqüentemente, a distribuição dos elétrons dos sítios A divide-se entre os dois planos, enquanto se mantém bem definida nos sítios B. Com efeito, estes sítios contribuirão com uma parcela maior da corrente de tunelamento que os sítios $\mathrm{A}$, tendo maior destaque nas imagens.

A elevada altura aparente dos átomos (giant corrugation) geralmente observada deve-se tanto à constituição eletrônica quanto a propriedades mecânicas da amostra. No âmbito das características eletrônicas, Tersoff associou este fenômeno aos estados de energia individuais presentes na superfície do grafite. A estrutura nodal destes estados, que apresentam máximos sobre os átomos de carbono e mínimos no centro dos hexágonos, dá origem a uma grande corrugação com a periodicidade da célula unitária. ${ }^{5}$

A influência da interação mecânica da ponta com a amostra sobre o relevo medido foi estudada por Soler e colaboradores. ${ }^{6}$ Em um semimetal como o grafite, que apresenta baixa densidade de estados superficiais, a varredura deve ser realizada com a ponta muito próxima da amostra. Nesta condição, é possível que deslocamentos verticais de alguns angströns originem um contato físico da ponta com a superfície. ${ }^{*} \mathrm{O}$ trabalho de Soler permitiu-lhe concluir que a força resultante deste contato era diferente quando a ponta estava localizada sobre os átomos de carbono (atrativa) ou sobre o centro dos hexágonos (repulsiva). Isto faz com que a superfície seja deformada de modo diferente em cada caso, aumentando assim a amplitude do relevo medida pelo STM. A despeito da conveniência do modelo proposto, Pethica apresentou alguns fatores técnicos limitantes. ${ }^{7}$ Entre eles, o mais importante é a energia elástica armazenada durante o contato, que deveria ser alta o bastante para gerar mudanças no arranjo atômico da amostra (como o surgimento de defeitos estruturais). Isto nunca foi observado, já que é possível obter a reprodução de imagens sobre a mesma região. Mamin e colaboradores ${ }^{8}$ contornaram esta limitação propondo que a interação mecânica acontecesse através de uma camada de contaminantes adsorvidos pela superfície. Isto distribuiria o esforço da ponta sobre uma área muito maior da amostra, reduzindo a energia armazenada por área e justificando a não formação dos defeitos. Neste modelo, o tunelamento ocorreria através da parte mais aguda da ponta, que penetraria a camada de contaminantes e chegaria próximo o bastante da amostra.

Freqüentemente, as imagens obtidas revelam a periodicidade da rede mas não a simetria triangular (ver, por exemplo, as imagens b e d da Figura 2 prevista pelo modelo de Batra. Vários autores atribuem esta anomalia à existência de pontas múltiplas sondando a amostra. Se (por exemplo) dois ápices se encontram na mesma ponta e conduzem porções comparáveis da corrente de tunelamento, a imagem final será associada à composição das imagens sondadas em regiões diferentes por cada um dos ápices. ${ }^{\dagger}$ Dependendo da posição relativa entre as pontas, esta composição pode gerar imagens que apresentam diversos tipos de formações (como as hexagonais e as lineares presentes na figura). As referências 9 e 10 dão inúmeros exemplos de imagens obtidas experimentalmente e simuladas numericamente, mostrando que esta suposição é plausível. P. J. Ouseph e seus colaboradores propuseram uma explicação alternativa. ${ }^{11}$ Em seu trabalho, Ouseph associa a visualização da estrutura hexagonal do grafite com o deslizamento do plano atômico superficial da amostra. Segundo ele, uma translação de apenas $0,79 \AA$ (correspondente a uma mudança de $-10,879 \mathrm{Ry}$ para $-10,872 \mathrm{Ry}$ na energia armazenada no

\footnotetext{
* O contexto deste trabalho tem validade apenas quando a imagem é adquirida no modo de corrente constante.

† Vale lembrar que, devido à periodicidade da estrutura, as pontas múltiplas sempre estarão localizadas dentro de uma mesma célula unitária do cristal, apesar delas poderem estar distantes umas das outras por vários vetores da rede.
} 
arranjo atômico ${ }^{4}$ ) seria suficiente para quebrar a assimetria entre os sítios A e B, que então contribuiriam com a mesma intensidade para a corrente de tunelamento tornando possível a visualização de ambos. A explicação da ocorrência de outros tipos de geometrias (linhas e formatos irregulares dos átomos) receberam a mesma justificativa.

\section{2- Espectroscopia I-V:}

Nesta etapa, o aparato para medidas de curvas I-V foi testado sobre o grafite. A literatura relata poucos estudos acerca deste tópico em particular, devotados à compreensão dos mecanismos de oxidação térmica, ${ }^{12}$ da adsorção de contaminantes pela superfície ${ }^{13,14}$ e da estrutura eletrônica ${ }^{15}$ deste material. Em nosso conhecimento, nenhum artigo analisa de modo conciso as características das curvas I-V adquiridas sobre o grafite. Assim, as comparações dos dados obtidos em nosso estudo teve de ser baseada em diversos artigos tanto experimentais quanto teóricos.

A amostra de HOPG foi clivada com uma fita adesiva imediatamente antes da medida. Ela é ligada ao fio terra usando cola de prata que forma um contato rígido e altamente condutor. Antes de realizar as curvas I-V, sempre efetuamos uma varredura topográfica da amostra a fim de obter uma imagem a nível atômico do grafite. A visualização de uma simetria triangular (esperada pelo modelo de Batra) mostra que a ponta recém-preparada é capaz de sondar localmente cada átomo, eliminando o risco da informação obtida referir-se a várias regiões diferentes (no caso de pontas múltiplas) ou a alguma impureza não retirada pelo processo de clivagem. Neste estudo, fizemos medidas I-V mantendo a tensão de tunelamento Vt ${ }^{*}$ constante e variando a corrente de referência do circuito de retroação. A tensão de tunelamento foi mantida em $55,6 \mathrm{mV}$, enquanto que a corrente de referência foi variada de forma crescente nos valores $0.16,1.00,2.00$ e $2.66 \mathrm{nA}$ entre aquisições sucessivas. Quando aumentamos a corrente de referência, com a retroação em modo ativo, o circuito aproxima a ponta da amostra, causando um decremento na impedância da junção túnel e, em conseqüência, uma característica I-V diferente. Os limites da rampa de tensão foram $-0,5$ a $+0,5 \mathrm{~V}$. O conjunto de 100 pontos que formam cada curva foi adquirido em aproximadamente $100 \mathrm{~ms}$, um tempo grande o bastante para eliminar efeitos indesejados da resposta do circuito que pudessem deformar a curva. As curvas obtidas são mostradas na Figura 3. As incertezas foram calculadas levando em conta o número de bits da placa conversora $\mathrm{AD}(\sigma= \pm 0,005 \mathrm{~V})$ e o erro do multímetro usado para aferir o ganho da eletrônica $(\sigma= \pm 1 \%$ para a faixa de medida realizada). Uma vez que a inclinação da curva I$\mathrm{V}$ é inversamente proporcional à impedância da junção túnel (por sua vez proporcional à distância ponta-amostra), conforme a ponta é aproximada da amostra (maior corrente de tunelamento) esta inclinação deve tornar-se mais elevada. ${ }^{14}$ Esta é a tendência mostrada pelo gráfico, comprovando em primeira instância a coerência dos dados e a qualidade do novo sistema instalado.

\footnotetext{
* É importante dar atenção à diferença entre a tensão de tunelamento Vt, que é aquela ajustada para a execução de imagens topográficas, e a rampa de tensão gerada pelo programa, que é sobreposta a esta tensão durante a espectroscopia.
} 


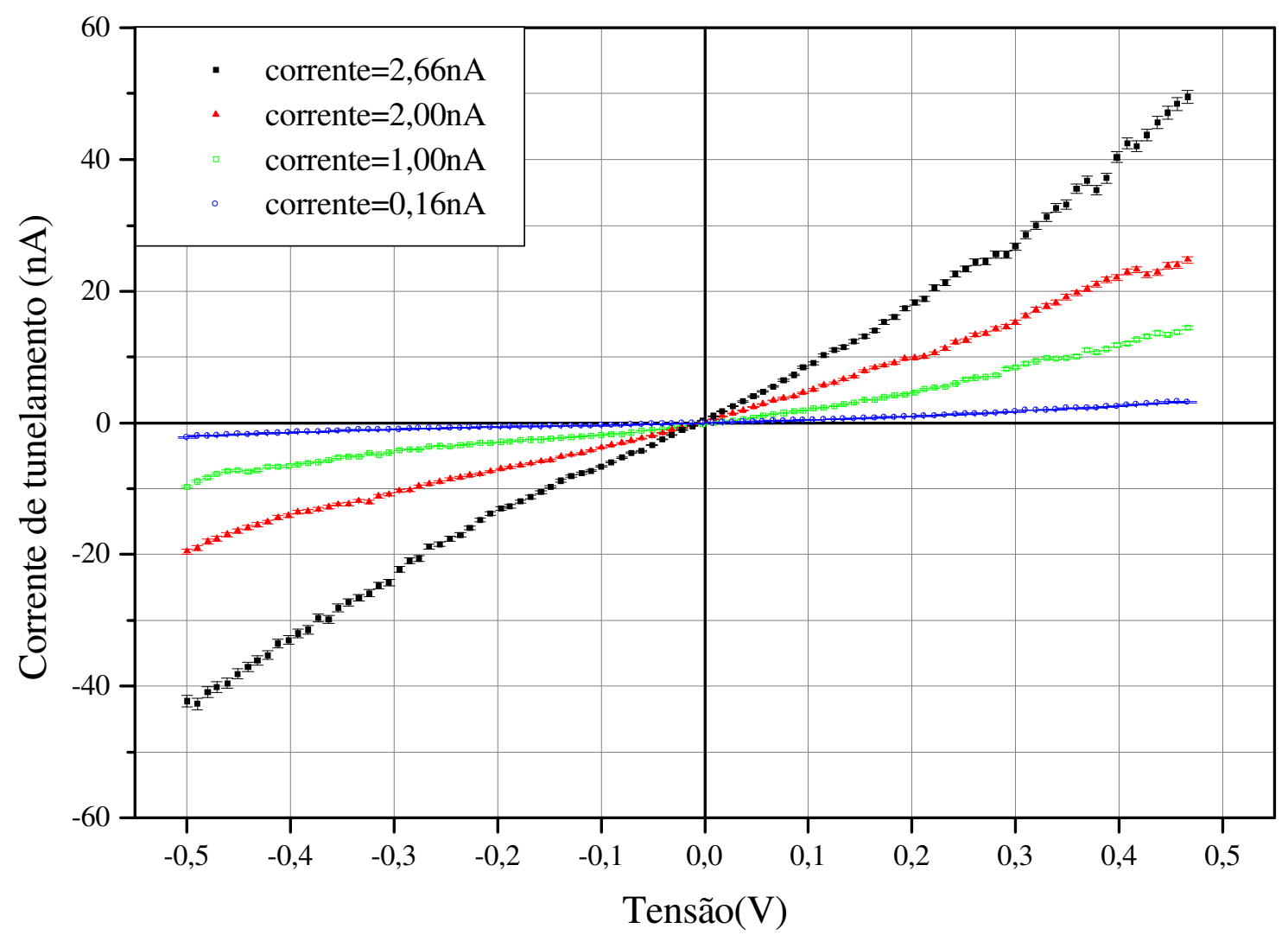

Figura 3: gráfico das curvas I-V obtidas sobre o grafite em diversas condições de corrente de tunelamento.

É possível notar que as curvas são assimétricas em relação à tensão nula, exibindo um sutil comportamento retificador, isto é, o módulo da corrente é maior em uma particular tensão positiva que no mesmo valor do ramo negativo. Para mostrar mais claramente esta propriedade, a Figura 4 traz um gráfico da condutância (derivada da corrente em relação à tensão) de uma curva obtida nas condições $\mathrm{V}=50 \mathrm{mV}$ e $\mathrm{I}=1 \mathrm{nA}$, na faixa de tensões de -1 a $1 \mathrm{~V}$. Neste gráfico, verificase um deslocamento do ponto de mínimo da parábola para valores negativos de tensão, revelando a assimetria da curva I-V. Em seu modelo, Brinkman ${ }^{16}$ (cujos principais resultados foram discutidos no primeiro capítulo desta dissertação) associou este deslocamento à diferença e à média dos valores da função trabalho dos dois eletrodos constituintes da junção. Tendo em vista a diferença entre os materiais que constituem a ponta (platina, $\phi \approx 5,4 \mathrm{eV}$ ) e a amostra (grafite $\phi \approx 5 \mathrm{eV}),{ }^{17}$ este comportamento está em pleno acordo com as previsões de Brinkman. Qualquer tentativa de comparação quantitativa deste resultado com as expressões do trabalho de Brinkman seria leviana, tendo em vista a diferença de contexto nos dois casos (junções planares e STM). 


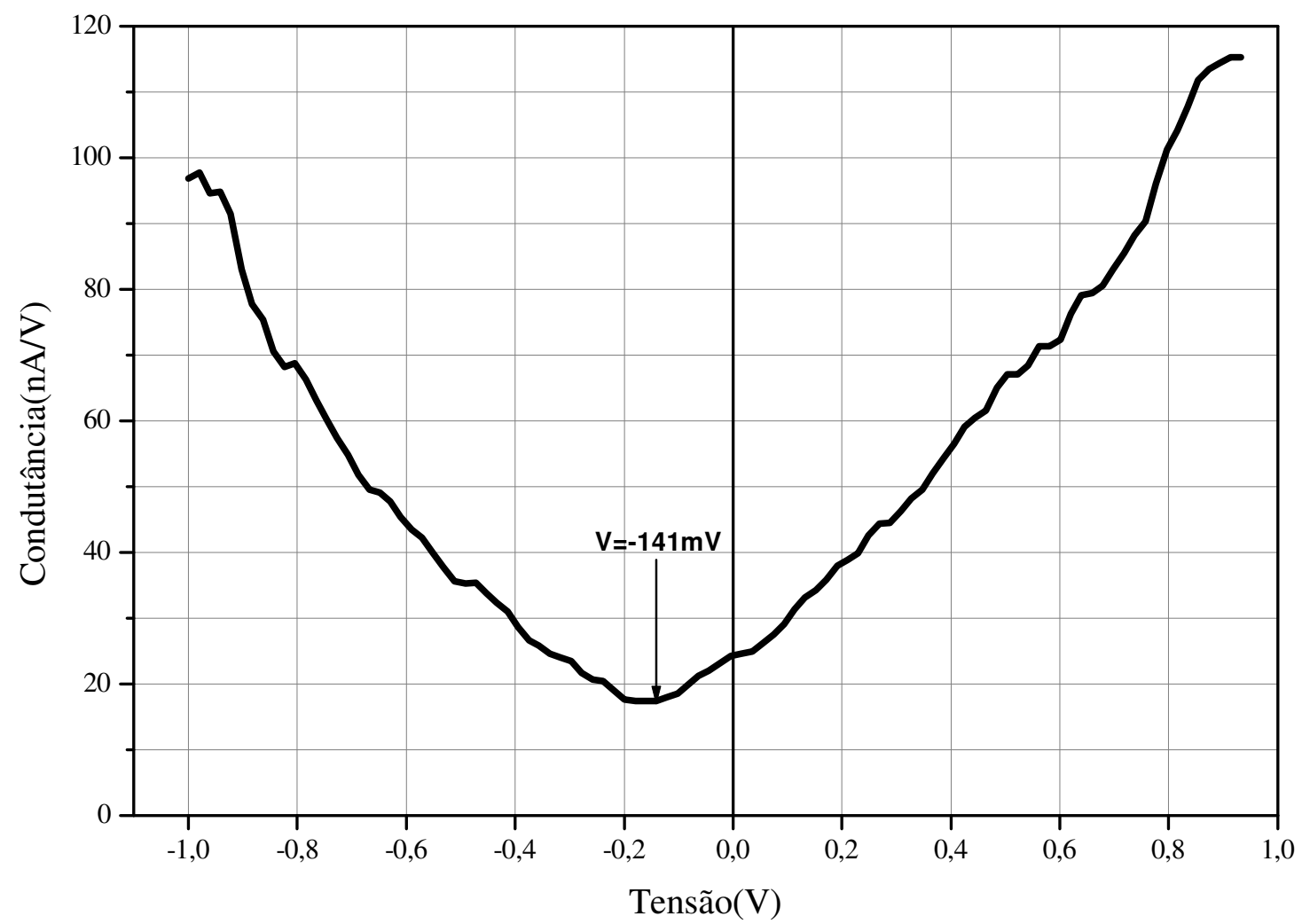

Figura 4: curva da condutância em função da tensão de tunelamento adquirida sobre HOPG. A seta indica o ponto de mínimo e o valor de seu deslocamento em relação à origem dos valores de tensão.

O passo final foi executar uma análise semiquantitativa, ajustando diversos polinômios a fim de verificar a coerência dos valores obtidos com o resultado do modelo de Brinkman (condutância parabólica). Como a condutância é a derivada da corrente de tunelamento em função da tensão, concluímos que nossas curvas I-V devem ser ajustadas por um polinômio de grau 3. Pelo método dos mínimos quadrados, foram ajustados polinômios de graus 1 até 6 sobre uma curva obtida pela média de mais de dez amostragens adquiridas sob as mesmas condições $(\mathrm{V}=55,6 \mathrm{mV}$ e $\mathrm{I}=2 \mathrm{nA})$. A Figura 5, juntamente com a Tabela 1, traz um resumo dos resultados dos ajustes. No gráfico da dispersão dos resíduos (a diferença entre o dado experimental e a curva ajustada dividida pelo desvio padrão da medida, na parte inferior da Figura 5), percebe-se um decréscimo da flutuação conforme o aumento do grau do polinômio, que cessa quando o grau 4 é atingido. A partir deste grau, a dispersão se torna praticamente invariável. Verificando a Tabela 1, nota-se o aumento das incertezas dos coeficientes ajustados nos graus 5 e 6 . Usando o teste t de Student (últimas 2 colunas da tabela), observam-se probabilidades de 81, 45 e $16 \%$ dos coeficientes de grau superior a 4 serem nulos (células destacadas na tabela). Portanto, podemos descartar os polinômios de graus superiores a 4, apesar da pequena dispersão nos resíduos. Em conclusão, a estatística dos ajustes nos deixou a escolha entre os polinômios de grau 3 ou 4 para modelar a curva I-V do grafite. Uma restrição fenomenológica permite excluir o ajuste de grau 4: o coeficiente ajustado para a ordem 4 neste caso tem sinal negativo. Isto não expressa um comportamento natural (neste sistema em particular), pois significa que a corrente de tunelamento diminuiria, após uma certa tensão, com o aumento da tensão na junção. $O$ método dos mínimos quadrados indicou que este era o melhor ajuste, mas para isso foi necessário o uso 
de um parâmetro fisicamente sem sentido. Com base nestes argumentos, podemos concluir que o polinômio de grau 3 se ajusta satisfatoriamente à curva I-V obtida, confirmando a consistência dos dados obtidos em relação aos resultados teóricos.
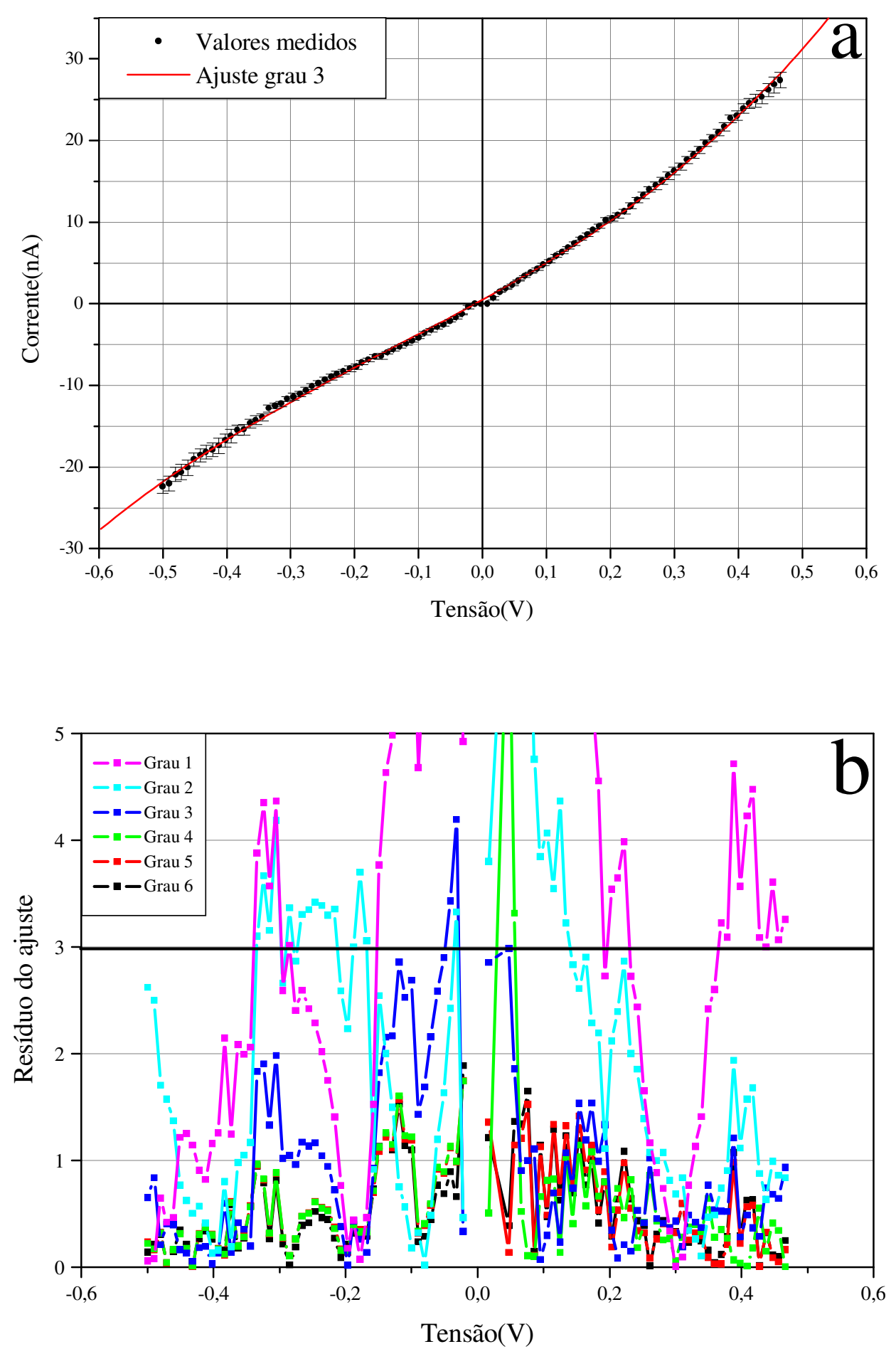

Figura 5: (a) gráfico da curva I-V obtida com a corrente de referência do integrador em 2,0nA (pontos pretos) juntamente com a curva ajustada por um polinômio de grau 3 (em vermelho). (b) dispersão dos resíduos dos ajustes feitos em diversos graus (o resíduo é a razão do erro do ajuste pelo desvio padrão da medida). 


\begin{tabular}{|c|c|c|c|c|}
\hline $\begin{array}{c}\text { Grau do polinômio de } \\
\text { regressão }\end{array}$ & Valor & Erro & Valor $\mathbf{t}$ & $\begin{array}{c}\text { Probabilidade } \\
>|\mathbf{t}|\end{array}$ \\
\hline \multicolumn{5}{|l|}{ GRAU 3} \\
\hline A & 0.49 & 0.05 & 9.54 & $<0.0001$ \\
\hline B1 & 43.4 & 0.3 & 142.85 & $<0.0001$ \\
\hline B2 & 16.8 & 0.5 & 34.11 & $<0.0001$ \\
\hline B3 & 38.5 & 1.9 & 19.67 & $<0.0001$ \\
\hline \multicolumn{5}{|l|}{ GRAU 4} \\
\hline $\mathrm{A}$ & 0.18 & 0.03 & 5.02 & $<0.0001$ \\
\hline B1 & 43.86 & 0.17 & 245.32 & $<0.0001$ \\
\hline B2 & 29.7 & 0.9 & 30.50 & $<0.0001$ \\
\hline B3 & 34.21 & 1.17 & 29.09 & $<0.0001$ \\
\hline B4 & -63 & 4 & 13.83 & $<0.0001$ \\
\hline \multicolumn{5}{|l|}{ GRAU 5} \\
\hline A & 0.19 & 0.03 & 4.99 & $<0.0001$ \\
\hline B1 & 43.9 & 0.3 & 142.38 & $<0.0001$ \\
\hline B2 & 29.71 & 1.01 & 29.32 & $<0.0001$ \\
\hline B3 & 33 & 5 & 6.49 & $<0.0001$ \\
\hline B4 & -63 & 5 & 12.90 & $<0.0001$ \\
\hline B5 & 4 & 18 & 0.23 & 0.81 \\
\hline \multicolumn{5}{|l|}{ GRAU 6} \\
\hline $\mathrm{A}$ & 0.15 & 0.04 & 3.63 & 0.0004 \\
\hline B1 & 44.0 & 0.3 & 140.12 & $<0.0001$ \\
\hline B2 & 32.41 & 2.18 & 14.82 & $<0.0001$ \\
\hline B3 & 30 & 5 & 5.74 & $<0.0001$ \\
\hline B4 & -97 & 25 & 3.88 & 0.0002 \\
\hline B5 & 15 & 20 & 0.75 & 0.45 \\
\hline B6 & 107 & 77 & 1.39 & 0.16 \\
\hline
\end{tabular}

Tabela 1:: comparação dos resultados da regressão dos polinômios de graus 3 até 6 . A nomenclatura dos coeficientes segue a convenção $y=\boldsymbol{A}+\boldsymbol{B} 1 * X+\boldsymbol{B} 2 * X^{2}+\boldsymbol{B} 3 * X^{3}+\ldots \boldsymbol{B} \boldsymbol{n}^{*} X^{n}$. As duas últimas colunas indicam o valor de $t$ de Student (=coeficiente/incerteza do ajuste) e a probabilidade do respectivo coeficiente ser nulo.

\section{3- Espectroscopia de Altura da Barreira:}

Com a finalidade de completar os testes iniciais do novo sistema espectroscópico, realizamos algumas medidas da altura aparente da barreira sobre amostras de HOPG. Como, neste modo, não precisamos de resolução lateral, os dados foram adquiridos com o programa que realiza apenas uma curva I-s em um ponto arbitrário da amostra. A obtenção dos dados se dá em duas etapas. Primeiramente, a curva I-s (corrente de tunelamento versus distância ponta-amostra) é adquirida com o programa. Calculando numericamente o logaritmo dos valores da corrente e depois a derivada $\mathrm{d} \ln (\mathrm{I}) / \mathrm{ds}$, obtém-se a raíz quadrada da altura aparente da barreira, a menos de uma constante multiplicativa $\left(0,9757(\mathrm{eV})^{1 / 2}\right)$.

Os trabalhos de N. D. Lang ${ }^{18}$ e Pitarke ${ }^{19}$ previam uma acentuada dependência entre a altura aparente da barreira e a distância ponta-amostra, como foi mostrado no capítulo inicial desta dissertação. As medidas preliminares efetuadas neste modo visaram verificar a consistência dos dados obtidos acerca desta dependência. Para isto, foram adquiridas diversas curvas variando a corrente de tunelamento entre medidas consecutivas. Este estudo foi conduzido tendo como parâmetro a corrente de tunelamento, uma vez que a determinação exata da distância pontaamostra é operacionalmente complexa (ver, por exemplo, a referência 20). Foi escolhida uma tensão de tunelamento de $75 \mathrm{mV}$. A amplitude de deslocamento usada em cada rampa foi de $1 \AA$, com uma incerteza de 1\%, aproximando a ponta da amostra. A velocidade de geração desta rampa e da aquisição da corrente foi variada entre $100 \mathrm{~ms}$ e $20 \mathrm{~ms}$, não proporcionando influência sobre os dados. A Figura 6 traz um gráfico com os resultados obtidos, no qual cada curva representa uma média de mais de dez aquisições sob os mesmos parâmetros. O eixo das ordenadas apresenta o valor do logaritmo da corrente, de maneira que a inclinação da curva é 
proporcional à raiz quadrada da altura aparente da barreira. Uma análise visual das curvas já permite observar a consistência dos resultados. Na curva inferior (correspondente a 60pA de corrente, a condição de maior distância ponta-amostra deste conjunto de medidas), observa-se a variação de um fator dez na magnitude da corrente ao longo do deslocamento de $1 \AA$ da ponta. Esta variação vai sendo atenuada conforme a corrente assume valores maiores (menor distância ponta-amostra). Ajustando retas aos dados apresentados, foi possível obter numericamente a altura aparente da barreira para cada valor da corrente de tunelamento. A Figura 7 traz um gráfico dos resultados. A escala das abscissas é logarítmica, de modo a representar graficamente a relação entre a corrente de referência e a distância ponta-amostra. A forma da curva é praticamente linear para os valores elevados da corrente (baixa distância ponta-amostra). Já o primeiro ponto da curva (correspondente à maior distância da amostra no conjunto) apresenta um aumento substancial da altura da barreira, em pleno acordo com a previsão teórica.

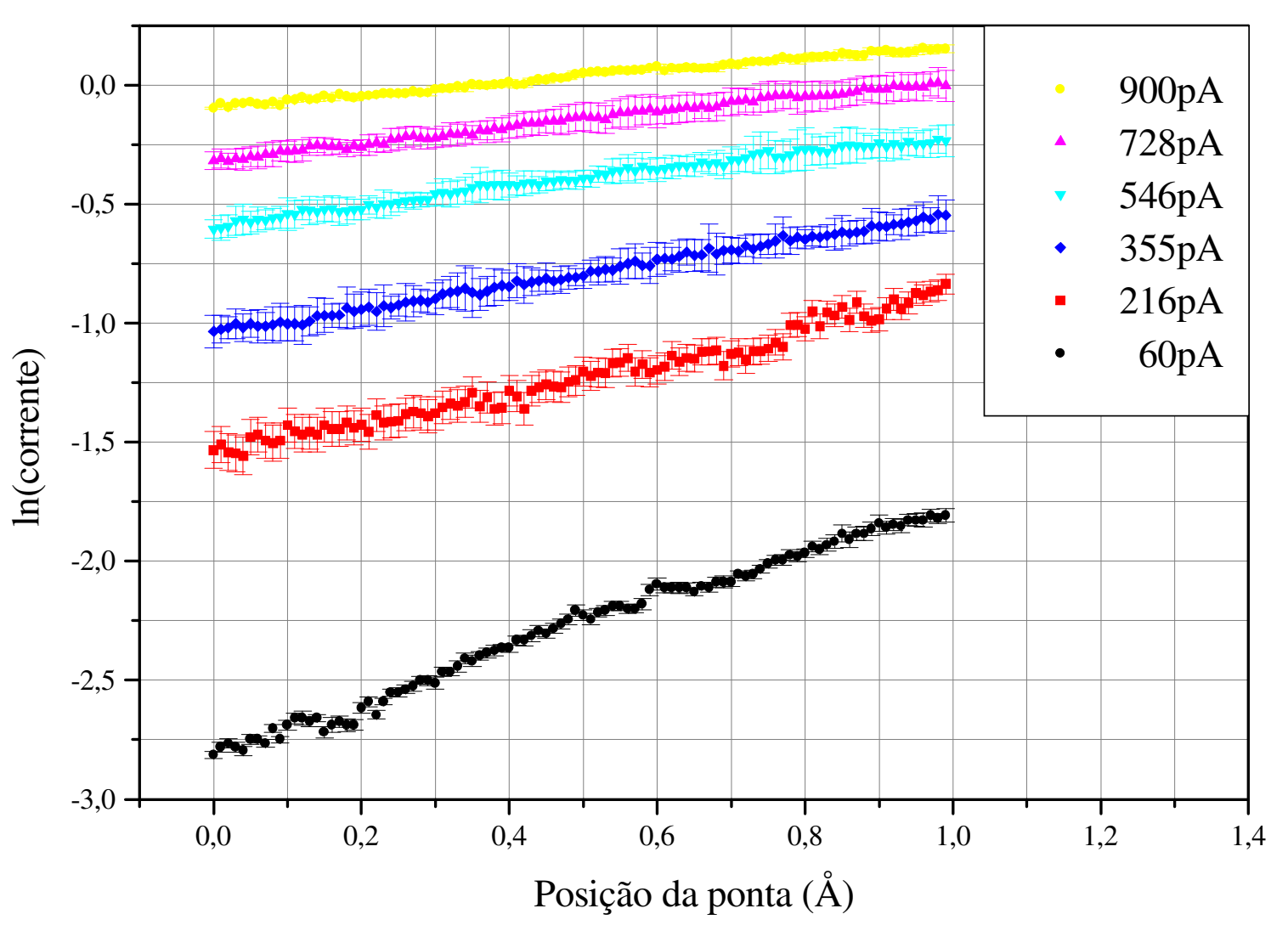

Figura 6: curvas mostrando a variação do logaritmo neperiano da corrente versus a posição da ponta obtidas sobre HOPG. Na legenda, são apresentados os diversos valores da corrente de tunelamento antes do início da aquisição (correspondentes a s=0A, ou seja, a posição inicial da ponta). 


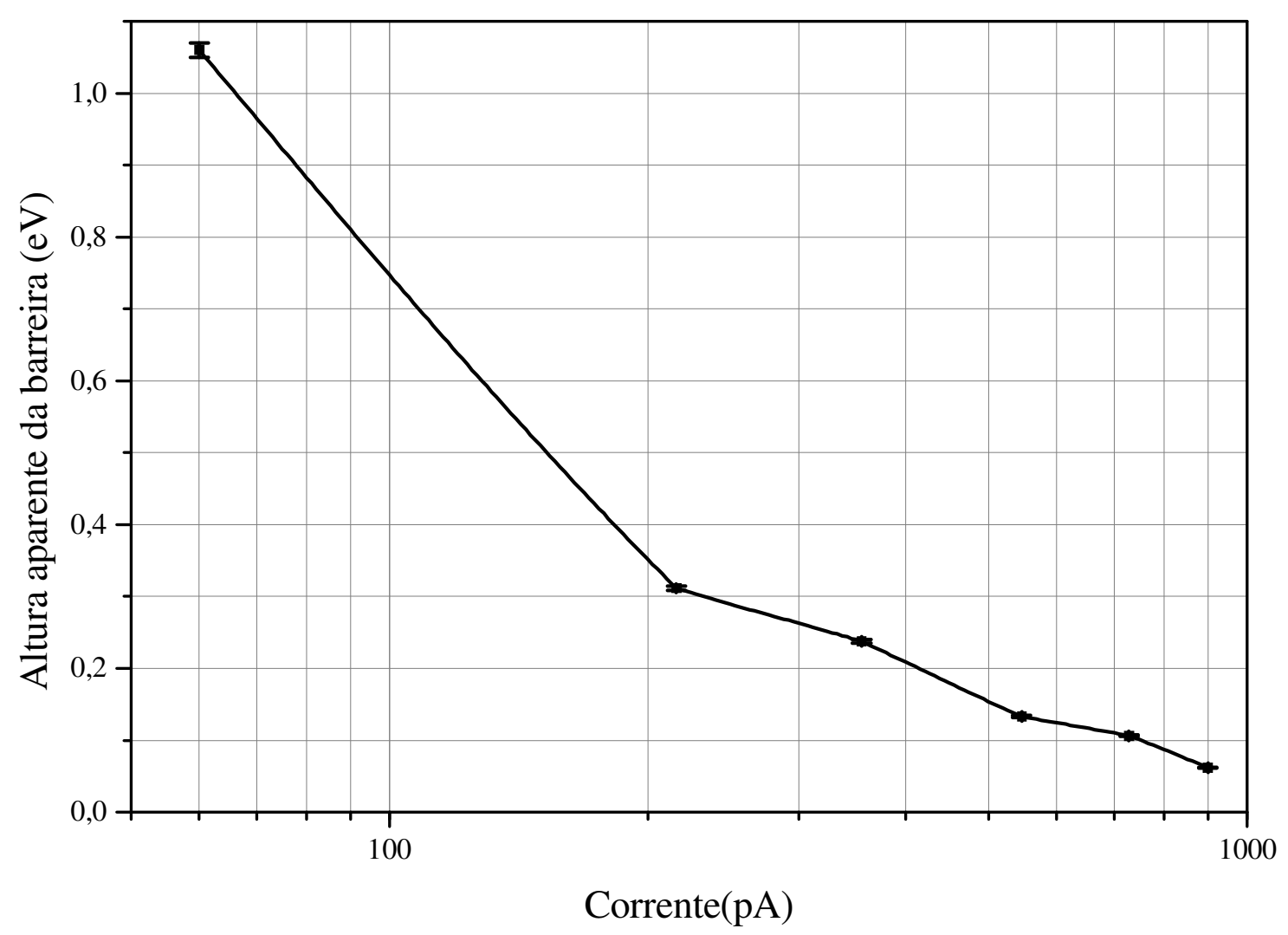

Figura 7: gráfico da altura aparente da barreira de tunelamento em função da corrente de tunelamento de referência.

Ainda incluindo a etapa de testes iniciais, um segundo estudo semelhante ao descrito foi realizado. Neste novo conjunto de medidas, a corrente de referência foi mantida constante (no valor de aproximadamente $2,75 \mathrm{nA}$ ) enquanto a tensão aplicada à junção de tunelamento foi gradualmente reduzida. Com este procedimento, foi possível variar a distância ponta-amostra de uma forma diferente da anterior. Em termos da instrumentação do STM, este novo processo é conveniente pois permite nos certificar, por exemplo, que as variações na inclinação da curva I-s não vêm de um efeito secundário da mudança da corrente de tunelamento de referência. Os resultados obtidos encontram-se na Figura 8. Cada uma das curvas representa a média de diversas aquisições nas mesmas condições experimentais. Qualitativamente, o mesmo comportamento encontrado no caso anterior foi reproduzido. Para a maior tensão do conjunto (V=100mV, ou seja, maior distância ponta-amostra) a inclinação da curva é máxima, correspondendo ao maior valor da altura aparente da barreira. Conforme a tensão é reduzida, a distância ponta-amostra vai diminuindo e a inclinação é atenuada. 


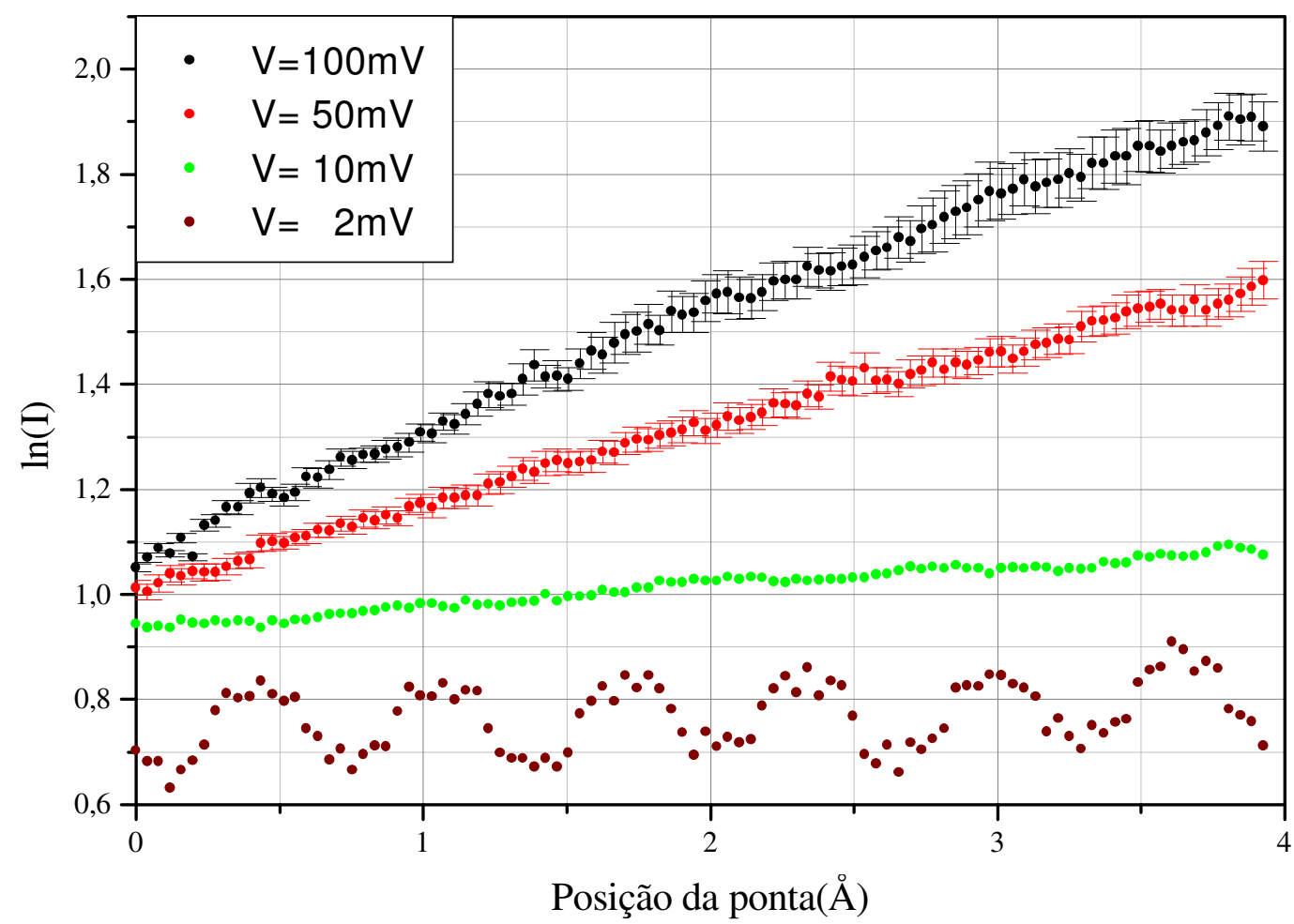

Figura 8: curvas do logaritmo da corrente de tunelamento versus posição da ponta sob diferentes tensões na junção. Nas curvas que não apresentam barras de erro, a incerteza associada a cada ponto é inferior à sua dimensão.

Um efeito interessante pode ser observado na curva inferior $(\mathrm{V}=2 \mathrm{mV})$. Nesta condição, foi possível detectar um sinal com freqüência de $60 \mathrm{~Hz}$, igual à freqüência da rede elétrica. Este fato indica possivelmente a ocorrência de um contato elétrico, de impedância comparável ou mesmo inferior à da junção de tunelamento, entre a ponta e a camada de impurezas adsorvida pela superfície da amostra. Esta explicação é plausível devido às próprias condições experimentais (baixa tensão e alta corrente) que causam uma proximidade acentuada entre ponta e amostra. Oscilações desta ordem foram observadas por Maslova e seus colaboradores ${ }^{13}$ e foram associadas ao tunelamento ressonante através de estados adicionais de energia presentes na camada de impurezas. Infelizmente, este não foi o caso de nossas medidas. Alterando a velocidade de geração da rampa de tensão aplicada ao elemento piezelétrico, o número de períodos de oscilação presentes em nossas curvas também mudava, indicando a detecção de um sinal assíncrono (portanto, independente) em relação à variação da corrente de tunelamento da junção.

O valor extremamente baixo medido para a altura aparente da barreira em cada caso é um fato que não pode ser ignorado. Em condições ideais, este deveria aproximar-se da função trabalho da amostra (como referência, para o carbono amorfo $\phi=5 \mathrm{eV}$ ). No entanto, o valor máximo obtido após diversas medidas variando os parâmetros experimentais não passou de $1,5 \mathrm{eV}$. Este efeito é bem conhecido na literatura, sendo freqüentemente associado à deformação da superfície da amostra pela ponta, o que muda momentaneamente a calibração de seu movimento. Exemplificando em números, enquanto o sistema tem a informação de ter movido a ponta $10 \AA$ em direção à amostra, este deslocamento não passou, na verdade, de $2 \AA$ devido à resistência provida ao movimento. A interação mecânica se dá através de uma camada isolante 
de contaminantes adsorvidos na superfície da amostra e da ponta. Na referência 21, Coombs e Pethica fazem um estudo teórico detalhado deste tipo de interação. Um artigo com resultados experimentais desta ordem é o de Mamin e colaboradores, ${ }^{8}$ que verificaram a mudança do comportamento da curva I-s em função da pressão na câmara de um STM. Conforme a pressão era reduzida, implicando na evaporação da camada superficial de contaminantes, o aumento da corrente de tunelamento ficava maior para um mesmo deslocamento da ponta, ou seja, a altura da barreira se aproximava do valor real da função trabalho. A influência desta camada de contaminantes é tão grande que supera o efeito proporcionado pelo potencial imagem sobre este tipo de medida.

Uma prova da ocorrência deste mecanismo de compressão da superfície em nossas amostras foi obtida através da medida da histerese nas curvas I-s. Uma modificação no programa utilizado permitiu a medida desta curva tanto na aproximação quanto no afastamento da ponta. Uma das curvas tipicamente obtidas é mostrada na Figura 9. As referências 8 e 22 relatam interações repulsivas mais intensas durante o afastamento da ponta, causando uma deformação maior da curva I-s neste percurso. Isto foi coerentemente reproduzido pelas nossas medidas. Devido à pequena amplitude do deslocamento implementado (menos de $4 \AA$ ), a possibilidade da histerese estar associada ao elemento piezelétrico pôde ser descartada.

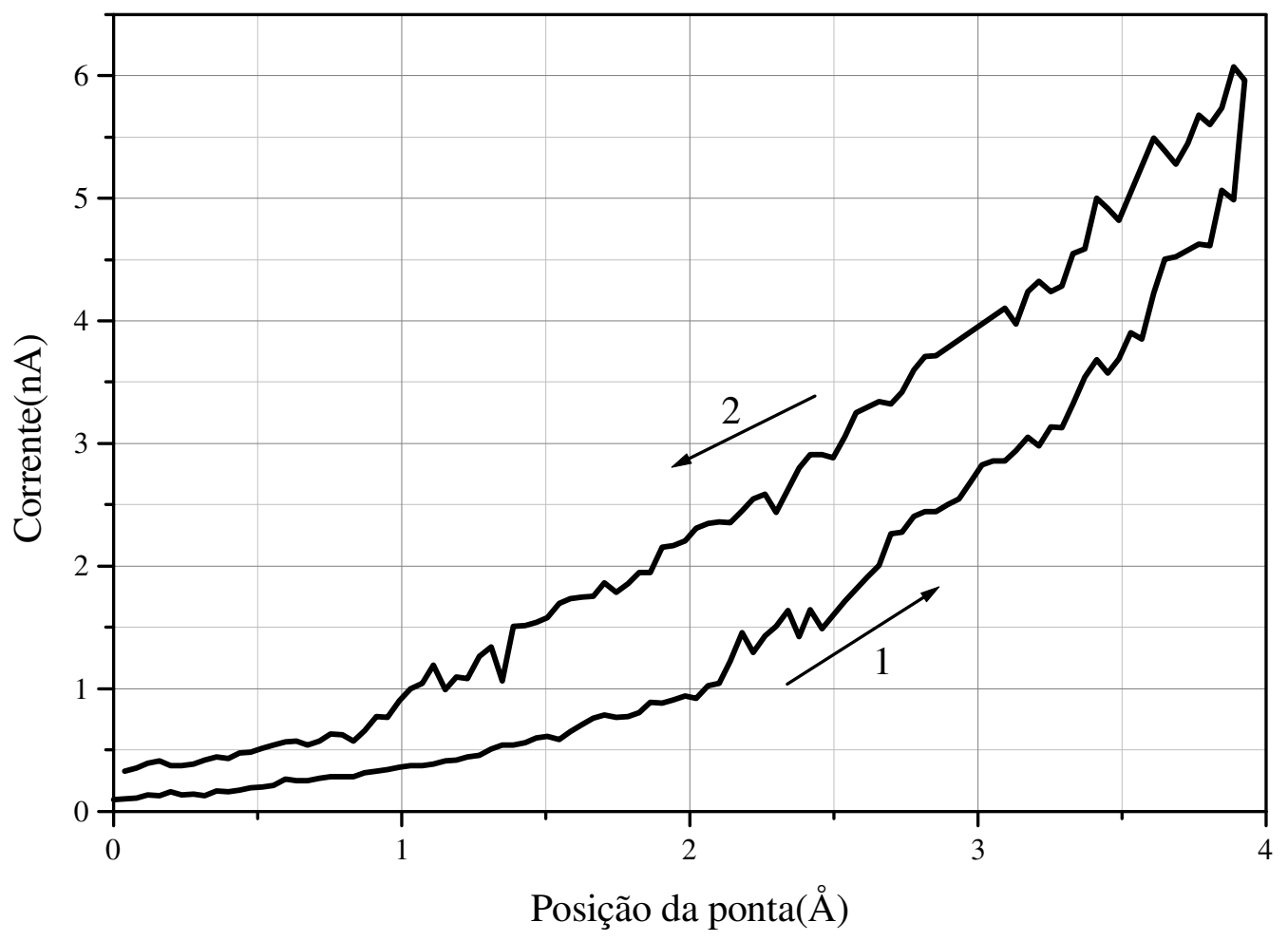

Figura 9: gráfico da corrente de tunelamento em função da posição da ponta. A medida foi iniciada com a aproximação da ponta em direção à amostra (ramo 1 da curva), seguida de um afastamento de mesma amplitude (ramo 2). Os parâmetros experimentais foram $\mathrm{V}=50 \mathrm{mV}$ e $\mathrm{I}=250 \mathrm{pA}$.

É importante notar que este mecanismo de deformação não modifica o comportamento (exponencial) da curva I-s. A natureza da interação mecânica envolvida neste processo é elástica e linear, alterando deste mesmo modo a constante de calibração do movimento da ponta. Isto muda apenas o eixo das abscissas do gráfico I-s (multiplicando esta escala por um fator positivo 
$\alpha<1$ ), conservando a dependência da corrente de tunelamento em relação à distância pontaamostra.

\section{4- Conclusões:}

Neste capítulo, foram relatados os testes iniciais do sistema recém-implementado de aquisição de dados em modo espectroscópico. A amostra escolhida nesta etapa foi o grafite, um material padrão para calibração e testes em microscopia de tunelamento. As curvas I-V mostraram um comportamento satisfatório em relação aos resultados tanto experimentais quanto teóricos disponíveis na literatura. Os dados se ajustaram adequadamente a um polinômio de grau 3, de acordo com o esperado em uma junção metal-isolante-metal. A assimetria da curva foi revelada através do cálculo da condutância (derivada da corrente de tunelamento em relação à tensão na junção). O ponto de mínimo do perfil parabólico correspondente estava deslocado do valor nulo da tensão, tornando flagrante a assimetria da curva e o caráter retificador da junção. Medidas da altura aparente da barreira de tunelamento foram conduzidas com sucesso. De modo qualitativo, a variação desta grandeza com a distância ponta-amostra foi satisfatoriamente reproduzida. Os valores medidos para a altura da barreira foram extremamente baixos, provavelmente devido às interações da ponta com camadas de contaminantes adsorvidas pela superfície do grafite. Esta hipótese foi confirmada através da medida da histerese de curvas I-s.

\section{Referências:}

${ }^{1}$ S. Park e C. F. Quate, Appl. Phys. Lett. 48, 112 (1986).

${ }^{2}$ G. Binnig, H. Fuchs, Ch. Rohrer, E. Stoll e E. Tosatti, Europhys. Lett. 1, 31 (1986).

${ }^{3}$ P. K. Hansma, R. Sonnenfeld, J. Schneir, O. Marti, S. A. C. Gould, C. B. Prater, A. L. Weisenhorn, B. Drake, H. Hansma, G. Slough, W. W. McNairy e R. V. Coleman em Scanning Tunneling Microscopy and Related Methods, cap. 15, editado por R. J. Behm, N. Garcia e H. Rohrer, Kluwer Academic Publishers (1990).

${ }^{4}$ I. P. Batra, N. Garcia, H. Rohrer, H. Salemink, E. Stoll e S. Ciraci, Surf. Sci. 181, 126 (1987).

${ }^{5}$ J. Tersoff, Phys. Rev. Lett. 57, 440 (1986).

${ }^{6}$ J. M. Soler, A. M. Baro, N. Garcia e H. Rohrer, Phys. Rev. Lett. 57, 444 (1986).

${ }^{7}$ J. B. Pethica, Phys. Rev. Lett. 57, 3235 (1986).

${ }^{8}$ H. J. Mamin, E. Ganz, D. Abraham, R. E. Thomson e J. Clarke, Phys. Rev. B 34, 9015 (1986).

${ }^{9}$ H. A. Mizes, Sang. il Park and W. A. Harrison, Phys. Rev. B. 36, 4491 (1987).

${ }^{10}$ L. Soethout em Scanning Tunneling Microscopy: Review and Application to Layered Materials, tese de Doutorado pela Katholieke Universiteit te Nijmegen, 1991.

${ }^{11}$ P. J. Ouseph, T. Poothackanal, G. Mathew, Phys. Lett. A 205, 65 (1995).

12 Z. Klusek, Appl. Surf. Sci. 125, 339 (1998).

13 N. S. Maslova, Yu. N. Moiseev, V. I. Panov, S. V. Savinov, S. I. Vasilev and I. V. Yaminskii, Phys. Stat. Sol. 131, 35 (1992).

${ }^{14}$ R. J. Colton, S. M. Baker, R. J. Driscoll, M. G. Youngquist and J. D. Baldeschwieler, J. Vac. Sci. Technol. A 6, 349 (1988).

15 H. Bando, N. Morita, H. Tokumoto, W. Mizutani, K. Watanabe et al., J. Vac. Sci. Techonol A 6, 344 (1988).

${ }^{16}$ W. F. Brinkman, R. C. Dynes e J. M. Rowell, J. Appl. Phys. 41, 1915 (1970). 
${ }^{17}$ CRC handbook of chemistry and physics, editado por David R. Lide, CRC Press (1997).

${ }^{18}$ N. D. Lang, Phys. Rev. B 37, 10395 (1988).

19 J. M. Pitarke e P. M. Echenique, Surf. Sci. 217, 267 (1989).

${ }^{20}$ S. Desogus, S. Lànyi, R. Nerino e G. B. Picotto, J. Vac. Sci. Technol. B 12, 1665 (1994).

${ }^{21}$ J. H. Coombs e J. B. Pethica, IBM J. Res. Develop. 30, 455 (1986).

${ }^{22}$ H. Yamada, T Fujii and K. Nakayama, J. Vac. Sci. Technol. A 6, 293 (1988). 


\section{Capítulo 5}

\section{ESPECTROSCOPIA SOBRE OURO:}

\section{1- Introdução:}

Com a finalidade de conduzir testes adicionais no sistema de aquisição de dados em modo espectroscópico, foram realizadas diversas medidas sobre ouro. O material foi analisado tanto em forma cristalizada quanto na forma de filmes finos obtidos por sputtering. $\mathrm{O}$ estudo destes filmes em microscopia eletrônica tem um caráter estritamente prático. Seu uso é aplicado na cobertura de espécimes isolantes para investigação tanto em microscopia de tunelamento ${ }^{1,2}$ quanto em microscopia eletrônica de varredura (SEM, scanning electron microscopy). Na forma cristalina, o ouro pode ser utilizado como substrato na preparação de amostras para STM, ${ }^{3}$ além de proporcionar algumas aplicações em nanolitografia. ${ }^{4,5}$

A mudança nos resultados obtidos com estas amostras em relação a aqueles relatados no capítulo anterior deve ser clara. A estrutura eletrônica do ouro é a de um metal nobre (possui um único elétron livre por célula unitária), em contraste com o grafite (um semimetal). Em termos morfológicos, filmes finos de ouro são constituídos por clusters (pequenos conjuntos de átomos que assumem orientação cristalográfica aleatória) cujo diâmetro é da ordem de dezenas de angströns. As amostras resultantes apresentam estruturas de fácil resolução com um STM.

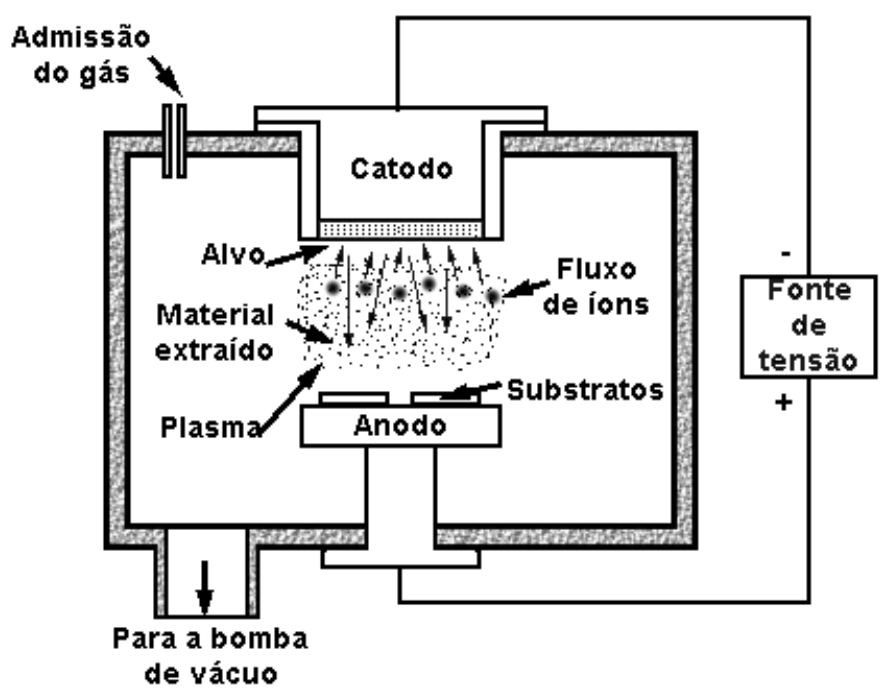

Figura 1: esquema da câmara de um aparelho de deposição de filmes finos por sputtering.

No processo de deposição por sputtering, o material a ser depositado é extraído de uma superfície sólida (alvo) pela troca de momento devido ao bombardeamento por partículas aceleradas. $\mathrm{O}$ alvo é disposto em uma câmara de vácuo juntamente com as amostras a serem recobertas (ver Figura 1). Esta câmara é evacuada até atingir uma pressão de $10^{-2}$ Torr. As partículas responsáveis pela extração do material são geralmente íons de um gás inerte (em nosso caso, argônio) injetado na câmara a baixa pressão. A deposição tem início com a ionização do 
gás quando submetido a uma diferença de potencial constante de magnitude entre 500 e $5000 \mathrm{~V}$, aplicada entre o alvo (catodo) e o porta-amostras (anodo). Desta forma, os ions $\mathrm{Ar}^{+}$são acelerados na direção do catodo, extraindo alguns de seus átomos com a colisão. Os substratos são posicionados em alinhamento com o alvo de modo a interceptar o fluxo de material gerado. ${ }^{6}$

Superfícies cristalinas de ouro podem ser obtidas seguindo o procedimento descrito por Schneir e colaboradores. ${ }^{4}$ Um fio de ouro $(0,5 \mathrm{~mm}$ de diâmetro e $99 \%$ de pureza) é introduzido em uma chama de acetileno-oxigênio. Com a fusão do fio $\left(\mathrm{a} 1064^{\circ} \mathrm{C}\right)$, uma esfera líquida é constituída em sua ponta. O resfriamento gradual conduz à cristalização deste material, formando uma superfície repleta de grandes terraços (de área aproximada $1500 \AA^{2}$ ) orientados na direção $(111)^{7}$

\section{2- Otimização dos parâmetros de deposição por sputtering:}

A deposição de filmes finos de materiais condutores é largamente usada na preparação de amostras em microscopia eletrônica. A finalidade destes filmes é formar uma camada contínua e condutora sobre amostras originalmente isolantes ou semi-isolantes. Tal camada deve conformar-se à superfície da melhor forma possível, não ocultando nem adicionando texturas ou morfologias sobre a amostra original. Em microscopia eletrônica de varredura, esta camada é responsável por gerar os sinais de resposta ao feixe de elétrons incidente, além de dissipar a carga acumulada neste processo.

A mesma técnica é utilizada para a microscopia de tunelamento. Todavia, pela maior resolução inerente ao STM, um maior cuidado deve ser tomado na escolha das condições de deposição do filme, de forma a minimizar sua rugosidade própria. Um estudo completo, mas não exaustivo, sobre este assunto já havia sido feito em meu trabalho de iniciação científica. ${ }^{8}$ Com a finalidade de complementá-lo, fizemos uma análise estatística da rugosidade de filmes finos de ouro depositados por sputtering, variando as condições de deposição. Em adição, a motivação atual deste trabalho é estudar a influência, se houver alguma, da superfície da amostra sobre as características espectroscópicas do filme fino. No âmbito teórico, esta hipótese parece remota. As informações medidas por um STM se devem às camadas atômicas mais externas da amostra, abrangendo um limite de, no máximo, alguns angströns dentro do material. Entretanto, vale a pena lembrar que os filmes finos obtidos por sputtering são compostos por clusters cujas dimensões podem ser bastante reduzidas. Nestas condições, um estudo como o nosso é muito pertinente, pois tais clusters podem ser sensíveis às propriedades eletrônicas locais da superfície da amostra. Cobrindo a superfície com um filme fino o suficiente apenas para formar uma camada contínua, a chance desta investigação lograr êxito é maior.

A primeira etapa deste estudo foi determinar as taxas de deposição do aparelho de sputtering usado (pertencente ao Laboratório de Microscopia Eletrônica do Instituto de Física da Universidade de São Paulo). A taxa de deposição é, até certo limite, proporcional à densidade de corrente entre os dois eletrodos, que depende por sua vez da pressão de argônio dentro da câmara. Acima de um certo valor desta pressão, a taxa de deposição tende a diminuir devido ao menor caminho livre médio dos íons. Este fenômeno é refletido na Tabela 1, na qual é mostrada a taxa de deposição em função da densidade de corrente. Esta tabela foi obtida pesando placas finas de vidro antes e depois da deposição de um filme durante um tempo arbitrário com uma densidade de corrente fixa e conhecida. Sabendo a dimensão das placas, a massa de ouro depositada, a densidade do material e o tempo total de deposição, determinou-se a espessura do 
filme e, conseqüentemente, a taxa de deposição do sistema para a corrente em questão. A incerteza da espessura estimada por este método é elevada (entre 10 e 18\%). Todavia, devido ao caráter comparativo deste estudo, o conhecimento exato desta grandeza é dispensável.

\begin{tabular}{ll}
\hline \hline $\mathrm{j}\left(\mathrm{mA} \cdot \mathrm{cm}^{-2}\right)$ & Taxa de deposição $\left(\AA . \mathrm{S}^{-1}\right)$ \\
\hline 2 & 0,7 \\
5 & 1,3 \\
10 & 2,5 \\
20 & 3,1 \\
30 & 3,7 \\
50 & 2,0 \\
\hline \hline
\end{tabular}

Tabela 1: Taxa de deposição do sistema de sputtering em função da densidade de corrente (j).

O próximo passo foi determinar, através de medidas de STM, a taxa de deposição que conduziria ao filme de mais baixa rugosidade. Para isto, foram depositados filmes de uma mesma espessura, escolhida arbitrariamente, sobre substratos de grafite. Este substrato foi escolhido por ser condutor e completamente liso, ${ }^{*}$ assegurando que toda a rugosidade proviria do próprio filme. Seis substratos foram cobertos com filmes de espessura $200 \AA$, cada um preparado com uma das taxas de deposição constantes na Tabela 1. Para cada amostra, foram adquiridas nove imagens de $1800 \AA$ de lado, cobrindo diferentes áreas permitidas (incluídas numa faixa de $9 \mu \mathrm{m}^{2}$ ) pelo movimento $\mathrm{X}-\mathrm{Y}$ do elemento piezelétrico vinculado à ponta. Após isto, mais uma série de nove imagens era adquirida em outra posição da amostra, distante de alguns milímetros do local anterior. Este procedimento permitiu comparar a homogeneidade do filme sob áreas distintas macroscopicamente, além de fornecer um número de dados relevante estatisticamente. Dispondo de, no mínimo, dezoito imagens de cada amostra, calculamos a rugosidade quadrática média (RMS, root mean square) para cada caso. Esta quantia é definida por:

$\mathrm{RMS}=\sqrt{\frac{1}{\mathrm{~N}} \sum_{\mathrm{i}=1}^{\mathrm{N}} \mathrm{h}_{\mathrm{i}}^{2}}$,

onde $h_{\mathrm{i}}$ é a altura, em relação à altura média, de cada um dos N pontos da imagem de STM. Esta é uma grandeza padrão para a medida da rugosidade de superfícies. ${ }^{9,10}$ Um programa de computador específico para tratamento e análise de imagens (Khorus) realizou o cálculo desta grandeza para cada imagem. Os resultados são mostrados na Figura 2 que resume o conjunto das mais de cem imagens adquiridas. O gráfico da rugosidade em função da corrente de deposição, apresentado na Figura 3, comprova um comportamento plausível. A menor corrente, correspondente à menor taxa de deposição, formou o filme com a rugosidade mais baixa do conjunto. Isto é devido provavelmente ao maior tempo que os clusters de ouro dispõem nesta condição para se conformarem uns aos outros sobre a superfície. A rugosidade aumenta com a corrente até o limite a partir do qual a taxa de deposição volta a cair. Neste ponto, temos também uma queda na rugosidade, mostrando a coerência dos resultados.

\footnotetext{
* A referência 9 cita cálculos teóricos da rugosidade superficial de uma rede cristalina de carbono, com número de coordenação igual a 3 (ou seja, três primeiros vizinhos por sítio), chegando ao resultado de $0,02 \AA$. Este valor esta muito aquém das incertezas envolvidas nas medidas desta etapa.
} 

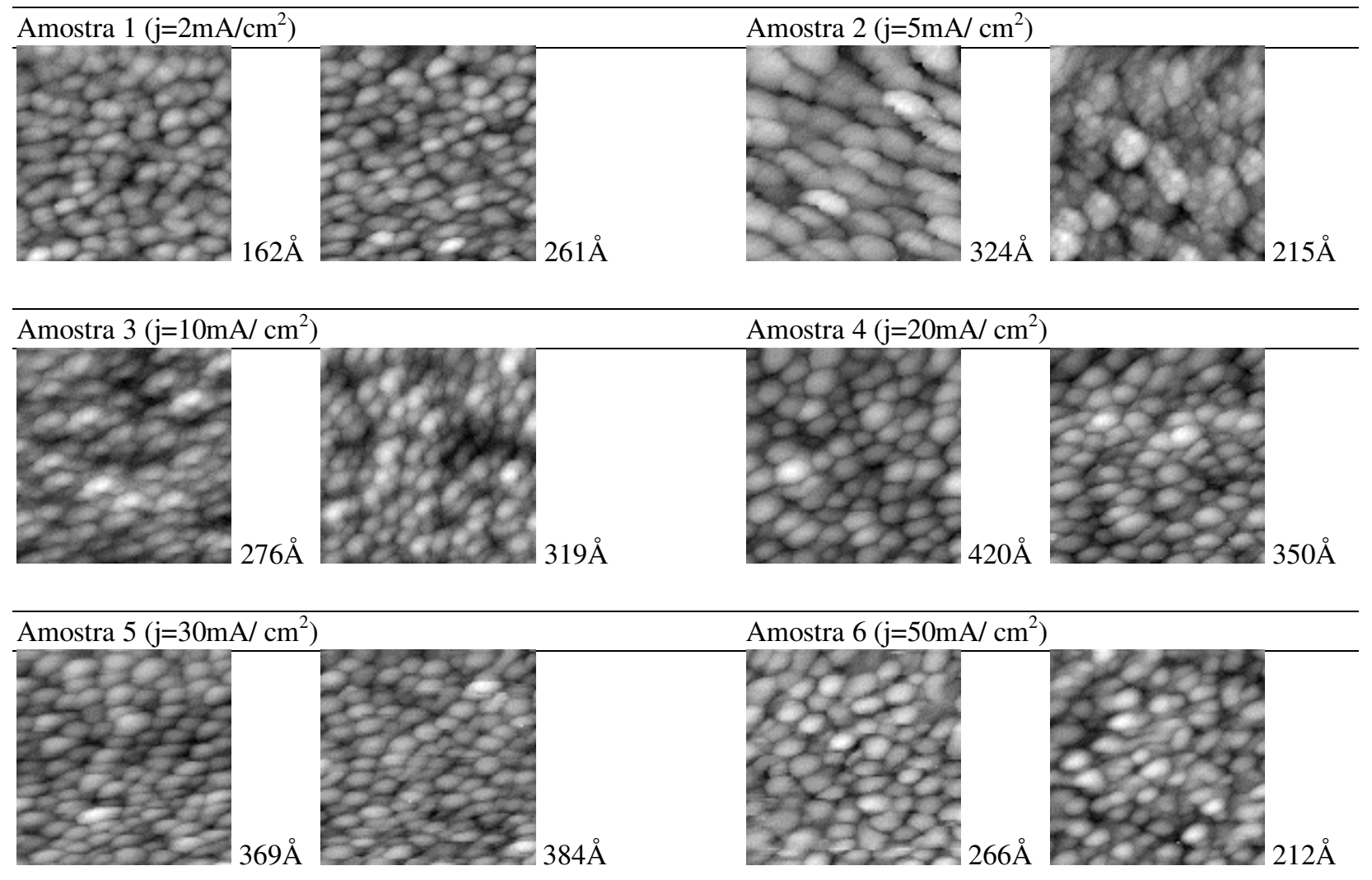

Figura 2: imagens, por STM, de 1800A de lado correspondentes a diferentes regiões de cada uma das amostras. A legenda de cada conjunto de figuras indica a densidade de corrente utilizada na deposição. A velocidade de varredura foi de aproximadamente $0,8 \mathrm{~Hz}$ na direção $x$. $O$ número à direita de cada imagem indica a amplitude da escala de cinza.

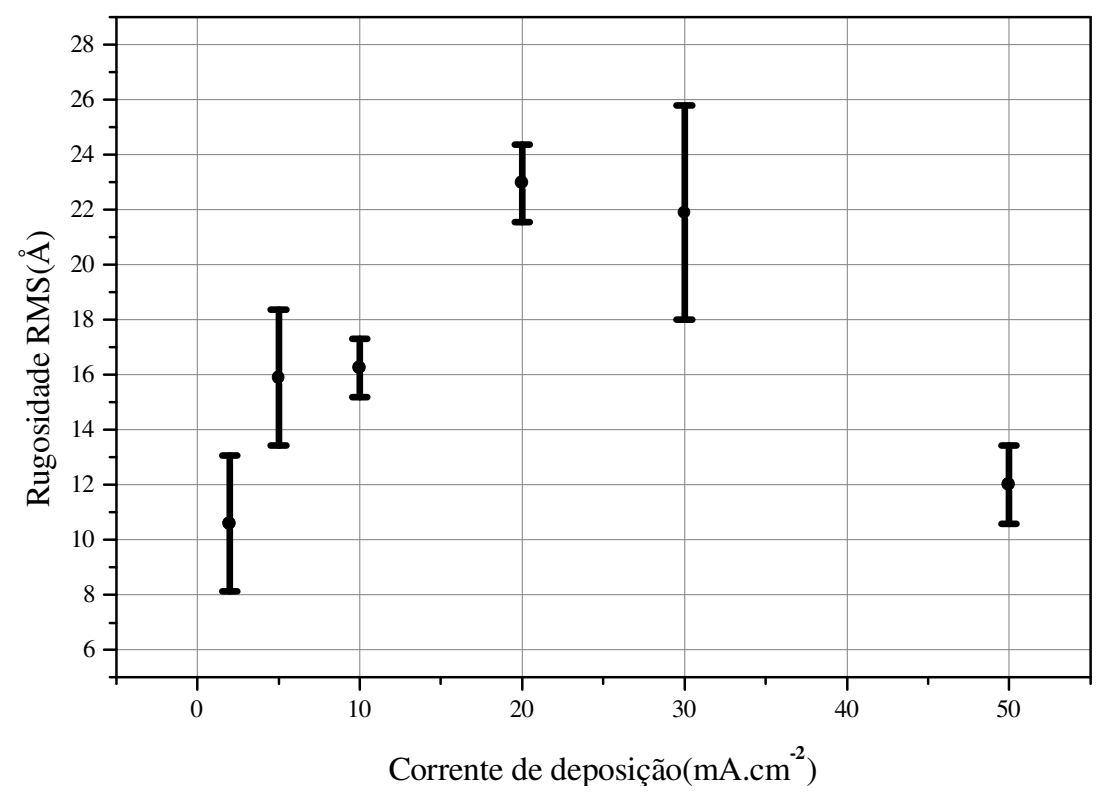

Figura 3: gráfico da rugosidade quadrática média em função da corrente de deposição usada em cada uma das amostras. As barras de erro são apresentadas como o desvio do valor da rugosidade média para as 18 imagens de cada amostra. 
Uma vez determinada a melhor taxa de deposição, restava definir a espessura ótima para o filme. Intuitivamente, quanto menor a espessura de um filme, menor sua rugosidade. Todavia, quanto menos espesso, maiores serão as chances da ocorrência de descontinuidades, o que é desastroso em uma amostra a ser analisada por STM (principalmente se ela for isolante). Portanto, a escolha da espessura do filme é uma questão crítica. Um procedimento semelhante ao anterior foi adotado nesta etapa. Depositamos filmes de espessuras variadas, como está resumido na Tabela 2, sobre substratos de grafite, usando a densidade de corrente de $2 \mathrm{~mA} / \mathrm{cm}^{2}$. As imagens por STM foram adquiridas com a mesma sistemática anterior, e as rugosidades calculadas para cada imagem. Algumas delas estão na Figura 4, enquanto o gráfico da rugosidade em função da espessura se encontra na Figura 5.

\begin{tabular}{lll}
\hline \hline Amostra \# & $\begin{array}{l}\text { Espessura do filme } \\
\text { depositado }(\AA)\end{array}$ & \\
\hline 01 & 500 & \\
02 & 300 & \\
03 & 150 & \\
04 & 100 & \\
05 & 70 & \\
06 & 40 & \\
07 & 20 \\
\hline \hline
\end{tabular}

Tabela 2: espessura dos filmes depositados nesta etapa. A densidade de corrente utilizada para a deposição de todas as amostras foi de $2 \mathrm{~mA} / \mathrm{cm}^{2}$.

O resultado obtido nesta etapa foi próximo ao esperado. A rugosidade claramente decresce conforme a espessura dos filmes é reduzida. Nas duas amostras menos espessas, nota-se que a variação na rugosidade não é significativa frente às barras de incerteza destes pontos. Eventualmente, a rugosidade pode até voltar a aumentar no limite de baixas espessuras, como foi mostrado no trabalho feito por nós há algum tempo. ${ }^{11}$

Apesar da consistência dos resultados, restou ainda a dúvida acerca da continuidade dos filmes menos espessos. Devido ao uso de um substrato condutor (grafite), a detecção desta ocorrência por STM não é trivial. Para sanar a dúvida, foi feita uma nova deposição dos filmes mais finos (20, 40 e $70 \AA$ ) sobre um substrato semi-isolante de GaAs usado em crescimentos por MBE. A superfície deste substrato é tão lisa e isenta de impurezas quanto a do grafite. Como este material possui uma resistividade elevada (tipicamente $1 \times 10^{8} \mathrm{ohm} . \mathrm{cm}$ ), a condição da ligação entre as ilhas do filme fino de ouro sobre a amostra é o fator determinante da resistência elétrica da amostra. A medida desta grandeza poderia trazer informações diretas da continuidade do filme. ${ }^{1}$ Uma vez que o processo de sputtering em todo nosso estudo foi realizado à temperatura ambiente, a hipótese da mudança do tipo de substrato alterar a qualidade final do filme pôde ser descartada. Em deposições realizadas sob condições mais controladas, podem ocorrer diversos efeitos (como texturização dos clusters em uma dada orientação cristalográfica ${ }^{12}$ ) conforme $o$ uso de diferentes substratos. 

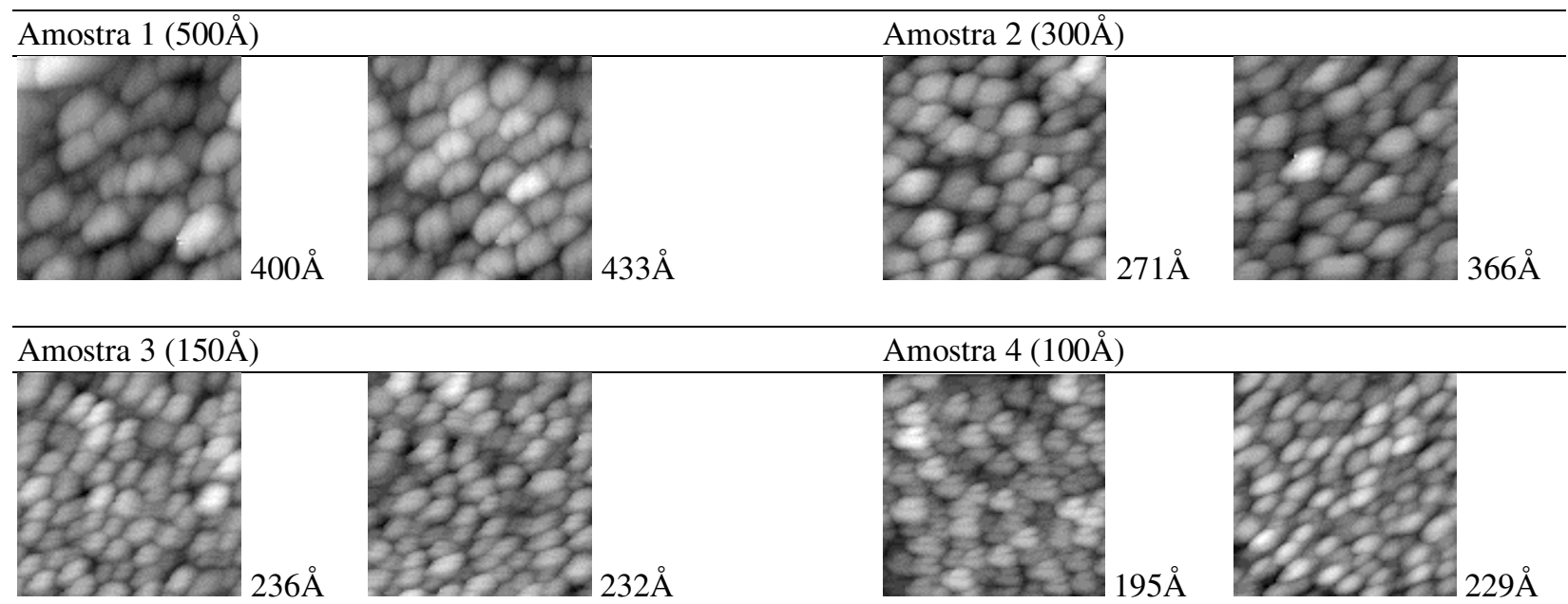

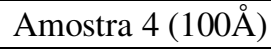
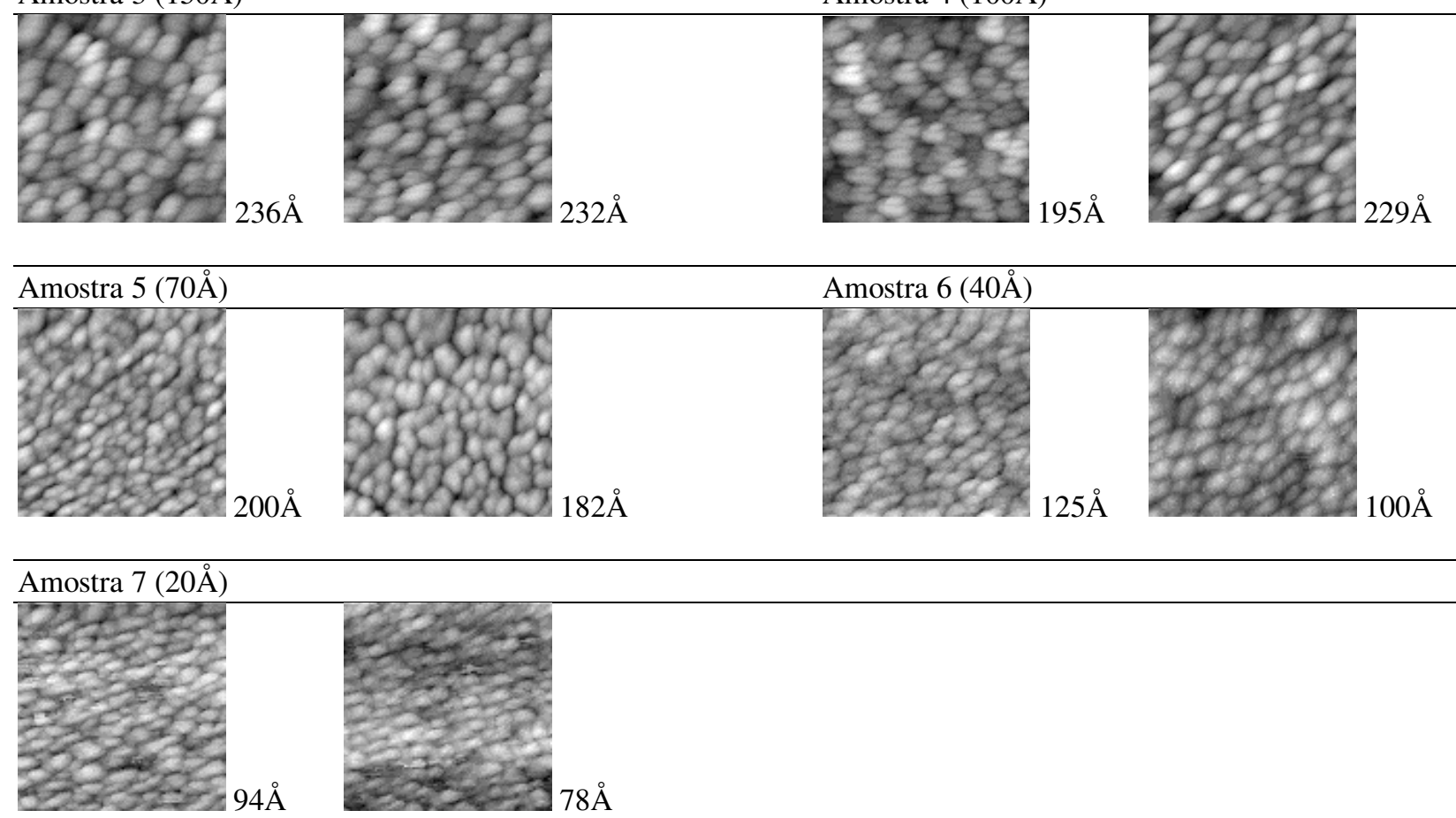

Figura 4: imagens, por STM, de 1800Å de lado correspondentes a diferentes regiões de cada uma das amostras. A legenda de cada conjunto de figuras indica a espessura do filme. A velocidade de varredura foi de $0,8 \mathrm{~Hz}$ na direção $x$. $O$ número à direita de cada imagem indica a amplitude da escala de cinza.

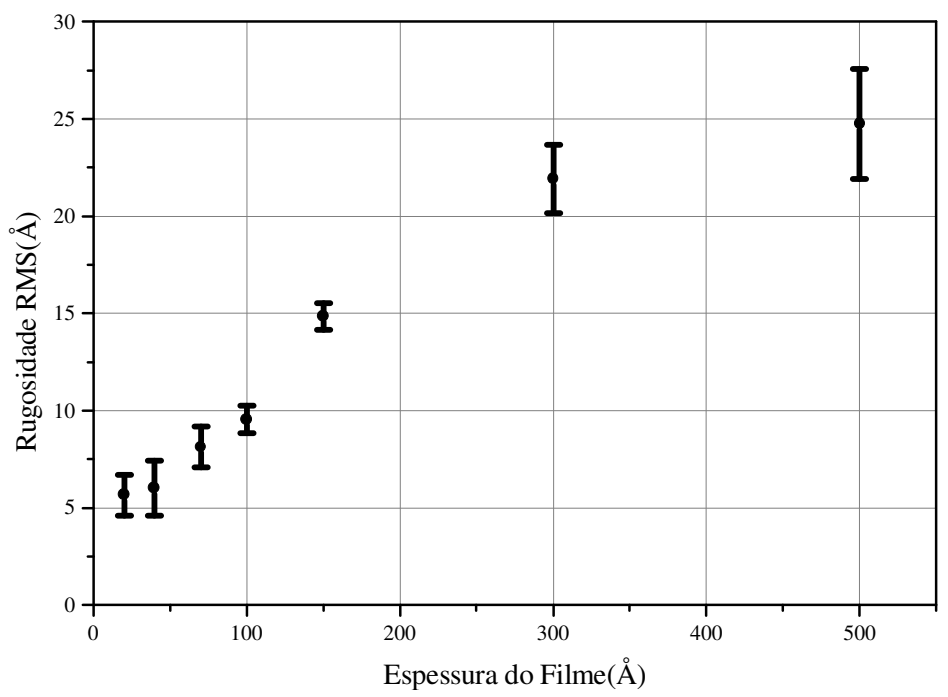

Figura 5: gráfico da rugosidade quadrática média em função da espessura dos filmes de ouro depositados sobre substratos de grafite. 
Usando um aparato eletrônico simples, uma diferença de potencial foi aplicada em contatos dispostos em vértices diagonalmente opostos da amostra. A corrente correspondente era amplificada por este circuito e monitorada em um osciloscópio. Um gerador de funções foi configurado de modo a produzir uma onda triangular simétrica de tensão (entre -5 e $5 \mathrm{~V}$ ). Aplicando este sinal aos contatos e monitorando-o juntamente com o sinal da corrente num osciloscópio ajustado em modo X-Y, a curva característica I-V de cada amostra pôde ser visualizada. A inclinação desta reta permitiu encontrar a resistência elétrica para cada caso. A Figura 6 traz um diagrama esquemático do aparato. Os contatos foram feitos diretamente na superfície do filme fino usando cola de prata. As amostras eram aproximadamente do mesmo tamanho, portanto a resistência elétrica em cada uma delas não deveria mudar significativamente devido apenas aos fatores geométricos.

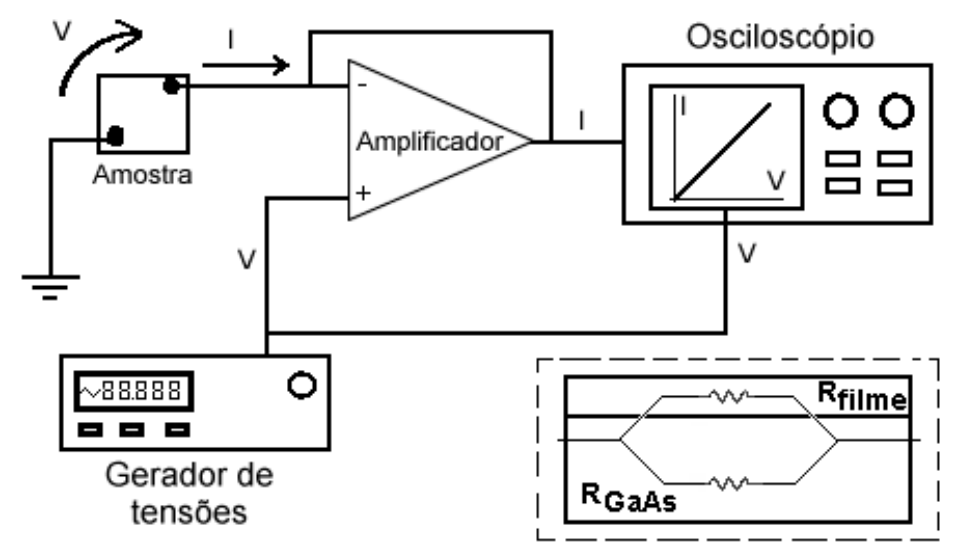

Figura 6: diagrama esquemático do aparato utilizado nas medidas de resistência elétrica dos filmes finos de ouro depositados sobre substratos de GaAs semi-isolantes. A possibilidade da escolha da impedância de entrada do circuito (através da troca de um único resistor do circuito amplificador) nos fez optar por este aparato de medida em vez do uso de um simples multímetro. No destaque (canto inferior direito) encontra-se um diagrama mostrando a associação das resistências na amostra, correspondentes à contribuição do filme $\left(R_{\text {filme }}\right)$ e do substrato $\left(R_{\text {GaAs }}\right)$. Devido às características do substrato, $R_{\text {GaAs }}>>R_{\text {filme. }}$.

Comparativamente, os valores obtidos para a resistência elétrica das amostras manifestaram um comportamento previsível. A amostra com filme mais espesso $(70 \AA)$ possuía uma resistência da ordem de $2 \mathrm{k} \Omega$. O filme de $40 \AA$ apresentou um valor na mesma ordem de grandeza. Finalmente, no filme de $20 \AA$ encontramos resultados interessantes: a resistência medida se situava na ordem de $14 \mathrm{M} \Omega$, mostrando uma diferença acentuada em relação aos resultados anteriores. Isto poderia indicar a existência de descontinuidades neste filme. Para comprovar esta hipótese, iluminamos a amostra com uma luz branca intensa (30W a uma distância de $10 \mathrm{~cm}$ ) durante a medida da resistência. Havendo descontinuidades, a luz incidiria diretamente sobre a superfície do substrato de GaAs, sofrendo absorção e reflexão adicionais sobre as ilhas contínuas. Como a gama de energias da radiação luminosa provida pela lâmpada situava-se em valores maiores que o gap do GaAs (região de energia proibida aos elétrons, que vale aproximadamente $1,42 \mathrm{eV}$ na temperatura ambiente para este material), elétrons da banda de valência seriam levados para a banda de condução, na qual participariam ativamente no transporte de corrente elétrica. Desta forma, as regiões entre ilhas apresentariam uma condutividade substancial, quando iluminadas, suficiente para conectar as ilhas eletricamente e diminuir a resistência total do filme. Portanto, a resistência de um filme descontínuo deveria oferecer uma resposta muito mais efetiva sob iluminação que aquela apresentada por filmes contínuos. Este comportamento foi comprovado por nossas medidas. Os filmes mais espessos 
(70 e 40Å) não apresentaram resposta alguma à iluminação, enquanto a resistência do filme de $20 \AA ̊$ de espessura sofria um decremento de um fator 5 nesta condição. A Figura 7 mostra a curva característica desta amostra nas duas condições de medida. Isto comprova a descontinuidade do filme de $20 \AA$, impedindo seu uso para investigação de amostras isolantes tanto por STM quanto por SEM. A bem da verdade, é possível varrer com o STM áreas na faixa de $3000 \AA ̊$ sem detectar descontinuidade alguma. No entanto, se for desejável a obtenção de resultados confiáveis e reprodutíveis em diversas áreas da amostra, o filme de $40 \AA$ de espessura (ou mais) deve ser o escolhido.

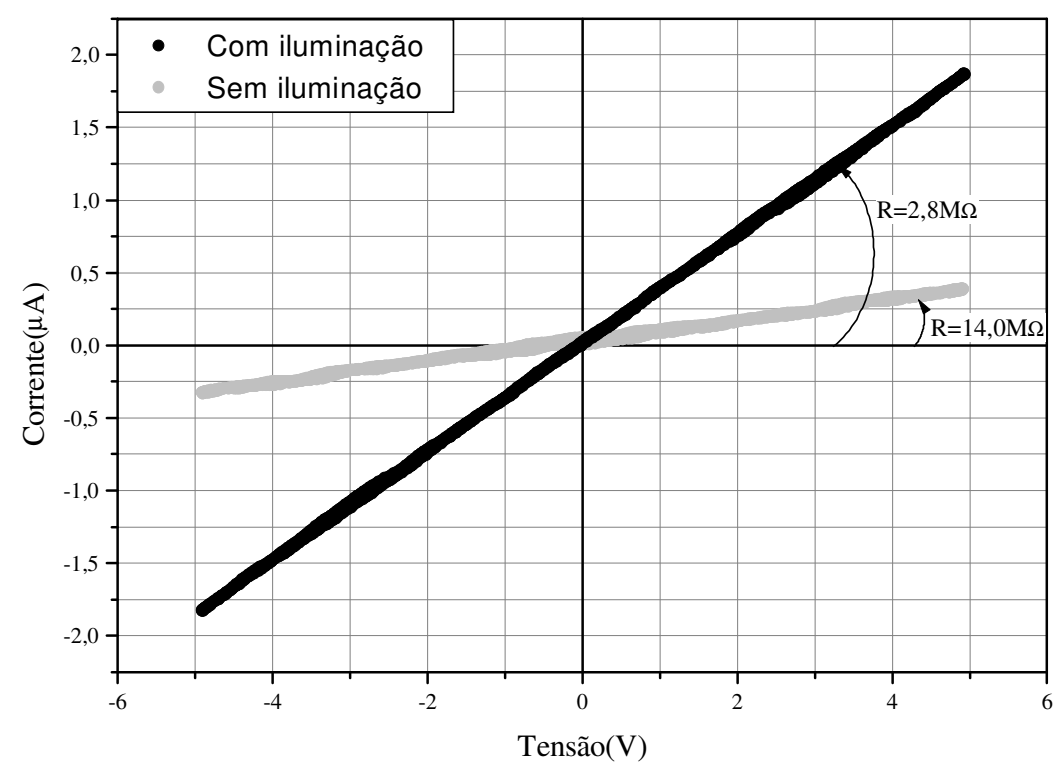

Figura 7: curva característica do filme fino de ouro (20A de espessura) depositado sobre substrato de GaAs; as medidas foram realizadas com e sem iluminação. As resistências calculadas através da inclinação de cada curva são indicadas. As curvas foram gravadas diretamente do aparato de medida usando o analisador digital HP 35670A.

\section{3- Espectroscopia I-V sobre filmes finos:}

\subsection{1- Características da curva I-V:}

Algumas curvas I-V foram adquiridas sobre um filme de ouro, com espessura $150 \AA$, depositado em um substrato de grafite. Sempre antes de qualquer medida espectroscópica, é conveniente a obtenção de uma imagem com resolução atômica da superfície. Isto assegura que a ponta é capaz de sondar individualmente cada átomo, além de redimir qualquer dúvida sobre a pureza da superfície no local estudado. Todavia, neste tipo de amostra, tal procedimento nem sempre é possível, pois os átomos constituintes dos clusters apresentam, individualmente, um sinal muito atenuado (a despeito disto, imagens com resolução atômica sobre clusters metálicos foram apresentadas na referência 13). De qualquer forma, uma imagem sempre era feita antes de qualquer medida espectroscópica, a fim de verificar as condições gerais da ponta e da amostra. Diversas curvas foram adquiridas com a mesma tensão na junção $(50 \mathrm{mV})$ e variando a distância ponta-amostra. Operacionalmente, isto é executado aumentando ou diminuindo a corrente de tunelamento de referência. Um conjunto dos resultados se encontra na Figura 8, juntamente com uma curva adquirida sobre um substrato de grafite recém-clivado. 


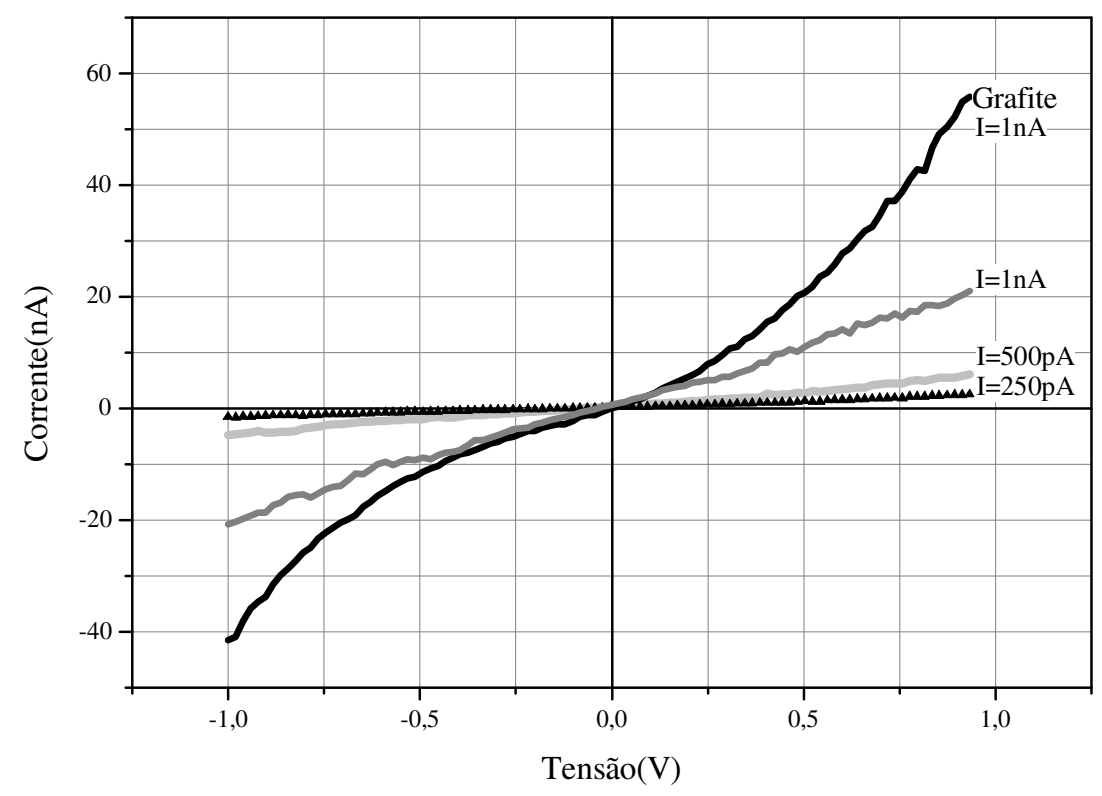

Figura 8: curvas I-V adquiridas em um filme fino de ouro depositado por sputtering sobre grafite. Para comparação, uma curva de uma amostra de grafite sem cobrimento algum é mostrada na mesma escala. As incertezas envolvidas na medida são desprezíveis frente à diferença na inclinação das curvas.

Neste gráfico, é possível observar a distinção das curvas I-V adquiridas sobre um metal nobre e um semi-metal. A condutância (derivada da corrente em relação a tensão) no caso do grafite aumenta para valores elevados de tensão, ${ }^{14}$ enquanto mantém-se constante (se comparada à incerteza da medida) para o filme de ouro em toda gama de tensões aplicadas. A inclinação das curvas adquiridas sobre ouro em diversas condições de corrente refletem corretamente a variação na impedância da junção com a distância ponta-amostra, que deve ser inversamente proporcional.

\subsection{2- Caracterização da descontinuidade de um filme fino:}

Uma vez conhecidas as características das curvas I-V do ouro e do grafite, foi possível executar uma aplicação muito interessante, que mostra um aspecto da capacidade da espectroscopia de tunelamento. Em uma das imagens feitas sobre um filme fino de ouro (de espessura nominal $20 \AA$ ) depositado sobre grafite, foi possível observar um acentuado desnível, com amplitude de $60 \AA \AA^{*}$. Tomando curvas I-V dentro e fora deste relevo, seria possível verificar a existência de uma descontinuidade no filme, determinando se a região mais baixa era coberta ou não por uma camada mais fina de ouro. A Figura 9 mostra na imagem os locais onde foram adquiridas as curvas I-V.

Utilizando os potenciômetros dispostos no painel frontal do circuito de comando do STM foi possível mover a ponta até os locais da aquisição de cada curva. Estes componentes regulam

\footnotetext{
* O aumento na espessura do filme nesta região pode estar associado ao próprio mecanismo de formação da descontinuidade. Alguma anomalia pode ter gerado localmente sítios de maior preferência para o acúmulo dos clusters, deixando uma parte da superfície descoberta.
} 
a tensão incremental ${ }^{*}$ DC que é aplicada ao elemento piezelétrico nas direções $\mathrm{X}$ e $\mathrm{Y}$. Este movimento gera a uma incerteza de 6 pixels em cada direção para este tamanho de imagem. A dimensão das marcações na Figura 9 dá uma idéia da incerteza envolvida neste posicionamento.

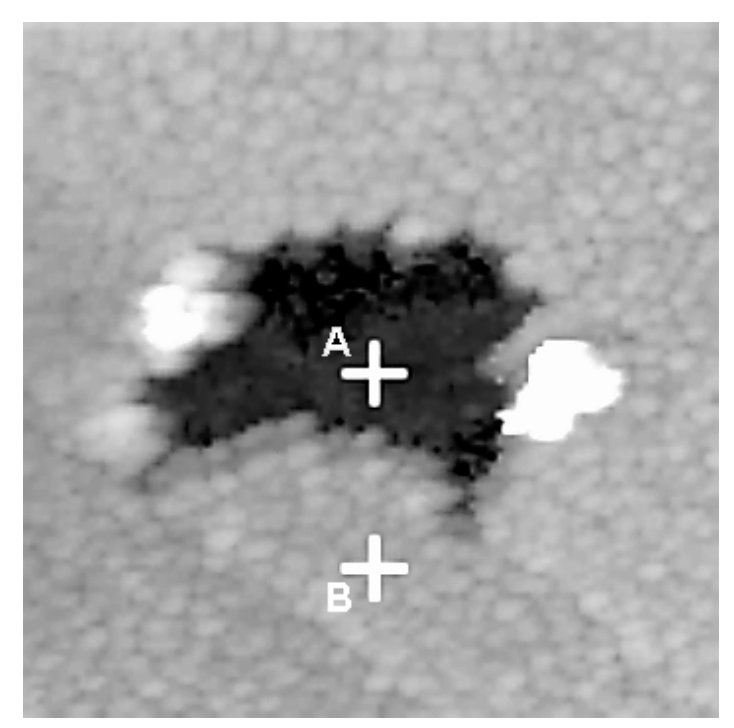

Figura 9: imagem, por STM, de um filme fino de ouro com uma suposta descontinuidade. As marcações A $e$ B indicam os locais onde foram adquiridas as curvas $I-V$ dentro e fora da região de interesse. A imagem tem $3600 \AA$ de lado e foi adquirida com uma freqüência de $0,5 \mathrm{~Hz}$ na direção $x$. A amplitude da escala de cinza é de $250 \AA$.

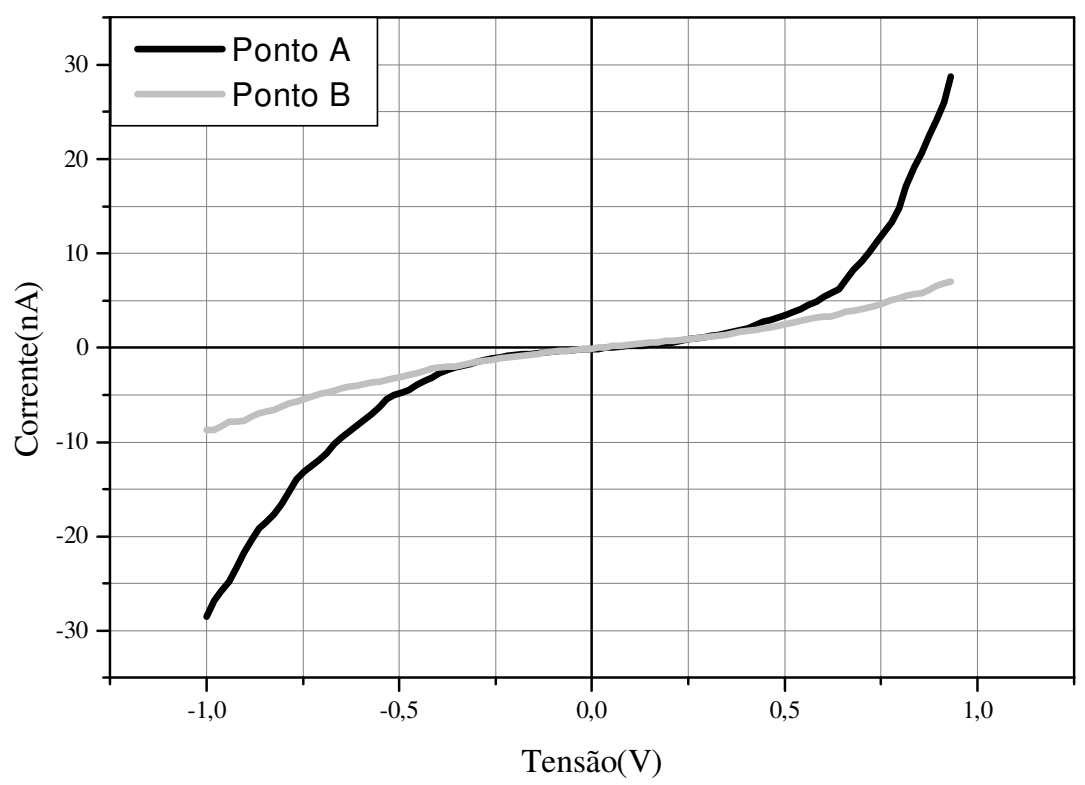

Figura 10: curvas I-V adquiridas nas locações A $e$ B da Figura 9, sob as mesmas condições experimentais $(V=50 \mathrm{mV}$ e $I=200 \mathrm{pA})$. As barras de erro da medida foram ocultadas no gráfico em benefício da clareza, mas suas dimensões são desprezíveis frente a distinção das curvas.

\footnotetext{
* Esta tensão é somada eletronicamente à varredura gerada pelo programa de aquisição do STM, permitindo efetuar deslocamentos arbitrários da janela de varredura sobre determinada área da amostra.
} 
Para assegurar que as curvas estavam sendo adquiridas nos pontos desejados, e que a ponta não havia sofrido danos, efetuava-se uma imagem antes e outra após cada aquisição de uma curva IV. As curvas obtidas nos pontos A e B são apresentadas na Figura 10. É bem clara a diferença entre ambas, permitindo concluir que existe uma distinção de materiais nas duas regiões. Nota-se a semelhança entre a curva adquirida sobre o ponto A e uma curva típica efetuada sobre grafite (ver Figura 8, por exemplo). Este fato possibilita associar a região mais baixa da imagem ao substrato de grafite, caracterizando a ocorrência de uma descontinuidade. Analisando a curva do ponto $\mathrm{B}$, observa-se um aumento da condutância (não-linearidade) em relação às curvas obtidas previamente sobre filmes de ouro de maior espessura. Este efeito é mais acentuado sob tensões positivas. Uma vez que a corrente de tunelamento é dependente da densidade local de estados da superfície investigada, esta curvatura adicional poderia indicar uma influência da estrutura eletrônica do filme fino pelas características do substrato de grafite. Alguns trabalhos devotados à aplicação de substratos de baixa função trabalho (como o Hexaboreto de Lantânio) na observação por STM de amostras fracamente condutoras reforçam esta possibilidade. ${ }^{15}$ Este importante resultado sugere que filmes suficientemente finos possam ser usados para prover informações espectroscópicas qualitativas acerca da amostra que foi recoberta. Deve haver, no entanto, um rigoroso compromisso entre a espessura e a continuidade do filme a ser aplicado.

\section{4- Espectroscopia de Altura da Barreira sobre Cristais de Ouro:}

Como uma continuidade do exame do circuito eletrônico e rotina computacional responsáveis pelas medidas de altura aparente da barreira, tomamos alguns dados sobre filmes finos de ouro depositados sobre grafite. Porém os valores obtidos não foram muito diferentes daqueles para o grafite sem cobertura alguma, não ultrapassando a faixa de $2 \mathrm{eV}$. Não satisfeitos com estes resultados, decidimos repetir estas medidas sobre um sistema diferente. Como foi relatado no capítulo passado, os planos que constituem o grafite interagem entre si através de forças de van der Waals. Isto faz com que a amostra seja facilmente deformada através de um mecanismo de interação entre a ponta e contaminantes dispersos em sua superfície, podendo reduzir os valores da altura de barreira medidos com o STM. Sobre uma amostra de ouro cristalino, este efeito não deveria ser observado, permitindo a medida de valores superiores aos já obtidos.

A amostra usada foi preparada em uma tocha de acetileno-oxigênio conforme descrito no primeiro item. Seu formato esférico ocupa um diâmetro de aproximadamente $2 \mathrm{~mm}$, possuindo uma coloração amarela brilhante. Antes das medidas, uma limpeza orgânica envolvendo banhos sucessivos em tricloroetileno, acetona e metanol foi realizada sobre a amostra. Uma imagem típica de sua superfície consta na Figura 11. É nítida a diferença desta topografia em relação aos clusters presentes nos filmes finos obtidos por sputtering. Terraços com uma rugosidade RMS de $\approx 15 \AA$ (próxima à dos filme finos mais lisos) se estendendo por áreas de alguns milhares de $\AA^{2}$ são freqüentemente observados. Este tipo de amostra também apresenta inúmeros degraus, cuja altura varia desde alguns planos atômicos até dezenas de angströns. 


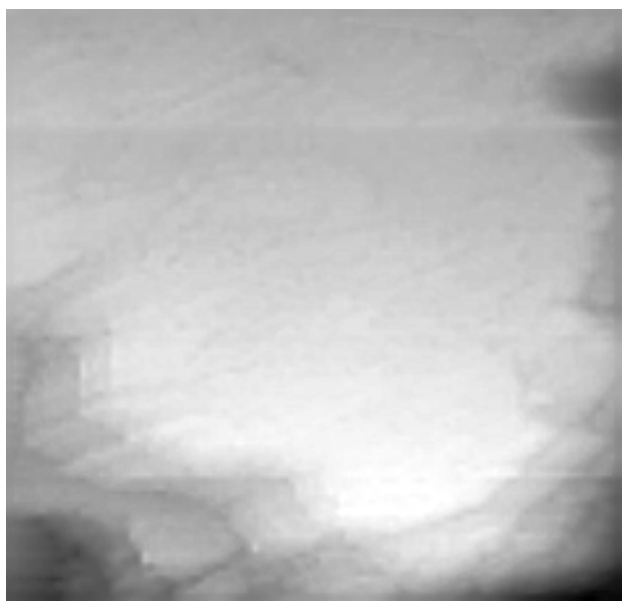

Figura 11; imagem por STM, com 7600A de lado, de uma amostra de ouro cristalizada. A escala de cinza abrange $1000 \AA$.

Uma média de mais de 10 aquisições sob as mesmas condições experimentais (corrente $\approx 800 \mathrm{pA} \mathrm{e}$ tensão na junção de $50 \mathrm{mV}$ ) proporcionou a curva $\ln (\mathrm{I})$ x s mostrada na Figura 12. A regressão linear destes dados conduziu à $(2,92 \pm 0,06) \mathrm{eV}$ para a altura da barreira. Apesar de ser um valor maior que aqueles obtidos para filmes finos de ouro sobre grafite, ele ainda está muito aquém da quantia real da função trabalho para o ouro $(\approx 5,4 \mathrm{eV})$.

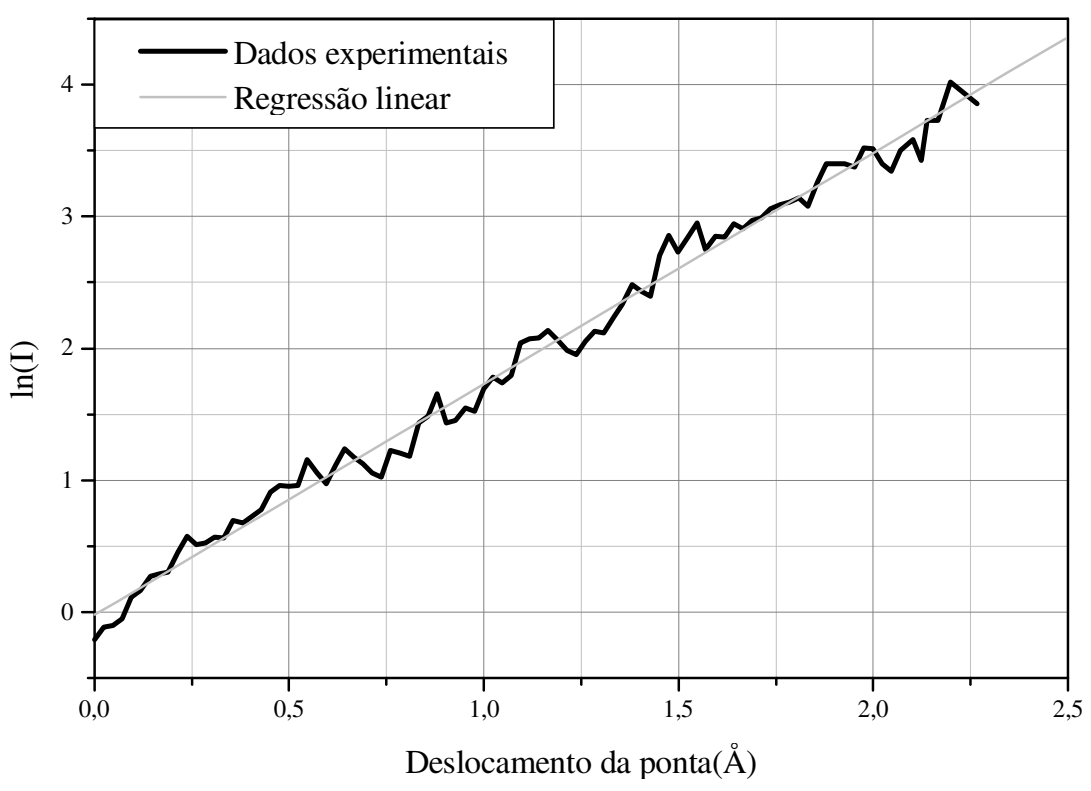

Figura 12: gráfico do logaritmo da corrente de tunelamento em função do deslocamento da ponta adquirido sobre uma amostra cristalizada de ouro. A figura mostra também a reta ajustada sobre os dados experimentais. Por clareza do gráfico, as barras de incerteza não são mostradas, mas sua grandeza não difere muito da própria variação estatística dos dados em torno da reta ajustada.

A explicação mais plausível para o baixo valor novamente obtido é, mais uma vez, a presença de impurezas sobre a superfície da amostra. Uma evidência deste fato foi dada pela detecção de histerese na curva I-s. A suposta camada residual de impurezas interage de modo distinto 
dependendo do sentido (aproximação ou afastamento) do movimento da ponta, gerando a histerese sobre a curva I-s da mesma forma como foi observado sobre grafite. A diferença fundamental é que agora a amostra apresenta uma rigidez muito maior, resistindo às pressões da ponta do STM. Porém, apenas a camada residual de impurezas parece ser suficiente para mudar a calibração do movimento da ponta, reduzindo o valor medido da altura aparente da barreira.

\section{5- Testes com a Espectroscopia $\pm \mathrm{V}$ :}

Um filme de ouro de espessura aproximada de $200 \AA$ foi visualizado usando o programa que implementa a espectroscopia $\pm \mathrm{V}$. Amostras metálicas não devem apresentar nenhuma diferença à mudança na polaridade da tensão de tunelamento. Este fator foi preponderante para optarmos por este tipo de amostra nos testes iniciais, pois qualquer diferença entre as imagens adquiridas sob polaridades opostas seria um efeito associado puramente à eletrônica ou ao programa de aquisição. Os resultados estão apresentados na Figura 13. Observa-se uma plena coincidência entre pares de imagens (adquiridas na mesma varredura), sem deformação ou instabilidade aparentes (ver imagens a e b). Em oposição, vale a pena compará-las com imagens adquiridas com o mesmo programa na sua fase inicial de desenvolvimento, quando o diagrama de tempos da aquisição não havia sido otimizado (imagens c e d).

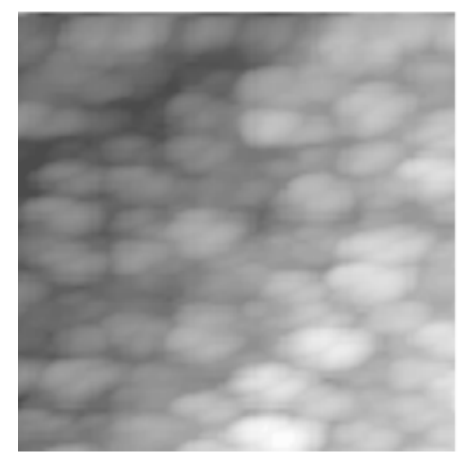

a

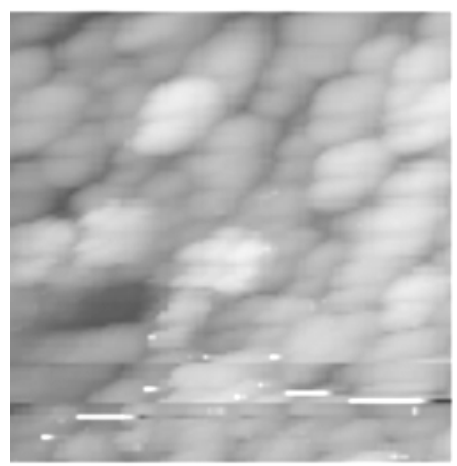

$\mathrm{c}$

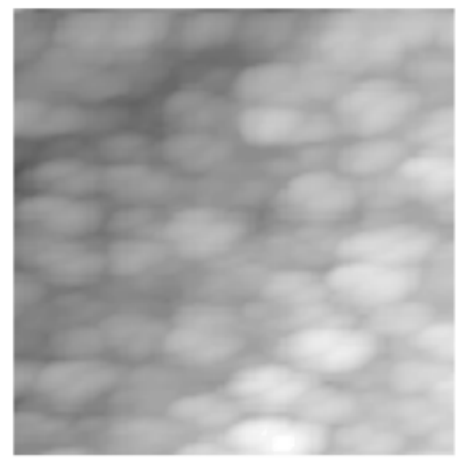

b

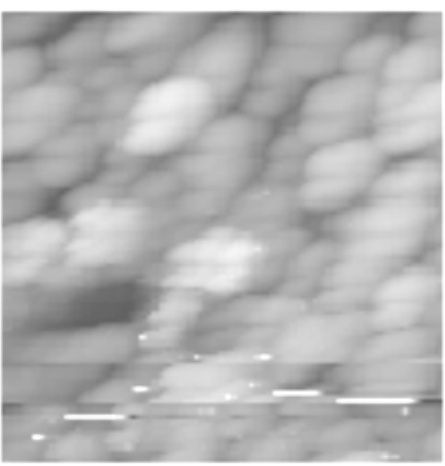

$\mathrm{d}$

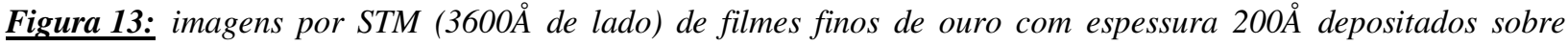
$H O P G$. A aquisição foi feita usando duas versões do programa para espectroscopia $\pm V$. As imagens da esquerda correspondem à aquisição com polaridade positiva. O módulo da magnitude da tensão foi de $50 \mathrm{mV}$. Em (a) e (b), observa-se imagens de qualidade satisfatória, obtidas através do programa cujo algoritmo foi convenientemente otimizado. Em $(c)$ e (d), observam-se as instabilidades geradas devido ao uso da versão do programa com um diagrama de tempos ineficiente. 


\section{6- Conclusões:}

Neste capítulo, aplicamos o instrumental para medidas espectroscópicas sobre ouro. Por ser um metal nobre, foi possível obter resultados substancialmente diferentes daqueles obtidos sobre HOPG.

Primeiramente, estudamos as condições ideais de deposição por sputtering de filmes finos de ouro. Esta etapa foi fundamental para determinar o limite inferior da espessura dos filmes, de modo a prover uma camada contínua e lisa sobre a superfície em questão. Concluímos que na taxa de deposição mais baixa permitida pelo equipamento utilizado $(\approx 0,8 \AA / \mathrm{s}$, correspondente à uma densidade de corrente de $\left.2 \mathrm{~mA} / \mathrm{cm}^{2}\right)$, um filme de $40 \AA$ de espessura é suficiente para recobrir completamente a amostra, com uma rugosidade muito reduzida $(\approx 6,5 \AA)$. Quantitativamente, estes valores devem ser vistos com precaução. As condições de controle da deposição por sputtering são cruciais: a tensão entre eletrodos e a pressão da câmara durante a deposição desempenham um papel primordial na qualidade final do filme. Qualquer mudança nestes parâmetros, devido a alterações na configuração do equipamento, é capaz de resultar num filme diferente do desejado para uma dada taxa de deposição, apresentando uma rugosidade demasiada ou descontinuidades.

Conhecidas as condições de deposição por sputtering, executamos curvas I-V sobre alguns destes filmes depositados sobre HOPG. O comportamento da inclinação das curvas em função da distância ponta-amostra foi coerentemente reproduzido. A diferença na estrutura eletrônica do filme e do substrato fornece curvas I-V distintas para cada caso, fato que propiciou a caracterização da descontinuidade de um filme fino, permitindo associar a região mais baixa da imagem ao substrato de grafite. Esta aplicação serviu como prova irrefutável da acuidade de nosso sistema de aquisição de curvas I-V, já que os resultados mostraram a distinção entre dois materiais na mesma amostra em condições experimentais idênticas. Além disto, a curva obtida sobre o trecho contínuo deste filme permitiu a detecção de uma não linearidade acentuada, incomum em filmes de maior espessura. É possível que o substrato tenha influência sobre a curva I-V do filme que o recobre, desde que este seja fino o suficiente.

Nas medidas de altura da barreira, resultados mais próximos dos ideais (se comparados aos alcançados com HOPG) foram obtidos sobre uma amostra de ouro cristalino. Devido a sua constituição mecânica, a medida foi limitada apenas pela camada residual de contaminantes presente na superfície, diferentemente do caso do grafite. Com o STM exposto ao ar, a possibilidade de obter valores da altura da barreira próximos à função trabalho é remota. Isto, porém, não restringe a capacidade espectroscópica da técnica, ou seja, a possibilidade de distinguir materiais através da variação desta grandeza numa mesma amostra.

Outro modo de aquisição testado sobre filmes finos de ouro depositados em HOPG foi a espectroscopia $\pm \mathrm{V}$. Imagens de boa qualidade foram obtidas na mesma varredura nas duas polaridades de tensão na junção. 


\section{Referências:}

R. C. Jaklevic, L. Elie, W. Shen e J. T. Chen, J. Vac. Sci. Technol. A 6, 448 (1988).

2 U. Mazur, G. Fried e K. W. Hipps, Surf. Sci. 243, 179 (1991).

3 R. Emch, J. Nogami, M. M. Dovek, C. A. Lang e C. F. Quate, J. Appl. Phys. 65, 79 (1989).

4 J. Schneir, R. Sonnenfeld, O. Marti, P. K. Hansma, J. E. Demuth e R. J. Hamers, J. Appl. Phys. 63, 717 (1988).

5 H. J. Mamin, P. H. Guethner e D. Rugar, Phys. Rev. Lett. 65, 2418 (1990).

6 Semiconductor Materials and Process Technology Handbook, editado por Gary E. McGuire, Noyes Publications, New Jersey, U.S.A. (1988).

7 R. C. Jacklevic e L. Elie, Phys. Rev. Lett. 60, 120 (1988).

8 T. E. Lamas, A. S. Ferlauto, P. K. Kyohara e A. A. Quivy, Acta Microscopica 5B, 388 (1996).

9 J. Yu e Y. Namba, Appl. Phys. Lett. 73, 3607 (1998).

${ }^{10}$ C. Schonenberger, S. F. Alvarado e C. Ortiz, J. Appl. Phys. 66, 4258 (1989).

11 A. S. Ferlauto, Construção e Aplicações de um microscópio de tunelamento, dissertação de mestrado apresentada ao Instituto de Física da USP (1996).

12 C. E. D. Chidsey, D. N. Loiacono, T. Sleator e S. Nakahara, Surf. Sci. 200, 45 (1988).

13 A. Piednoir, E. Perrot, S. Granjeaud, A. Humbert, C. Chapon e C. R. Henry, Surf. Sci. 391, 19 (1997).

14 R. J. Colton, S. M. Baker, R. J. Driscoll, M. G. Youngquist e J. D. Baldeschwieler, J. Vac. Sci. Technol. A 6, 349 (1988).

15 A. A. Marchenko, V. V. Cherepanov, D. T. Tarashchenko, Z. I. Kazantseva e A. G. Naumovets, Surf. Sci. 416, 460 (1998). 


\section{Capítulo 6}

\section{ESPECTROSCOPIA SOBRE SEMICONDUTORES DOS GRUPOS III-V:}

\section{1- Introdução:}

Um dos objetivos desta dissertação foi a caracterização topográfica e espectroscópica, com o STM, de diversos tipos de amostras semicondutoras dos grupos III-V crescidas (ou diretamente envolvidas) no sistema de epitaxia por feixe molecular (molecular beam epitaxy, MBE) existente em nosso laboratório. No âmbito tecnológico, as estruturas desenvolvidas por este sistema têm aplicações diversas em optoeletrônica, como por exemplo na construção de lasers $^{1}$ e fotodetectores. ${ }^{2}$

Entre os materiais analisados nesta etapa, encontra-se o arseneto de gálio (GaAs). Ele apresenta uma estrutura cristalina do tipo zincblend, na qual cada sítio apresenta quatro primeiros vizinhos. O GaAs é clivado facilmente no plano (110) e (110) expondo uma face não polar que apresenta um número idêntico de cátions e ânions, correspondentes aos átomos de gálio e arsênio respectivamente. Alternativamente, a superfície (100) pode ser terminada (idealmente) tanto em átomos de Ga como As dependendo de sua clivagem. Esta é portanto uma superfície polar. ${ }^{3}$ A largura da região de energias proibidas (gap) na temperatura ambiente é $1,42 \mathrm{eV}$.

Outro sistema estudado neste trabalho está relacionado com pontos quânticos de InAs (arseneto de índio, cujo gap é de $0,36 \mathrm{eV}$ na temperatura ambiente) crescidos sobre substratos de GaAs. Tais estruturas têm a propriedade de confinar portadores nas três dimensões espaciais, devido ao fato de seu tamanho ser da mesma ordem de grandeza da extensão da função de onda dos elétrons. O efeito causado pelo confinamento sobre os níveis de energia dos elétrons dá origem a todas as aplicações deste tipo de estrutura. ${ }^{4}$ No sistema MBE, os pontos quânticos são formados pelo método da auto-organização de camadas tensas de InAs depositadas sobre GaAs. Em condições normais (sem tensões), estes dois materiais possuem um parâmetro de rede diferente $(\mathrm{GaAs} \approx 5,65 \AA$, InAs $\approx 6,06 \AA)$. No início do crescimento, as primeiras camadas de InAs se conformam ao parâmetro de rede do GaAs (crescimento bidimensional, camada por camada), acumulando uma energia de deformação elástica da camada proporcional a esta diferença. Após uma espessura crítica, torna-se desfavorável energeticamente para a camada de InAs prosseguir o crescimento neste regime. Para diminuir a energia armazenada, a camada se reorganiza espontaneamente, formando pequenas ilhas de InAs que constituem os pontos quânticos. Este modo de crescimento é descrito pelo modelo de Stranski-Krastanov. ${ }^{5}$ As amostras assim 
crescidas apresentam pontos de tamanhos similares, uniformemente distribuídos sobre a superfície.

Algumas características dos semicondutores tornam crítica a coleta de dados com um STM. A baixa condutividade da amostra limita a obtenção de uma corrente de tunelamento com magnitude substancial para a análise. A área reduzida da ponta confina o fluxo de elétrons numa pequena região da superfície na qual surge uma resistência da ordem de grandeza da impedância da junção de tunelamento. Isto causa uma queda adicional na tensão aplicada através da junção que pode deformar dados espectroscópicos, uma vez que o potencial aplicado à amostra não mais representará a energia dos elétrons em relação ao nível de Fermi. ${ }^{6}$ Os dois efeitos citados são geralmente minimizados com o aumento da dopagem do semicondutor, acréscimo na temperatura ou com a iluminação da amostra durante sua análise. ${ }^{7}$ Estes procedimentos, através de mecanismos físicos diferentes, aumentam o número de portadores na banda de condução, diminuindo a resistividade da amostra e, como consequiência, a queda indesejada de tensão. Além dos problemas já discutidos, amostras semicondutoras analisadas no ar ficam rapidamente cobertas por uma camada de óxido (superior a $10 \AA$ de espessura ${ }^{8}$ ), formando uma barreira isolante sobre sua superfície que prejudica (ou mesmo impede) o tunelamento. Em adição, a superfície sobre a qual está sendo feita a varredura é sujeita a uma densidade de corrente elevada, aumentando sua taxa natural de oxidação. Alguns testes foram feitos logo após a construção de nosso STM. Nesta ocasião, removemos quimicamente a camada de óxido da superfície da amostra e medimos imediatamente sua topografia. Assim que algumas varreduras foram executadas, o sinal da corrente de tunelamento tornou-se instável, impedindo a obtenção de imagens após alguns minutos. Resultados semelhantes são descritos na referência 9.

Neste contexto, fica clara a importância da preparação das amostras semicondutoras para análise no ar com um STM. Nos itens seguintes, é dada uma descrição dos diversos métodos de preparação implementados com sucesso em nossas amostras, seguida de alguns resultados de medidas espectroscópicas.

\section{2- Métodos para a preparação de amostras semicondutoras:}

\subsection{1- Cobertura da amostra com um líquido inerte:}

Este método consiste em cobrir diretamente a amostra com uma substância líquida, de forma que sua superfície seja isolada do contato com o oxigênio ambiente, retardando assim a oxidação. A ponta do microscópio deve transpor esta fina camada e posicionar-se próximo o bastante da superfície para que o tunelamento ocorra. A literatura descreve o uso de vários tipos de líquidos (de viscosidade variadas) para esta finalidade, como parafina e óleo de bomba de vácuo. ${ }^{10}$ Nos diversos estudos relatados, não foram detectadas diferenças na configuração atômica medida pelo STM sobre amostras de grafite cobertas desta forma, comprovando que a viscosidade da camada líquida não tem influência alguma sobre o movimento da ponta. $\mathrm{O}$ líquido utilizado deve possuir uma alta resistividade elétrica para impedir a ocorrência de correntes de fuga entre a ponta e o restante da amostra recoberta. É também desejável que a substância não reaja com a superfície ou com a ponta, provocando danos em sua morfologia. 
Tendo em vista estes requisitos, o líquido escolhido para recobrir nossas amostras foi o Nujol, uma substância mineral inerte utilizada pela indústria farmacêutica na preparação de medicamentos. Sua aparência é translúcida e a viscosidade é semelhante à de óleos lubrificantes comuns.

Antes da aplicação do Nujol sobre amostras semicondutoras, é necessário efetuar a remoção da camada de óxido nativo presente na superfície, sejam as amostras substratos de GaAs ou pontos quânticos de InAs. Esta camada pode ser composta por óxidos dos elementos gálio, arsênio e índio com diversas proporções estequiométricas $\left(\mathrm{Ga}_{2} \mathrm{O}_{3}, \mathrm{As}_{2} \mathrm{O}_{5}, \mathrm{As}_{2} \mathrm{O}_{4}\right.$ e $\mathrm{GaAsO}_{4}$ para GaAs ou $\mathrm{In}_{2} \mathrm{O}_{3}$, InAsO $\mathrm{Is}_{4}, \mathrm{As}_{2} \mathrm{O}_{3}$, e $\mathrm{As}_{2} \mathrm{O}_{5}$ no caso do InAs). ${ }^{11}$ Enquanto os óxidos de arsênio são solúveis mesmo em água, os demais são removidos eficientemente apenas através de ácidos (como $\mathrm{HCl}$ e $\mathrm{H}_{2} \mathrm{SO}_{4}$ ) ou bases $\left(\mathrm{N}_{2} \mathrm{OH}_{4}\right)$. No âmbito da preparação das amostras para análise com um STM, e de modo mais genérico na sua aplicação em optoeletrônica, não é desejável que os procedimentos utilizados gerem um aumento na rugosidade natural de sua superfície. Portanto, a escolha do melhor processo para a remoção do óxido é uma etapa fundamental. Um ponto importante a ser destacado é que ácidos em estado concentrado devem remover apenas a camada de óxido, mantendo intacta a superfície da amostra. As soluções usadas para remover camadas da amostra (decapagem ou etching) são sempre elaboradas misturando um ácido, peróxido de hidrogênio $\left(\mathrm{H}_{2} \mathrm{O}_{2}\right.$, água oxigenada) e água. Quando a amostra é colocada em contato com esta solução, o peróxido de hidrogênio e a água oxidam continuamente a superfície, enquanto o ácido trata de remover este óxido recém-formado, promovendo assim a corrosão desejada.

Com a finalidade de escolher a melhor forma para a remoção do óxido, comparamos os resultados obtidos usando $\mathrm{HCl}$ e $\mathrm{H}_{2} \mathrm{SO}_{4}$. A questão era saber se, neste processo de limpeza inicial, a superfície já não seria comprometida de alguma forma. Selecionamos duas partes de uma mesma amostra bem conhecida de pontos quânticos de InAs (\#618) crescidos por MBE sobre um substrato de GaAs. Uma delas foi imersa em $\mathrm{HCl}$ e a outra em $\mathrm{H}_{2} \mathrm{SO}_{4}$ por aproximadamente 2 minutos, enxaguadas em água deionizada (D.I.) por 30s e secas em um fluxo de $\mathrm{N}_{2}$. Ambas foram analisadas usando microscopia de força atômica (AFM, atomic force microscopy), no equipamento Nanoscope III (marca Digital Instruments) presente no Laboratório de Física de Plasmas do IFUSP. Esta técnica permite a rápida caracterização topográfica da amostra sem nenhum tratamento posterior, seja ela isolante ou não. Esta análise mostrou que o $\mathrm{HCl}$ é bem menos danoso à superfície, como mostra a Figura 1. De fato, $\mathrm{o}_{2} \mathrm{SO}_{4}$ é uma substância muito viscosa. Provavelmente, esta acentuada viscosidade faz com que os resíduos da reação fiquem depositados na superfície após o processo, mesmo que através de uma interação muito fraca, demandando um enxágüe mais rigoroso que o utilizado.

Uma vez escolhida a forma de remover o óxido nativo, o processo de preparação das amostras consistiu em:

- Remover o óxido nativo, imergindo a amostra em $\mathrm{HCl}$ concentrado por 2 minutos;

- Retirar os produtos da reação, através de um enxágüe em água D.I. por $\approx 30$ s;

- Secar a amostra num fluxo de $\mathrm{N}_{2}$ gasoso por 1 minuto;

- Aplicar uma pequena quantia de Nujol sobre a superfície. 


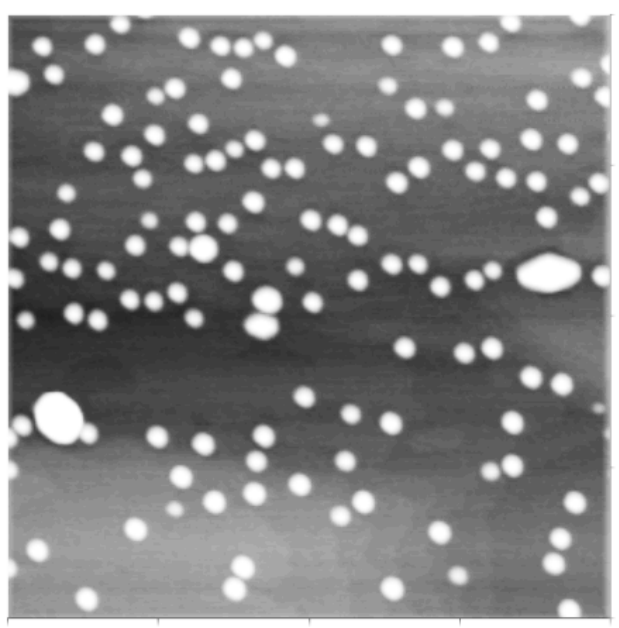

a

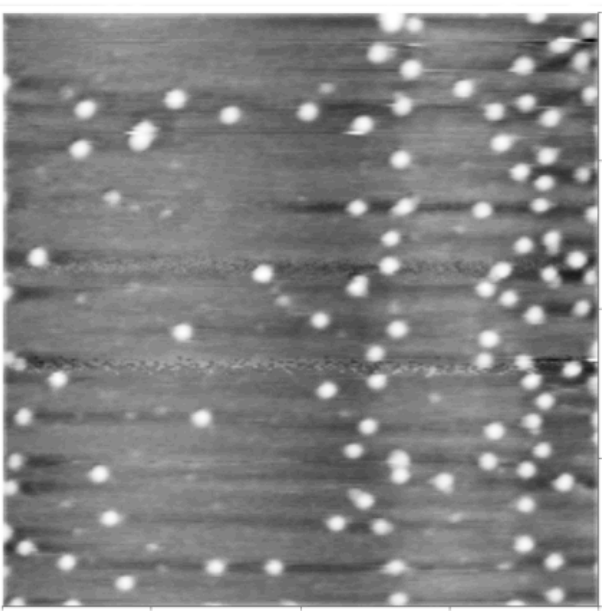

b

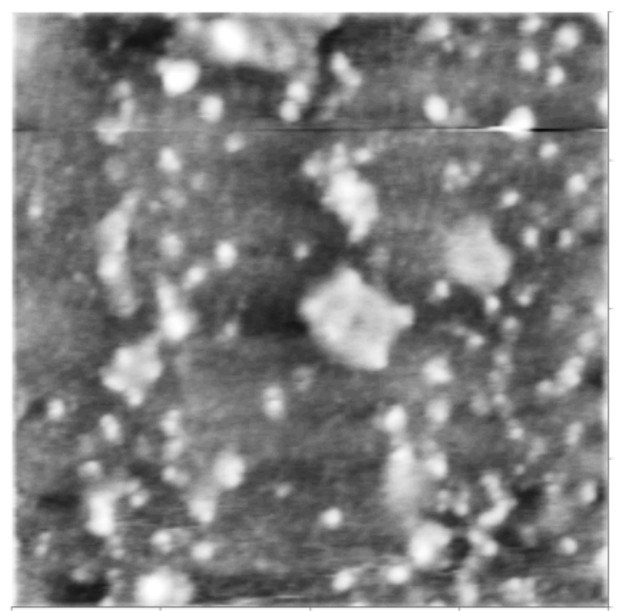

c

Figura 1: imagens por AFM (modo de contato) de três amostras de pontos quânticos. a) referência (sem tratamento); as outras duas correspondem à remoção do óxido nativo usando b) $\mathrm{HCl}$ e c) $\mathrm{H}_{2} \mathrm{SO}_{4}$. As imagens têm $1 \mu \mathrm{m}$ de lado e foram adquiridas com uma frequência de varredura de $2 \mathrm{~Hz}$ na direção $\mathrm{x}$. A escala de cinza (diferença entre os níveis preto e branco) é de 60nm para cada uma delas.

Esta preparação foi implementada em uma amostra de pontos quânticos (\#600), e algumas imagens foram feitas com nosso STM. A tensão de tunelamento utilizada foi de $2 \mathrm{~V}$ (ponta positiva em relação à amostra) e a corrente de 200pA. Uma das imagens obtidas pode ser vista na Figura 2. Apesar da boa definição dos pontos quânticos, o contraste da imagem não é adequado. Imagens semelhantes de amostras preparadas da mesma forma são mostradas na referência 12.

A despeito desta técnica geralmente oferecer bons resultados, nossa experiência comprovou que o processo de preparação é de difícil reprodutibilidade. Esta imagem em particular apresentou um ótimo contraste em relação a algumas tentativas anteriores que não foram tão bem sucedidas. Devido a isto, tentamos outras técnicas para a preparação destas superfícies, como será descrito nos próximos itens. 


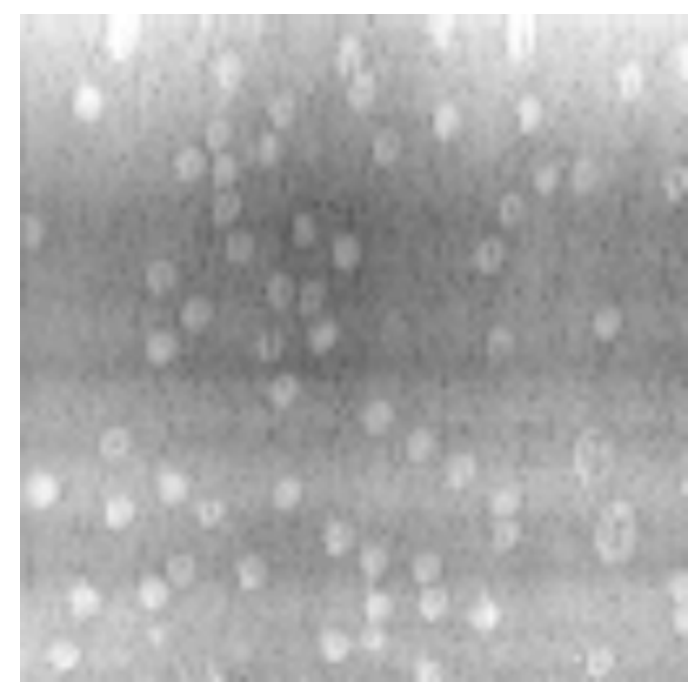

Figura 2: imagem por STM, com $7200 \AA$ de lado, mostrando a amostra de pontos quânticos de InAs (\#600) preparada para análise com uma cobertura de Nujol. A escala de cinza abrange $100 \AA$ e a freqüência de varredura foi de $0,6 \mathrm{~Hz}$ na direção horizontal.

\subsection{2- Metalização da amostra com um filme fino de ouro:}

A idéia básica da técnica de metalização é formar uma camada fina, homogênea e condutora que se conforme da melhor maneira possível à morfologia da superfície da amostra. No capítulo anterior, foi descrito o procedimento utilizado na otimização dos parâmetros de deposição de filmes de ouro para que fosse obtida uma camada com a menor rugosidade permitida pelo sistema de sputtering utilizado. O filme que melhor satisfez este requisito foi depositado com uma densidade de corrente de $2 \mathrm{~mA} / \mathrm{cm}^{2}$ e uma espessura de $40 \AA$.

Recobrindo uma amostra semi-isolante de pontos quânticos de InAs (\#1008), foi possível comprovar a utilidade do filme em medidas de STM. Devido à baixa resolução lateral de nosso microscópio para imagens com dimensões acima de $1 \mu \mathrm{m},{ }^{*}$ decidimos utilizar o STM da marca Digital presente no laboratório de Física de Plasmas do IFUSP. As imagens obtidas podem ser observadas na Figura 3. A alta resolução da imagem $(512 \times 512$ pontos $)$ permite mesmo a visualização dos clusters de ouro recobrindo cada um dos pontos quânticos. É possível verificar a semelhança entre as imagens por STM e AFM (esta última foi obtida antes da deposição do filme) comparando a conformação geométrica dos pontos. Houve um alinhamento ao longo de uma dada direção que foi reproduzido nas duas imagens.

\footnotetext{
* Com o programa atual, só conseguimos adquirir 100 linhas com 100 pontos de amostragem; no caso de uma varredura de $1 \mu \mathrm{m}$ de lado, isto significa uma distância de $100 \AA$ entre cada aquisição, sendo que o diâmetro de um ponto quântico varia entre $200 \AA$ e $400 \AA$. Assim, cada ponto quântico será definido, no máximo, por 16 pontos.
} 


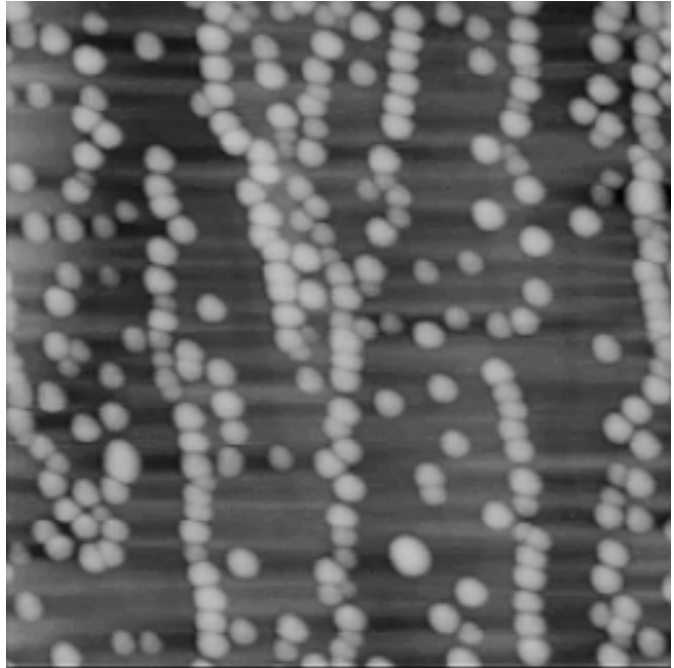

a

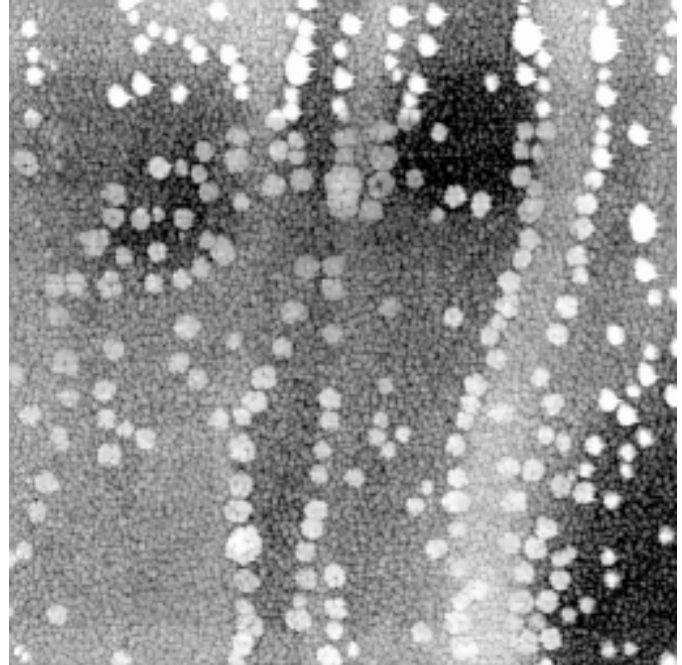

b

Figura 3: imagens (com $1 \mu \mathrm{m}$ de lado) de uma amostra semi-isolante de pontos quânticos de InAs. (a) imagem obtida por AFM, antes do recobrimento da amostra, cuja escala de cinza abrange 50nm. (b) imagem por STM de outra região da mesma amostra depois de recoberta com um filme fino de ouro. A escala de cinza é de $15 \mathrm{~nm}$.

Apesar da cobertura da amostra por um filme fino de ouro fornecer imagens topográficas de excelente qualidade, este procedimento oculta parcialmente as propriedades espectroscópicas da amostra. Investigamos então uma terceira técnica de preparação de superfícies semicondutoras que possibilitasse sem equívoco algum tanto o estudo topográfico quanto espectroscópico.

\subsection{3- Passivação da superfície:}

A qualidade da superfície dos compostos semicondutores dos grupos III-V é um fator limitante para a sua aplicação em dispositivos e, particularmente, para caracterização por STM no ar. O problema fundamental é a alta densidade de estados de superfície, relacionada com a migração de átomos de arsênio na formação do óxido nativo, tornando a superfície repleta de ligações químicas pendentes. ${ }^{13}$ Visando uma performance ainda melhor dos dispositivos construídos com estes compostos, diversos pesquisadores desenvolveram a passivação das superfícies. ${ }^{14,15}$ Este processo consiste em substituir o óxido nativo por uma camada fina e inerte que impeça a aproximação de átomos de oxigênio da superfície da amostra, evitando a oxidação (passivação química) e reduzindo assim o número de estados na superfície (passivação eletrônica). O uso desta técnica foi aprimorado para análise topográfica e espectroscópica em STM sobre semicondutores III-V no ar por J. A. Dagata e colaboradores. ${ }^{16,17}$ Seus estudos comprovaram que, se a reação for bem controlada, a passivação adiciona apenas algumas monocamadas de material sobre a superfície da amostra, não comprometendo o tunelamento.

Os elementos químicos utilizados para a passivação devem ser fortemente adsorvidos pela superfície da amostra. Em semicondutores dos grupos III-V, o uso de compostos baseados em enxofre é largamente difundido. ${ }^{18,19}$ Isto é devido à energia requerida pelo enxofre para constituir sua ligação com os átomos dos grupos III-V, menor que a energia necessária para formação dos óxidos. Assim, durante a reação, a formação da camada passivadora é favorecida 
em relação à oxidação da amostra. A Figura 4 traz uma ilustração do mecanismo da passivação. Primeiramente, a solução remove a camada residual de óxido sobre a superfície da amostra, graças ao seu caráter alcalino. A reação propriamente dita com a superfície é descrita pela fórmula:

$$
\mathrm{A}^{\mathrm{III}} \mathrm{B}^{\mathrm{V}}+\mathrm{HS}^{-}+\mathrm{R}-\mathrm{OH} \rightarrow\left(\mathrm{A}^{\mathrm{III}}\right)_{\mathrm{x}} \mathrm{S}_{\mathrm{y}}+\left(\mathrm{B}^{\mathrm{V}}\right)_{\mathrm{x}} \mathrm{S}_{\mathrm{y}}+\mathrm{R}^{-} \mathrm{O}^{-}+\mathrm{H}_{2} \uparrow
$$

onde $\mathrm{A}^{\mathrm{III}}$ e $\mathrm{B}^{\mathrm{V}}$ são os elementos dos grupos III e $\mathrm{V}$ respectivamente, $\mathrm{R}$ pode ser um átomo de hidrogênio (para soluções aquosas) ou um radical alquila (para soluções diluídas em álcool). Os coeficientes estequiométricos $\mathrm{x}, \mathrm{y}, \mathrm{x}$ ' e y' podem assumir valores entre 1 e 5 (gerando compostos como $\mathrm{GaS}$ e $\operatorname{In}_{2} \mathrm{~S}_{3}$ ). Partindo desta fórmula, convém fazer uma análise fenomenológica do processo. Cada átomo do cristal pode fazer quatro ligações (pois esta é uma estrutura zincblend), cada uma delas formada por dois elétrons. Por outro lado, cada composto que será formado na superfície entre os átomos A ou B e o enxofre possuirá apenas três ligações químicas. Isto implica que, após o processo de sulfuração, haverá uma ligação pendente por molécula. Para formar a camada passivadora, os elétrons localizados nessas ligações deverão migrar para a solução ou serem transferidos para outros estados de energia no semicondutor. A energia necessária para isto pode vir tanto da reação de formação dos compostos $A_{x} S_{y}$ e $B_{x}$ ' $S_{y}$ ' quanto da absorção de fótons com energia superior à do gap do material. Este processo pode ser entendido com as seguintes equações de oxi-redução:

$$
\begin{aligned}
& \mathrm{A}^{\mathrm{III}} \mathrm{B}^{\mathrm{V}} \rightarrow\left(\mathrm{A}^{\mathrm{III}}\right)^{3+}+\left(\mathrm{B}^{\mathrm{V}}\right)^{3+}+6 \mathrm{e}^{-}, \\
& 6 \mathrm{H}^{+}+6 \mathrm{e}^{-} \rightarrow 3 \mathrm{H}_{2} \uparrow
\end{aligned}
$$

O solvente desempenha um papel fundamental no resultado final da passivação. Apesar de não se envolver diretamente na reação química, sua permissividade elétrica influi nas interações eletrostáticas que ocorrem na interface da amostra com a solução passivadora. ${ }^{20}$ Quanto maior a permissividade, mais fracas serão estas interações, reduzindo a saída de elétrons da superfície da amostra e prejudicando assim a qualidade da superfície após o processo. Por esta razão, resultados mais efetivos são obtidos escolhendo-se álcool como solvente (por exemplo, metanol com permissividade $\varepsilon=33,0$ ou isopropanol com $\varepsilon=20,2$ ) em alternativa à água $(\varepsilon=80,1)^{21}$

Outro fator recorrente na literatura é o potencial corrosivo da solução passivadora. Embora os mecanismos de sua ocorrência não sejam bem esclarecidos, experimentalmente sua ação pode ser desastrosa para a morfologia da amostra. As taxas de decapagem relatadas dependem da amostra e da solução utilizada, variando desde $100 \AA$ /hora (para GaAs ${ }^{22}$ em uma solução de $\left(\mathrm{NH}_{4}\right)_{2} \mathrm{~S}$ ) até $12000 \mathrm{~A} /$ hora (para $\mathrm{GaSb}^{15}$ em uma solução de $\mathrm{Na}_{2} \mathrm{~S}: 9 \mathrm{H}_{2} \mathrm{O}$ ). No estudo de amostras homogêneas, como o caso do GaAs, isto não é prejudicial desde que não aumente a rugosidade da superfície. Entretanto, para uma amostra de pontos quânticos (cuja altura é da ordem de dezenas de angströns) deve-se tomar o devido cuidado na escolha dos parâmetros da reação, de modo a conservar a estrutura original da superfície. 

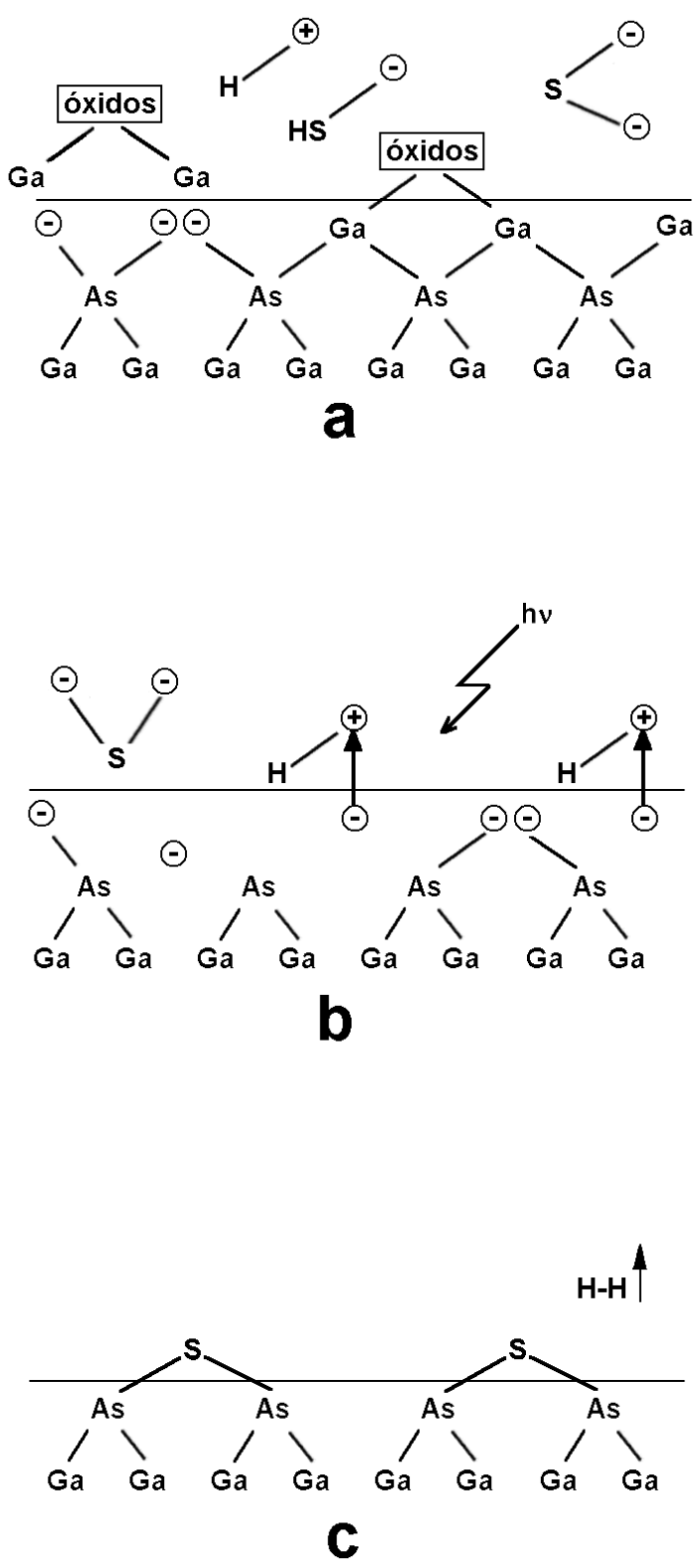

Figura 4: ilustração do processo de passivação de uma amostra de GaAs em uma solução aquosa. (a) remoção da camada de óxido (com a ruptura das ligações entre Ga e As) e dissociação dos íons $H S^{-}$; (b) transferência dos elétrons do semicondutor para a solução, usando fótons de energia hv; (c) formação das ligações químicas entre os átomos de enxofre e a amostra.

Pesquisando a grande variedade de substâncias e procedimentos existentes, experimentamos diversas dessas reações sobre nossas amostras de GaAs e pontos quânticos a fim de comparar a qualidade dos resultados, tanto no aspecto topográfico quanto eletrônico. No âmbito topográfico, é desejável que a reação não danifique a superfície. A caracterização neste aspecto foi feita tanto por AFM quanto STM. Eletronicamente, o processo de passivação deve saturar as ligações pendentes da superfície. Isto diminui o número de centros de recombinação não radiativa, fato que pode ser evidenciado por medidas de fotoluminescência (photoluminescence, PL). ${ }^{23}$ 
Entre os reagentes relatados pela literatura, selecionamos três deles para um estudo sistemático dos parâmetros de reação: $\mathrm{Na}_{2} \mathrm{~S}, \mathrm{P}_{2} \mathrm{~S}_{5}$ e $\left(\mathrm{NH}_{4}\right)_{2} \mathrm{~S}$. O $\mathrm{P}_{2} \mathrm{~S}_{5}$, juntamente com $\left(\mathrm{NH}_{4}\right)_{2} \mathrm{~S}$, foram os reagentes usados por Dagata na preparação de amostras para microscopia de tunelamento. Portanto, esta foi a primeira das reações estudadas por nós. Providenciamos os principais reagentes, que são o $\mathrm{P}_{2} \mathrm{~S}_{5}$ em forma de pó e a solução de $\left(\mathrm{NH}_{4}\right)_{2} \mathrm{~S}$ em concentração de $20 \%$. A solução passivadora é obtida dissolvendo o $\mathrm{P}_{2} \mathrm{~S}_{5}$ na solução $(0,5 \mathrm{~g}$ do pó para $10 \mathrm{ml}$ de $\left(\mathrm{NH}_{4}\right)_{2} \mathrm{~S}$, onde são adicionados $30 \mathrm{ml}$ de água D.I.). A amostra passa pelos seguintes passos:

- Remoção do óxido nativo usando $\mathrm{HCl}$ concentrado por 2 minutos;

- Transferência rápida para a solução passivadora onde a amostra é deixada por $\mathbf{1 0}$ minutos para dissolução dos produtos resultantes da reação entre o ácido, usado na remoção do óxido, e a solução alcalina de passivação;

- Aquecimento até $50^{\circ} \mathrm{C}$ do conjunto por mais 10 minutos, durante os quais a reação de passivação ocorre;

- Enxágüe em banhos sucessivos de $\mathrm{HCl}: \mathrm{H}_{2} \mathrm{O}$ (12 gotas para 30ml) e água DI para remoção dos produtos da reação;

- Secagem em um fluxo de nitrogênio gasoso.

Estudamos a influência desta reação sobre substratos de GaAs (J10210 dopados do tipo $\mathrm{n}$ com Si, numa concentração de $10^{18} \mathrm{~cm}^{-3}$ ) e sobre pontos quânticos de InAs crescidos por MBE (amostra \#618). Durante a análise no STM, a corrente de tunelamento se mostrou estável, proporcionando a obtenção de imagens reprodutíveis e mostrando a eficiência do processo no aspecto eletrônico. Várias tentativas foram implementadas mudando os tempos de reação (tanto a permanência na solução à temperatura ambiente quanto a $50^{\circ} \mathrm{C}$ ). No entanto, as imagens obtidas sempre apresentaram um aumento da rugosidade natural que fica flagrante quando comparadas com as imagens por AFM das mesmas amostras sem tratamento algum. As melhores imagens obtidas por STM estão na Figura 5. É nítido o aumento da rugosidade da superfície, exigindo uma nova forma de passivação.

A solução usada como alternativa foi o $\left(\mathrm{NH}_{4}\right)_{2} \mathrm{~S}$ (solução aquosa de concentração $20 \%$ ) diluído em metanol. Em nosso conhecimento, a literatura não traz registros da preparação de amostras para STM em modo topográfico com esta solução. No caso de AFM, imagens com resolução atômica sobre um substrato de GaAs assim tratado foram relatadas. ${ }^{24} \mathrm{O}$ processo implementado por nós consistiu em:

- remover o óxido nativo da superfície usando $\mathrm{HCl}$ concentrado durante 2 minutos;

- enxágüe em água D.I. por 30s;

- secagem em $\mathrm{N}_{2}$ gasoso por 1 minuto;

- imersão da amostra na solução de $\left(\mathrm{NH}_{4}\right)_{2} \mathrm{~S}$ diluída em metanol (10\% em volume) durante alguns minutos;

- enxágüe rápido em água D.I. e secagem em fluxo de $\mathrm{N}_{2}$ durante 2 minutos; 


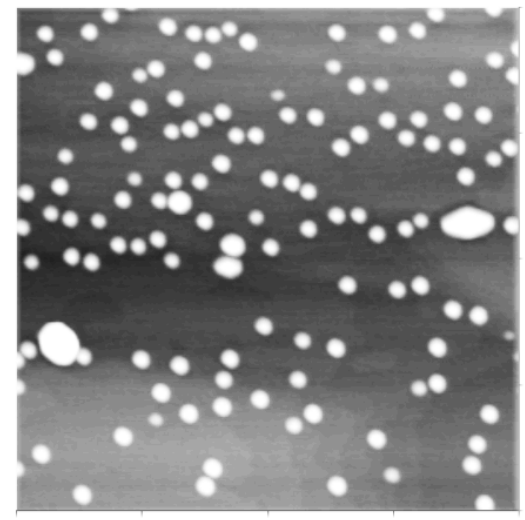

a

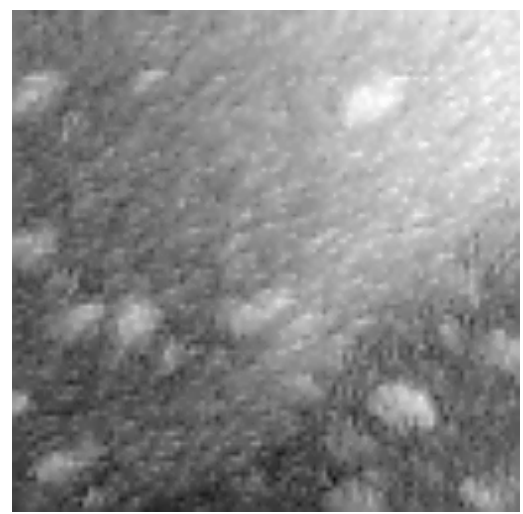

$\mathrm{C}$

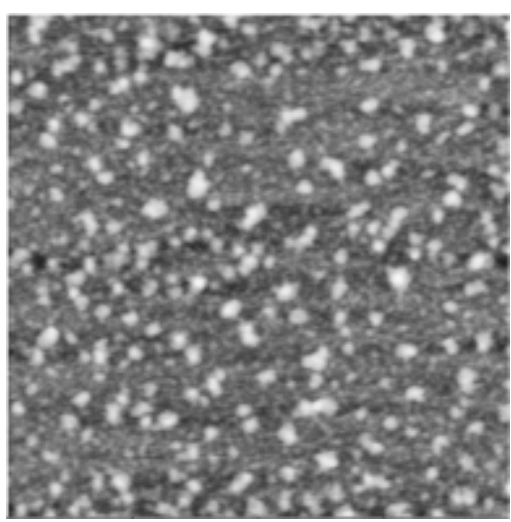

b

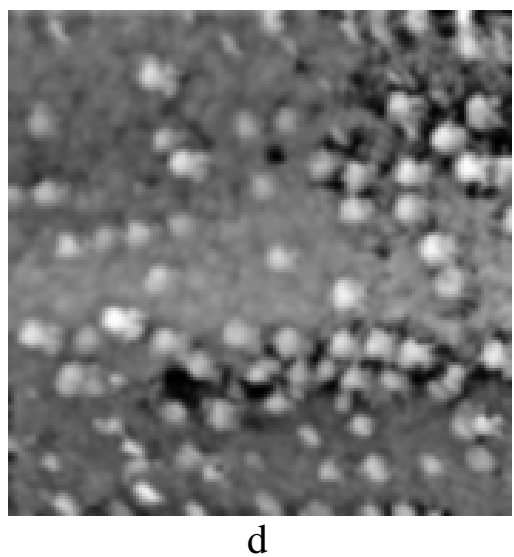

Figura 5: (a) imagem, por AFM, de uma amostra de pontos quânticos (\#618) sem tratamento algum (escala de cinza igual a 550A) com $1 \mu \mathrm{m}$ de lado e adquirida com frequência de $2 \mathrm{~Hz}$ na direção horizontal e (b) imagem por AFM com os mesmos parâmetros, da mesma amostra tratada pelo processo de passivação

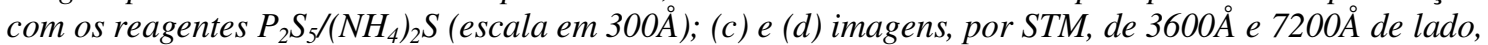
respectivamente, da mesma amostra tratada. É possível observar em ambas uma boa definição, sem ruídos aparentes, mas o formato dos pontos quânticos foi bastante modificado. A escala de cinza abrange $100 \AA \mathrm{em}(\mathrm{c})$ e $140 \AA \mathrm{em}(\mathrm{d})$, e as imagens foram adquiridas com uma freqüencia de varredura de $0,7 \mathrm{~Hz}$ na direção horizontal.

As primeiras preparações realizadas desta forma sobre amostras de GaAs e pontos quânticos propiciaram imagens de qualidade superior, sem aumento aparente da rugosidade original da superfície. A corrente de tunelamento no microscópio apresentou-se tão estável quanto no caso anterior. Com a finalidade de obter mais informações quanto ao aspecto eletrônico promovido por esta reação sobre a amostra, realizamos medidas de fotoluminescência em substratos de GaAs (100) não dopados (E2026-7 SI). Esses substratos foram escolhidos, pois quanto menor o nível de dopagem da amostra, mais acentuado é o aumento da intensidade da PL para superfícies passivadas. ${ }^{18}$ Isto permite medidas mais precisas, já que o efeito da reação será muito maior que as incertezas experimentais envolvidas. Além disto, a taxa de formação da camada passivadora depende fracamente da condutividade da amostra, ${ }^{25}$ não impedindo que apliquemos estes resultados nas amostras dopadas que devem ser utilizadas para a análise por STM. 
O primeiro dos estudos foi focalizado no tempo de contato da amostra com a solução. Variamos os tempos de tratamento entre 2 e 25 minutos e obtivemos o espectro de PL para cada amostra. A experiência foi conduzida na temperatura do nitrogênio líquido, com um laser de argônio (comprimento de onda $5145 \AA$ ) com uma potência de $25 \mathrm{~mW}$. Um espectro típico pode ser visto em destaque na Figura 6. Calculando a razão da intensidade do pico correspondente à transição do $\mathrm{GaAs}(\approx 1,507 \mathrm{eV}$ nesta temperatura) entre amostras tratadas e de referência, foi possível construir o gráfico presente na Figura 6. É nítida a saturação do aumento da intensidade para valores acima de 15 minutos de reação. O aumento de intensidade é resultado do decréscimo da velocidade de recombinação não radiativa, intimamente relacionada com a diminuição da densidade de estados de superfície na faixa de energia do gap do semicondutor. $\mathrm{O}$ ponto de saturação desta curva pode ser associado ao momento no qual a maioria desses estados de superfície foi neutralizada pela reação.

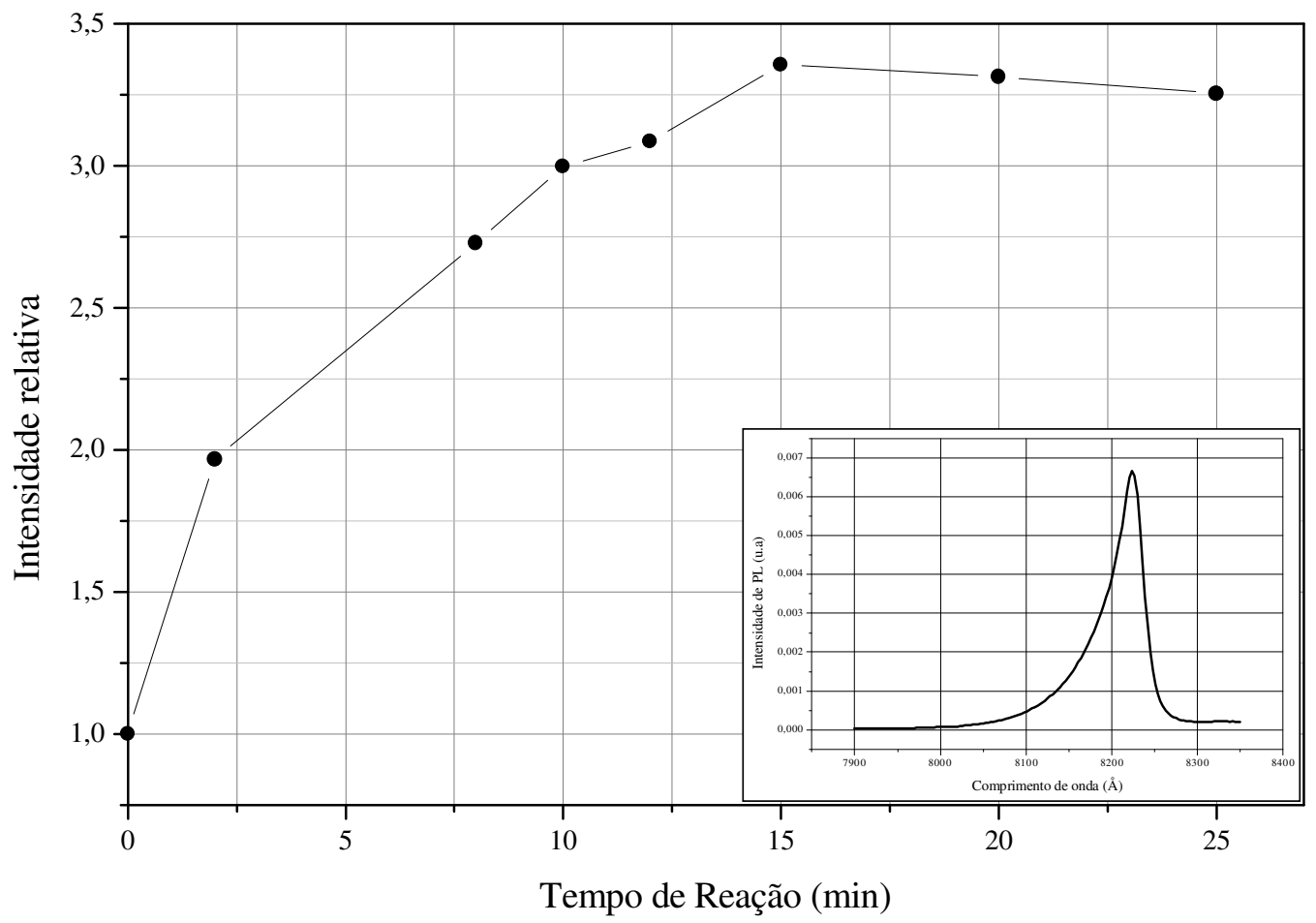

Figura 6: gráfico da intensidade relativa da PL (razão da intensidade do pico da amostra tratada pela não tratada) para cada uma das amostras (do mesmo substrato E2026-7) submetidas a diversos tempos de imersão na solução de $\left(\mathrm{NH}_{4}\right)_{2} \mathrm{~S}$ em metanol. Em destaque, um espectro típico de PL de uma das amostras analisadas.

Apesar da relevância dos resultados descritos acima, conduzimos outra experiência de PL na temperatura do hélio líquido. Os espectros assim obtidos forneceram informações adicionais importantes. Uma amostra do mesmo substrato de GaAs usado anteriormente foi tratada durante 15 minutos na solução de $\left(\mathrm{NH}_{4}\right)_{2} \mathrm{~S}$ diluída em metanol. A experiência de fotoluminescência foi conduzida a $1,5 \mathrm{~K}$, com o laser de argônio ajustado com uma potência de $250 \mathrm{~mW}$. Os espectros obtidos na amostra tratada e na de referência podem ser vistos na Figura 7. Os picos mais intensos, presentes tanto no espectro da amostra tratada quanto na de referência, são relacionados com a luminescência proveniente da recombinação excitônica intrínseca do GaAs $(1,515 \mathrm{eV})$ e intermediada por impurezas de carbono $(1,493 \mathrm{eV})$. Analisando a intensidade desses picos, tem- 
se a prova irrefutável do sucesso, no aspecto eletrônico, da reação de passivação. Enquanto o pico de carbono tem uma intensidade comparável em ambas as amostras, o pico correspondente ao GaAs apresenta um aumento significativo (aproximadamente um fator 7) na amostra tratada, tornando flagrante a eliminação de centros de recombinação não radiativos da superfície. Este resultado permite também concluir que o processo não contamina a amostra com carbono, já que a intensidade do pico correspondente não mudou consideravelmente. Esta possibilidade não seria intuitivamente tão remota, dado que a solução usada era diluída em uma substância orgânica (metanol), que eventualmente poderia possuir contaminações espúrias de carbono facilmente passíveis de adsorção pela superfície.

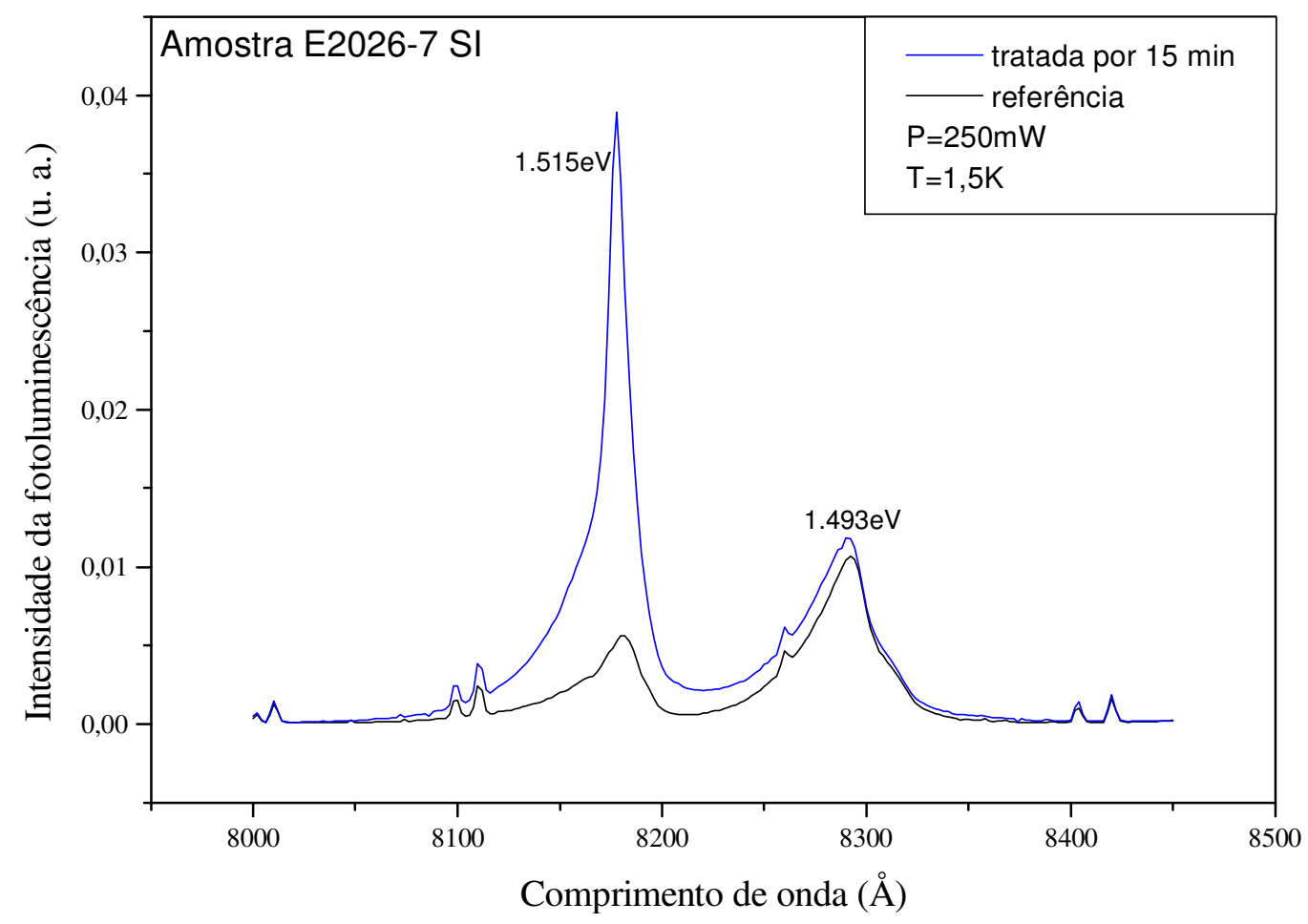

Figura 7: espectros de fotoluminescência da amostra tratada durante 15 minutos (azul) e da amostra padrão (curva em preto). No gráfico são indicadas as energias de emissão (em eV) ao lado de cada um dos picos principais correspondentes ao GaAs $(1,515 \mathrm{eV})$ e às impurazas de carbono $(1,493 \mathrm{eV})$.

Tendo em vista os resultados deste estudo, concluímos que o tratamento de nossas amostras para análise no STM poderia ser interrompido após 15 minutos de reação. Preparamos duas amostras de pontos quânticos (\#600 e \#616) com este procedimento, e as imagens obtidas por STM podem ser vistas na Figura 8. Foi usada uma tensão de 2V (amostra aterrada) e uma corrente de referência da ordem de 200pA. Um contraste superior aos casos anteriores pode ser notado, indicando que esta é a melhor das reações para a aplicação em nossas amostras. Todavia, este procedimento ainda deforma um pouco a dimensão das estruturas. Partindo da dimensão original, como vista por AFM, o processo de passivação retira o óxido nativo da superfície, diminuindo em cerca de $10 \AA ̊$ o tamanho original da estrutura. Além disto, a própria reação de passivação eventualmente pode retirar algum material da superfície. No entanto, este empecilho não restringe nosso objetivo de estudar as diferenças nas características espectroscópicas nas amostras preparadas desta forma. 


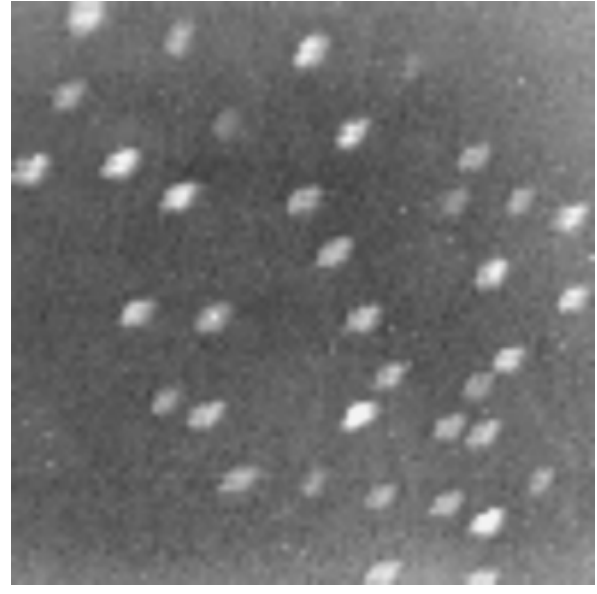

a

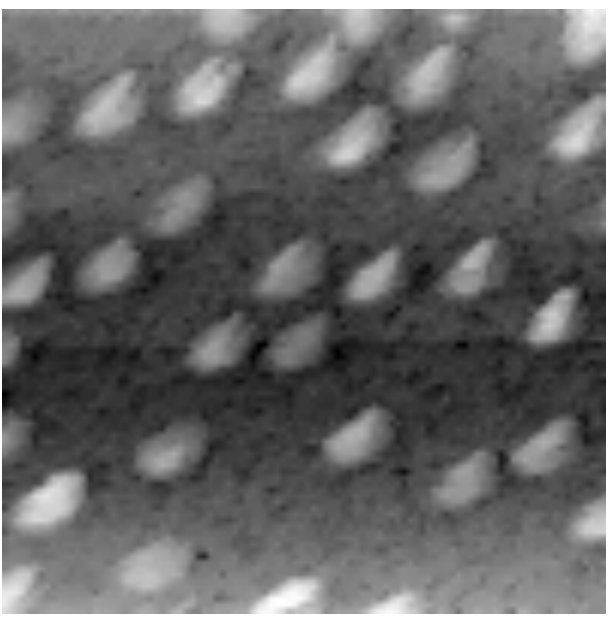

C

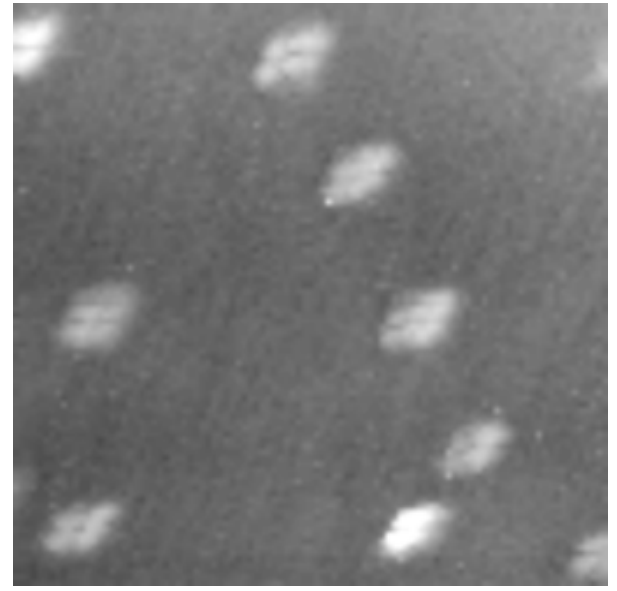

b

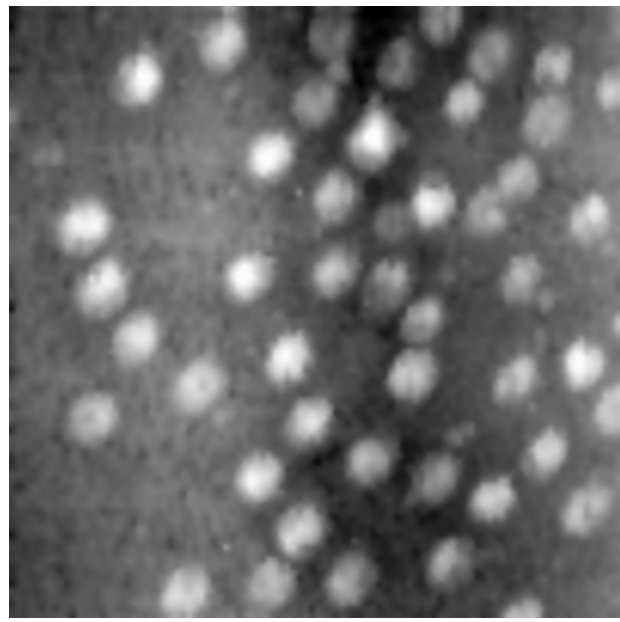

d

Figura 8: imagens, por STM, das amostras de pontos quânticos \#618 (a e b) e \#600 (c) e (d), preparadas com a solução de $\left(\mathrm{NH}_{4}\right)_{2} \mathrm{~S}$ por 15 minutos. A dimensão lateral da imagem é $7200 \AA$ em (a) e $3600 \AA$ em (b), (c) e (d). A escala de cinza abrange cerca de $90 \AA$ em cada uma das imagens.

Apesar dos resultados positivos nesta etapa, tentamos ainda realizar a passivação com o $\mathrm{Na}_{2} \mathrm{~S}: 9 \mathrm{H}_{2} \mathrm{O}$. Este compostos é formado por cristais solúveis em água ou álcool. A solução assim formada tem caráter alcalino forte, exigindo tempos reduzidos de reação. Preparamos a solução com concentração 1 molar e tratamos um substrato de GaAs durante 1 minuto, seguindo o procedimento descrito na literatura de não remover o óxido nativo com $\mathrm{HCl}^{26}{ }^{26}$ enxágüe rápido e a secagem em um fluxo de $\mathrm{N}_{2}$ foram realizados para retirar os produtos da reação. As medidas de fotoluminescência mostraram um aumento significativo do pico de GaAs, indicando a efetividade da reação no aspecto eletrônico. Todavia, a análise por AFM mostrou a formação de cristais sobre toda a superfície da amostra, como mostra a Figura 9. Isto é indesejável para nossas aplicações, e portanto este procedimento foi descartado. 


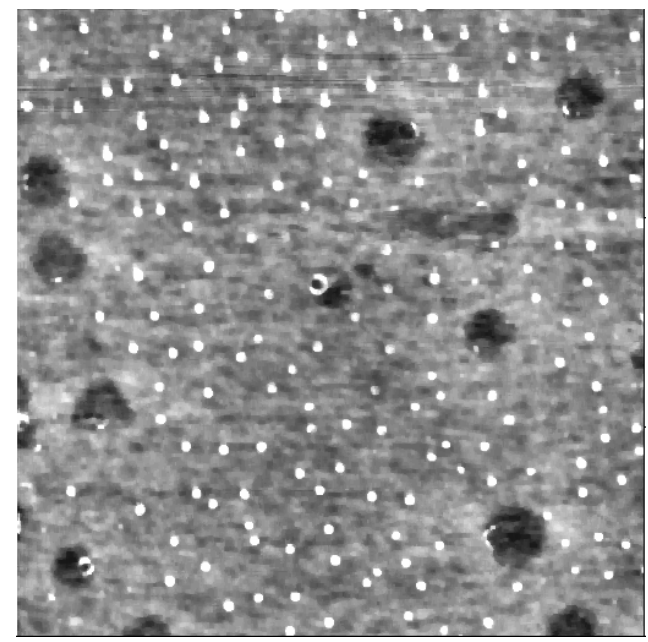

Figura 9: imagem por AFM (modo contato, $3 \mu \mathrm{m}$ de lado) mostrando um substrato de GaAs (sem o crescimento de pontos quânticos!) tratado com a solução contendo $\mathrm{Na}_{2} \mathrm{~S}$. A reação criou alguns buracos na superfície, juntamente com pequenas protuberâncias associadas provavelmente à formação de cristais do soluto (pequenos pontos brancos). A escala de cinzas abrange $150 \AA$.

O tempo de estabilidade da superfície após o processo de passivação é um fator muito variável conforme o tipo de tratamento. As referências citam tempos desde 42 horas (para GaAs (100) tratado com $\left.\mathrm{P}_{2} \mathrm{~S}_{5} /\left(\mathrm{NH}_{4}\right)_{2} \mathrm{~S}\right)^{27}$ até mais de 10 dias (para a mesma amostra tratada com $\left.\mathrm{P}_{2} \mathrm{~S}_{5} / \mathrm{NH}_{4} \mathrm{OH}\right)^{13}$ para que a intensidade da fotoluminescência decaia de modo significativo. Com o tratamento em $\left(\mathrm{NH}_{4}\right)_{2} \mathrm{~S}$, medidas de fotoluminescência realizadas em nosso grupo até 25 dias após a preparação ainda mostravam um aumento substancial na intensidade do pico de GaAs, indicando que o óxido nativo não voltou a cobrir completamente a amostra.

\section{3- Espectroscopia I-V:}

Uma vez otimizados os métodos de preparação das amostras, o próximo passo foi tentar obter informações espectroscópicas das amostras assim preparadas. Como obtivemos excelentes resultados usando o método da passivação, resolvemos focalizar nossos esforços em amostras preparadas desta forma.

\subsection{1- GaAs (100) dopado tipo n:}

Após termos verificado o efeito da passivação no aspecto topográfico, efetuamos curvas I-V sobre substratos de GaAs(100) (J10210-67) dopados do tipo n com Si. A concentração de portadores para esta amostra é da ordem de $10^{18} \mathrm{~cm}^{-3}$, o que a torna de fácil análise com um STM. Sua preparação foi feita com a solução de $\left(\mathrm{NH}_{4}\right)_{2} \mathrm{~S}$ durante 15 minutos. Duas curvas I-V adquiridas sob mesma tensão de tunelamento e diferentes correntes de referência (ou seja, diferentes distâncias ponta-amostra) são apresentadas na Figura 10. A tensão de tunelamento inicial foi de $-2 \mathrm{~V}$. 


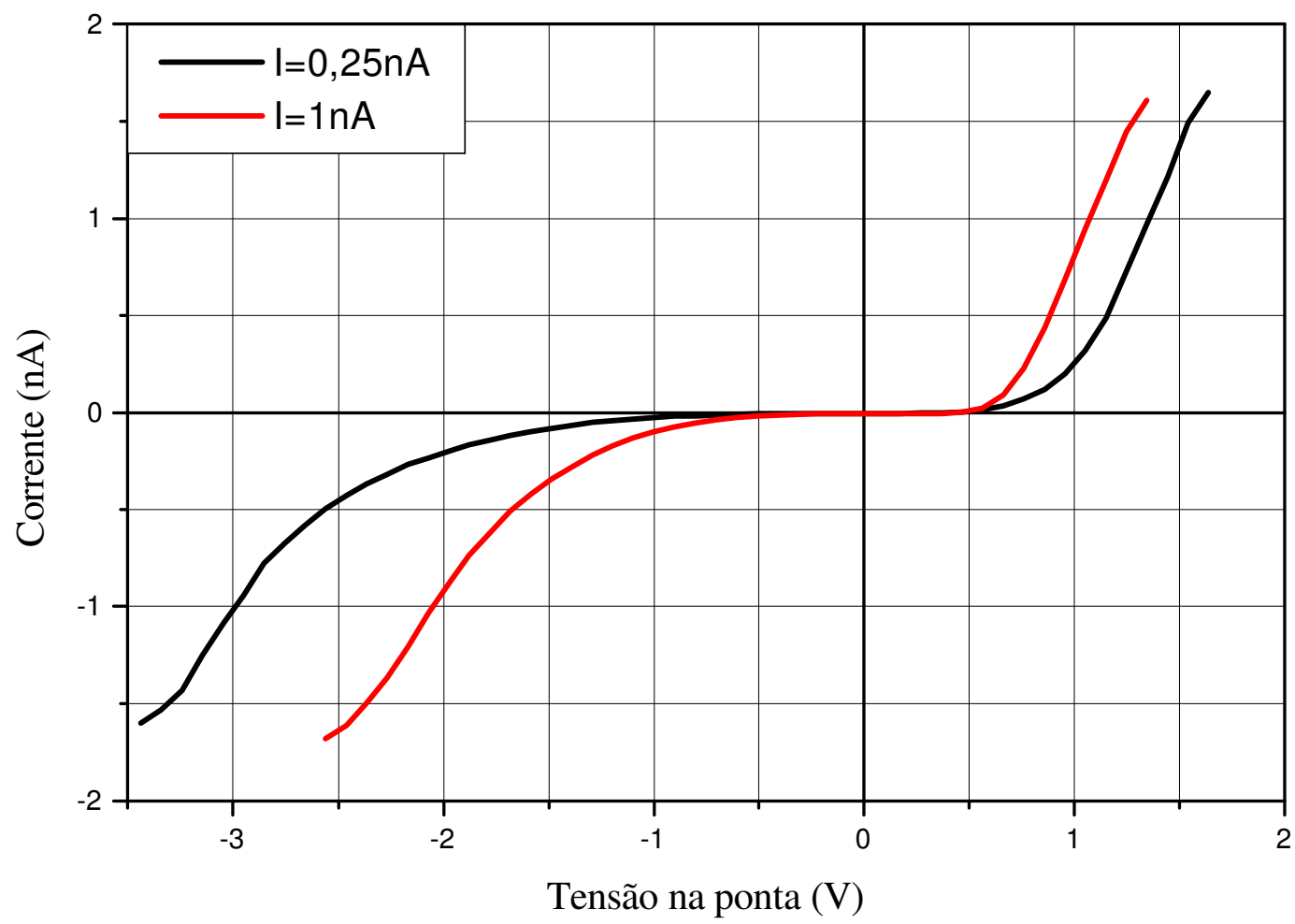

Figura 10: curvas I-V adquiridas com diferentes condições iniciais de corrente sobre um substrato dopado de GaAs(100) (J10210-67) tratado com $\left(\mathrm{NH}_{4}\right)_{2} \mathrm{~S}$.

Estas curvas apresentam grandes diferenças em relação a aquelas apresentadas nos capítulos anteriores. É possível observar agora uma região onde a corrente de tunelamento se anula, acusando a presença da região de energia proibida do material. A assimetria é muito acentuada, mostrando o caráter retificador esperado para uma junção metal-vácuosemicondutor. ${ }^{28}$ Este comportamento não é claramente detectado em amostras com alta densidade de estados na superfície (ou seja, não tratadas) ${ }^{29}$ devido ao pinning do nível de Fermi proporcionado por estes estados. $\mathrm{O}$ mecanismo deste fenômeno pode ser compreendido com a Figura 11. Considerando um semicondutor intrínseco, o nível de Fermi estará localizado entre as bandas de condução e valência (condição de flat band, Figura 11a). Com a dopagem (tipo n, neste exemplo), o nível de Fermi se aproxima da banda de condução (Figura 11b). A fim de atingir uma condição de equilíbrio, ocorre uma transferência de cargas para os estados desocupados na superfície (causados pela oxidação), fazendo com que o nível de Fermi afaste-se da banda de condução e se fixe em uma determinada energia (o que é chamado de pinning). Esta configuração de cargas forma dentro da amostra a camada de depleção, uma região que apresenta um potencial elétrico cuja amplitude decai quadraticamente com a distância a partir da superfície. A mudança na energia dos níveis eletrônicos próximo à superfície do cristal em resposta a este potencial é conhecido como encurvamento das bandas (band bending, Figura 11c). ${ }^{3}$ O campo elétrico nesta camada é um empecilho para medidas com STM, pois pode blindar a tensão aplicada entre a ponta e a amostra, fazendo com que a corrente medida não reflita as informações correspondentes à determinada tensão. O processo de passivação é capaz de reduzir consideravelmente os estados de superfície, minimizando o pinning do nível de Fermi e permitindo a observação da característica da barreira Schottky formada pela junção. 
Uma informação importante que pode ser facilmente extraída desta curva é o tipo da dopagem ( $\mathrm{p}$ ou $\mathrm{n}$ ) do semicondutor. Enquanto dopagens do tipo $\mathrm{n}$ propiciam uma corrente maior sob tensões positivas da ponta, uma amostra dopada tipo $\mathrm{p}$ apresenta o efeito contrário. Uma técnica para determinação quantitativa do nível de dopagem de várias amostras de GaAs(100) tipo $\mathrm{n}$ foi relatada por Dagata e colaboradores na referência 17.

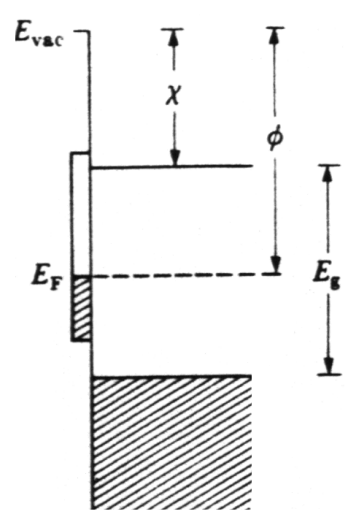

a

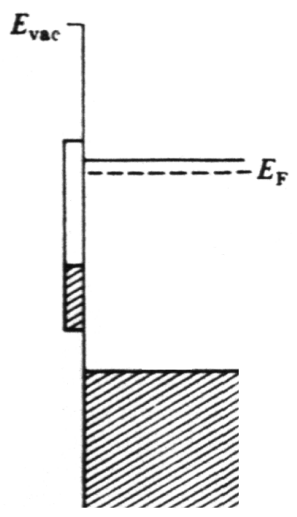

b

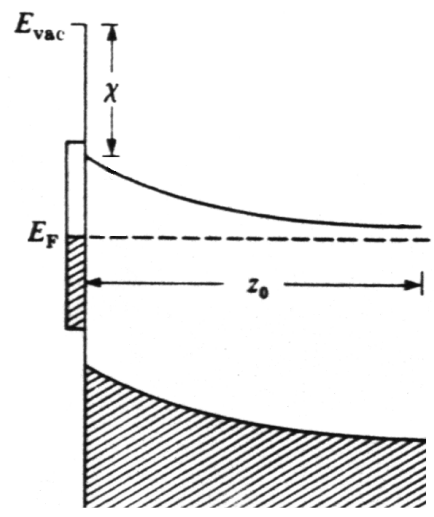

$\mathrm{c}$

Figura 11: níveis de energia próximos à superfície de um semicondutor. Em (a), tem-se o caso de um semicondutor intrínseco; a figura (b) mostra a situação de desequilíbrio de cargas entre o bulk dopado do tipo $n$ e a superfície. Esta é uma situação hipotética e intermediária entre a e c. Em (c) é mostrado o band bending $e$ o pinning do nível de Fermi quando o equilíbrio de cargas é atingido. A camada de depleção possui uma espessura de $\mathrm{z}_{\mathrm{O}}, \chi$ é a afinidade eletrônica e $\phi$ é a função trabalho. Figura extraída da referência 3 .

Outro aspecto visível nas curvas I-V apresentadas é a possibilidade de detecção de uma pequena corrente mesmo na região correspondente ao gap do material. Esta observação também foi feita por Feenstra e Stroscio na referência 30 em medidas sobre GaAs(110) em UHV. Este fato é relacionado com o encurvamento das bandas induzido pela ponta do STM (tip-induced band bending), ${ }^{31}$ como mostra a Figura 12. Este efeito é significativo apenas em amostras com reduzido número de estados de superfície. Quando a ponta é aproximada da amostra, surge um campo elétrico na região da junção que é função da diferença de função trabalho dos dois eletrodos $\left(\Delta \phi=\phi-\left(\chi+\phi_{m}\right)\right)$. Este campo causa o encurvamento das bandas na região próxima à superfície, formando dentro da amostra a camada de depleção, proibida para a passagem dos elétrons (chamada pela literatura de space-charge region). Feenstra e Stroscio sugeriram a possibilidade dos elétrons sofrerem tunelamento através desta região quando a tensão aplicada à amostra é pequena o bastante, conforme as condições da junção. Em nossas curvas I-V, é possível observar que, quanto maior a corrente de tunelamento de referência (maior proximidade da ponta em relação a amostra), uma amplitude maior de corrente é detectada em tensões baixas. Uma vez que o efeito de band bending é mais acentuado quanto menor a distância pontaamostra, o tunelamento neste regime de baixas tensões é privilegiado nesta condição, resultando em uma maior magnitude da corrente medida. Apesar deste fenômeno, é possível, sob condições experimentais otimizadas (principalmente distância ponta-amostra e tensão de tunelamento), medir a largura exata do gap do material. As referências 32 e 33 citam exemplos deste caso. 


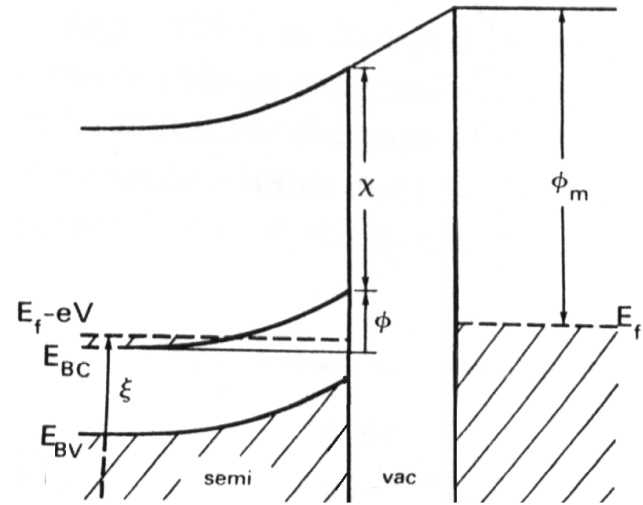

a

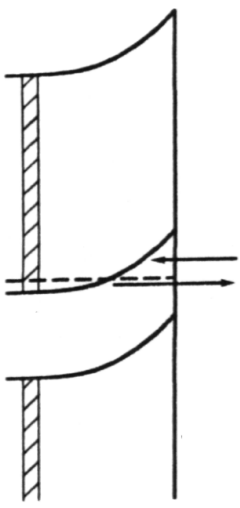

b

Figura 12: (a) ilustração do mecanismo do encurvamento de bandas induzido pela ponta. Neste caso, supomos que não há estados de superfície. Em (b), as setas indicam a ocorrência de tunelamento na região proibida dentro do material (space-charge region), responsável pela medida de corrente sob baixas tensões. Figura extraída da referência 30.

\subsection{2- GaAs (100) intrínseco:}

Como já foi discutido no início deste capítulo, amostras não condutoras representam um grande problema para a análise com um STM. Não obstante, alguns trabalhos com microscopia de tunelamento são devotados para a análise de materiais semi-isolantes ${ }^{7}$ ou mesmo isolantes. ${ }^{34}$ Para isto, a amostra é irradiada com uma luz de freqüência $v$, cuja energia correspondente hv seja superior ao gap do material. Desta forma, elétrons da banda de valência são enviados para a banda de condução, reduzindo de modo significativo a resistividade da superfície e permitindo sua análise. Neste contexto, decidimos realizar um estudo das curvas I-V de um substrato de GaAs intrínseco utilizando esta técnica, e assim efetuar comparações com as curvas obtidas em amostras dopadas."

A amostra foi um substrato de GaAs semi-isolante (E2026-7). Para o GaAs, a irradiação com luz visível é suficiente para atingir o objetivo desejado. Por isso, usamos um laser de He-Ne $(\lambda=6328 \AA)$ com potência de $5 \mathrm{~mW}\left(\mathrm{E}_{\lambda}>\mathrm{E}_{\text {gap }}=1,42 \mathrm{eV}\right.$ na temperatura ambiente). Foi feita a passivação com a solução de $\left(\mathrm{NH}_{4}\right)_{2} \mathrm{~S}$ por 15 minutos, impedindo assim a oxidação durante a medida. A luz do laser foi dirigida diretamente à junção de tunelamento, sem o uso de lentes ou espelhos. Todo cuidado teve de ser tomado para minimizar o aquecimento da amostra. Para isso, o feixe do laser era interrompido quando a medida não estava sendo realizada.

A Figura 13 traz uma curva $\mathrm{I}-\mathrm{V}$ adquirida com o microscópio na luz ambiente, tendo como condições iniciais uma tensão de $-2 \mathrm{~V}$ na ponta e corrente $0,25 \mathrm{nA}$. A corrente de tunelamento foi detectada apenas no ramo das tensões negativas, correspondendo ao tunelamento dos elétrons dos níveis ocupados da ponta para os níveis desocupados da banda de condução da amostra. Sob tensão positiva, nenhuma corrente significativa pode ser medida. Ainda no ramo negativo, pode-se notar uma forte influência de um ruído de frequiência $60 \mathrm{~Hz}$, causado provavelmente por uma condição de proximidade extrema da ponta com a amostra.

\footnotetext{
* A amostra utilizada é denominada intrínseca pois não é dopada intencionalmente.
} 


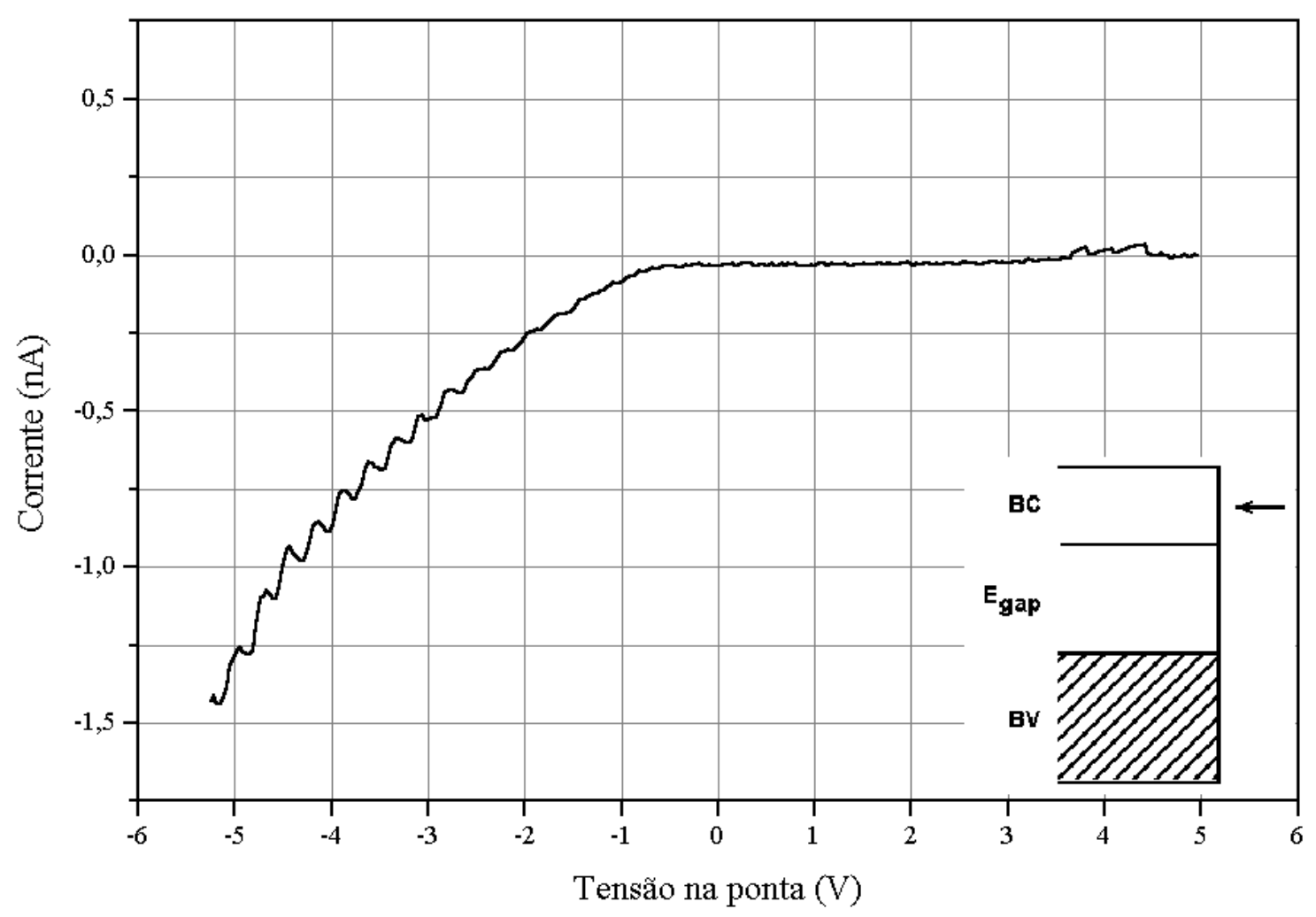

Figura 13: curva I-V da amostra semi-isolante adquirida apenas sob iluminação ambiente. $O$ diagrama no gráfico ilustra a ocorrência do tunelamento para os estados desocupados da banda de condução (BC).

Logo após a aquisição desta curva, o feixe do laser foi direcionado sobre a junção e tomou-se uma nova curva I-V com os mesmos parâmetros. A Figura 14 mostra a diferença entre as curvas adquiridas nas duas condições. Sob iluminação, o tunelamento se torna possível nas duas polaridades de tensão devido à criação de buracos na banda de valência, proporcionados pela luz do laser. É notável também o aumento da faixa dos valores da corrente medida, propiciada pelo decréscimo da resistividade da amostra devido aos portadores fotogerados pela irradiação do laser. ${ }^{35}$ A largura do gap que pode ser observada na curva é muito próxima do valor nominal para o GaAs na temperatura ambiente $(=1,42 \mathrm{eV})$. Isto foi possível graças à não ocorrência do pinning do nível de Fermi. A assimetria apresentada pela curva não chega a ser significativa, podendo ser completamente atribuída a fatores experimentais, confirmando que o nível de Fermi se posicionou no centro do gap de energia do material. 


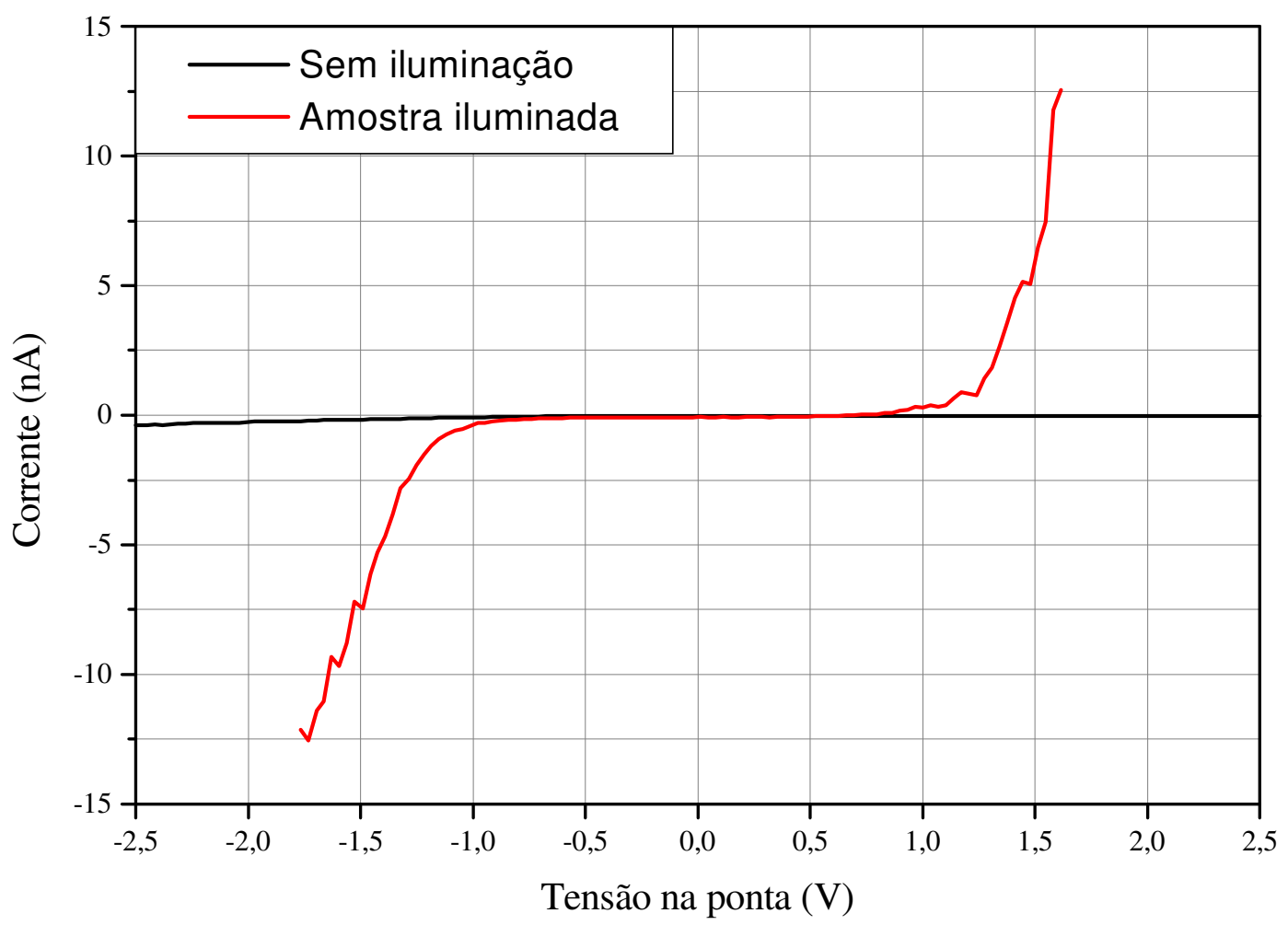

Figura 14: curvas I-V da amostra de GaAs semi-isolante adquiridas com os mesmos parâmetros, mostrando na mesma escala a curva obtida com e sem iluminação da luz do laser.

\subsection{3- Pontos quânticos de InAs:}

Nesta etapa, visamos estudar as características da curva I-V apresentada por pontos quânticos de InAs crescidos sobre substratos de GaAs. Este tipo de medida pode fornecer informações importantes a partir da diferença entre as curvas I-V apresentadas pelos pontos quânticos e pela região intermediária entre eles.

A amostra estudada foi a de número \#600, dopada do tipo n com densidade de portadores $10^{18} \mathrm{~cm}^{-3}$. A passivação foi realizada com a solução de $\left(\mathrm{NH}_{4}\right)_{2} \mathrm{~S}$ diluída em metanol por 15 minutos. Novamente, imagens de boa qualidade puderam ser obtidas, comprovando a reprodutibilidade deste processo de preparação. Infelizmente, não foi possível adquirir simultaneamente a imagem topográfica e as curvas $\mathrm{I}-\mathrm{V}$ ponto a ponto. O problema mais recorrente neste procedimento foi a instabilidade dos dois principais sinais envolvidos nesta medida (retroação e corrente de tunelamento) no momento da transição entre a aquisição de ambos. Era necessário aguardar um tempo grande (dezenas de milisegundos) entre a medida dos dois sinais, o que prejudicava sobremaneira a imagem topográfica. Como alternativa, optamos por um procedimento menos rigoroso mas que permitiu a aquisição de dados consistentes. Após a aquisição de uma imagem topográfica (de $3600 \AA$ de lado), a ponta do STM era deslocada para o centro da imagem, e 20 curvas I-V, adquiridas em pontos igualmente espaçados $(\approx 180 \AA)$, eram adquiridas em uma mesma linha. Os resultado obtido em uma das diversas regiões estudadas é reportado na Figura 15. 


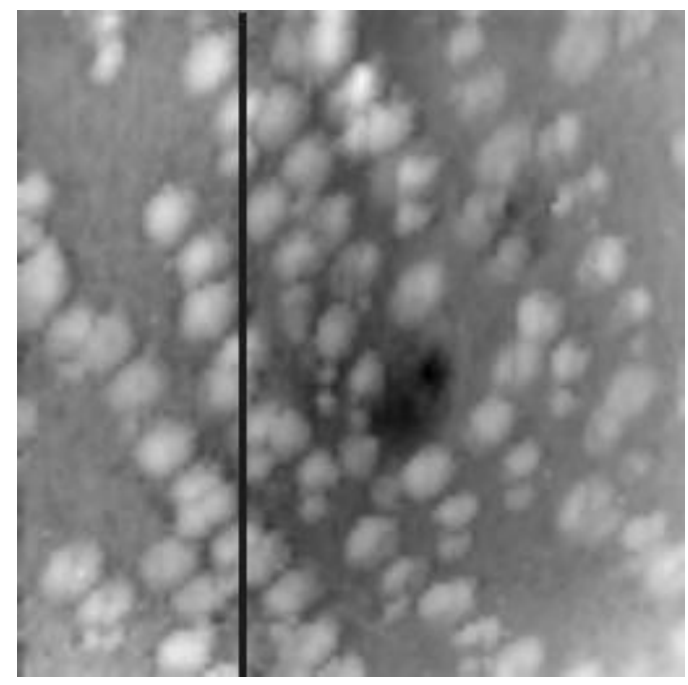

a

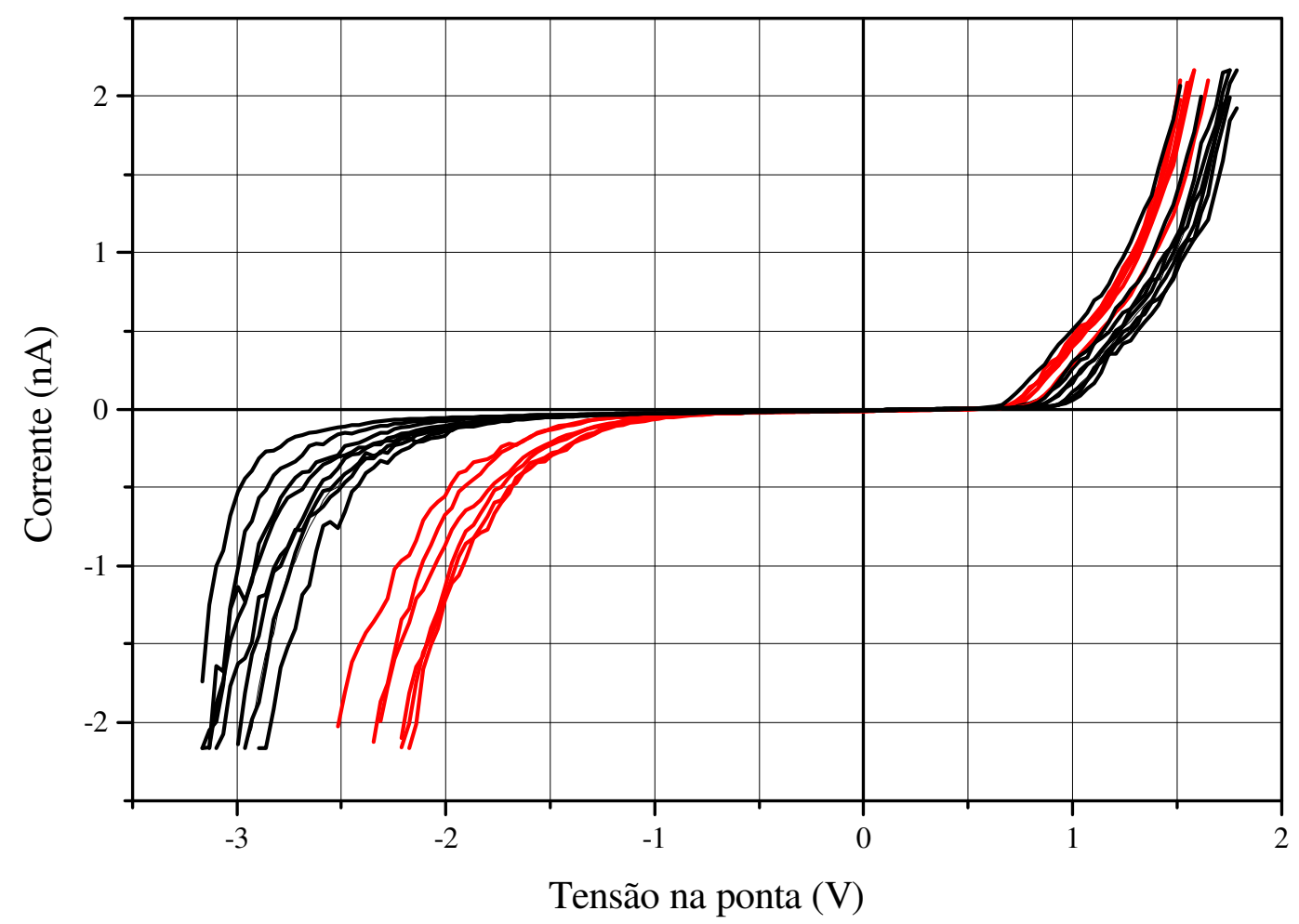

b

Figura 15: (a) imagem da amostra de pontos quânticos de InAs (\#600), mostrando (em azul) a linha sobre a qual foi obtida a série de curvas I-V mostradas em (b). A tensão de tunelamento antes da aquisição das curvas era de 1,5V e a corrente de tunelamento de referência valia 1,5nA.

Na figura acima, é possível observar dois grupos de curvas cuja diferença marcante é a largura apresentada do gap. É possível distinguir claramente os dois conjuntos de curvas no ramo de tensões negativas da ponta, correspondente ao tunelamento no sentido ponta-amostra. As curvas de menor gap se apresentam em número ligeiramente inferior, fato que também foi 
comprovado em medidas sobre outra regiões da mesma amostra. Estas informações permitem concluir que as curvas em vermelho devem corresponder às regiões sondadas sobre os pontos quânticos, enquanto as demais correspondem às suas vizinhanças. $\mathrm{O}$ gap das curvas apresentadas em vermelho é muito mais largo que o esperado para o InAs $(0,36 \mathrm{eV})$. Isto é consistente com o reportado pelas referências 36 e 37, cujos resultados confirmam que o gap do InAs em uma estrutura como esta é alargado devido a efeitos de confinamento quântico e tensões mecânicas. Devido à alta densidade de pontos na região, não foi possível associar com precisão uma dada curva à região sobre a qual ela foi adquirida. Isto apenas pôde ser realizado sobre outra região da mesma amostra, com densidade de pontos muito inferior, com os resultados mostrados na Figura 16.

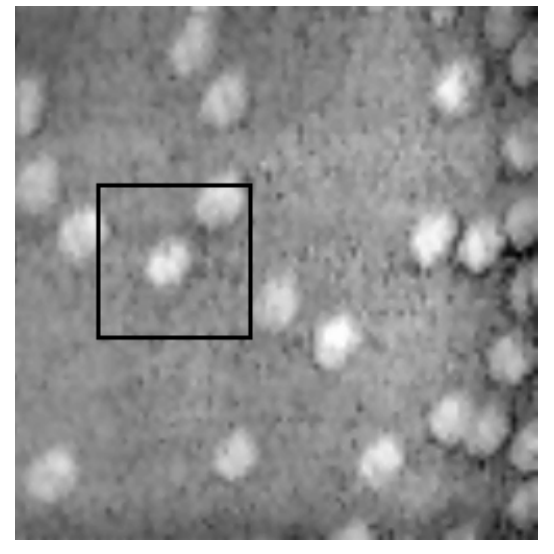

a

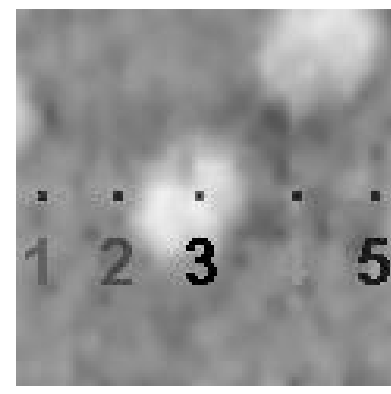

b

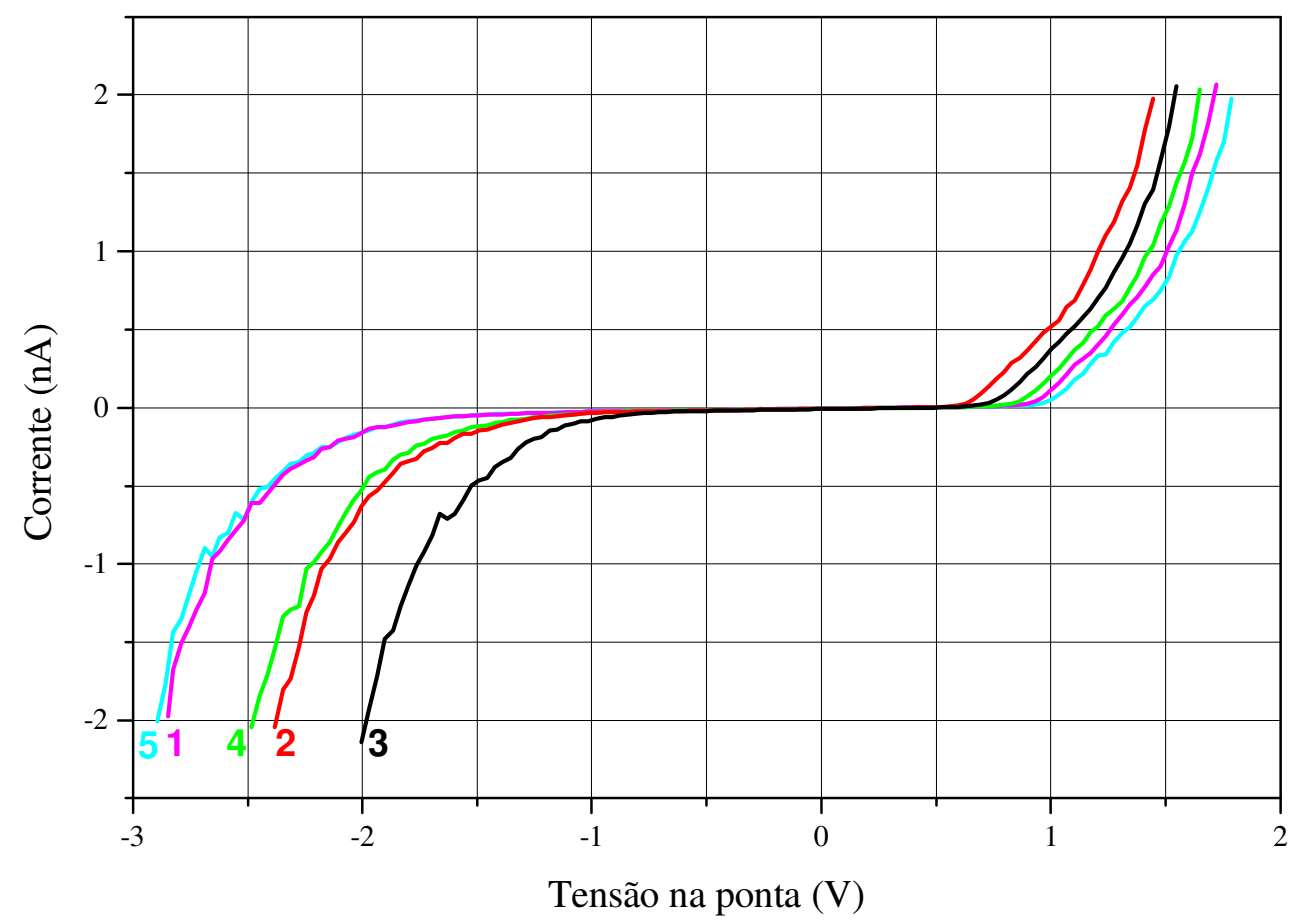

$\mathrm{C}$

Figura 16: (a) imagem por STM de 3600Å de lado da amostra \#600, numa região que apresentou uma baixa densidade de pontos quânticos. (b) região destacada da figura (a), mostrando os pontos sobre os quais as curvas I-V da figura (c) foram adquiridas. A tensão de tunelamento inicial foi de 1,5V (ponta positiva), com a corrente de referência de 1,5nA. 
Em uma primeira análise, estes resultados reproduzem e confirmam os anteriores, ou seja, sobre o ponto quântico (curva 3) o gap medido é inferior ao da região intermediária, agora claramente resolvida. A informação adicional fornecida por esta série de aquisições é a variação do gap com a distância do ponto quântico. Partindo da curva 1, adquirida a uma distância de aproximadamente $360 \AA$ do centro do ponto quântico, tem-se um decréscimo do gap nos pontos 2 ( $180 \AA ̊$ do centro) e 3 (no centro do ponto quântico). Na posição simétrica, este mesmo comportamento foi satisfatoriamente reproduzido. Em posições muito distantes do centro (acima de $400 \AA$ ), as curvas não apresentaram valores de gap superiores ao das curvas 1 e 5 . Estes resultados são consistentes com o relatado por J. H. Noh na referência 33, que verificou uma variação semelhante do gap das curvas em relação à distância do cume de pontos quânticos de $(\mathrm{GaP})_{2}(\mathrm{InP})_{2,5}$ crescidos sobre $\mathrm{GaAs}(311) \mathrm{A}$. Esta variação foi atribuída pelos autores à mudança de composição da liga $(\mathrm{GaP})_{\mathrm{n}}(\mathrm{InP})_{\mathrm{m}}$. No caso de nossa amostra de pontos quânticos de InAs, a explicação mais plausível para esta ocorrência é uma combinação dos efeitos de confinamento ${ }^{38}$ e da variação da tensão mecânica nas vizinhanças dos pontos quânticos. As medidas de PL demonstram que o gap de um ponto quântico é menor que o da wetting layer, concordando com os resultados da Figura $16 .{ }^{39}$ Vários trabalhos relatam a presença de um gradiente de tensão na wetting layer se estendendo por cerca de $400 \AA$ fora dos pontos quânticos. ${ }^{40}$ Uma vez que o gap do InAs aumenta com a tensão e a wetting layer é mais tensa que os pontos quânticos, o gap da wetting layer deve aumentar quanto mais a ponta se afasta dos pontos quânticos, e saturar na região em que o gradiente se anula (já que a tensão é máxima longe dos pontos quânticos).

Uma característica das curvas I-V que não foi esclarecida é a igualdade das curvas na polaridade positiva de tensão na ponta. Isto indica que toda a diferença entre as curvas sobre os pontos quânticos e sobre suas vizinhanças foi proveniente dos estados desocupados da amostra. Um resultado semelhante a este foi relatado na referência 41 em medidas sobre uma amostra de pontos quânticos de InAs sobre GaAs (100) clivada na direção (110).

\section{4- Conclusões:}

Neste capítulo, foram descritos três métodos de preparação de superfícies semicondutoras implementados com sucesso sobre nossas amostras para análise por STM. Imagens de boa qualidade puderam ser obtidas, seja recobrindo a amostra com um líquido inerte (Nujol), metalizando a superfície ou utilizando a passivação com compostos baseados em enxofre. Dentre estes três métodos, a passivação (com $\left(\mathrm{NH}_{4}\right)_{2} \mathrm{~S}$ diluído em metanol) se mostrou a mais atrativa para a realização de medidas tanto topográficas quanto espectroscópicas com o STM. Em nosso conhecimento da literatura, a passivação nunca foi utilizada no estudo topográfico de pontos quânticos com um STM, o que foi conseguido por nós com sucesso. Medidas de fotoluminescência mostraram o êxito desta reação em melhorar as características eletrônicas da superfície.

Após a obtenção de resultados reprodutíveis da preparação com a passivação, realizamos medidas de curvas I-V com o STM sobre as amostras assim tratadas. As medidas sobre um substrato dopado de GaAs permitiram verificar o caráter retificador esperado para a junção metal-vácuo-semicondutor. Uma experiência utilizando a luz de um laser de He-Ne permitiu observar a contribuição dos portadores fotogerados no aspecto de curvas I-V de um substrato de GaAs não dopado. O último tipo de amostra abordado disse respeito a pontos quânticos de InAs crescidos por MBE sobre GaAs(100). Adquirindo curvas I-V sobre estas estruturas e nas regiões 
vizinhas, foi possível observar a variação do gap, devido a tensões mecânicas e propriedades de confinamento envolvidas neste sistema.

\section{Referência:}

1 G. Fasol, Science 275, 941 (1997).

2 D. D. Nolte, J. Appl. Phys. 85, 6259 (1999).

3 A. Zangwill, Physics at Surfaces, Cambridge University Press (1988).

4 L. Kouwenhoven e C. Marcus, Physics World Junho, 35 (1998).

5 I. N. Stranski e L. Krastanov, Sitzungsber. Akad. Wiss. Wien Math. Naturwiss. Kl. Abt. $2 B$ Chemie 146, 797 (1937).

6 L. L. Soethout em Scanning Tunneling Microscopy: Review and Application to Layered Materials, tese de doutorado pela Katholieke Universiteit te Nijmegen, (1991).

7 G. F. A. van de Walle, H. van Kempen, P. Wyder e P. Davidsson, Appl. Phys. Lett. 50, 22 (1987).

8 H. K. Lee em Estudo do contato metal-semicondutor em GaAs e sua contribuição na construção de MESFET, dissertação de mestrado pela Escola Politécnica da Universidade de São Paulo, (1990).

9 I. Tanaka, T. Kato, S. Ohkouchi e F. Osaka, J. Vac. Sci. Technol. A 8, 567 (1990).

${ }^{10}$ P. K. Hansma, R. Sonnenfeld, J. Schneir, O. Marti, S. A. C. Gouls, C. B. Prater, A. L. Weisenhorn, B. Drake, H. Hansma, G. Slough, W. W. McNairy e R. V. Coleman, em Scanning Tunneling Microscopy and Related Methods, cap. 15, NATO ASI series, editado por R. J. Behm, N. Garcia e H. Rohrer, Kluwer Academic Publishers, (1990).

11 G. Hollinger, R. Skheyta-Kabbani e M. Gendry, Phys. Rev. B 49, 11159 (1994).

12 G. M. Guryanov, G. E. Cirlin, V. N. Petrov, N. K. Polyakov, A. O. Golubok, S. Y. Tipissev, V. B. Gubanov, Y. B. Samsonenko, N. N. Ledentsov, V. A. Shchukin, M. Grundmann, D. Bimberg e Z. I. Alferov, Surf. Sci. 352-354, 651 (1996).

${ }^{13}$ H. H. Lee, R. J. Racicot e S. H. Lee, Appl. Phys. Lett 54, 724 (1989).

14 C. J. Sandroff, R. N. Nottenberg, J. -C. Bischoff e R. Bhat, Appl. Phys. Lett. 51, 33 (1987).

15 I. A. Andreev, E. V. Kunitsyna, V. M. Lantratov, T. V. L'vova, M. P. Mikhailova e Y. P. Yakovlev, Semiconductors 31, 556 (1997).

16 J. A. Dagata, W. Tseng, J. Bennet, J. Schneir e H. H. Harary, Appl. Phys. Lett. 59, 3288 (1991).

17 J. A. Dagata, W. Tseng e R. M. Silver, J. Vac. Sci. Technol. A 11, 1070 (1993).

18 V. N. Bessolov e M. V. Lebedev, Semiconductors 32, 1141 (1998), e as referências neste citadas.

19 T. Ohno, Phys. Rev. B. 44, 6306 (1991).

${ }^{20}$ V. N. Bessolov, E. V. Konenkova, M. V. Lebedev e D. R. T. Zahn, Semiconductors 31, 1164 (1997).

21 V. N. Bessolov, E. V. Konenkova e M. V. Lebedev, J. Vac. Sci. Technol. B 14, 2761 (1996).

22 J.-W. Seo, T. Koker, S. Agarwala e I. Adesida, Appl. Phys. Lett. 60, 1114 (1992).

${ }^{23}$ C. Colvard em Encyclopedia of materials characterization :surfaces, interfaces, thin films, cap. 7, editado por C. Richard Brundle, Charles A. Evans, Jr. e Shaun Wilson, Boston: Butterworth-Heinemann (1992).

${ }^{24}$ Y. Ke, S. Milano, X. W. Wang, N. Tao e Y. Darici, Surf. Sci. 415, 29 (1998).

25 V. N. Bessolov, M. V. Lebedev, E. B. Novikov e B. V. Tsarenkov, J. Vac. Sci. Technol. B 11, 10 (1993). 
${ }^{26}$ E. Yablonovitch, C. J. Sandroff, R. Bhat e T. Gmitter, Appl. Phys. Lett. 51, 439 (1987).

27 L. Ferrari, M. Fodonipi, M. Righini e S. Selci, Surf. Sci. 331-333, 447 (1995).

28 S. M. Sze, Physics of Semiconductor Device, Wiley, New York (1969).

29 W. J. Kaiser, L. D. Bell, M. H. Hecht e F. J. Grunthaner, J. Vac. Sci. Technol. A 6, 519 (1988).

30 R. M. Feenstra e J. A. Stroscio, J. Vac. Sci. Technol. B 5, 923 (1987).

31 M. Weimer, J. Kramar e J. B. Baldeschwieler, Phys. Rev. B 39, 5572 (1989).

32 O. Albrektsen, D. J. Arendt, H. P. Meier e H. W. M. Salemink, Appl. Phys. Lett. 57 , 31 (1990).

33 J. H. Noh, H.Asahi, S. J. Kim e S. Gonda, Jpn. J. Appl. Phys. 36, 3818 (1997).

${ }^{34}$ M. Ito, K. Murata, K. Aiso, M. Hori, T. Goto e M. Hiramatsu, Appl. Phys. Lett. 70, 2141 (1997).

35 T. Takahashi, M. Yoshita e H. Sakaki, Appl. Phys. Lett. 68, 502 (1996).

36 T. Takahashi, M. Yoshita, I. Kamiya e H. Sakaki, Appl. Phys. A. 66, S1055 (1998).

37 K. Hirakawa, Y. Hashimoto, K. Harada e T. Ikoma, Phys. Rev. B 44, 1734 (1991).

38 T. Saito, J. N. Schulman e Y. Arakawa, Phys. Rev. B 57, 13016 (1998).

39 K. H. Schmidt, G. M. Ribeiro, J. Garcia e P. M. Petroff, Appl. Phys. Lett. 70, 1727 (1997).

${ }^{40}$ Q. Xie, P. Chen e A. Madhukar, Appl. Phys. Lett. 65, 2051 (1994).

41 B. Legrand, B. Grandidier, J. P. Nys e D. Stiévenard, Appl. Phys. Lett. 73, 96 (1998). 


\section{Conclusões:}

Neste trabalho, acrescentamos no microscópio de tunelamento desenvolvido e construído no Laboratório de Novos Materiais Semicondutores do IFUSP o sistema necessário para realizar medidas espectroscópicas (curvas I-V, função trabalho e topografia $\pm \mathrm{V}$ ). Os módulos eletrônicos e as rotinas computacionais que os controlam foram instalados de modo a não interferir com o funcionamento do microscópio em modo topográfico que está operacional há alguns anos.

Os testes deste novo sistema foram realizados sobre dois materiais muito estudados em microscopia de tunelamento: grafite e ouro. As curvas I-V adquiridas sobre grafite recém-clivado mostraram o comportamento esperado segundo a teoria, comprovando a acuidade do sistema implementado. Algumas medidas malogradas da função trabalho da mesma amostra revelaram a forte influência que a camada de contaminantes adsorvida na superfície exerce sobre a ponta do STM. Os valores extremamente baixos obtidos (da ordem de $20 \%$ do valor nominal da função trabalho) são consistentes com os divulgados pela literatura e permitem explicar um dos mecanismos (giant corrugations) envolvidos nas imagens com resolução atômica do grafite. Quando as medidas de função trabalho foram realizadas sobre ouro em forma cristalina, valores relativamente superiores foram obtidos, mostrando que, adicionalmente à camada de contaminantes, a própria estrutura do grafite influi consideravelmente nos resultados. Filmes finos de ouro depositados sobre grafite também foram estudados. Primeiramente, otimizamos as condições de deposição por sputtering para conhecer o limiar que proporcionaria filmes de espessura reduzida e, ao mesmo tempo, contínuos. As curvas I-V destes filmes revelaram um caráter linear quando comparadas com as curvas sobre grafite. Esta diferença nas características da curva dos dois materiais permitiu a detecção de uma descontinuidade presente em um filme fino, manifestando um aspecto da potencialidade desta técnica. O programa computacional que adquire a topografia de amostras em duas polaridade $( \pm \mathrm{V})$ foi testado com sucesso sobre um filme fino de ouro.

Amostras semicondutoras de compostos III-V foram também analisadas, em particular substratos de GaAs e pontos quânticos de InAs crescidos por MBE. Uma das partes mais importantes desta etapa foi o estudo de vários métodos de preparação das amostras para a análise por STM no ar. A aplicação de um líquido mineral inerte (Nujol) e a metalização da amostra com o filme fino de ouro otimizado anteriormente se mostraram bons métodos para análise topográfica destas amostras, apesar da primeira não ser totalmente reprodutível. Um método relativamente recente de preparação de semicondutores para análise por STM é a passivação da superfície, que também foi abordada neste trabalho. Os resultados proporcionados por diversos tempos de reação de três soluções químicas diferentes foram verificados tanto no aspecto topográfico (usando AFM e STM) quanto eletrônico (com a fotoluminescência). A reação com $\left(\mathrm{NH}_{4}\right)_{2} \mathrm{~S}$ mostrou-se a mais efetiva nestes dois aspectos. Imagens de qualidade satisfatória foram obtidas com nosso STM sobre amostras de pontos quânticos assim tratadas. Uma vez otimizado o processo de preparação, efetuamos medidas de curvas I-V sobre algumas amostras tratadas com a passivação. Sobre um substrato de GaAs dopado, verificamos a assimetria dessas curvas, esperada teoricamente para uma junção metal-vácuo-semicondutor. Isto indicou que a amostra estava parcialmente livre de estados de superfície e, portanto, com reduzido pinning do nível de Fermi, permitindo a observação desta característica. A análise de um substrato de GaAs semiisolante foi possível mediante a irradiação de luz laser sobre a junção. Os portadores fotogerados 
contribuíram para aumentar a condutividade da superfície e tornar possível a medida de curvas IV. Devido à ausência de dopagem, as curvas obtidas eram simétricas (graças à não formação da barreira Schottky), e a largura do gap do GaAs (próxima ao valor nominal) foi observada sem a necessidade de qualquer ajuste de tensão e corrente de tunelamento. Finalmente, adquirindo curvas I-V sobre uma amostra de pontos quânticos, foi possível obter informações diretas sobre a variação do gap na região em torno de uma dessas estruturas. Esta variação pode ser atribuída ao gradiente de tensão mecânica presente na wetting layer cercando os pontos quânticos e também a efeitos de confinamento presentes neste tipo de estrutura. 